DOE/AL/82993-26

Dist. Category UC-1290

\title{
PVUSA EXPERIENCE WITH POWER CONVERSION FOR GRID-CONNECTED PHOTOVOLTAIC SYSTEMS
}

November 1995

Walt Stolte, Bechtel Corporation and PVUSA.Project Team

for

Pacific Gas and Electric Company

Research and Development

San Ramon, CA 94583

Published November 1995

PREPARED UNDER CONTRACT WTTH THE UNTTED STATES

DEPARTMENT OF ENERGY

Cooperative Agreement No. DE-FC04-92AL82993 
?

$\because$ 


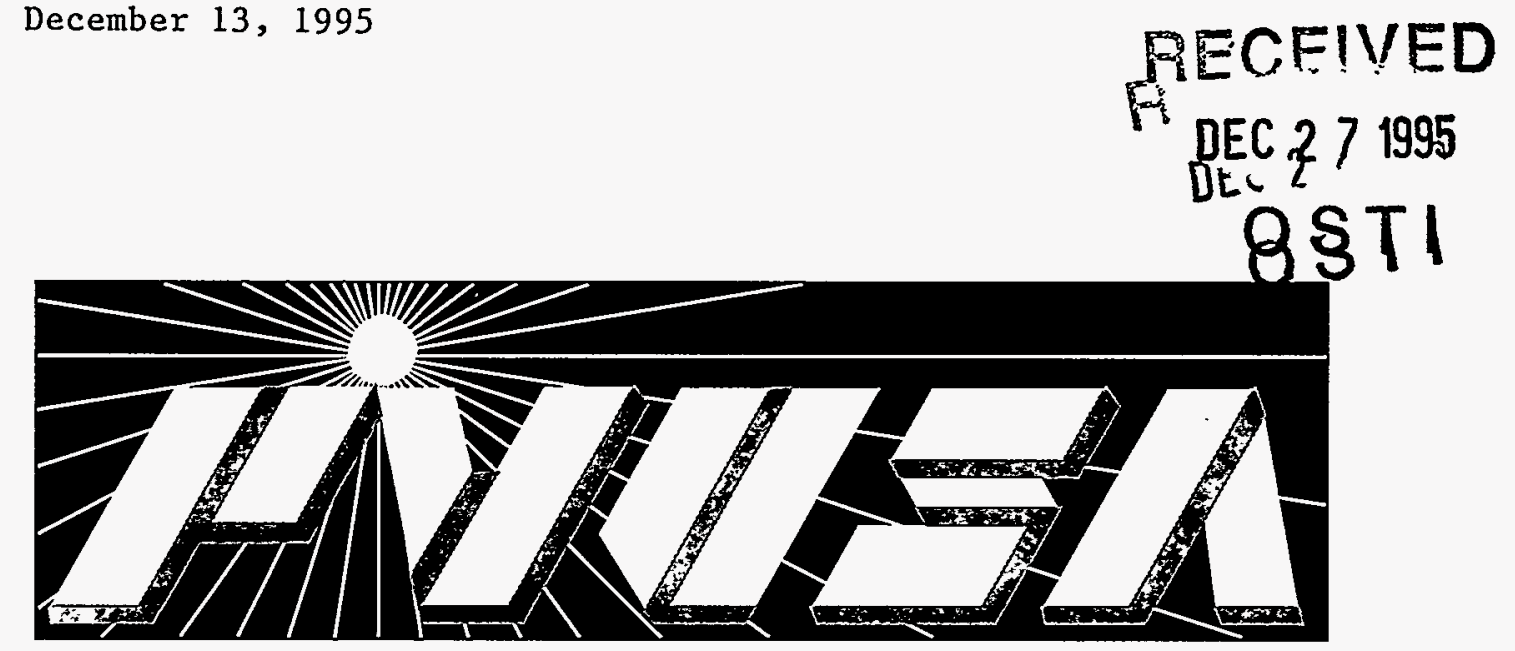

PVUSA Experience with

Power Conversion for

Grid-Connected Photovoltaic Systems

November 1995

Prepared by:

Walt Stolte

Bechtel Corporation

and

PVUSA Project Team

Project Manager:

Brian K. Farmer

The Goverment reserves for itself and others acting on its behalf a royalty free, nonexclusive, irrevocable, world-wide license for governmental purposes to publish, distribute, translate, duplicate, exhibit, and perform any such data copyrighted by the contractor. 


\section{DISCLAIMER}

The Pacific Gas and Electric Company (PG\&E) and the United States Government or any agency thereof, or any of their employees, contractors, subcontractors and their employees, (1) make no representation or warranty, expressed or implied; (2) assume no legal liability for damages, including any consequential damages, even if PG\&E and/or the U.S. Government, or any of their representatives, have been advised of the possibility of such damages; or (3) take no responsibility for the accuracy, completeness, or usefulness of any information, apparatus, product, method, or process disclosed, nor does PG\&E or the U.S. Government represent that its use would not infringe the privately held rights of others. Reference herein to any commercial product, process, or service by trade name, trademark, manufacturer, or otherwise, does not constitute or imply its endorsement, recommendation, or favoring by PG\&E or the U.S. Government, any agency thereof, or any of their contractors or subcontractors.

The work disclosed in this report was done with the support of the U.S. Department of Energy, Cooperative Agreement No. DE-FC04-92AL82993. However, any opinions, findings, conclusions, or recommendations expressed herein are those of the author(s) and do not necessarily reflect the views of PG\&E or the U.S. Government, any agency thereof, or any of their contractors or subcontractors.

\section{COPYRIGHT NOTICE}

Copyright 1995, PG\&E, subject to license retained by the U.S. Government under 48 CFR 952,227-75. All other rights reserved. This report and the underlying research were funded and developed for use by PG\&E, members of the PVUSA project, and contributing institutions, including the U.S. Government, the Electric Power Research Institute, and the California Energy Commission. Copies of this report may be obtained for a charge from PG\&E or, if for government use or purposes, from the National Technical Information Service in Springfield, Virginia. Reproduction and/or distribution in any form of this report or any part thereof by anyone other than the U.S. Government is forbidden without express written permission from the copyright owner. 


\section{PROJECT PARTICIPANTS}

In addition to the U.S. Department of Energy (including Sandia National Laboratory, National Renewable Energy Laboratory, and Jet Propulsion Laboratory), the Electric Power Research Institute, and the California Energy Commission, the support of all the PVUSA project members in conducting this research and developing this report is greatly appreciated. Members at the time of publication are:

Central and South West Services, Inc.

City of Austin, Texas

New York State Energy Research and Development Authority

Niagara Mohawk Power Corporation

Public Service Company of Colorado

Sacramento Municipal Utility District

Salt River Project

San Diego Gas \& Electric

State of Hawaii/Maui Electric Company

U.S. Department of Defense

Virginia Power Company/Commonwealth of Virginia

\section{DISCLAIMER}

This report was prepared as an account of work sponsored by an agency of the United States
Government. Neither the United States Government nor any agency thereof, nor any of their
employees, makes any warranty, express or implied, or assumes any legal liability or responsi-
bility for the accuracy, completeness, or usefulness of any information, apparatus, product, or
process disclosed, or represents that its use would not infringe privately owned rights. Refer-
ence herein to any specific commercial product, process, or service by trade name, trademark,
manufacturer, or otherwise does not necessarily constitute or imply its endorsement, recom-
mendation, or favoring by the United States Government or any agency thereof. The views
and opinions of authors expressed herein do not necessarily state or reflect those of the
United States Government or any agency thereof. 


\section{ACKNOWLEDGMENTS}

The authors wish to thank the members of PVUSA's Project Team, the Technical Review Committee, and the Steering Committee for their reviews and suggestions. 



\begin{abstract}
The Photovoltaics for Utility Scale Application (PVUSA) project was established to demonstrate photovoltaic (PV) systems in grid-connected utility applications. One of PVUSA's key objectives is to evaluate the performance, reliability, and cost of the PV balance of system (BOS). Power conditioning units (PCUs) are the interface between the dc PV arrays and the ac utility lines, and have proved to be the most critical element in grid-connected PV systems. There are five different models of PCUs at PVUSA's Davis and Kerman sites. This report describes the design, testing, performance characteristics, and maintenance history of each of these PCUs.
\end{abstract}

PVUSA required PCUs in the power range $25 \mathrm{~kW}$ to $500 \mathrm{~kW}$ which could operate automatically and reliably under changing conditions of sunlight and changing conditions on the utility grid. Although a number of manufacturers can provide PCUs in this power range, none of these PCUs have been produced in sufficient quantity to allow. refinement of a particular model into the highly reliable unit needed for long-term, unattended operation. Factory tests were useful but limited by the inability to test under full power and changing power conditions. The inability to completely test PCUs at the factory resulted in difficulty during startup, field testing, and subsequent operation.

PVUSA has made significant progress in understanding the requirements for PCUs in grid-connected PV applications and improving field performance. This record of PVUSA's experience with a variety of PCUs is intended to help utilities and their suppliers identify and retain the good performance characteristics of PCUs, and to make improvements where necessary to meet the needs of utilities.

This is one of several reports documenting experience and lessons learned at PVUSA. Other topical reports in this series address:

- Construction and safety experience in installing and operating PV systems

- Five-year assessment of EMTs

- BOS designs and costs

- Validation of the Kerman 500-kW, grid-support PV plant benefits

- Procurement, rating, and acceptance practices

- Data acquisition and analysis 
. 


\section{EXECUTIVE SUMMARY}

The Photovoltaics for Utility Scale Applications (PVUSA) Project is a nationwide public-private partnership, established to demonstrate photovoltaic (PV) systems for use in grid-connected utility applications. This is one of a series of PVUSA topical reports. It describes PVUSA's experience with the procurement, testing, operation, and maintenance of the power conditioning units (PCUs) used to interface the PV arrays with utility lines at the PVUSA sites at Davis and Kerman, California. Conclusions and recommendations are also presented.

\section{PCU CHARACTERISTICS}

At present, there are five different models of PCUs at PVUSA's Davis and Kerman sites. Each of the six emerging module technology (EMT) PV systems at Davis is connected to a Delta Electronic Control Company (DECC) 25-kW PCU, which PVUSA procured through competitive bidding. There are three utility-scale (US) PV systems operating at Davis, ranging in size from a nominal 100 to $500 \mathrm{~kW}$. These US systems, including PCUs, were part of a competitively bid turnkey system procurement, designated "US-1." The two 275-kW PCUs at the Kerman site were also part of a turnkey PV system procurement, designated "US-2." Characteristics of the five PCU models are highlighted in Table ES-1.

Three of the PCUs track the maximum power point voltage of the connected PV source circuits, and two operate at a fixed voltage. One supplier of a fixed-voltage PCU calculated that this type of operation collects about $971 / 2$ percent of the energy that would be collected with maximum power tracking. Morning wakeup for the fixed-voltage PCUs is achieved by sensing current from pilot cells (modules); wakeup for the others is achieved by sensing that the array voltage exceeds a setpoint.

Above 40 percent of rated power, all of the PCUs have efficiencies of $941 / 2 \pm 1 \frac{1}{2}$ percent. However, efficiency falloff at low power differs from one PCU to another. The efficiency curves for the two Omnion PCUs (IPC and Kerman) are flatter at the top than those of the line-commutated Dickerson and APS units.

Unbalance among the ac output phase currents ranges from less than 0.3 percent to 2.3 percent for the US systems. Unbalance for the DECC units ranges from 1.4 to 5.1 percent, with an average of 3 percent. Since all of the PCUs use isolation transformers, dc current injection is not possible. 
Table ES - 1

PCU Characteristics

\begin{tabular}{|c|c|c|c|c|c|}
\hline & EMT & \multicolumn{3}{|c|}{ US-1 } & US-2 \\
\hline System Integrator & PVUSA & IPC & SSI & APS & SSI \\
\hline PCU Manufacturer & DECC & Omnion & Dickerson & APS & Omnion \\
\hline Manufacturer's Rating & $25 \mathrm{~kW} \mathrm{dc}$ & $200 \mathrm{~kW} \mathrm{ac}$ & $200 \mathrm{~kW}$ ac & $500 \mathrm{~kW} \mathrm{ac}$ & $550 \mathrm{~kW}$ ac \\
\hline PV Syst. Rating @PTC & 15 to $18 \mathrm{~kW} \mathrm{dc}$ & $196 \mathrm{~kW} \mathrm{ac}$ & $134 \mathrm{~kW} \mathrm{ac}$ & $479 \mathrm{~kW} \mathrm{ac}$ & $498 \mathrm{~kW}$ ac \\
\hline Unit Configuration & $1 \times 25 \mathrm{~kW} \mathrm{dc}$ & $1 \times 200 \mathrm{~kW} \mathrm{ac}$ & $2 \times 100 \mathrm{~kW} \mathrm{ac}$ & $4 \times 125 \mathrm{~kW} \mathrm{ac}$ & $2 \times 275 \mathrm{~kW} \mathrm{ac}$ \\
\hline Type of Commutation & Self & Self & Line & Line & Self \\
\hline Switching Device & Transistor & IGBT & SCR & SCR & IGBT \\
\hline Morning Wakeup Sensing & Array voltage & Array voltage & Pilot cell & Pilot cell & Array voltage \\
\hline Maximum Power Tracking & Yes & Yes & Fixed voltage & Fixed voltage & Yes \\
\hline Efficiency $^{1}$ & $94.1 \%$ & $93.6 \%$ & $93.9 \%$ & $96.1 \%$ & $93.3 \%$ \\
\hline Current Unbalance & $3.0 \%$ & $2.0 \%$ & $2.3 \%$ & $0.3 \%$ & $0.4 \%$ \\
\hline THD Current ${ }^{1}$ & $51 / 2 \%$ & $2 \frac{1}{2} 2 \%$ & - & $31 / 2$ to $51 / 2 \%$ & $21 / 2$ to $51 / 2 \%$ \\
\hline THD Voltage $^{1}$ & 0.6 to $0.8 \%$ & 1 to $11 / 2 \%$ & - & 0.8 to $1.2 \%$ & $21 / 2 \%$ \\
\hline Power Factor @ $>40 \%$ P PATED & 1.0 & 1.0 & 0.8 to 0.9 & 0.85 to 1.0 & 1.0 \\
\hline Run-On, sec & 1.5 & 0.03 to 0.11 & 0.03 & 0.1 to 0.12 & - \\
\hline Enclosure $\mathrm{kW} / \mathrm{ft}^{2}$ & 2.2 & 3.1 & 2.0 & 5.5 & 4.9 \\
\hline Cooling & Nonventilated & HVAC & Forced air & Forced air & HVAC \\
\hline Location & Under array & In sunlight & In sunlight & Under array & In sunlight \\
\hline
\end{tabular}

Voltage and current total harmonic distortions (THDs) generally conform to IEEE 519-1992 (see Table ES-1). At lower output powers, the percentage current THD increases but the magnitudes of the harmonic currents decrease. The power levels of the PCUs are relatively low compared with those of the connected utility lines and thus do not greatly affect the voltage harmonics. These data should be used with caution, as the THD is affected by power level and the impedance of the utility line. EMI/RFI and magnetic fields were measured on the DECC EMT units and were judged not to be a problem because they were very low level.

The power factors of the two self-commutated, pulse-width-modulated Omnion PCUs are nearly identical and are above 0.99 for power levels greater than 10 percent of rated power. The line-commutated APS and Dickerson units have fixed capacitors, which result in power factors varying with power level. 
Tests performed during startup showed that the PCUs disconnect and do not run on upon loss of the utility line voltage (and when no load is present). However, special tests on the DECC PCUs resulted in run-on for up to several minutes when the connected load was 10 to 20 percent above the power being generated by the PCU. Given the correct load impedance, any of the PCUs might run on. However, run-on (islanding) continues to be a concern for utility companies.

\section{PCU OPERATION AND MAINTENANCE}

The PCUs passed prescribed factory and field startup tests, but all encountered difficulties that required corrective actions. For the US units, factory tests were limited to less than each PCU's rated power due to the capacity of available dc source array simulator equipment. These tests were followed by major and minor difficulties during initial operation. Figure ES-1 shows the occurrences of failures and trips, but does not show downtimes and times to implement repairs.

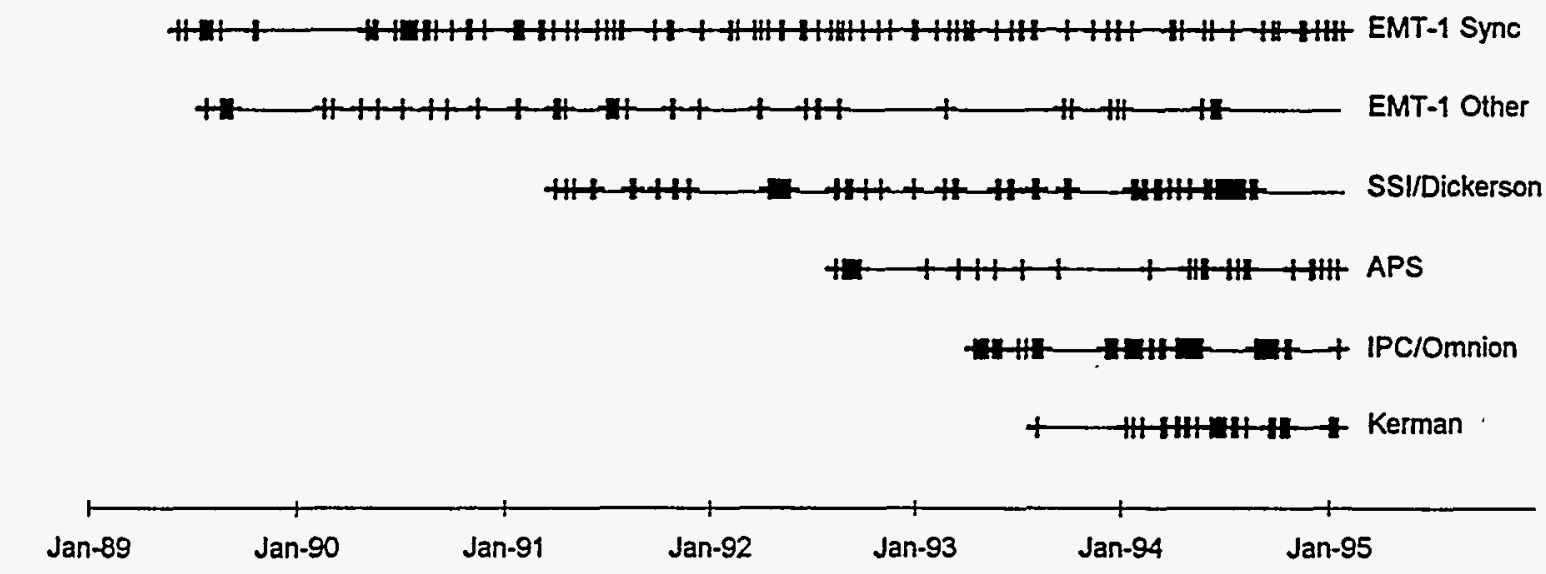

Figure ES-1. PCU failure chronology.

Entries in Figure ES-1 for EMT-1 are for five DECC units, which were brought on line at various times as the EMT-1 PV systems were installed. The synchronizing errors are related to the PCU's morning wakeup procedure and require a manual reset. This nuisance problem is ameliorated with biannual adjustments of the starting voltage to accommodate seasonal variations in array voltages. Early problems included trips, failures to start, and failures to power track accurately. Corrective actions over time included adding capacitors across the ac power transducer, adjusting transducer gains and delay times, and repairing loose or broken connections and faulty resistors. 
When connected in parallel, the Dickerson PCUs were not reliable and, at most, operated only a few weeks at a time. Repairs produced limited success. A consultant, engaged at PVUSA's urging, concluded that the design was viable, but that workmanship and material selection could be improved. Modifications were made, including repackaging the units. Failures and component damage continued to occur. Under the direction of its Technical Review Committee (TRC), PVUSA developed an operational reliability test, requiring 28 consecutive days with 95 percent availability. The PCUs passed this test, but problems persisted. In July 1994, PVUSA settled the contract and the system was accepted as is. Since then, one of the two units has operated reliably. The other unit is inoperative and is used as an inventory of spare parts.

Field modifications to the IPC/Omnion PCU included changes to the controls that shed PV source circuits during high irradiance. Based on experience at Kerman, high temperature was suspected as the cause of bridge fault trips. Omnion retrofitted the PCU with an air conditioning unit, with little improvement. Sometimes the PCU did not start in the morning and displayed a dc overvoltage message. IGBTs were damaged on two occasions. Several printed circuit boards, cables, and other components were replaced but $\mathrm{dc}$ overvoltage and bridge fault problems persisted. With no resolution apparent and the design superseded, the TRC in 1995 elected to replace the unit rather than continue troubleshooting.

APS replaced several components and made minor repairs to correct trips and failures to wake up at sunrise. After operating several months with only a few failures, the APS unit was damaged by a utility line fault that took some time to clear. There were several incidents of cleared fuses after utility line outages. The line-commutated APS PCU seems to be more sensitive to line transients than other PCUs. The APS PCUs operate at a fixed dc voltage (manually adjustable). Due to aging of the array and/or other causes, the desired maximum power point dc operating voltage during summer decreased to a point below the adjustment range. Overall, the APS unit has been the most reliable and efficient of the PCUs installed.

Initially, the two Omnion PCUs at Kerman would not operate in parallel due to high-frequency circulating currents in the neutral. Installing an isolation transformer on Unit 2 eliminated this problem. The total harmonics were within specifications, but additional capacitors were required to reduce high-frequency harmonics which interfered with other electronic equipment. Cloud transients caused excessive dc input power before source circuits could be shed. This problem was lessened by reprogramming time delays 
and increasing the number of source circuits shed. PCU overtemperature trips were corrected by replacing the original cabinet air conditioners with significantly larger units.

\section{CONCLUSIONS}

Although the PCUs passed factory tests, numerous difficulties were encountered during field startup. The factory tests proved useful for early identification and correction of several problems and design oversights. More problems would have been corrected at the factory had test equipment been available to operate the units at full power. All of the PCUs had problems as components aged and were exposed to field operating conditions. The field conditions included line transients, cloud enhancement, and other effects that would be difficult to duplicate at most factories. Repairs and corrections made in the field are expensive, both for PVUSA and the equipment manufacturer. It is relatively easy to detect a problem, but determining its root cause is more difficult and time-consuming, particularly for intermittent failures.

The DECC PCU was specifically designed to accommodate the diverse parameters of the PVUSA EMT systems. In general, the units have done so with good reliability, average efficiency, and acceptable harmonic levels. The IPC/Omnion PCU has had problems, but when operating it has had good efficiency, fair harmonic distortion, and excellent power factor. Though not immune to line voltage transients, this unit has survived transients that damaged other PCUs at Davis. The SSI/Dickerson PCU appears to have been at a more developmental stage than originally thought and required more than a simple scaleup of the Sandia test unit. However at present, one of the two units is continuing to function satisfactorily, except for occasional morning start failures. The APS PCU has the highest efficiency and $\mathrm{kW} / \mathrm{ft}^{2}$ and has been one of the most reliable of all PVUSA inverters, but protects itself by blowing fuses in response to certain line transients. The Omnion PCU at Kerman has average efficiency, acceptable harmonic level, and excellent power factor.

The DECC and Kerman PCUs were purchased as "commercial" equipment. However, the DECC PCUs were specifically designed for this project, and the Kerman PCU design differed from that of previous Omnion units. Startup and repair problems with these units were different from, but no less significant than, those encountered with US-1 units, where innovation was encouraged. While acceptable for the present, PCUs are not truly a commercial product for the power levels and PV systems tested at PVUSA. There are probably two reasons for this: insufficient market volume has prevented full development and mass production, and PCU designs continue to evolve. PVUSA has worked purposefully with suppliers, not only to correct problems and deficiencies, but to encourage these suppliers to learn from this 
experience and incorporate appropriate changes. Purchasers should look forward to future product offerings which will resolve many of the issues addressed here.

\section{RECOMMENDATIONS}

Preparing a PCU specification should include careful evaluation of the requirements of the utility company where the unit will be connected. Expected responses to line transients and faults, as well as restart delay times, should be explicitly defined. The PCU supplier should be made aware of conditions at the site, including extremes. The PCU design should address (among other things):

- Site ambient temperature and humidity extremes

- Solar heat gain effects on cabinet interior and component temperatures

- Irradiance transients (up to $1,500 \mathrm{~W} / \mathrm{m}^{2}$ at Davis)

- Effects of seasonal changes in ambient temperature and irradiance spectra, and module aging on array wakeup voltage or pilot cell current

- Utility line disturbances, voltage surges and sags, and phase unbalance

The purchaser and supplier should discuss features of the PCU specification or design that might be changed to improve performance, reliability, or cost-effectiveness.

The PCU should be tested at the factory at full power and in the configuration to be installed in the field. This may be difficult (or impossible) for high-power PCUs. Further, the morning wakeup process should be simulated and tested as close to expected field conditions as possible. This would include simulating variations in array voltage with seasonal variations in moming temperatures. It would also be desirable to test the PCU at off-design operating points, such as at the ends of the dc and ac operating voltage ranges.

PCU supplier personnel should be on site during startup of units with design elements not yet fieldproven. Items covered by warranty should be described as thoroughly as possible. The warranty should also specify when the period starts and whether elapsed time while the unit is unavailable due to repairs is included in the warranty time.

Project Manager

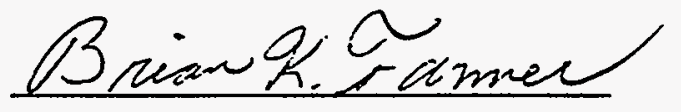

Brian K. Farmer

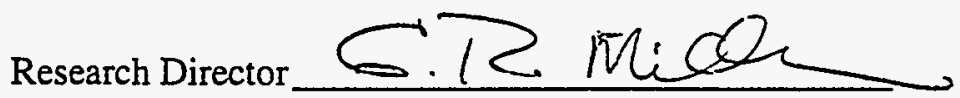

Gerald R. Miller 


\section{CONTENTS}

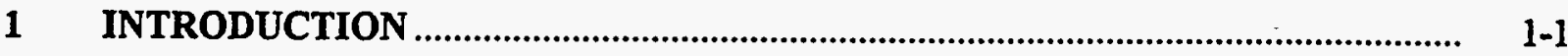

PVUSA BACKGROUND........................................................................... $1-1$

PCU DESCRIPTIONS ................................................................................. $1-2$

INTERCONNECTION REQUIREMENTS......................................................... 1 1-3

REPORT ORGANIZATION ........................................................................

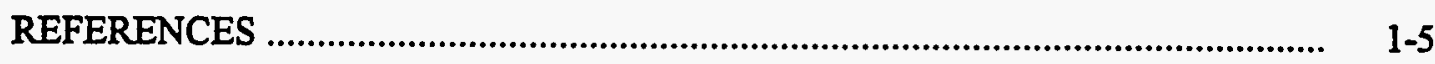

2 PCU TECHNOLOGY ..................................................................................... 2-1

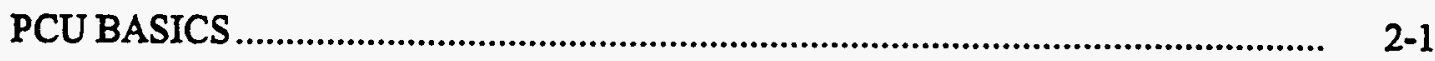

PVUSA PCU SPECIFICATIONS ................................................................. 2-11

REFERENCES ....................................................................................... $2-18$

3 EMT, DECC/HELIONETICS ...........................................................................

PCU DESCRIPTION .................................................................................

FACTORY AND STARTUP TESTS ...............................................................

OPERATION AND MAINTENANCE .......................................................... $\quad 3-12$

PCU CHARACTERISTICS ........................................................................

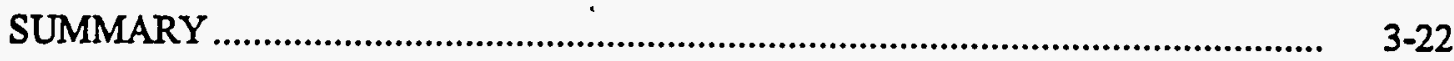

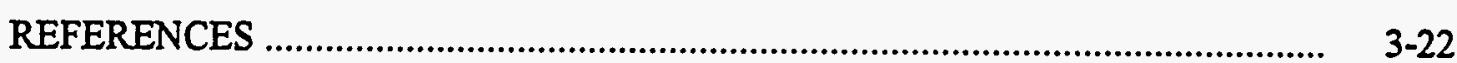

4 US-1, IPC/OMNION....................................................................................

PCU DESCRIPTION .................................................................................. 4-1

FACTORY AND STARTUP TESTS ................................................................. 4.

OPERATION AND MAINTENANCE ............................................................... $\quad 4$ 4-12

PCU CHARACTERISTICS .......................................................................... 4 4-14

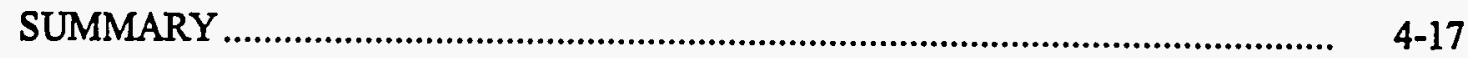

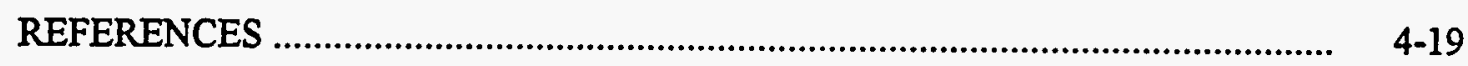

5 US-1, SSI/DICKERSON................................................................................. $5-1$

PCU DESCRIPTION .....................................................................................

FACTORY AND STARTUP TESTS .............................................................. $\quad 5-8$

OPERATION AND MAINTENANCE............................................................... 5

PCU CHARACTERISTICS ......................................................................... 5

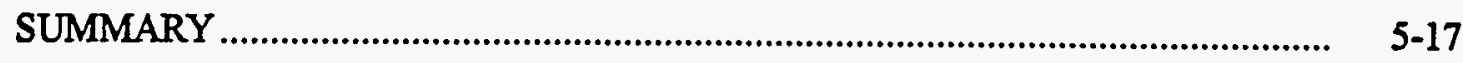

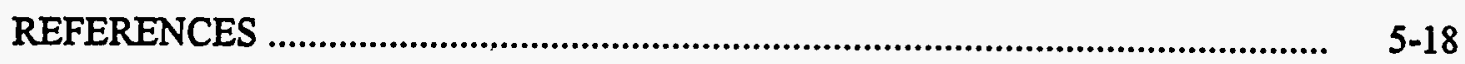

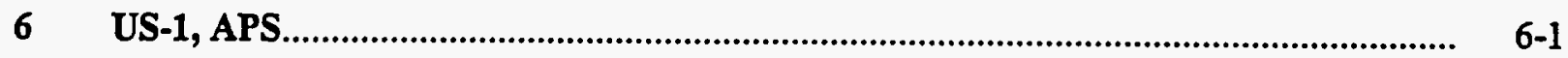

PCU DESCRIPTION ........................................................................................

FACTORY AND STARTUP TESTS .................................................................. $\quad 6-7$

OPERATION AND MAINTENANCE ................................................................... $\quad 6-11$ 


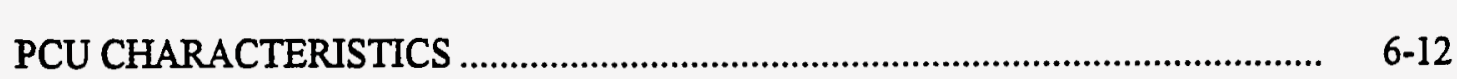

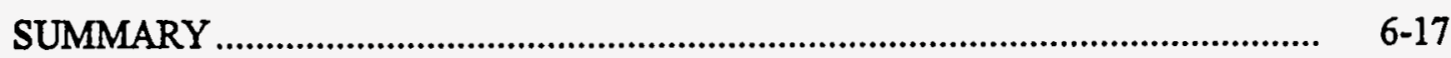

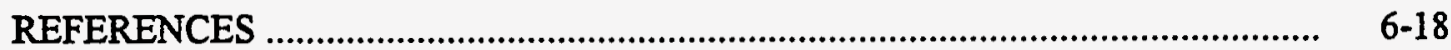

$7 \quad$ US-1, SSI/OMNION, KERMAN.........................................................................

PCU DESCRIPTION ................................................................................

FACTORY AND STARTUP TESTS ................................................................. $\quad 7-4$

OPERATION AND MAINTENANCE .......................................................... $\quad$ 7-10

PCU CHARACTERISTICS ..........................................................................

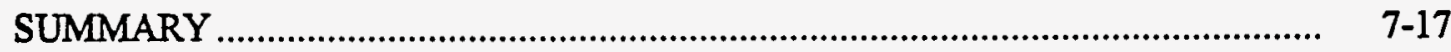

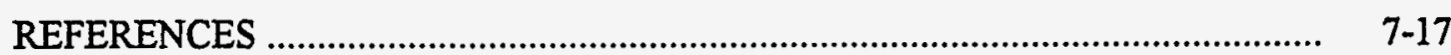

8 SUMMARY, CONCLUSIONS, AND RECOMMENDATIONS …….......................... 8-1

SUMMARY .........................................................................................

CONCLUSIONS ....................................................................................

RECOMMENDATIONS............................................................................... $\quad 8-10$

Appendix A:

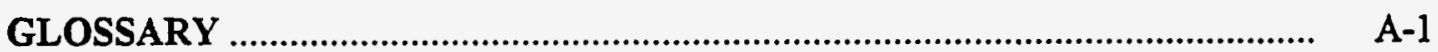

Appendix B:

EXCERPTS FROM PG\&E'S POWER PRODUCER'S INTERCONNECTION

HANDBOOK

Appendix C:

PCU TROUBLE LOG DATABASE 


\section{FIGURES}

Figures • Page

1-1 US-1 PV system interface diagram for the PVUSA Davis site .............................. 1-3

2-1 Simplified PCU circuit and output ac waveform.................................................... 2-2

2-2 Simplified schematic for a current-fed PCU ........................................................... 2-4

2-3 Simplified schematic for a voltage-fed PCU ......................................................... 2-4

2-4 Representative waveforms for a six-pulse inverter .............................................. 2-6

2-5 Representative waveform for a 12-pulse inverter ............................................... 2-7

2-6 Representative waveform for a pulse-width-modulated inverter.................................. 2-7

2-7 Waveform with 3 percent total harmonic distortion ............................................... 2-9

2-8 Representative PCU real and reactive power operating region................................. 2-11

2-9 Simplified electrical single line for the PVUSA Davis site ....................................... 2-13

3-1 Simplified schematic of DECC Model 61635 PCU at Davis, California...................... 3-2

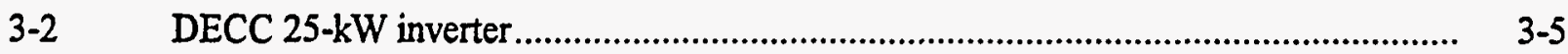

3-3 Exterior and interior of DECC PCU................................................................... 3-6

3-4 Efficiency characteristics of the DECC EMT PCUs ................................................ 3-9

3-5 Current THD characteristics of the DECC EMT PCUs ......................................... 3-10

3-6 De voltage and ac power during morning wakeup process for DECC PCUs................ 3-12

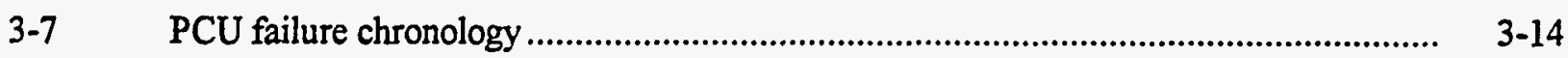

3-8 EMT PCU efficiencies as a function of power......................................................... 3-16

3-9 Phase currents in DECC PCU Unit 1 (SSI) .................................................... 3-18

3-10 Run-on characteristics of DECC EMT PCU ..................................................... 3-20

4-1 Single-line diagram of Omnion/PC US-1 PCU at Davis, California ............................ 4.. 4-2

4-2 Enclosures for Omnion US-1 PCU..................................................................... 4-5

4-3 . Exterior and interior of Omnion US-1 PCU.......................................................... 4-6

4-4 Total harmonic distortion versus power.................................................................. 4-9

4-5 Representative waveforms from run-on tests ....................................................... 4-12

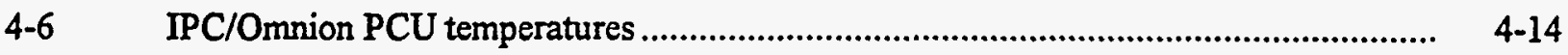

4-7 Efficiency as a function of rated power ................................................................ 4-15

4-8 Ac output currents as a function of rated power .................................................... 4-16

4-9 Power factor and reactive power as a function of rated power.................................. 4-17

4-10 Harmonic distortion at the IPC/Omnion PCU....................................................... 4-18 
Figures

5-1 Simplified schematic of a Dickerson PCU ........................................................ 5-2

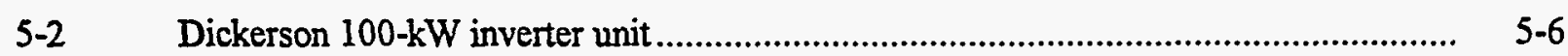

5-3 Dickerson 200-kW PCU transformer/substation................................................. 5-6

5-4 Exterior and interior of a Dickerson 100-kW inverter unit ....................................... 5-7

5-5 Original configuration of a Dickerson 100-kW inverter ........................................ $5-8$

5-6 Run-on test for the SSI/Dickerson inverter .................................................... 5-12

5-7 Efficiency as a function of power ...................................................................... $5-15$

5-8 Ac output currents as a function of power ......................................................... $5-15$

5-9 Power factor and reactive power as a function of power ....................................... 5-16

6-1 Single-line diagram of APS US-1 PCU at Davis, California ..................................... 6-2

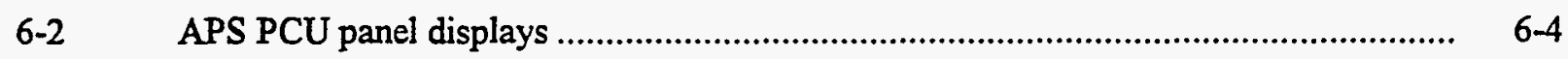

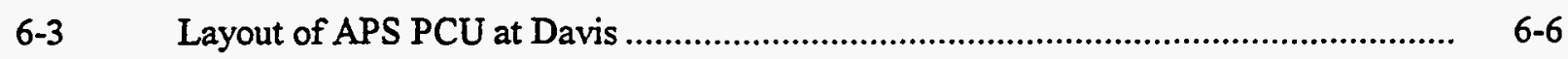

6-4 Photographs of the exterior and interior of the APS PCU container at Davis ............... 6..8

6-5 Lineup of APS PCU modules in container............................................................

6-6 Efficiency as a function of power ........................................................................

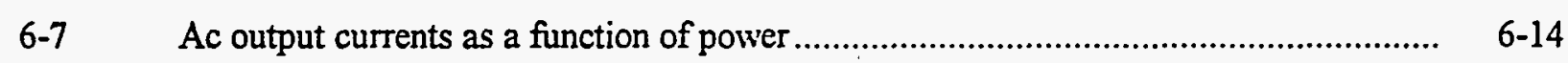

6-8 Power factor and reactive power as a function of power ............................................. $6-14$

6-9 Voltage and current THDs as functions of power ...................................................

6-10 Harmonic distortion at the APS PCU ................................................................... 6-16

7-1 Single-line diagram of the US-2 PV system at Kerman, California.............................. 7-2

7-2 Photographs of the exterior and interior of Omnion PCU at Kerman, California........... 7-5

7-3 Kerman voltage waveform before and after additional filters .................................... 7-11

7-4 Kerman frequency spectra before and after additional filters................................... 7-12

7-5 Efficiency as a function of rated power ...................................................................

7-6 Power factor and reactive power as a function of power level .................................... 7-15

7-7 Current THD as a function of power level................................................................ 7-16

7-8 Voltage THD as a function of power level............................................................ 7-16

8-1 PCU efficiencies as a function of power ................................................................. 8-3

8-2 PCU power factors as a function of power ...........................................................

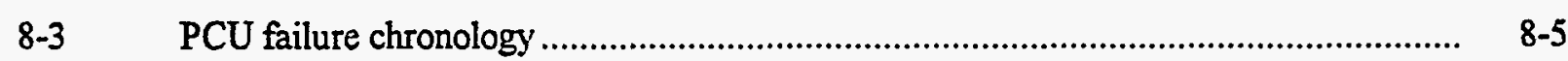




\section{TABLES}

Tables

Page

2-1 Synopsis of EMT PCU Specifications................................................................... 2-14

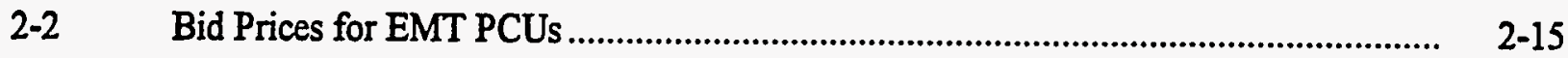

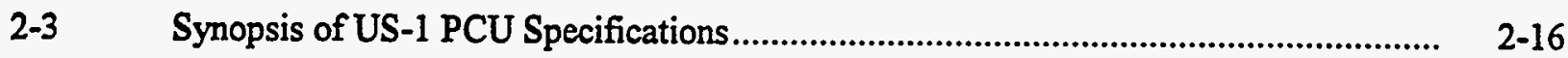

2-4 Highlights of Differences between US-1 and US-2 Specifications .............................. 2-17

3-1 Summary of Manufacturer's Ratings for EMT PCU ............................................... 3-1

3-2 Summary of Factory Test Sequence for EMT PCUs ..................................................

3-3 Summary of Field Test Sequence for EMT PCUs.................................................... 3-11

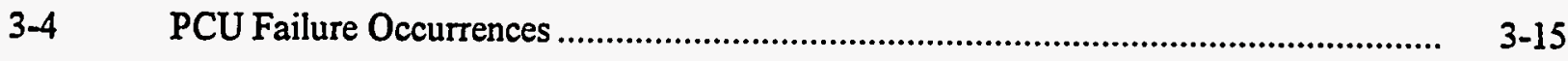

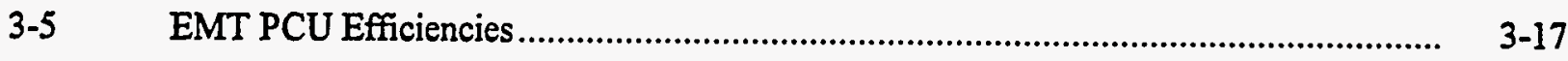

3-6 EMT-1 Harmonics at the Davis Site ................................................................... 3-19

4-1 Summary of Manufacturer's Ratings for IPC/Omnion PCU ...................................... 4-1

4-2 Summary of Factory Tests on Circuit Boards for Omnion US-1 PCU........................ 4-7

4-3 Summary of Factory Tests for Omnion US-1 PCU....................................................

4-4 Summary of Field Test Sequence for Omnion US-1 PCU .......................................... 4-10

4-5 Summary of PVUSA Preparallel Field Test for Omnion US-1 PCUs .......................... 4-11

5-1 Summary of Manufacturer's Ratings for SSI/Dickerson PCU ................................ 5-1

5-2 Summary of Factory Tests for SSI/Dickerson US-1 PCU......................................... 5-10

5-3 Summary of Field Test Sequence for SSI/Dickerson US-1 PCU ................................ 5-11

6-1 Summary of Manufacturer's Ratings for APS PCU ...................................................

6-2 Summary of Factory Tests for APS US-1 PCU........................................................

7-1 Summary of Factory Test Sequence for US-2 (Kerman) PCU.................................... 7-6

7-2 No-Load Power Consumption for US-2 (Kerman) PCU ............................................. 7-8

7-3 . Summary of Field Test Sequence for US-2 (Kerman) PCU....................................... 7-9

8-1 PCU Ratings, Data, and Characteristics................................................................ 8-1 
$$
\text { . }
$$ 


\section{Section 1}

\section{INTRODUCTION}

This is one of a series of topical reports that document experience and lessons learned from the Photovoltaics for Utility Scale Applications (PVUSA) project. The report describes.PVUSA's experience with the procurement, testing, operation, and maintenance of the power conditioning units (PCUs) for the PVUSA Davis and Kerman sites. The PCU is the interface between the photovoltaic arrays and the utility lines, and its operation is greatly influenced by these two elements.

This section presents background information on the PVUSA project and its objectives, summarizes the PCUs evaluated, briefly discusses grid connection requirements, and describes the contents of this report.

\section{PVUSA BACKGROUND}

Established in conjunction with the U.S. Department of Energy (DOE), PVUSA is a national publicprivate partnership that is assessing and demonstrating the viability of utility-scale (US) photovoltaic (PV) electric-generating systems. PVUSA offers utilities the hands-on experience needed to evaluate maturing PV technology, provides manufacturers with a test bed for their products, and encourages technology improvement and cost reductions in PV modules and balance-of-system (BOS) components. The project also facilitates communication between utilities, government laboratories, and the PV industry, which is vital for developing and commercializing utility PV systems.

In 1986, PG\&E proposed the PVUSA concept to DOE, the Electric Power Research Institute (EPRI), and the California Energy Commission (CEC) to establish a demonstration and technology transfer bridge between then-current R\&D activities and the expected large utility PV power plants of the future. Today, PVUSA's participants include 18 utilities, research institutes, and government agencies.

Three groups manage the project: the Steering Committee coordinates overall project direction and approves the project's scope, schedule, and budget; the Technical Review Committee assesses and reviews the technical aspects of the project; and the Project Team, led by PG\&E and its principal subcontractor, Bechtel, conducts daily operations, manages construction, and facilitates technology transfer. A second major subcontractor, Endecon, provides PV engineering support and operates the data acquisition system (DAS). 
The PVUSA project has five principal objectives:

- Evaluate the performance, reliability, and cost of promising PV modules and BOS components side by side at a single location

- Assess PV system operation and maintenance (O\&M) in a utility setting

- Compare PV technologies in diverse geographic areas

- Provide U.S. utilities with hands-on experience in designing, procuring, and operating PV systems

- Document and disseminate knowledge gained from the project

This report helps meet the last of these five objectives. The data used to prepare the report were obtained in the course of meeting the first and second of the above objectives for the project. A glossary of commonly used terms and abbreviations is found in Appendix A.

\section{PCU DESCRIPTIONS}

At present, there are five different models of PCUs at PVUSA's Davis and Kerman sites.

Each of the six Emerging Module Technology (EMT) PV systems at Davis is connected to a 25-kW PCU, which was supplied by the Delta Electronic Control Company (DECC) Division of Helionetics, Inc. of Irvine, California, via a competitive bidding procurement process. The units are designed for fully automatic, unattended operation. These PCUs have a relatively large dc voltage range and power rating in order to make it possible to connect them to a variety of PV systems, which had not yet been selected at the time the PCU specifications were issued for bidding. Similarly, the units have a rather full complement of instrumentation to facilitate evaluation of the EMT PV arrays.

There are three US PV systems at Davis. These three systems were all part of the first procurement of US systems, designated "US-1." Their PCUs were procured as parts of competitively bid turnkey PV systems. Figure 1-1 gives an overview of a representative electrical interface of a US-1 system at Davis.

The Integrated Power Corporation (IPC) US-1 PV system uses a PCU provided by Omnion Power Engineering Corporation in East Troy, Wisconsin. The PCU is an Omnion Series 3200 static power converter and is rated at $200 \mathrm{~kW}$. 


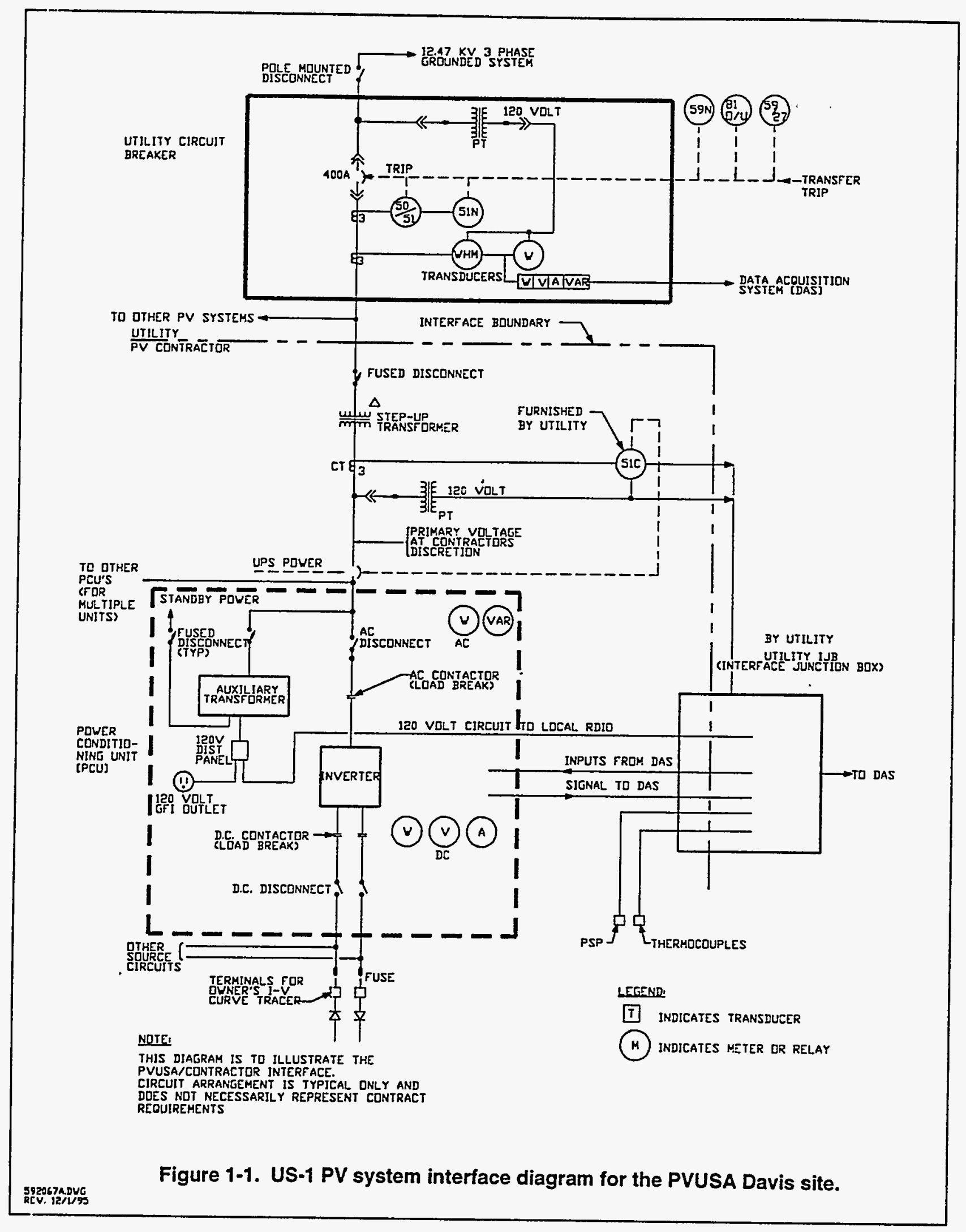


The Siemens Solar Industries (SSI) US-1 PV system uses a PCU provided by Bluepoint Associates, Ltd., of San Luis Obispo, California. The unit comprises two Dickerson 100-kW inverters. Each of these inverters consists of two $50-\mathrm{kW}$ inverter "cores" which, in tum, consist of two $25-\mathrm{kW}$ SCR inverter bridges.

Advanced Photovoltaic Systems (APS) (successor to Chronar) of Princeton, New Jersey, fabricated the PCU for its US-1 PV system. The PCU includes four collocated 125-kVA inverter modules whose outputs are combined in a single 530-kVA transformer.

In a second US system procurement, designated "US-2," Siemens Solar Industries, Inc. installed at Kerman a 500-kW (nominal) system with a PCU supplied by Omnion Power Engineering Corporation. The PCU consists of two Omnion Series 3200 static power converters. The two $275-\mathrm{kW}$ units are connected in parallel to a step-up transformer.

\section{INTERCONNECTION REQUIREMENTS}

PG\&E has a variety of non-PG\&E-owned generators connected to its lines. To ensure that such systems are compatible, nondisruptive, and safe for connection to the utility lines, PG\&E compiled its Power Producer's Interconnection Handbook [1-1]. The basis for the interconnection requirements is Electric Rule No. 21, as approved by the California Public Utilities Commission (CPUC). The handbook describes the interconnection process from the planning of a project through project operation. It also presents details on required protective devices, metering, and preparallel testing. The requirements in this handbook are applicable to the PVUSA project at both the Davis and Kerman sites. Excerpts from the handbook are presented in Appendix B.

\section{REPORT ORGANIZATION}

Section 2 describes the basics of PCU operation, the characteristics of relevance, and other items as may be needed to aid in understanding the report; highlights EMT PCU procurement specifications and relevant portions of the US-1 and US-2 system procurement specifications; and presents electrical singleline diagrams for the Davis and Kerman sites. Further details on procurement and acceptance testing are in a PVUSA topical report [1-2]. 
Sections 3 through 7 each address one of the five PCUs, as follows:

- Section 3. EMT, DECC/Helionetics

- Section 4. US-1, IPC (Omnion)

- Section 5. US-1, SSI (Dickerson)

- Section 6. US-1, APS

- Section 7. US-2 - SSI (Omnion) - Kerman site

Each of these five sections comprises a parallel set of subsections:

- PCU Description. Describes PCU components and operation, and includes drawings and photographs of the unit.

- Factory and Startup Tests. Describes and comments on factory and field startup testing. Describes actions and modifications as may have been required to bring the unit up to specifications or accomplish other desired functions.

- Operation and Maintenance. Summarizes problems encountered and corrective actions implemented for the units in the field.

- PCU Characteristics. Presents data on efficiency, ac output current unbalance, power factor, and harmonic distortion. Summarizes the unit's performance.

- Summary. Presents conclusions and discusses lessons learned on design, operation, and maintenance, as applicable.

Section 8 presents a summary which compares characteristics, performances, O\&M, and similar items for the five PCUs. This section also includes broader conclusions and overall recommendations.

There are three appendices: a glossary of abbreviations, acronyms, terms, etc.; PG\&E interconnection requirements; and a summary of data condensed from PVUSA's PCU trouble log database.

\section{REFERENCES}

1-1 Power Producer's Interconnection Handbook, Pacific Gas and Electric Company, March 1993.

1-2 PVUSA Procurement, Acceptance and Rating Practices for Photovoltaic Power Plants, report prepared for Pacific Gas and Electric Company, DOE/AL/82993-21, September 1995. 


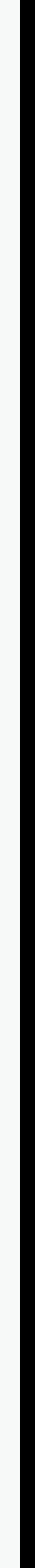




\section{Section 2 \\ PCU TECHNOLOGY}

This section briefly discusses power conditioning unit (PCU) basics and presents relevant portions of the PVUSA PCU specifications. The discussion of PCUs is intended to provide an inșight into the material that follows; it is not intended to be a comprehensive tutorial. Additional background information is available in several text books and reports [2-1, 2-2, 2-3].

\section{PCU BASICS}

PCUs convert the dc produced by a PV system to the ac used in electric utility systems. After the PV modules and array structures, the PCU can be the most significant contributor to the total system cost. The PCU also has been one of the major maintenance items.

The term power conditioning unit (PCU) is used in this report. The terms power conditioning system (PCS), converter, and inverter also are used somewhat interchangeably to describe the same type of equipment. The term inverter implies equipment that changes dc to ac. (A rectifier changes ac to dc.) The other terms are also used to describe bidirectional equipment (capable of rectifying as well as inverting), such as is needed to charge and discharge a battery or superconducting energy storage system.

There are a number of possible approaches for converting dc to ac for PV, battery, fuel cell, and other dcbased systems. Motor-generator sets have been employed in the past, but because of maintenance and efficiency considerations associated with rotating equipment, these sets have generally been replaced by static (i.e., no rotating/moving parts) PCU equipment using solid-state (e.g., transistors) switches. With this type of circuit, the active elements are alternately switched between full-on and full-off conditions.

Figure 2-1 shows a simplified single-phase inverter circuit.

Inversion from dc to ac is accomplished as follows. Closing switches 1 and 4 causes a current to flow through the load, as illustrated by the dashed line in Figure 2-1. After 8 milliseconds (for a $60-\mathrm{Hz}$, singlephase unit), switches 1 and 4 open, and switches 2 and 3 close. This causes the current to flow through switches 2 and 3, and in the opposite direction through the load (not illustrated). The current, of course, 

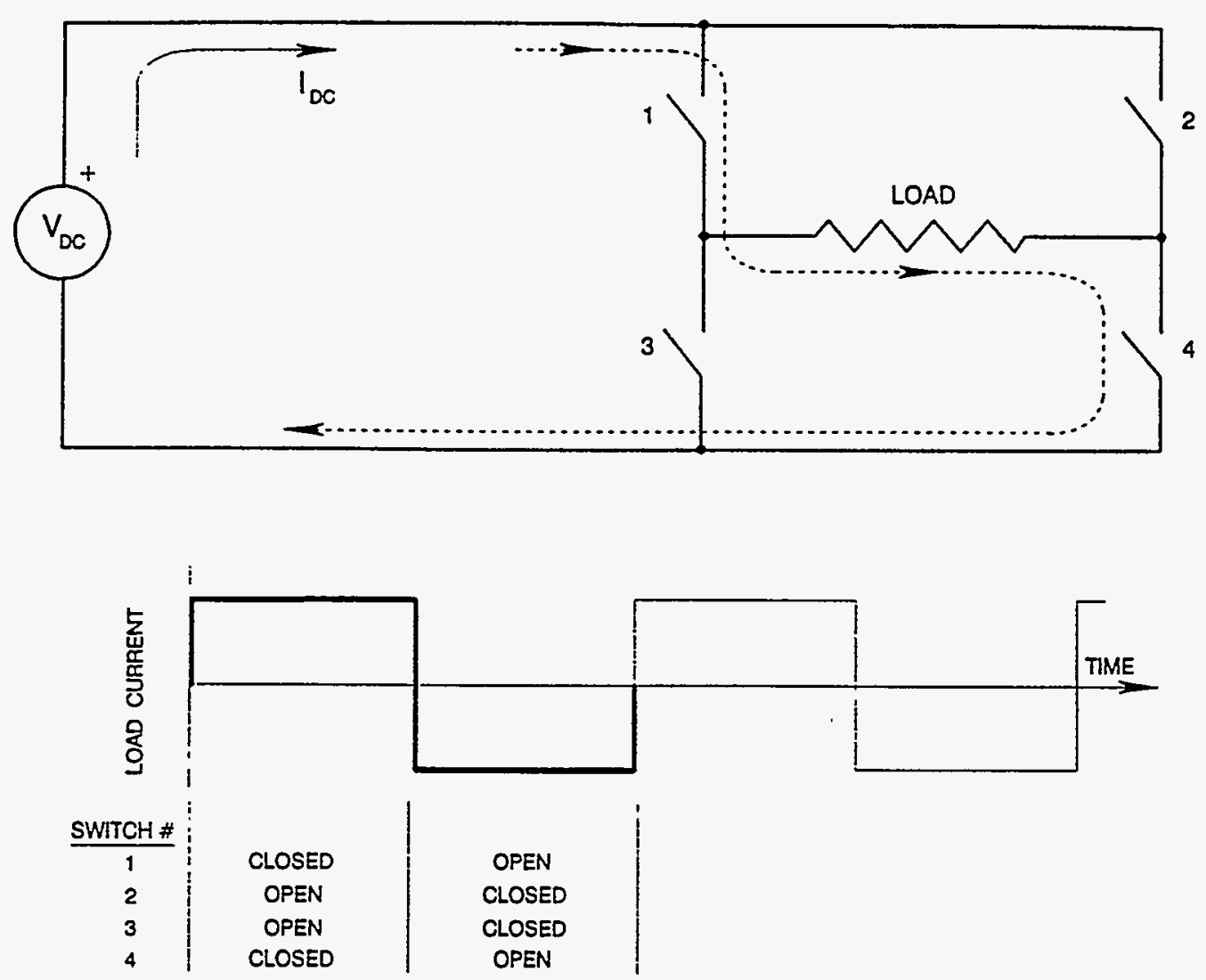

Figure 2-1. Simplified PCU circuit and output ac waveform.

continues to flow in the same direction in the dc portion of the system. After another 8 milliseconds, switches 2 and 3 open, and switches 1 and 4 close. This cycle is repeated 60 times per second, and an alternating current is produced in the load, as indicated by the waveform in the lower half of the figure. The table under the waveform shows the conditions of the four switches during the two 8-millisecond time periods discussed above. The waveform illustrated is for a resistive load; inductive or capacitive load components will alter the waveform. Additional features are incorporated into practical PCUs so that the ac output more closely resembles a sine wave. (The waveshapes produced by some of the earliest low-power inverters were not too much better than those illustrated in Figure 2-1.)

In actual PCU equipment, the switches are replaced by any of a number of solid-state devices. (The earliest PCUs for high-voltage dc [HVDC] lines had mercury-arc tubes.) Today silicon control rectifiers (SCRs) are the switching elements in high-power inverters (hundreds of megawatts) and related applications, such as rectifiers and HVDC line terminals. SCRs can be turned on by a low-power control 
signal, but cannot be turned off by a control signal. The current through the SCR must go to zero before these devices turn off and a blocking (open switch) condition is established.

A second type of switching device is the gate turn-off (GTO) SCR. This type of device can be turned off by a pulse to its control gate terminal.

Switching transistors, such as insulated-gate bipolar transistors (IGBTs), can also be turned on and off by low-power control signals. This technology has advanced to the point where IGBTs and similar devices can be used in moderate power (i.e., megawatt) PCUs.

Although switching devices are controlled by relatively low-power signals, control signals usually must be amplified from the low-power levels in logic circuits. Amplifiers and other components, such as fiber optic cables, are employed to isolate logic circuits from power circuits.

Each of the above solid-state switches has current, voltage, and other characteristics (including costs) that may lead to its selection for a particular PCU and application. The SCR has the greatest power handling capability, and the lowest cost and switching speed. The IGBT has the lowest power handling capability, the highest cost and switching speed, and the lowest losses. GTO SCR values for these characteristics lie somewhere between those of the other two devices.

Regardless of the device used, most PCUs with a rated capacity over a few hundred kilowatts have an efficiency of about 95 percent when operating at full power (with one to two percentage points of the efficiency due to an output transformer). Other things being equal, the lowest PCU costs result from the fortuitous and/or deliberate design effort of matching dc circuit voltage and current to the switching device characteristics to fully utilize its capacity. Solid-state device technology continues to advance, and optimum voltages and currents are also changing. From a pragmatic aspect, the lowest cost for equipment from a given manufacturer may be for a PCU whose requirements allow the use of previous designs and parts from existing equipment.

At powers levels above a few kilowatts, the PCU will have a three-phase output (rather than the singlephase output shown in Figure 2-1). Figures 2-2 and 2-3 illustrate two typical three-phase bridge configurations. The assembly of switching devices shown in both figures is called an inverter bridge, and the constituent elements are called power poles. At higher power levels, several switching devices in a 


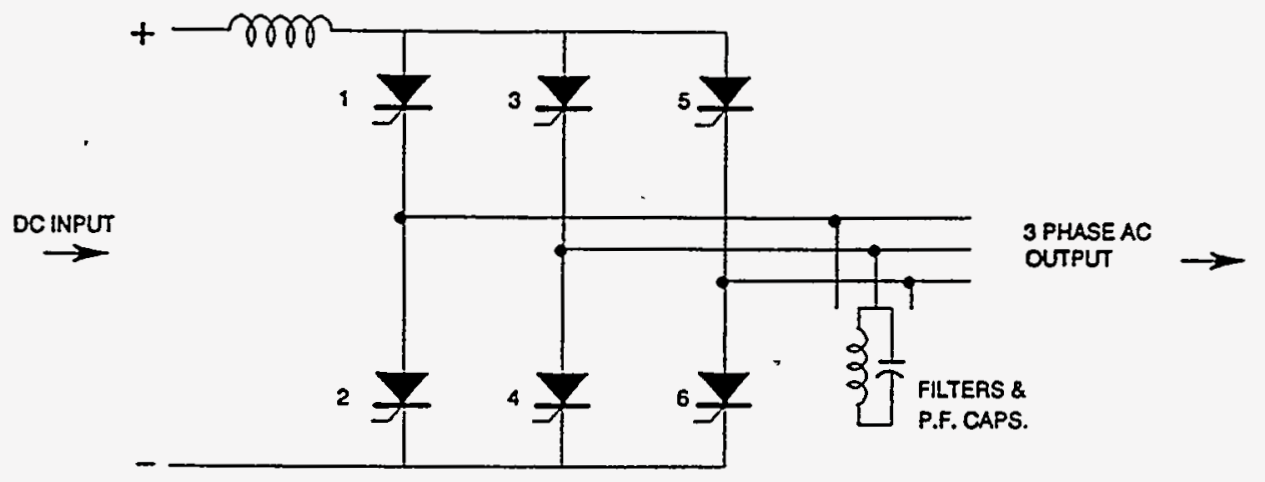

Figure 2-2. Simplified schematic for a current-fed PCU.

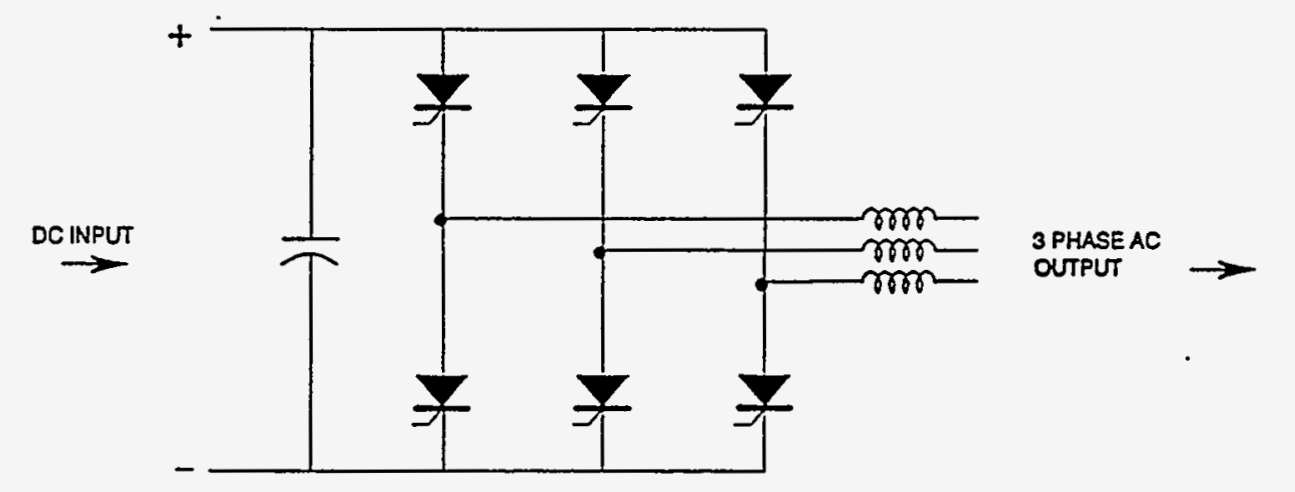

Figure 2-3. Simplified schematic for a voltage-fed PCU

PCU power pole may be connected in series or parallel to attain a required voltage or current that exceeds the ratings of a single device. More commonly, multiple bridge assemblies are connected in parallel. For PV systems, the dc voltage is generally such that series connections are not required (but they are used in HVDC terminals and other applications). Some PCU designs (not illustrated) may include a dc-to-dc converter to match input voltages and currents to those of existing bridge equipment.

The switching of current flow from one branch of a circuit to another (e.g., 1-4 to 2-3 in Figure 2-1) is called commutation. Inverters are often classified according to their method of commutation. Inverter circuits may be broadly categorized as either line- or self-commutated, which relates back to turning off 
SCR-based inverters. The energy to do this may be supplied either internally by circuit elements, such as capacitors (self-commutated), or externally by connecting the inverter to a stiff ac line (line-commutated). Since line-commutated inverters rely on a stiff ac bus to provide the energy required to turn off SCRs, this type of circuit is operated in parallel with a utility line. Line-commutated inverters can be forced to be self-commutating by the addition of external capacitors, but their cost then approaches or exceeds that of similar self-commutated equipment.

Current-sourced inverters almost invariably use SCRs and are line-commutated. Their attractive features include, on a relative basis, high-power capability (for SCRs compared to present turnoff devices, such as GTOs and transistors), simplicity of design, and low cost. Unattractive features include consumption of reactive power (VARs) from the ac line (or from harmonic filters or an added capacitor system), high harmonic current injection, and susceptibility to commutation failure faults due to disturbances on the ac line. As illustrated by the schematic in Figure 2-2, this type of PCU is generally characterized by a large inductor on the dc side, and harmonic filters and VAR-supplying capacitors on the ac side.

Since GTOs and transistors can be biased off, inverters using such devices are inherently selfcommutating. Self-commutated inverters can operate into a passive load, a feature that is required for remote, non-grid-connected installations and that must be controlled to prevent run-on in grid-connected applications. Run-on (also called islanding) is a condition wherein the PCU continues to supply power into a line after the utility power source is disconnected, which can be a safety hazard. This type of PCU is normally characterized by a capacitor on the dc side and series inductors on the ac side, as shown in Figure 2-3.

The simplified circuit and switching described for Figure 2-1 produce a rather rudimentary and generally unacceptable approximation of a sine wave. Resolution of this waveform by Fourier analysis shows the waveform in Figure 2-1 to be rich in harmonics (multiples of the fundamental $60 \mathrm{~Hz}$ sine wave). Practical PCUs employ phase-shifted multiple bridges, pulse-width modulation, and other schemes to produce acceptable waveforms and levels of harmonic distortion.

Figure 2-4 shows waveforms for a three-phase, line-commutated PCU. The upper three curves illustrate the gating and on/off states of the six SCRs as functions of time; the lower curve shows the resulting current for one phase. The SCR numbers refer to Figure 2-2. This configuration is known as a six-pulse 


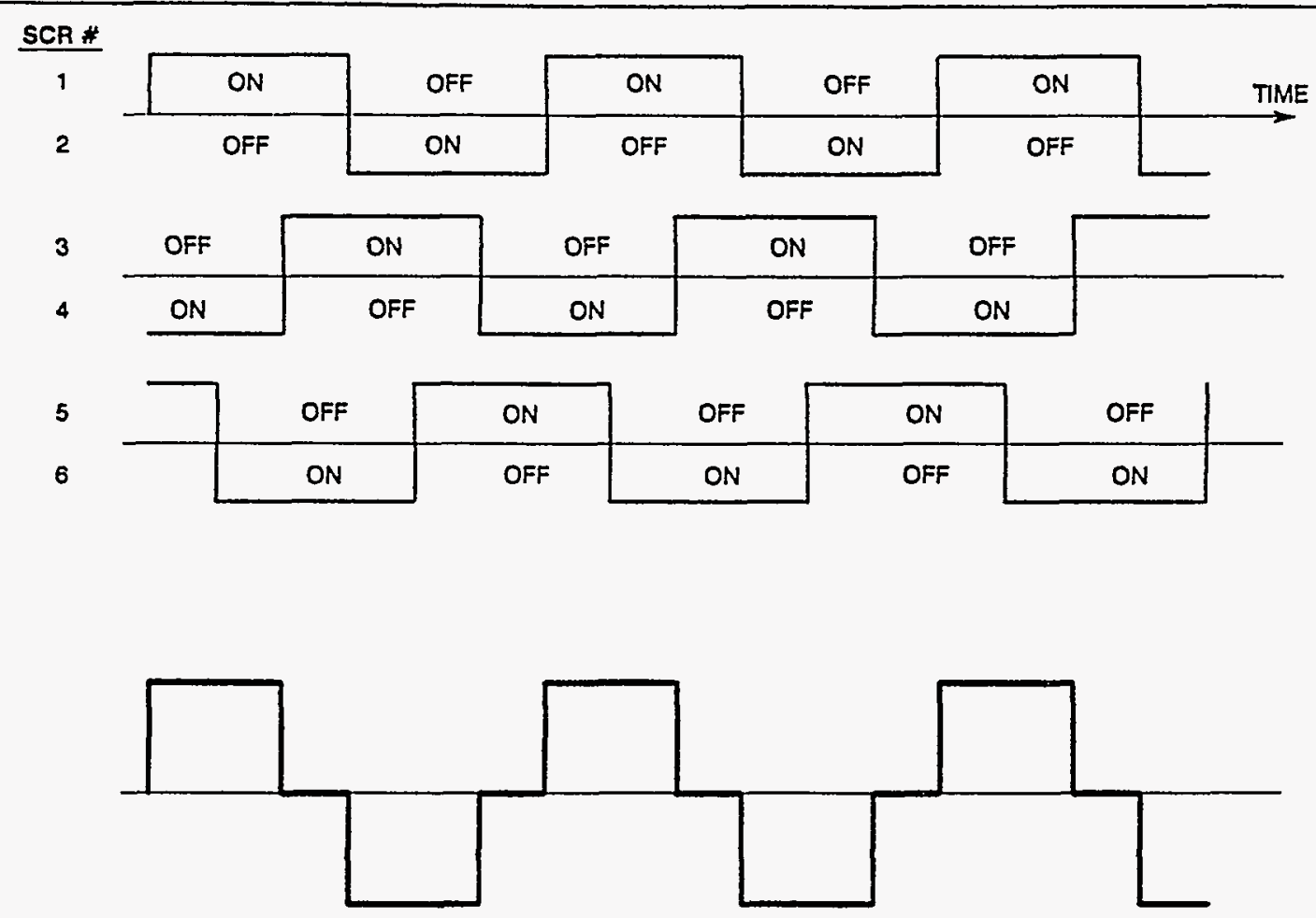

Figure 2-4. Representative waveforms for a six-pulse inverter.

inverter (per the number of SCRs). Mathematically, the theoretical output waveshape is an odd function, i.e., $F(t)=-F(-t)$. As a result, there are no even-numbered harmonics. This holds true in practice, although mismatches and tolerances in PCU components or malfunctions may result in a very small amount of even harmonics. The three-phase configuration eliminates triplen harmonics (i.e., the third harmonic and all of its multiples), except perhaps when the load is unbalanced (i.e., when the currents are not equal in all three phases). The remaining harmonics are given by $\mathrm{n}=\mathrm{pq} \pm 1$, where $\mathrm{n}$ is the harmonic number, $p$ is the number of pulses and $q$ is $1,2,3, \ldots$, etc. For the six-pulse configuration $(p=6)$, the lowest $(q=1)$ harmonics are the fifth and seventh $(5=6 \times 1-1$ and $7=6 \times 1+1)$. The next lowest harmonics $(q=2)$ are the 11 th and 13 th. As can be seen, the \pm 1 term in the expression for harmonic numbers means that harmonics appear in pairs. The magnitude of the harmonics is proportional to $1 / \mathrm{n}$. In practice, this is modified by filters.

A PCU may include two or more three-phase bridges. The gating signals and bridges are typically phased to eliminate the lowest set(s) of harmonics. A two-bridge configuration can produce a 12-pulse output wherein the lowest harmonics are the 11 th and 13 th $(11=12 \times 1-1$ and $13=12 \times 1+1)$. The left half of 
Figure 2-5 shows the waveform for this type of configuration. As can be seen, this waveform more closely approximates a sine wave than does a six-pulse waveform, but filtering is still required to produce the sine wave shown in the right half of Figure 2-5. Larger numbers of bridges, phased to give higher pulse numbers, are typically used in HVDC terminals; Southern California Edison's 10-MW battery energy storage facility uses an 18-pulse PCU configuration.

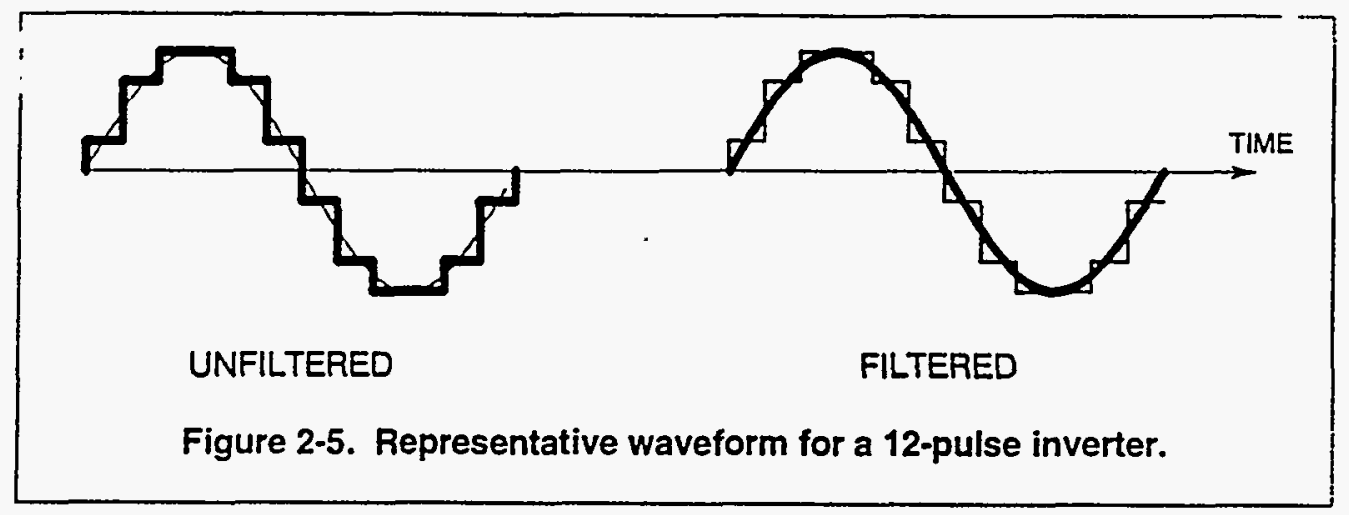

Many of the recent PCUs in the power range below $1 \mathrm{MW}$ are IGBT-based, self-commutated designs which use some form of pulse-width modulation. The left half of Figure 2-6 shows representative waveforms for this type of PCU. As indicated in the figure, individual switching devices are typically turned on and off many times per cycle and on the order of thousands of times per second. This requires a solid-state device with a suitably high switching frequency capability. A small amount of filter capacitance may be added to produce the sine wave shown in the right half of Figure 2-6.

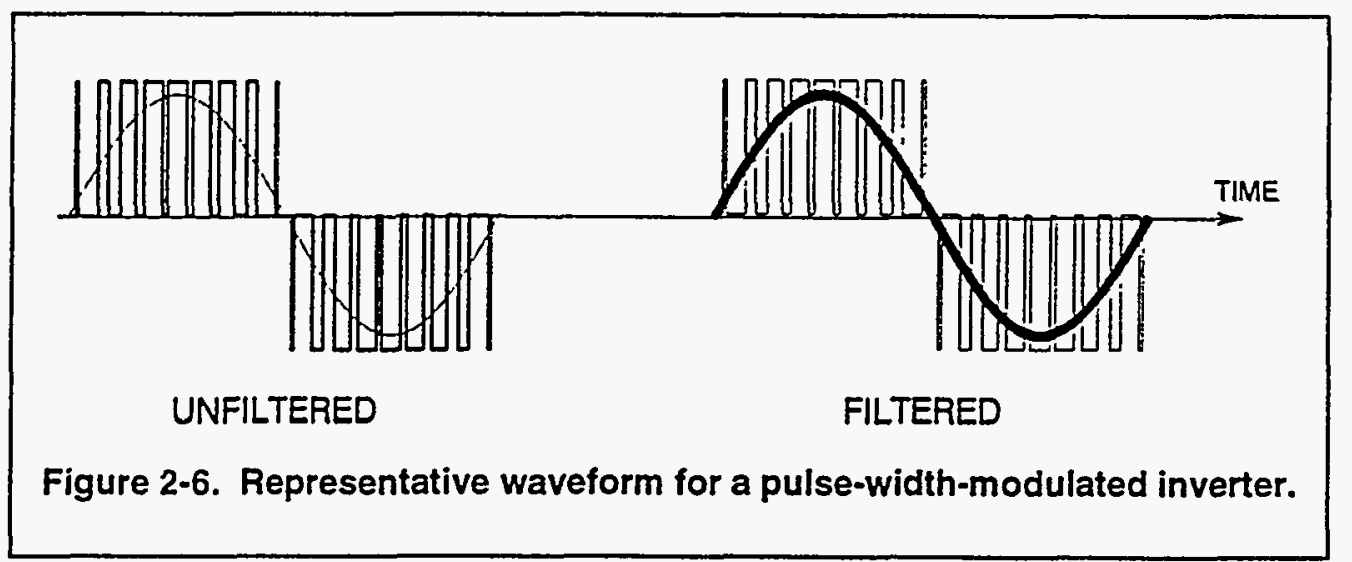

In general, self-commutated inverters are harmonic voltage sources and line-commutated inverters are harmonic current sources. In this respect, a self-commutated inverter resembles a conventional utility generator, a voltage source behind an impedance. Both types of inverter can reduce or cancel lower order harmonics by the phase-shifting multibridge techniques discussed above. The remaining harmonic 
currents in self-commutated inverters are limited by the ac-side reactance, particularly where the connected ac line has a low impedance. As illustrated in Figure 2-3, they have a series inductor on the ac side, in addition to transformer leakage reactance. With weak ac lines, additional filtering may be required. As shown in Figure 2-2, line-commutated inverters have large reactors on the dc side and, usually, only transformer leakage reactances on the ac side. The large inductance on the dc side forces harmonic currents to flow on the ac side, and these harmonic currents must be diverted by relatively large, low-impedance filters.

Harmonics are undesirable. They may cause electronic equipment to malfunction, result in higher than usual heating in other equipment (particularly higher harmonics in items such as motors and transformers), and do not deliver useful energy (except to resistance heaters and similar loads). At present, IEEE 519-1992 offers guidance as to allowable levels of harmonics. (This document is currently a guide/recommended practice and may eventually become a standard.) IEEE 519-1992 calls for limiting voltage total harmonic distortion (THD) to 5 percent, with no more than 3 percent at any single frequency (for points of common connection below $69 \mathrm{kV}$ ). Mathematically, THD is the square root of the sum of the squares of all of the harmonic voltages (or currents) divided by the voltage (or current) at the fundamental frequency (e.g., $60 \mathrm{~Hz}$ ). IEEE 519-1992 also cautions that meeting recommended limits does not guarantee the absence of difficulties. This is illustrated by the waveform in Figure 2-7. The waveform has a low THD ( 3 percent) and is representative of a 12-pulse output with filtering. The light line shows a perfect sine wave (i.e., 0 THD). The phases of the harmonics were adjusted to produce worst case results, but it still serves to illustrate the point. The extraneous zero crossing may cause difficulties in electronic equipment that uses the (expected) $60 \mathrm{~Hz}$ to derive internal timing signals (e.g., clocks).

The discussion of switch gating, waveshapes, and harmonics thus far has been for PCU operation at full power. PV systems and their PCUs will operate many hours per year at less than rated power. The timing of the turn-on and turn-off signals is changed to reduce the power, which also changes the output waveforms, harmonic distribution, and THD. The discussion also does not cover the characteristics of the connected ac line, its impedances (including time varying factors such as loads and switched capacitors), unbalance, dc and ac voltage levels (relative to their nominal values), other paralleled PCUs and their filters (if present), and possible resonances associated with such components and/or the ac line. 


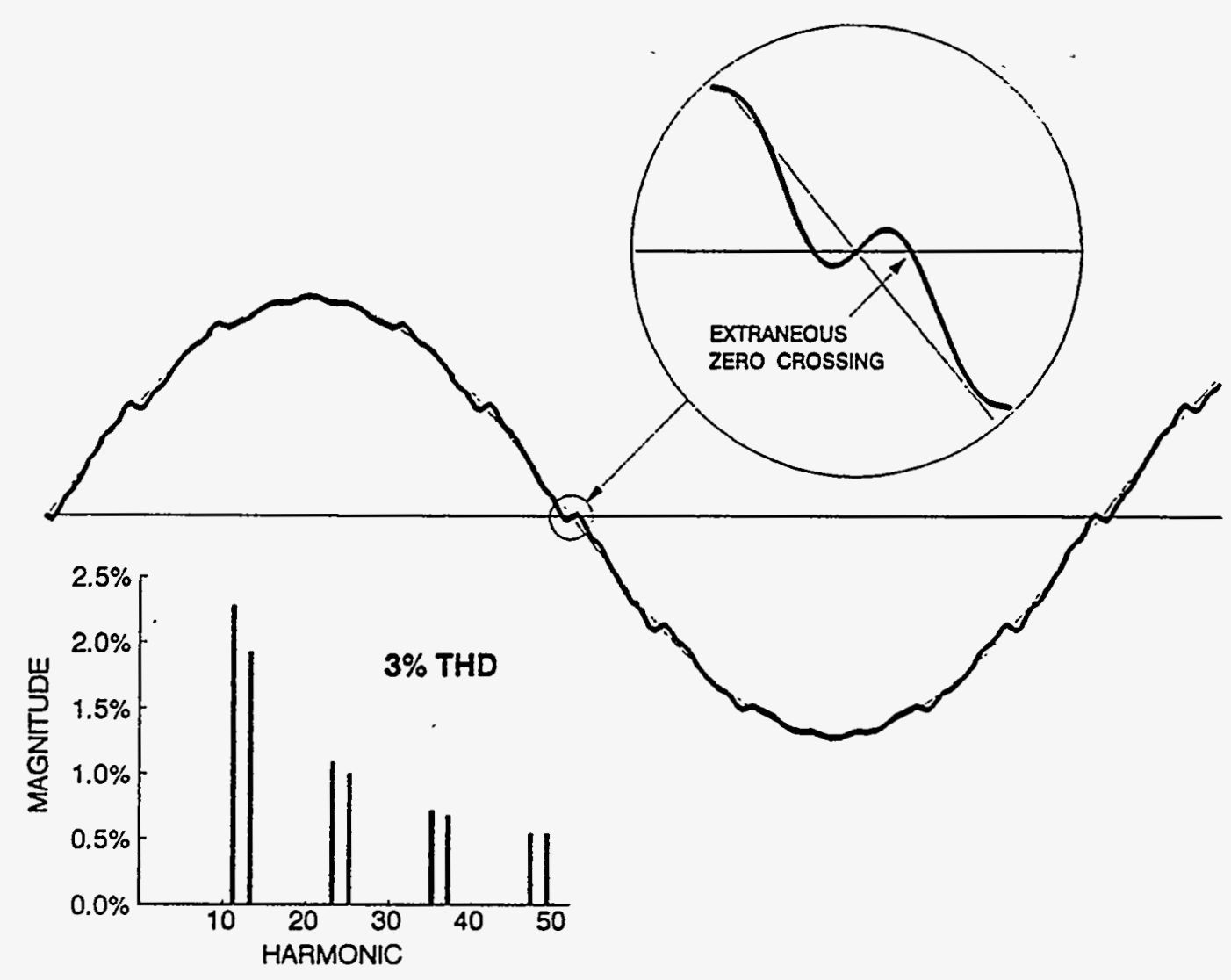

Figure 2-7. Waveform with 3 percent total harmonic distortion.

The physics of a PV cell (and total array system) requires it to operate at a specific combination of voltage and current in order to deliver the maximum available power. This maximum power point changes with the amount of incident sunlight and with temperature. PCUs for a PV system generally include sensors, logic, and controls to determine and operate the system at the maximum power point of the connected PV array. Several approaches are used to accomplish this function. For the most part, these involve the PCU controls changing to operate at a slightly higher dc voltage and determining whether the output power increases. If the power increases, the dc voltage operating point is increased further; if it decreases, the operating voltage is lowered. This process is automatic, and the PCU continuously tracks the PV array's maximum power point.

Other control aspects include automatic starting and stopping of the PCU as the presence of sufficient power is detected. Depending on the design, startup may be initiated when the array voltage reaches a preset level, and shutdown may be initiated when no net power is delivered to the connected ac line. PCU 
controls also have provisions for synchronizing with the ac line, detecting that the ac voltage and frequency are within preset limits, and shutting down when an out-of-tolerance condition is detected. PCU controls may limit power (to prevent damage to the unit) by operating off the maximum power point, or may disconnect a portion of the array if the dc input exceeds preset values. Other provisions to prevent damage include fuses on the switching devices, dc and ac buses, and various internal components; circuit breakers and/or contactors; sensors for overtemperature, overvoltage, presence of control signals, and monitoring various internal functions. A PCU may also include logic to prevent external control signals from causing damage (a requirement for PVUSA).

The PCUs for PVUSA are operated only as inverters; that is, they change a dc input from a PV array to an ac output compatible with the connected utility line. Some PV installations may incorporate an energy storage system. Most PCUs are inherently capable of being operated in a rectifier mode to allow charging of an associated battery energy storage system from the utility line, but such operation would require modification of the hardware and control software of a PCU designed purely for PV system operation (e.g., higher voltages on charge, reverse power trip settings). Self-commutated voltage-fed PCUs reverse power flow by reversing the direction of the dc current (with the same dc voltage polarity), which is suitable for charging batteries. Line-commutated current-fed PCUs reverse power flow by reversing the dc voltage polarity and would require a reversing dc contactor to be suitable for battery charging. These would, however, be suitable for a superconducting energy storage (SMES) system, which requires reversing of the dc voltage polarity between discharge and charge.

A PCU may deliver or consume reactive power (VARs). Line-commutated inverter bridges are net consumers of VARs, which may be supplied in part by harmonic filters or by the addition of capacitors. VAR consumption varies with power level and dc and ac voltages, and the capacitors may be switched to maintain the power factor near unity. Self-commutated inverters may be controlled to either consume or deliver VARs. A four-quadrant PCU is capable of delivering and withdrawing both real and reactive power from a utility line within its operating ratings, as indicated in Figure 2-8. Four-quadrant power factor control can be designed into self-commutated inverters, and switched capacitors may offer limited capability in this regard for line-commutated inverters. In practice, actual PCU characteristics may deviate from the circular operating region shown in the figure. This deviation may be due to voltage limits and other factors in the design. 


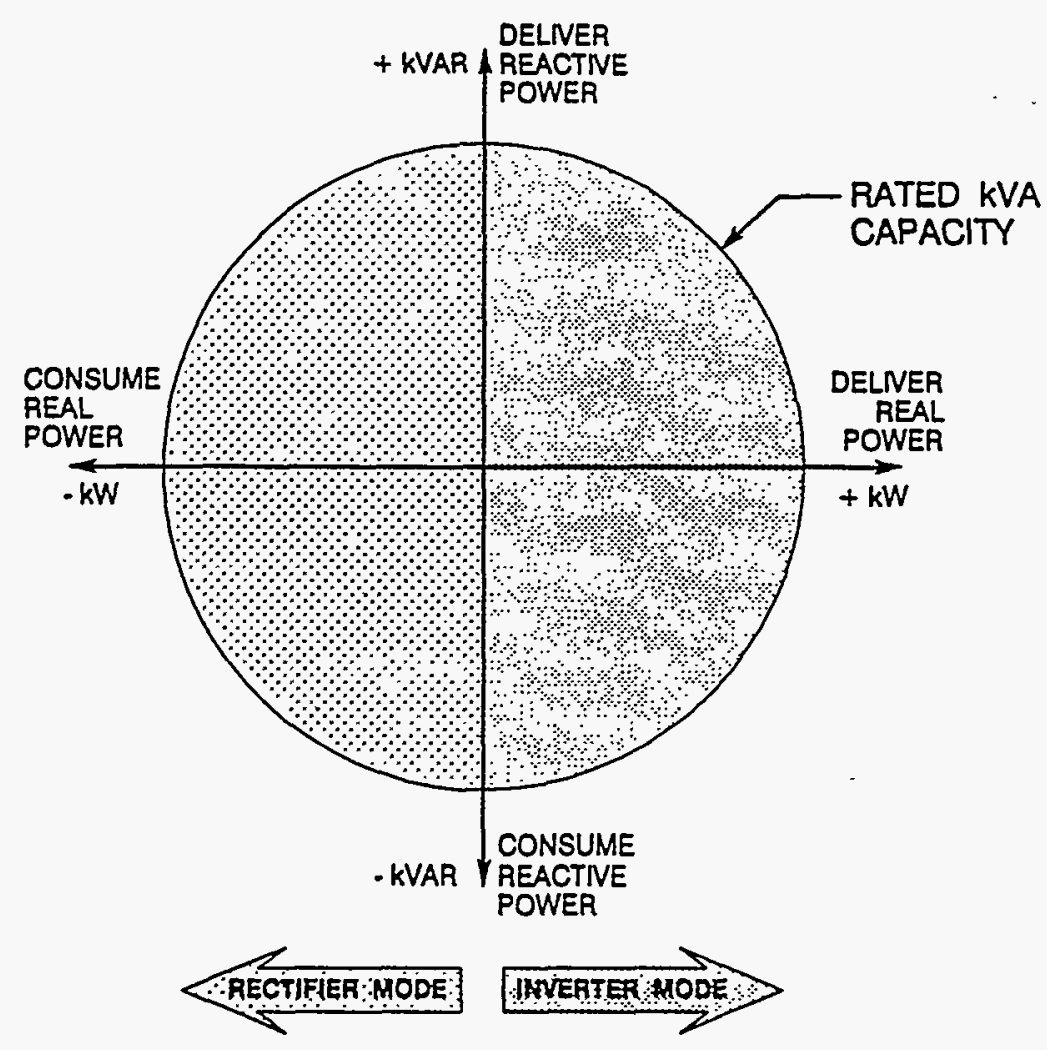

Figure 2-8. Representative PCU real and reactive power operating region.

The power rating of the PCU depends on several factors, including the voltage and current ratings of its internal components. It also depends on the thermal characteristics of the components and design. A PCU may be capable of delivering five times its rated power (or more) for a short, nonrepetitive pulse of a fraction of a second to a few seconds in duration. A manufacturer may use this capability to permit its equipment to ride through transient events without shutting down.

\section{PVUSA PCU SPECIFICATIONS}

The specifications for the EMT PCUs and the PCU portions of the US-1 and US-2 Requests for Proposals (RFPs) were developed by PVUSA personnel. These were reviewed by utility, national laboratory, and other personnel on the PVUSA Technical Review Committee, whose comments were incorporated prior to issuing the RFPs for the equipment. 
Figure 2-9 shows how the EMT and US-1 PCUs, utility line, and loads are electrically interconnected at the PVUSA Davis site.

\section{EMT Power Conditioning Unit}

The RFPs for the EMT PCU was issued for competitive bidding on January 8, 1988, approximately 2 months before the bids were due for the EMT PV systems. To accommodate the expected, plausible range in PV system parameters, the PCU operating dc voltage range was larger than would be required for a PCU designed for a specific PV system, and the power level was higher to cover plausible needs. Additionally, the level of instrumentation was higher, as befits a test facility.

Table 2-1 presents a synopsis of the specifications in the RFP for the EMT PCU. Further details on the PCUs actually installed are presented in Section 3.

The RFP required a bid to supply an initial complement of five units and a bid to supply additional units at a fixed price. Data on the bid prices are summarized in Table 2-2. The contract was awarded to the lowest bidder (based on supplying a total of 12 units).

\section{US-1 Power Conditioning Units}

The US-1 PV systems were procured as complete turnkey systems, including the PCU. The RFP for the US-1 systems was issued for competitive bidding on November 23, 1988. Table 2-3 presents a synopsis of PCU specifications. The RFP included specifications for over/under voltage and frequency protection to be incorporated in the PCUs (see Table 2-4). As a result of a review by utility personnel at the time the contracts were finalized, the utility provided these functions via protective relays, which tripped the main 12.47-kV fault interrupter, as shown in Figure 1-1. The PCUs do not duplicate this protection. Details on the characteristics of the PCUs actually installed are presented in Sections 4, 5, and 6. These units incorporate features that are not specifically requested, but that are desired by the manufacturers.

As mentioned, the US-1 PCUs were procured as parts of complete systems and information on PCU prices as separate items is not available. 


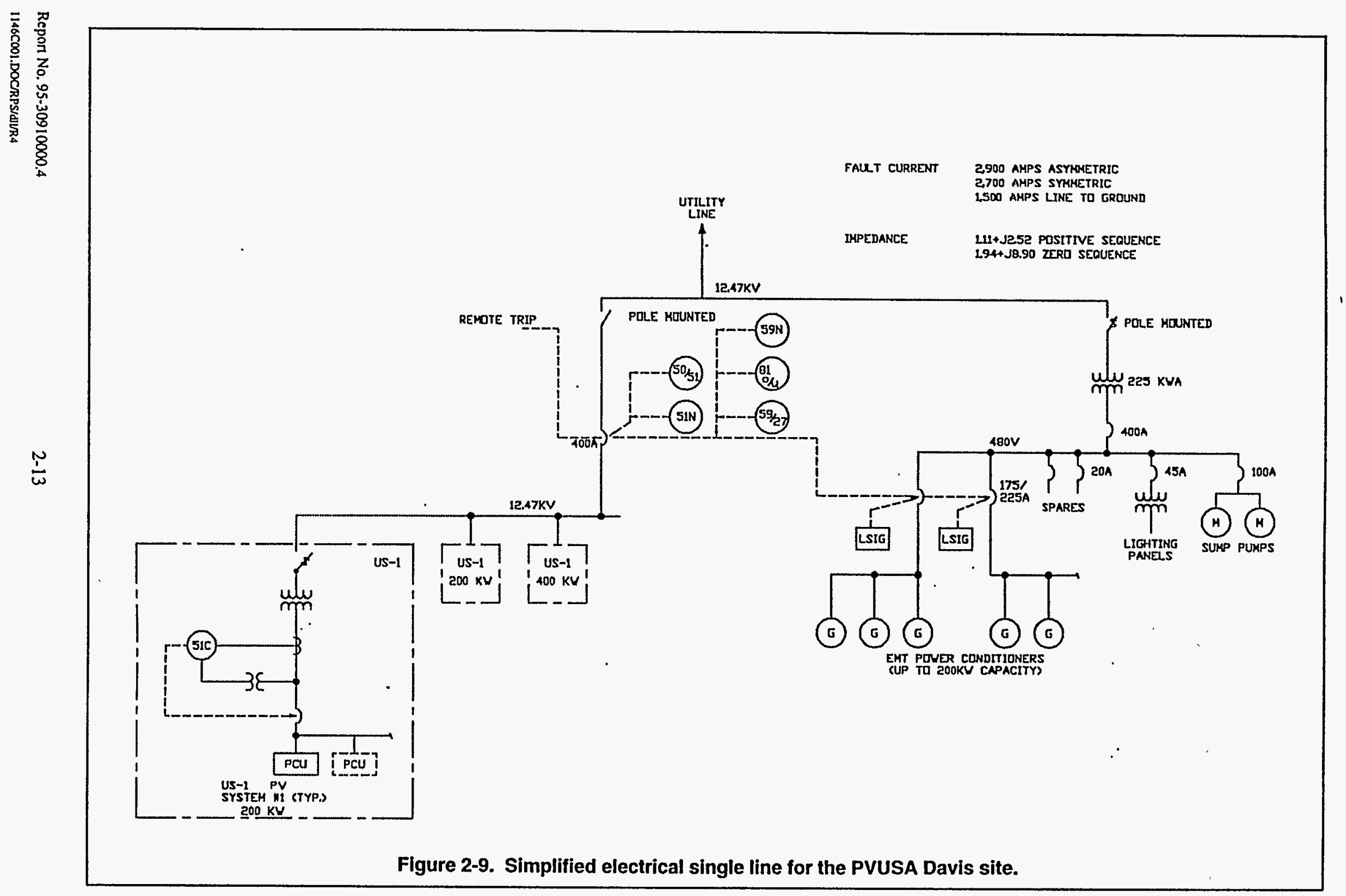


Table 2-1

\section{Synopsis of EMT PCU Specifications}

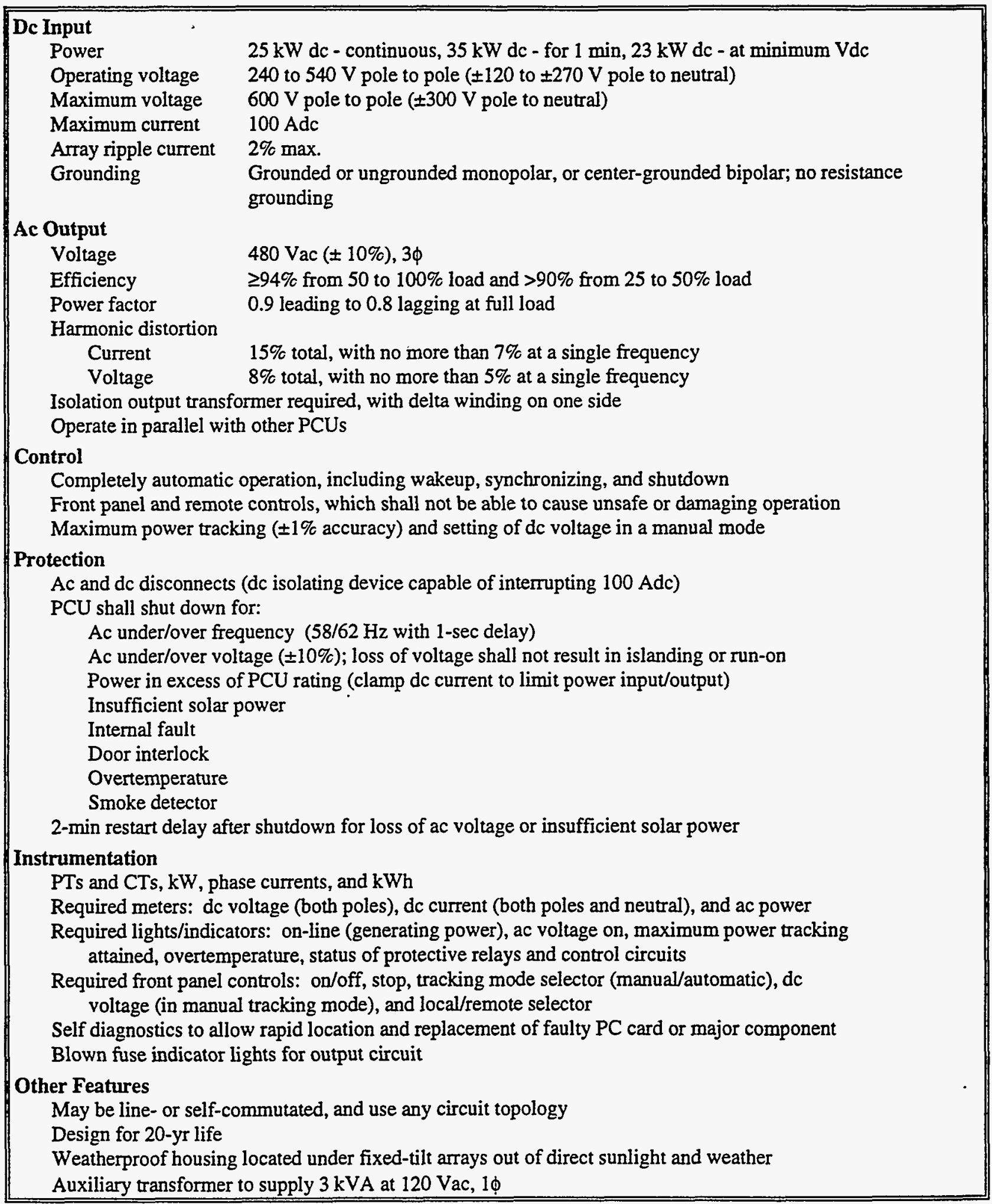


Table 2-2

Bid Prices for EMT PCUs

\begin{tabular}{|c|c|c|c|c|c|c|}
\hline \multirow[b]{2}{*}{ Bidder } & \multicolumn{2}{|c|}{ First 5 Units } & \multicolumn{2}{|c|}{ Additional Units } & \multicolumn{2}{|c|}{ Total for 12 Units } \\
\hline & Price & $\$ / W$ & Price & $\$ / W$ & Price & $\$ / W$ \\
\hline 1 & $\$ 236,000$ & 2.01 & $\$ 22,214$ & 0.95 & $\$ 391,500$ & 1.39 \\
\hline 2 & $\$ 216,200$ & 1.84 & $\$ 30,086$ & 1.28 & $\$ 426,800$ & 1.51 \\
\hline 3 & $\$ 300,000$ & 2.55 & $\$ 53,557$ & 2.28 & $\$ 674,900$ & 2.39 \\
\hline $\begin{array}{l}\text { Notes: } \\
\text { 1988\$ } \\
\text { S/W based }\end{array}$ & ac (specif & $c \times 94$ & & & & \\
\hline
\end{tabular}

\section{US-2 Power Conditioning Unit}

Like the US-1 systems, the US-2 PV system was procured as a complete turnkey system. The RFP for the US-2 system was issued for competitive bidding in January 1992. The PCU specifications included in the RFP for US-2 are essentially the same as for US-1. Table 2-4 highlights some of the differences between the two specifications. Details on the characteristics of the PCU actually installed are presented in Section 7. Since the US-2 PCU is part of a complete turnkey system, information on the price of the PCU is not available.

For both US-1 and US-2 PCUs, the difference between the standby and shutdown conditions is that automatic restarts are attempted from a standby signal after a fault condition and noncritical power supplies may be turned off in shutdown. Restart from shutdown requires either a local or remote reset signal, except for the remote disable and nightly shutdown with US-2.

Two issues that are not completely resolved are the use of conventional protective relaying equipment versus incorporation of protective relaying functions in the PCU, and the degree of manual versus automatic PCU reset when conditions return to normal after a fault. After several years of operation, the incorporation of protective relaying functions in the PCU and the use of automatic resets are gaining acceptance, especially for commercial (as opposed to research) applications. 
Table 2-3

\section{Synopsis of US-1 PCU Specifications}

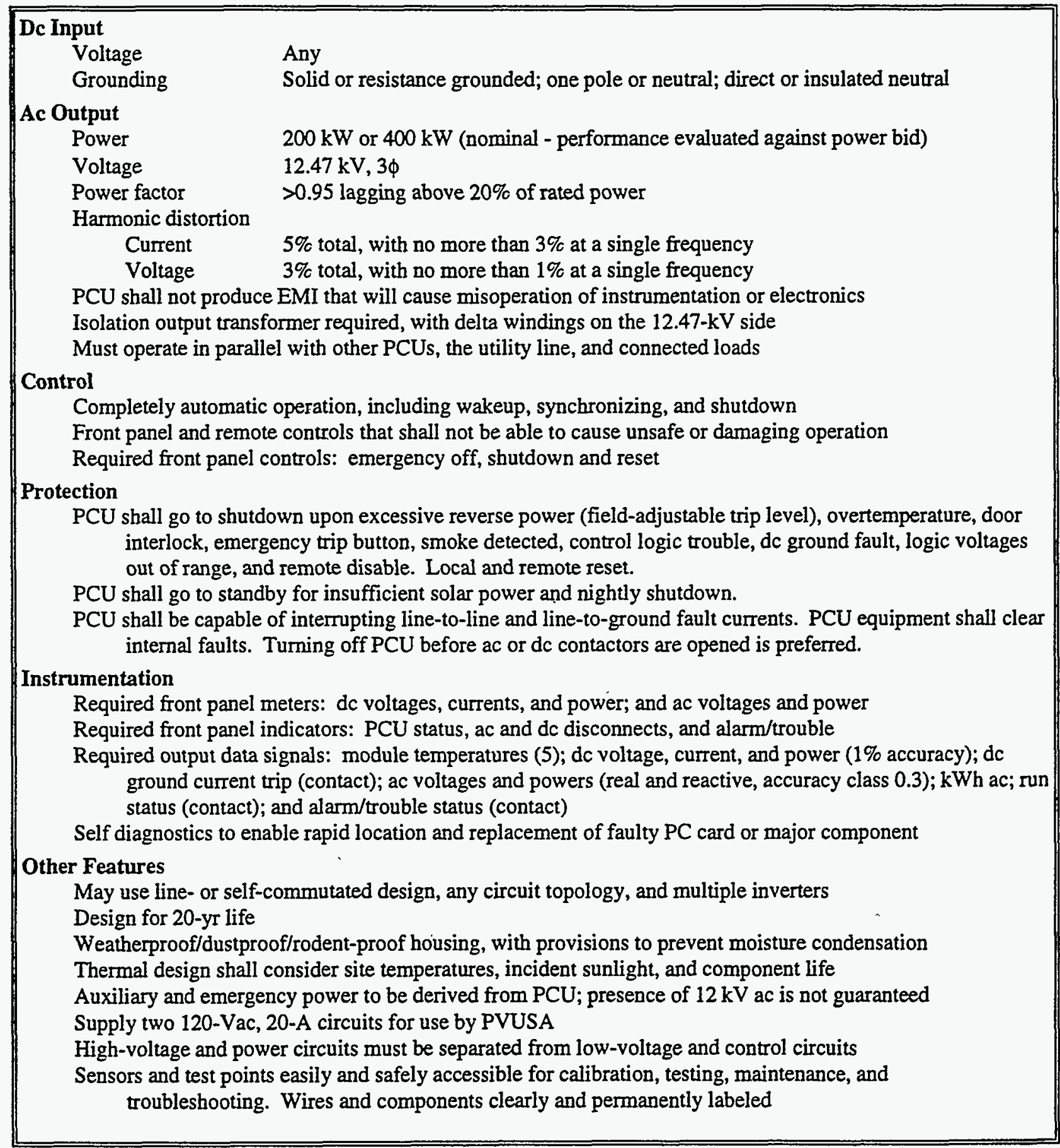




\section{Table 2-4}

Highlights of Differences between US-1 and US-2 Specifications

\begin{tabular}{|c|c|c|}
\hline Parameter & US-1 & US-2 \\
\hline Ac voltage & Go to standby ${ }^{1}$ & Go to shutdown \\
\hline Overvoltage & +5 to $+10 \%$, adjustable, $2-\sec$ delay & $+10 \%$, no delay, adjustable ${ }^{2}$ \\
\hline Undervoltage & -5 to $-10 \%$, adjustable, 2-sec delay & $-10 \%, 5-$ sec delay, adjustable ${ }^{2}$ \\
\hline Ac frequency & Go to standby ${ }^{1}$ & Go to shutdown \\
\hline Overfrequency & $>61 \mathrm{~Hz}$ for 1 to $60 \mathrm{sec}$, both adjustable & $>61 \mathrm{~Hz}$ for $0.25 \mathrm{sec}$, adjustable ${ }^{2}$ \\
\hline Underfrequency & $<59 \mathrm{~Hz}$ for 1 to $60 \mathrm{sec}$, both adjustable & $<58.5 \mathrm{~Hz}$ for $2 \mathrm{sec}$, adjustable ${ }^{2}$ \\
\hline Synchronization error & Go to standby & Not separate from O/U frequency \\
\hline Ac voltage unbalance & $>2.5 \%$; go to standby & Not specified \\
\hline Ac reverse power & Trip level adjustable & Trip level not adjustable \\
\hline Nightly turnoff & Go to standby & $\begin{array}{l}\text { Go to shutdown/standby (no reset } \\
\text { required for restart) }\end{array}$ \\
\hline Automatic restart & $\begin{array}{l}\text { 10- to } 120 \text {-sec delay } \\
\text { Go to shutdown if fault recurs } \\
\text { within } 30 \text { to } 300 \mathrm{sec} \text { (adjustable) }\end{array}$ & $\begin{array}{l}\text { 30-sec delay, not adjustable }{ }^{3} \\
\text { Go to shutdown after } 3 \text { restart attempts }\end{array}$ \\
\hline Instrumentation & $1 \%$ Vdc voltage divider accuracy & $\begin{array}{l}0.1 \% \text { Vdc voltage divider accuracy } \\
\text { Front panel meters for Vac eliminated }\end{array}$ \\
\hline \multicolumn{3}{|c|}{$\begin{array}{l}\text { Present relay settings at Davis: overvoltage }+20 \% \text {, no delay; undervoltage }-10 \%, 2 \text {-sec delay; overfrequency } 61 \mathrm{~Hz} \text { for } 2.5 \\
\text { sec; and underfrequency } 58.5 \mathrm{~Hz} \text { for } 2 \mathrm{sec} \text {. The PCUs themselves do not have these functions. } \\
2 \text { For the Omnion PCU installed, adjustment requires replacement of an EPROM on the master control printed circuit board. } \\
{ }^{3} \text { Retrofit installed March } 1995 \text { on Omnion units has both units going to shutdown/standby, with Unit } 1 \text { resetting } 5 \text { minutes } \\
\text { after restoration of normal conditions and Unit } 2 \text { with a 51/2-minute delay. }\end{array}$} \\
\hline
\end{tabular}




\section{REFERENCES}

2-1 Alec Bulawka et al., Photovoltaic Power Conditioners: Development, Evolution, and the Next Generation, Proc. 29th Intersociety Energy Conversion Engineering Conference, p. 1681, August 7-11, 1994.

2-2 Photovoltaic Power Conditioning: Status and Needs, EPRI Report GS-7230, June 1991

2-3 IEEE Tutorial on Adjustable Speed Drives, IEEE Power Engineering Education Committee \& Electric Machinery Committee, 92 EHO 362-4-PWR. 


\section{EMT, DECC/HELIONETICS}

This section presents data on the DECC/Helionetics PCUs installed at the PVUSA site at Davis, California.

\section{PCU DESCRIPTION}

The PCUs for all of the emerging module technology (EMT) systems were obtained from the Delta Electronic Control Company (DECC) Division of Helionetics, Inc. of Irvine, California, via a competitive bidding procurement process. These PCUs were to be essentially a commercial product, while the US PCUs were to be innovative. A total of nine PCUs were obtained in two phases (EMT-1 and EMT-2). DECC designates these $25-\mathrm{kW}$ dc units as Model 61635. Designed for fully automatic, unattended operation, the units have a relatively large dc voltage range and power rating in order to make it possible to connect them to a variety of PV systems, none of which had been selected at the time the PCU specifications were issued for bidding. Similarly, the units have a rather full complement of instrumentation to facilitate evaluation of the EMT PV arrays.

Table 3-1 summarizes the manufacturer's ratings for these units [3-1]. The simplified single-line diagram in Figure 3-1 provides an overview of the PCU's electrical configuration.

\section{Table 3-1}

\section{Summary of Manufacturer's Ratings for EMT PCU}

\begin{tabular}{|ll|ll||}
\hline \multicolumn{2}{|c|}{ Dc Input } & \multicolumn{2}{c|}{ Ac Output } \\
\hline Voltage Range & 240 to $540 \mathrm{Vdc}$ & Voltage & $480 \mathrm{Vac} \pm 10 \%, 3 \phi$ \\
Max. Voltage (Open Ckt.) & $600 \mathrm{Vdc}$ & Power Factor & -0.8 to +0.9 adjustable \\
Maximum Current & $100 \mathrm{Adc}$ & Frequency Range & 59 to $61 \mathrm{~Hz}$ \\
Maximum Power & $25 \mathrm{~kW}$ & Efficiency (50-100\% Power) $>94 \%$ \\
Maximum Power Tracking & & THD & $2 \%$ (typical) \\
Error (10-100\% Power) & $1 \%$ & (\% of Rated Current) & $5 \%$ (maximum) \\
Array Grounding &,+- , or center & & \\
\hline
\end{tabular}




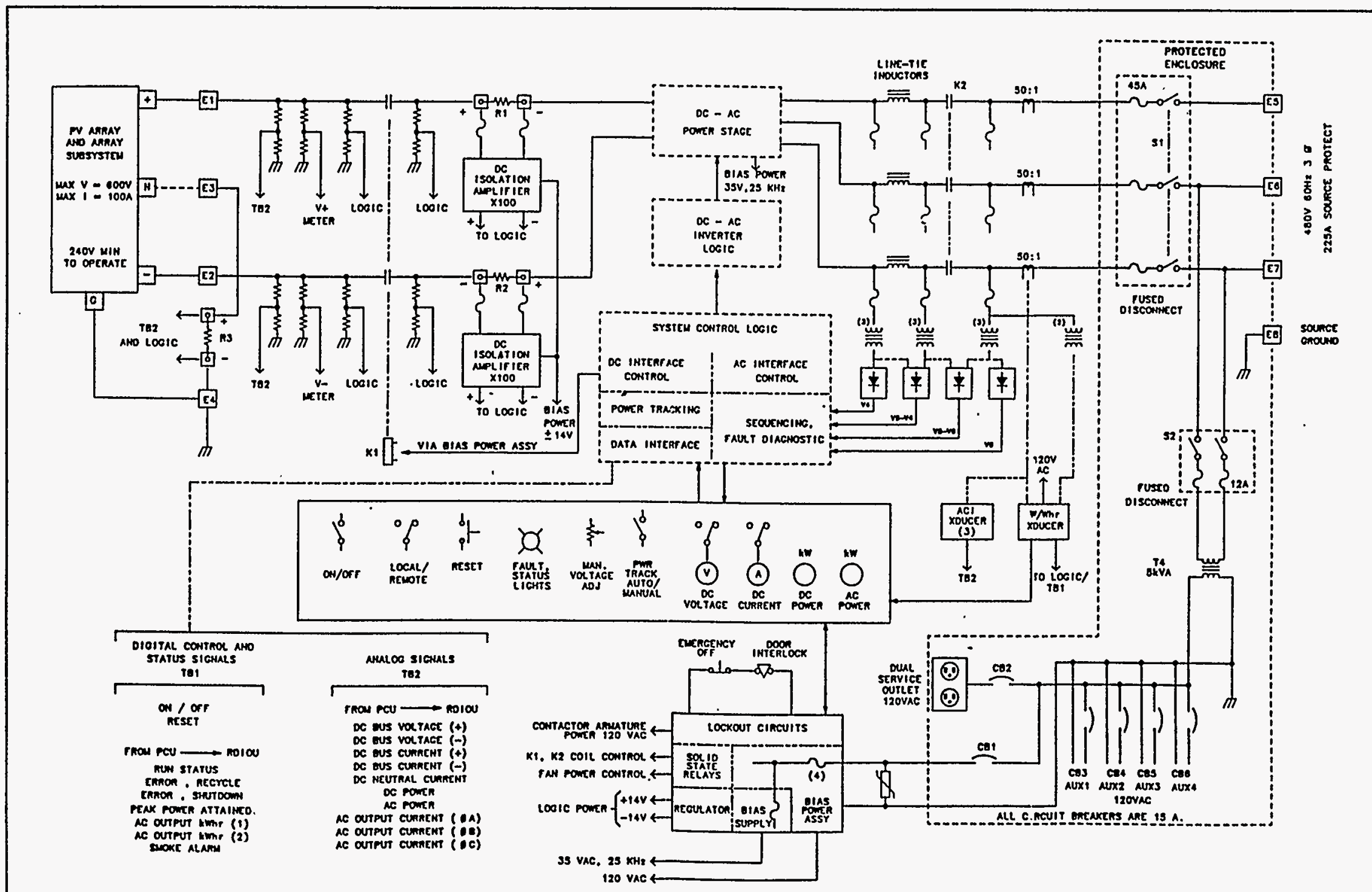

Figure 3-1. Simplified schematic of DECC Model 61635 PCU at Davis, California. 
The dc power from the EMT PV array is brought to the PCU by plus, minus, and neutral cables. Within the PCU, a center-grounded neutral circuit is formed by means of a neutral-to-ground connection through a current shunt. Several sets of resistive dividers are used to measure the plus and minus bus voltages to ground for panel metering, data acquisition, and control. These are on the array side of a dc contactor and allow measurement of array voltages and ground current with the PCU disconnected. Current shunts, with associated isolation amplifiers, measure the dc currents on the plus and minus buses for use by the control logic, data acquisition, and panel display circuits.

The dc power stage includes an EMI filter on the plus and minus buses. There are two transistor inverter bridges, each shunted by fused, electrolytic capacitors. The transistor bridges are pulse-width-modulated (PWM), at a relatively low frequency $(300 \mathrm{~Hz})$. Each bridge output proceeds through series reactors to an isolation transformer. The two transformer outputs are summed to produce a 12-pulse, stepped waveform (in addition to the PWM). The output circuit has filter capacitors and connects to the ac line through a contactor and fused disconnect switch. A set of current transformers and three sets of potential transformers monitor the ac output and provide signals to the control logic, data acquisition, and panel display circuits.

A single-phase, 5-kVA transformer supplies 120 -Vac power (through a circuit breaker panel) for a utility outlet, contactor coils, fans, and internal power supplies for the PCU electronics.

Front panel displays include meters for dc voltage and current (with switches to read either plus or minus buses), and dc and ac kilowatts. Twenty-two panel lights show PCU status and fault conditions. Front panel controls include a control selector switch (off/local/remote) and a switch to select the maximum power tracking mode (manual/automatic, with a knob to set the dc voltage in the manual mode). The panel also has buttons for manual fault reset and emergency off. The PCU provides signals for remote monitoring. Individual contact closures indicate dc ground fault, PCU on, PCU fault, shutdown, standby/ready, standby/fault, ac breaker status, overtemperature, smoke detected, synchronize failure, and automatic power tracking mode enabled. Analog data are furnished on dc voltage (plus and minus), dc current (plus, minus, and neutral), dc and ac power, and ac current (all three phases). Digital outputs are run status, error recycle, error shutdown, peak power tracking attained, and smoke alarm. Ac output kilowatt-hours is also a digital output (one 50-millisecond switch closure per kilowatt-hour). Remote control inputs are "on/off" and "fault reset." 
The DECC Model 61635 PCUs are designed for fully automatic, unattended operation. Operational features in addition to those mentioned above include a field-adjustable setting for the array voltage at which the PCU starts (and shuts down if the array voltage falls below about $15 \mathrm{~V}$ when current is drawn). The dc overvoltage trip is also field-adjustable. The power factor can be adjusted, within limits, to compensate for field conditions. The ac under/over voltage and frequency functions are provided by internal electronics, rather than by separate external relaying; test points added after startup allow adjustment/calibration of these functions. To minimize operator intervention, the PCU attempts to restart approximately 35 seconds after the occurrence and clearing of selected faults conditions (under/over voltage and frequency, synchronization error, and ac overcurrent). If the same fault occurs within approximately 100 seconds, the PCU goes to shutdown and must be reset (manually on the front panel or by a remote signal). A front panel light (but not the data acquisition system) displays the cause of the shutdown. The PCU goes directly to shutdown for other fault conditions, such as emergency off button, door interlocks, overtemperature, smoke detector, excessive reverse ac power, dc overvoltage, internal dc ground fault, cleared fuse, and control logic voltage out of range.

The PCU is housed in a nonventilated NEMA 4 enclosure, shown in Figure 3-2. The enclosure is 52 inches wide by 32 inches deep by 60 inches tall, which translates to $2.2 \mathrm{~kW} / \mathrm{ft}^{2}$. The PCU is designed to operate in an ambient relative humidity range of 0 to 95 percent and an ambient temperature range of $-10^{\circ} \mathrm{C}$ to $45^{\circ} \mathrm{C}\left(14^{\circ} \mathrm{F}\right.$ to $\left.113^{\circ} \mathrm{F}\right)$, when shaded from direct sunlight by placement under the north side of fixed-tilt arrays.

Figure 3-3 shows photographs of the exterior and interior of one of the DECC PCUs. The upper photograph illustrates placement of the PCU under a fixed-tilt array. It also shows a typical adjacent dc collection cabinet (far left) and data acquisition enclosure (center). 


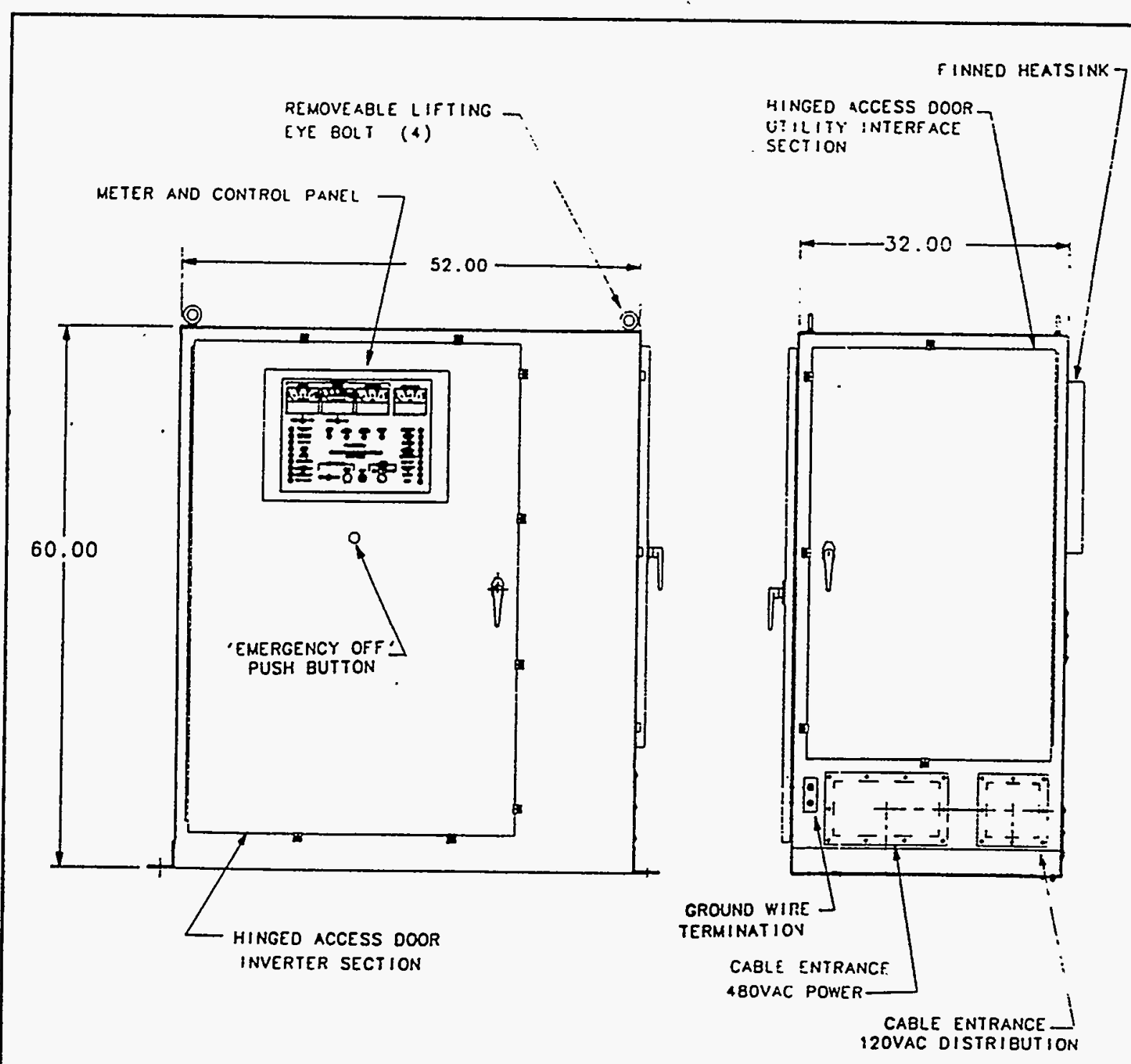

Figure 3-2. DECC 25-kW inverter. 

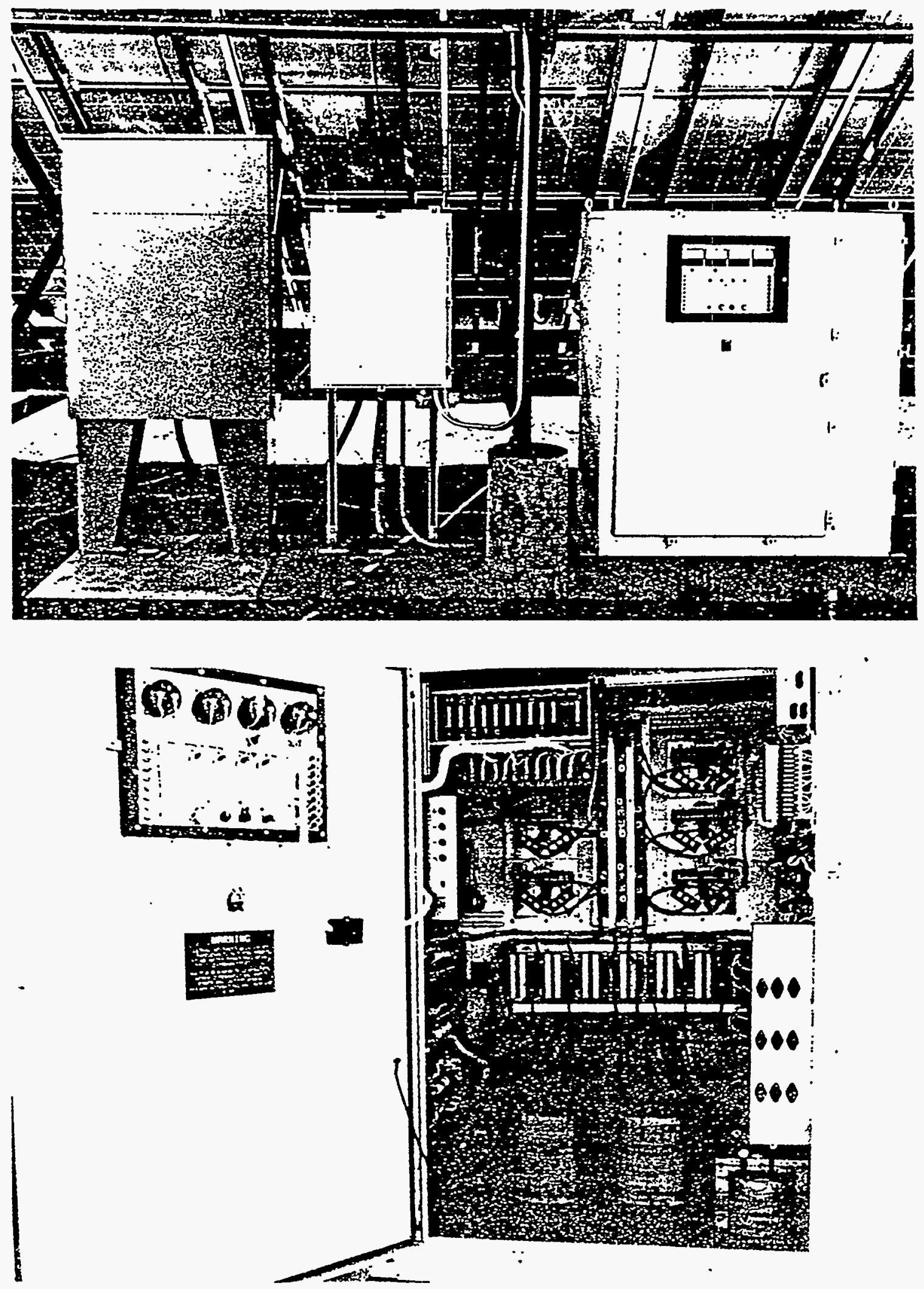

Figure 3-3. Exterior and interior of DECC PCU. 


\section{FACTORY AND STARTUP TESTS}

. The test program included testing at the manufacturer's facility prior to shipping, startup testing at the PVUSA Davis site, initial operation, and special tests.

\section{Factory Tests}

DECC prepared and submitted a Factory Test Plan for its PCU [3-2]. A summary of the test sequence is presented in Table 3-2.

\section{Table 3-2}

\section{Summary of Factory Test Sequence for EMT PCUs}

\begin{tabular}{|rl|}
\hline 1 & Verify that all monitoring equipment has current date calibration stickers. \\
2 & Verify conformance with the latest drawings, workmanship, and pretesting for operability. \\
3 & Hi-pot the input circuits (with input filters and resistive voltage dividers disconnected). \\
4 & Perform two 8 -hour burn-ins (full power at $40^{\circ} \mathrm{C}$ to $50^{\circ} \mathrm{C}$; and 0.6 power at room temperature). \\
5 & Verify the operation of the utility grid (over/under voltage) front panel lamp and circuits. \\
6 & Verify that unit shuts down (within 10 seconds) on loss of ac voltage (utility line). \\
7 & Verify restart time delay and automatic reconnection with reapplication of ac voltage. \\
8 & Adjust for zero ac power out, measure dc input, and calculate tare loss. \\
9 & Measure the upper and lower limits of the front panel manual dc voltage control. \\
10 & Operate at $1 / 4$ power and Vdc at mid-range; measure voltages, VARs, etc.; calculate efficiency. \\
11 & Operate at $1 / 2$ power and Vdc at mid-range; measure voltages, VARs, etc.; calculate efficiency. \\
12 & At full power, measure voltages, currents, powers; calculate efficiency; measure THD. \\
13 & Reduce the input to $1 / 2$ power; measure THD. (Note: DECC refers its THD to current at full power.) \\
14 & Reduce the input to $1 / 4$ power; measure THD. \\
15 & At full power and Vac $=480 \mathrm{~V}+5 \%$, measure voltages, VARs, THD, etc.; calculate efficiency. \\
16 & At full power and Vac $=480 \mathrm{~V}-5 \%$, measure voltages, VARs, THD, etc.; calculate efficiency. \\
17 & At full power and Vdc near the upper end of its range, measure voltages, etc.; calculate efficiency. \\
18 & Verify the operation of the fault protection circuits; simulate faults, conditions, etc. as necessary. \\
19 & Verify the operation and calibration of data signals. \\
\hline
\end{tabular}


The PCUs were tested at DECC's facilities in Irvine, California. The test setup included a dc power supply that allowed testing at full rated power $(25 \mathrm{~kW})$ and at several, setable ac and dc voltages. A few difficulties were encountered with instruments, wiring, and the PCUs. However, the units passed the tests prescribed in Table 3-2 and met PVUSA requirements.

Items of interest include the efficiency of the PCUs. The efficiency as a function of power is illustrated by the top graph in Figure 3-4. Measurements were made at (approximately) 100, 50, and 25 percent of full power, and at 75 percent for two of the units. The average efficiency is 93.4 percent at full power and 93.2 percent for power levels above 50 percent of rated power, only slightly below the manufacturer's rated efficiency of 94 percent.

The preceding data are for rated conditions of the ac line voltage at $480 \mathrm{~V}$ and the dc input voltage at $350 \mathrm{~V}$, near the center of the operating range. The center graph in Figure 3-4 shows how efficiency is affected by $a \pm 5$ percent variation in ac line voltage, with the unit operating at full power. Note that there is a trend (less than a half percentage point) toward higher efficiency at higher ac voltages. The bottom graph in Figure 3-4 shows how efficiency is affected by operating with the dc voltage near the upper end of the range. (Data were not taken at the lower end of the dc voltage range.) The graphs indicate that the effects of variations in ac or dc voltage on efficiency are less than a percentage point and approximately the same as the variation from unit to unit.

The average tare loss (dc power for zero ac output) is $405 \mathrm{~W}$ (1.6 percent of full power) and is essentially equal to the manufacturer's rated loss of $400 \mathrm{~W}$. Tare losses ranged from 200 to $646 \mathrm{~W}$ for the units tested. The rated ac power consumed by a PCU in the standby condition is $100 \mathrm{~W}(0.4$ percent).

The top graph in Figure 3-5 shows the total harmonic distortion (THD) of the current waveform as a function of power level. (The data are adjusted to percent of current at the measurement power level, versus percent of current at full power.) At full power, the average THD is 1.63 percent, below the manufacturer's "typical" rating of 2 percent. The center graph in Figure 3-5 indicates the effect of a \pm 5 percent variation in ac line voltage, with the unit operating at full power. The average THD is slightly higher away from $480 \mathrm{Vac}(2.1 \%$ @ -5\% Vac and 1.9\% @ +5\% Vac), but below 3 percent for all of the units tested. The bottom graph in Figure 3-5 shows current as a function of dc operating voltage. As can be seen, operating at the upper end of the dc voltage range results in a higher THD (3.6 percent average). Field test data on THDs are presented in the section on PCU characteristics. 

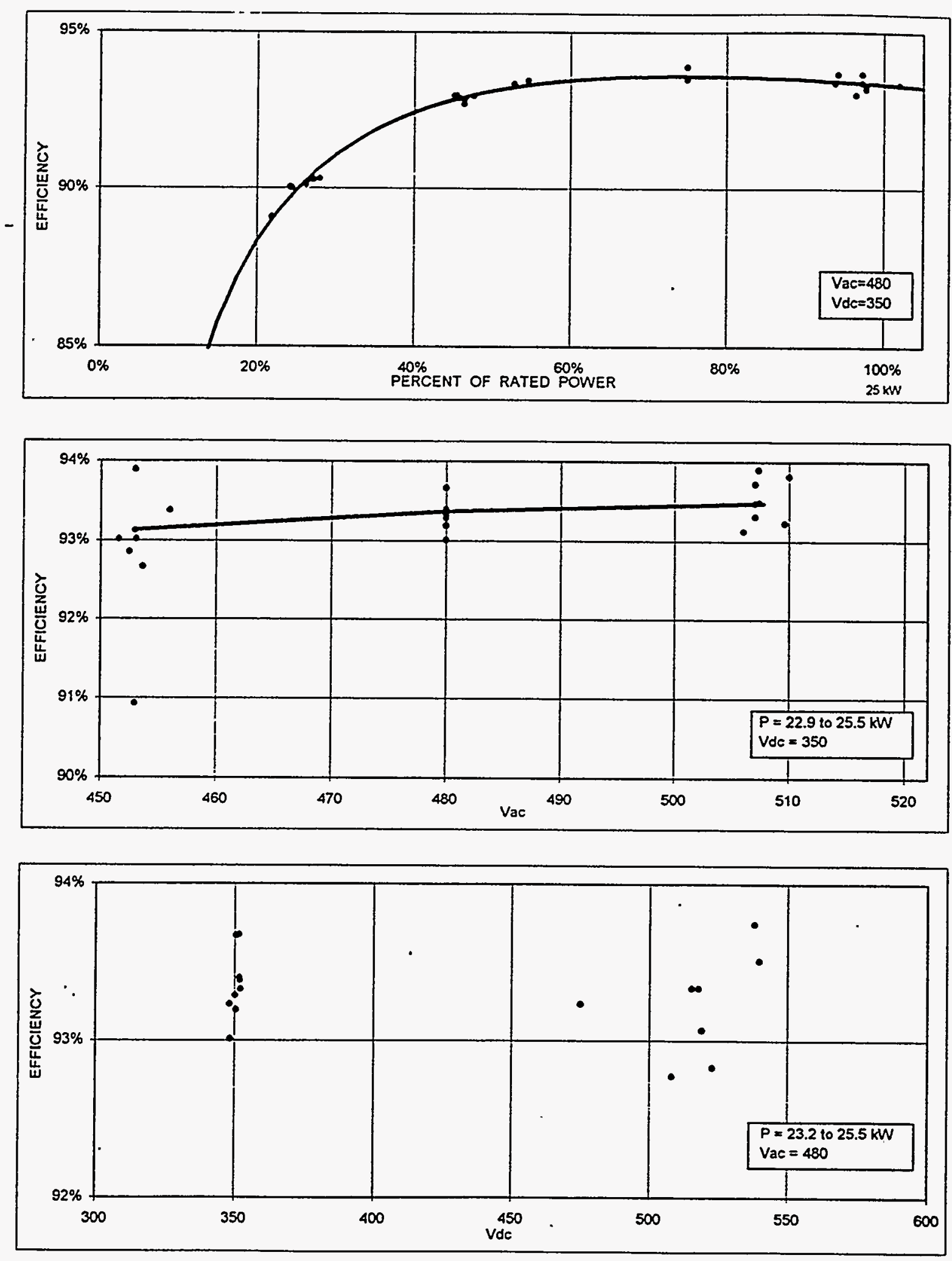

Figure 3-4. Efficiency characteristics of the DECC EMT PCUs. 

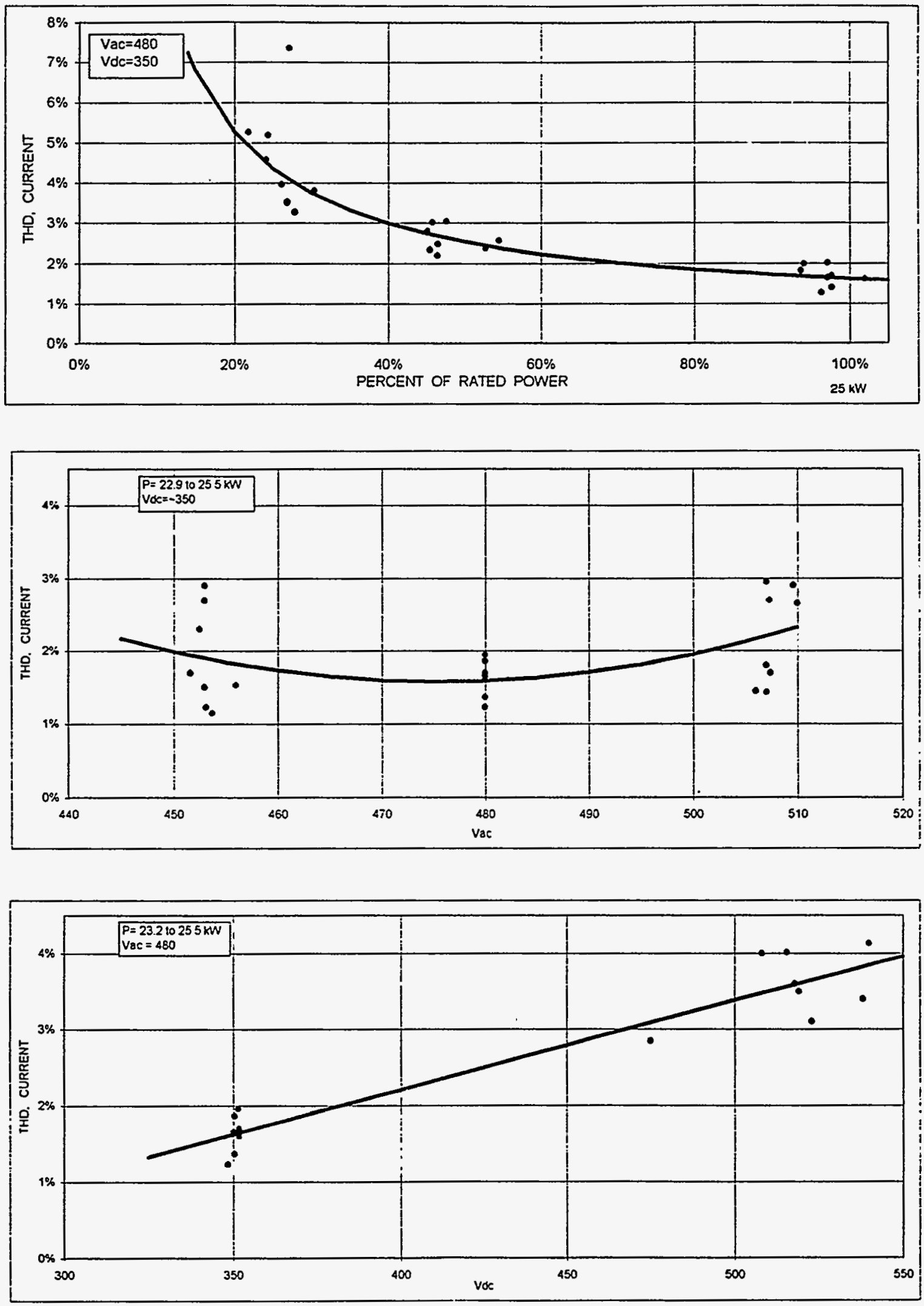

Figure 3-5. Current THD characteristics of the DECC EMT PCUs. 


\section{Startup Tests}

The startup field tests are summarized in Table 3-3. The first EMT PCU arrived at Davis on December 8, 1988 and passed these tests successfully. All of the other units also passed these tests successfully.

\section{Table 3-3}

\section{Summary of Field Test Sequence for EMT PCUs}

\begin{tabular}{|rl|}
\hline 1 & Inspect for shipping damage (broken wires, dislodged assemblies or circuit boards, etc.). \\
2 & Set the PCU to "off," tracking to "manual," and voltage to "midpoint," output and control switches off. \\
3 & Connect the ac; turn on the control power switch; close the ac breaker. \\
4 & Verify that the time delay inhibit indicator is lit and remains lit for about 2 min. \\
5 & Turn on the output switch; observe for any problems; verify that the utility grid indicator is lit. \\
6 & Turn the PCU on to "local"; verify that the insufficient solar power indicator is lit. \\
7 & Turn PCU to "off" and connect the PV array. \\
8 & Verify that the panel meter reads "Vdc" and that the solar array indicator is lit (if Vdc>300 V, factory \\
9 & Turn the PCU on to "local"; verify that the sequencing indicator is lit. \\
10 & After 5 sec, verify that the dc contactor is closed, the sequencing indicator is out, and the input indicator is \\
11 & lit. \\
12 & After 2 sec, verify that the ac contactor is closed and that the panel meter reads "kW ac." \\
13 & Set the tracking to "auto"; verify operation. \\
14 & Verify the operation and calibration of the overfrequency and underfrequency trip circuit. \\
15 & Verify the operation and calibration of the overvoltage and undervoltage trip circuit. \\
16 & Verify the calibration of the monitor jack on the voltage trip circuit test panel.
\end{tabular}




\section{OPERATION AND MAINTENANCE}

PG\&E system protection engineers allowed the PCU to incorporate the functional equivalent of over/under voltage and frequency relaying into the units' controls. At the time of startup on the first unit, the utility found the DECC implementation to be inadequate in that conventional external generators could not be used to test and calibrate these functions. After being tested on Unit 1 and found acceptable, all of the EMT PCUs were retrofitted with a small test panel, including a normal/test function switch, and test jacks to access PT outputs and frequency trip circuits. (In February 1989, conventional over/under voltage and frequency relaying was added at the $12.47-\mathrm{kV}$ ac US-1 bus, with wiring to also trip the main EMT 480-Vac circuit breakers; see Figure 2-9.)

Figure 3-6 shows typical dc voltage and ac power profiles (10-minute averages) for a crystalline silicon array during the morning startup/wakeup process. The figure indicates a tare loss (ac power consumed by the PCU with zero dc input) of about $410 \mathrm{~W}$. As the dc array voltage rises above the setpoint, the PCU starts operating. Experience with operation indicates that the startup voltage should be set close to the maximum power point voltage. After the start voltage has been reached, the dc contactor closes and the PCU draws array current to charge the input capacitors for approximately 10 seconds. The transistors are then gated on.

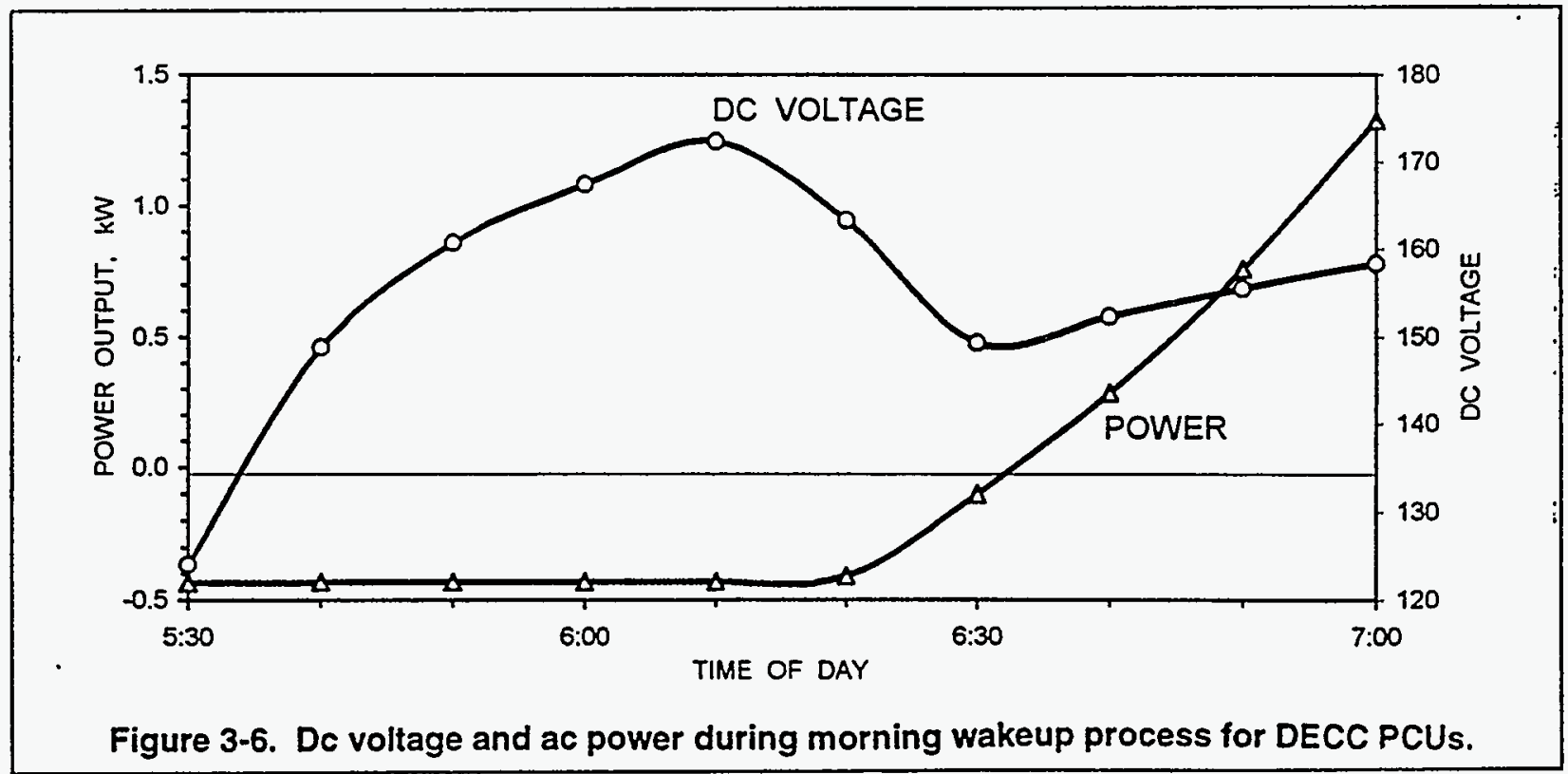


If there is insufficient solar power, the PCU goes to a sequencing hold state until the array voltage increases further or to the off state if the array voltage drops. If there is sufficient array power, the PCU output voltage rises to the level of the utility line voltage, which is on the other side of the still open output contactor. If the PCU output is not in voltage and phase synchronization with the utility line, the PCU goes to an error recycle mode and retries after 35 seconds. If the retry fails, the PCU goes to synchronization error shutdown, which requires a reset signal. Unfortunately, this latter sequence has occurred more often than desired. Setting the wakeup/start voltages to suit the characteristics of the individual PV arrays has been the best remediation, but this is a time-consuming trial-and-error process. A particular problem seemed to be finding voltage settings to accommodate seasonal variations in array dc voltage (e.g., due to seasonal variations in array temperature in the mornings). Some consideration was given to modifying the PCU or allowing a remote reset, but this has not been implemented and synchronization error shutdowns at wakeup remain a minor annoyance.

The upper plot in Figure 3-7 shows the occurrences of synchronization error shutdowns and other PCU failures for the five EMT-1 systems. The cross marks in Figure 3-7 indicate the occurrence of an event but not the repair times, which varied widely. As can be seen, these shutdowns persist. The Sovonics and UPG PCUs have the fewest and most shutdowns, respectively. Both of the connected arrays for these systems are of amorphous silicon; the modules, however, seem to have some differences (e.g., spectral sensitivity). The center plot in Figure 3-7 shows the occurrences of other PCU shutdowns. These seem to be less frequent of late. They are also fewer than for the US-1 and US-2 systems, shown in the lower plot of Figure 3-7 for comparison (and discussed in subsequent sections). Table 3-4 summarizes these data, but the graphs provide a better insight into the rates of occurrence and trends. Further details are in Appendix C.

It was suspected that several of the PCUs had inaccurate power readings due to faulty sensors. These sensors are also used by the control circuits and were thought to be responsible for a series of intermittent failures to start properly, trip off line and/or not maximum power track. Corrective actions taken over a period of time included adding 100-pF capacitors across the ac power transducer terminals, adjusting the gain on the dc power transducer, and adjusting the inhibit and error cycle times. 

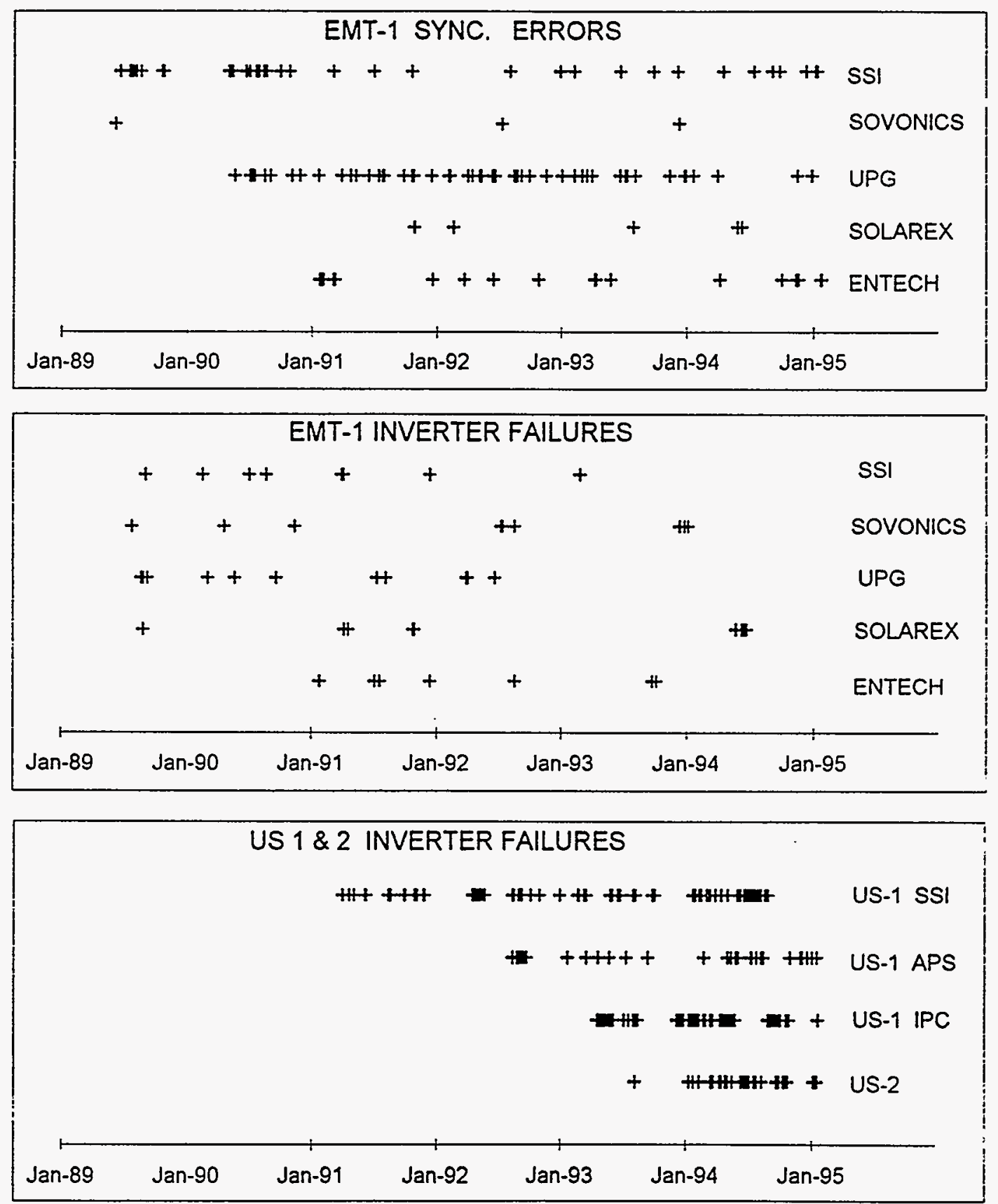

Figure 3-7. PCU failure chronology. 
Table 3-4

PCU Failure Occurrences

\begin{tabular}{|c|c|c|c|c|c|c|c|c|c|c|c|}
\hline & \multicolumn{5}{|c|}{ EMT-1 } & \multirow[t]{2}{*}{ Subtotal } & \multicolumn{3}{|c|}{ US-1 } & \multirow{2}{*}{$\frac{\text { US-2 }}{\text { Kerman }}$} & \multirow[t]{2}{*}{ Total } \\
\hline & ENT & Sov. & SSI & SX & UPG & & APS & IPC & SSI & & \\
\hline Sync. Error & 20 & 3 & 41 & 7 & 57 & 128 & 1 & 0 & 3 & 2 & 134 \\
\hline PCU Failure & 10 & 10 & 8 & 12 & 12 & 52 & 36 & 109 & 118 & 43 & 358 \\
\hline Other & 2 & $\underline{3}$ & $\underline{3}$ & $\underline{3}$ & $\underline{2}$ & 13 & $\underline{4}$ & 6 & $\underline{9}$ & 1 & 33 \\
\hline Total & 32 & 16 & 52 & 22 & 71 & 193 & 41 & 115 & 130 & 46 & 525 \\
\hline
\end{tabular}

In the course of diagnosing the problems, several printed circuit cards were interchanged among the units, and it was found that corresponding cards (e.g., Card A2J1 on Unit 1, Card A2J1 on Unit 2) were not always identical. Despite attempts to correct this, the cards are still not totally interchangeable. Additionally, the cards were given a protective coating to remedy a suspected problem with humidity. Other problems included various loose or broken connections, faulty resistors, burned-out indicator lamps, and similar items. There were also problems that did not affect performance directly (e.g., difficulties with door latches and keys, a misaligned viewing window door, and inadequate labeling on terminal blocks).

\section{PCU CHARACTERISTICS}

\section{Efficiency}

Figure 3-8 shows the dc-to-ac efficiencies as a function of power for each of the five currently operating EMT-1 system PCUs. The rated power is that of the PCU, $25 \mathrm{~kW}$ dc. The dc input is calculated from measured plus $\mathrm{dc}$ voltage (to neutral) times the plus $\mathrm{dc}$ current and minus dc voltage times the minus $\mathrm{dc}$ current. The ac output is from the ac watt transducer in the PCU. Several hundred data points are used for each graph. Figure 3-8 also shows the efficiencies of all five units plotted on a single graph.

Figure 3-8 shows the PCU efficiency to be relatively constant in the region where the output is above 40 percent of rated power, as is typical for power conditioning equipment. Although not entirely evident from the graphs in Figure 3-8, the clustering of data points with the uniform measurement intervals indicates that (as expected) most of the energy is delivered with the array and PCU operating in this region. 

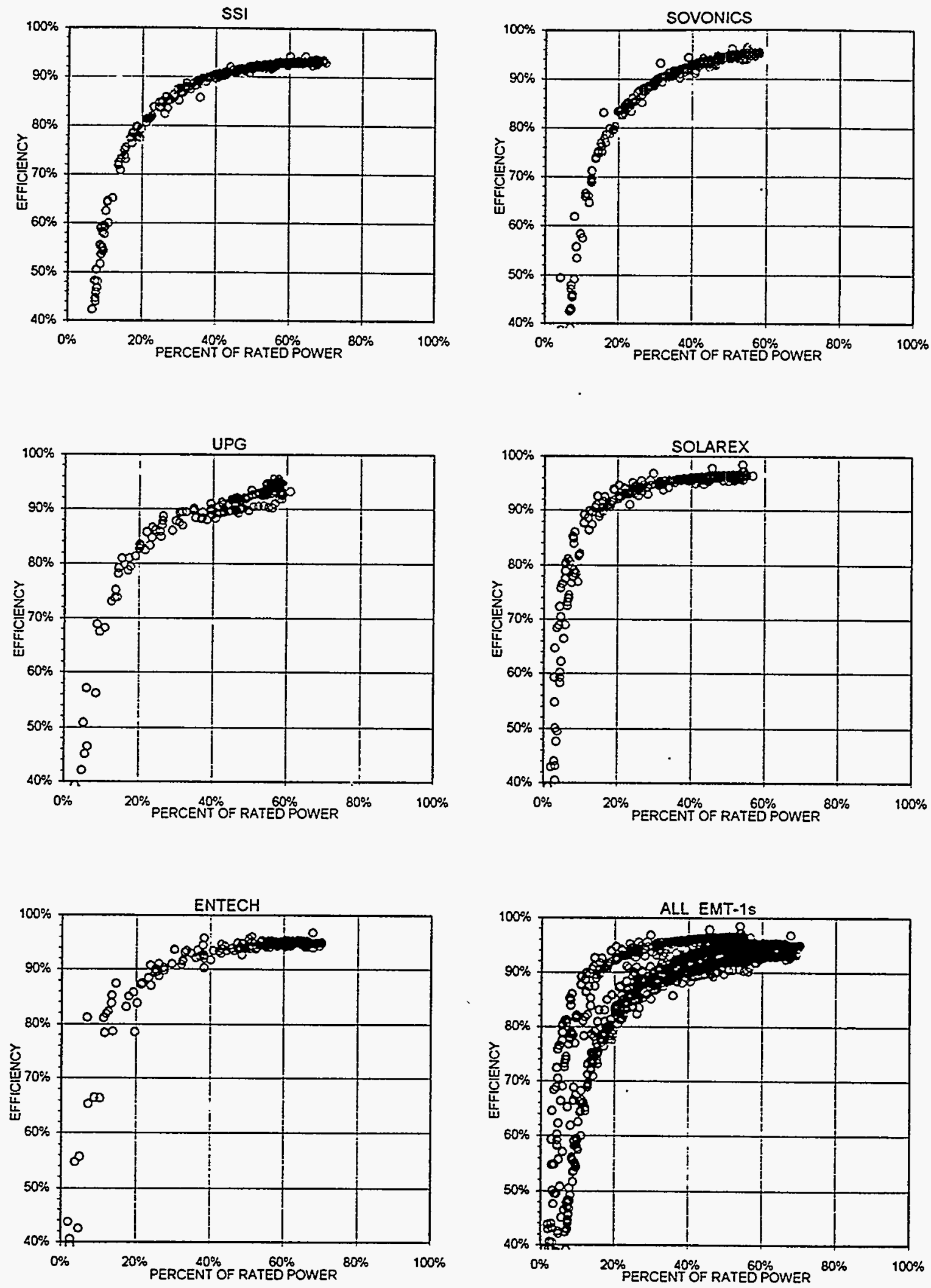

Figure 3-8. EMT PCU efficiencies as a function of power.

Report No. 95-30910000.4 
Table 3-5 gives the average efficiencies in the region where these curves flatten $(P>40$ percent of

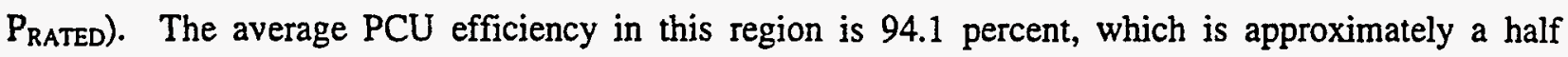
percentage point higher than measured in the factory tests of these units. The table also lists the rated powers of the several EMT PV systems, both in $\mathrm{kW}$ dc and as percentages of the PCU's rated power of 25 $\mathrm{kW}$ dc. As mentioned, the PCU voltage range and power were selected to accommodate a variety of EMT system designs, with the result that the PCU is not being utilized to its maximum power capacity (at least with the currently installed EMT PV array systems). The last column in Table 3-5 gives the average pole-to-pole dc array voltages in the region where the ac output is greater than 40 percent of the PCU's rated power, which is approximately where the wakeup starting voltage should be set.

Table 3-5

EMT PCU Efficiencies

\begin{tabular}{|c|c|c|c|c|c|}
\hline \multirow[b]{2}{*}{ Unit } & \multirow{2}{*}{$\begin{array}{c}\text { PV } \\
\text { Array }\end{array}$} & \multirow{2}{*}{$\begin{array}{c}\text { Average } \\
\text { Efficiency } \\
\text { (for P>40\%) }\end{array}$} & \multicolumn{2}{|c|}{$\begin{array}{l}\text { PV System } \\
\text { Rated Power }\end{array}$} & \multirow{2}{*}{$\begin{array}{c}\text { Average } \\
\text { Dc Voltage } \\
\text { (for P>40\%) } \\
\end{array}$} \\
\hline & & & $\mathrm{kW} \mathrm{dc}$ & $\%$ of $25 \mathrm{~kW} \mathrm{dc}$ & \\
\hline 1 & Siemens & $92.6 \%$ & 18.7 & $74.8 \%$ & 314 \\
\hline 2 & Solarex & 94.5 & 15.7 & 62.8 & 332 \\
\hline 3 & Sovonics & 92.4 & 17.3 & 69.2 & 288 \\
\hline 4 & UPG & 96.3 & 15.7 & 62.8 & 285 \\
\hline \multirow[t]{2}{*}{5} & ENTECH & 94.8 & 16.5 & 66.0 & 299 \\
\hline & Average & $94.1 \%$ & & & \\
\hline
\end{tabular}

Attempts were made to correlate PCU efficiency with dc and ac voltages, both for the average efficiencies (Table 3-5) and the data for the individual PCU efficiency curves (Figure 3-8). However, the point scatter is about the same as shown in Figure 3-4 for the factory tests, and a meaningful correlation was not found. This may be due, in part, to the fact that the ac outputs were not calibrated (except at the factory) since these PCUs are used primarily as a maximum power tracking load for the several PV technologies being tested. Also, dc power and the ac power are each derived through four sensors and several associated amplifiers. Small accuracy and/or calibration errors (e.g., less than 0.5 percent) could more than account for the \pm 2 percentage point variation in the calculated efficiencies. In addition, it is not known why the curves for Units 4 and 5 have slightly sharper knees and why these occur at a lower power level. 


\section{Current Unbalance}

An unbalance in the 480-Vac output currents of Unit 1 (SSI) was noticed in February 1989. The exact cause was not determined, and no remedy was found. DECC believes the unbalance is due to mismatches among the line-tie inductors (series reactors) in the output circuit (see Figure 3-1). The manufacturer ensures that these reactors are within \pm 5 percent of one another. Evaluation of data on phase currents indicates that these reactors may in fact not be within this tolerance. Figure 3-9 shows the currents in the three phases as percentages of the average current for Unit 1. Although there is considerable point scatter (particularly at lower current and power levels), the plot shows a definite trend for the currents in Phase A to be about 5 percent above the average. The currents in Phases $\mathrm{B}$ and $\mathrm{C}$ are approximately equal. It turns out that Unit 1 has the worst current unbalance of the first five EMT units, 5 percent on average.

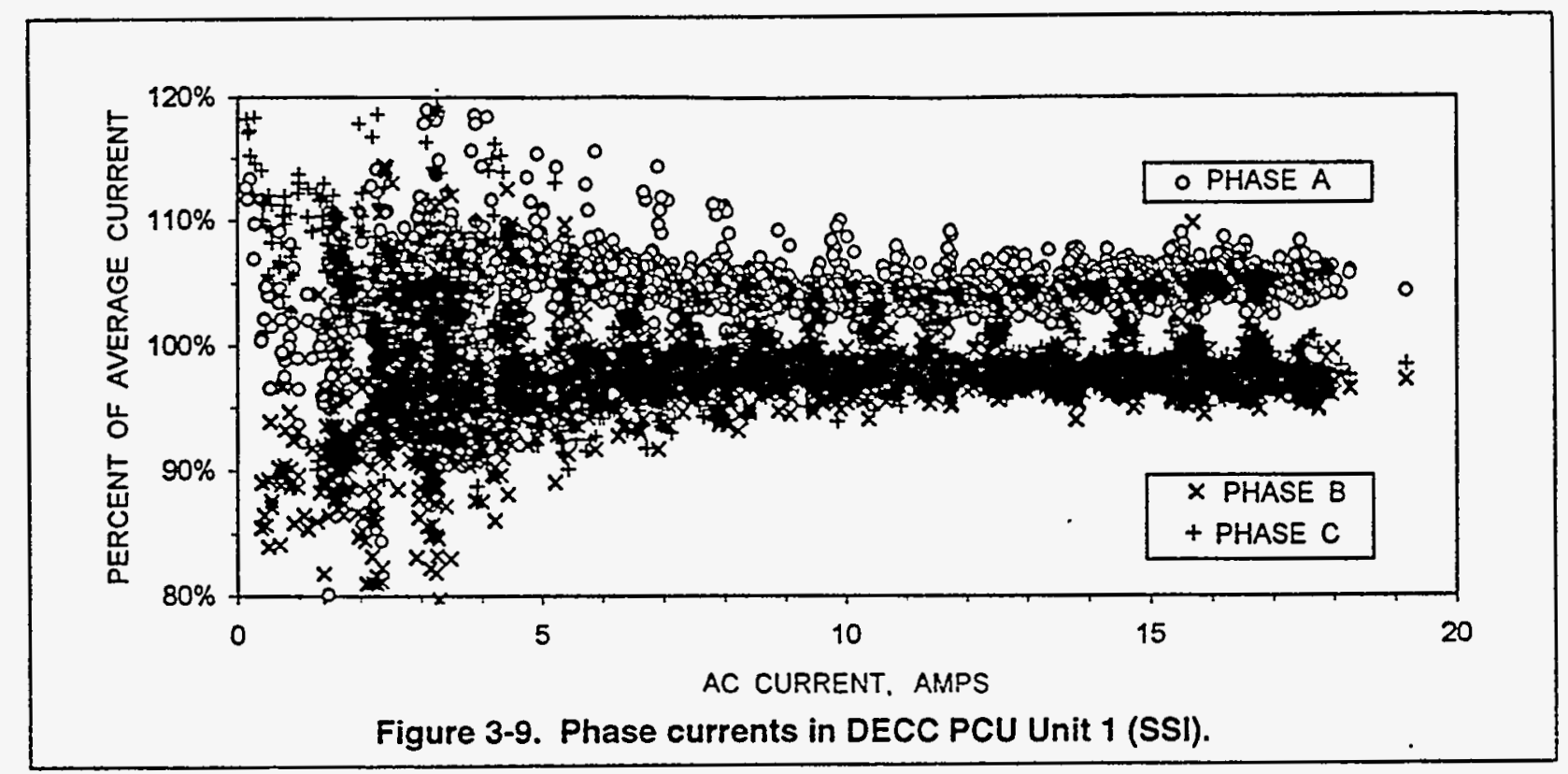

Typical average current unbalances for the EMT-1 PCUs are as follows:

- SSI

- Solarex

- Sovonics

- UPG

- ENTECH

Average

\section{$5.1 \%$}

1.4

2.1

3.1

3.2

$3.0 \%$ 


\section{Harmonic Distortion}

Harmonics were measured for the first three EMT-1 systems on April 13, 1990. Each PCU was operated individually. Then all three were operated together in parallel (the normal operation condition at the site), and a background measurement was performed with all three PCUs off. Several sets of measurements were made. Representative results are presented in Table 3-6 for measurements at 11:00 a.m. and 1 p.m. The current THDs are higher than measured at the DECC factory, but, as expected, decrease with increasing power level (see Figure 3-5). The harmonic levels are affected by several factors, including ac line impedance, $\mathrm{dc}$ and ac voltage levels, and power level. The data also show that operating the DECC PCUs (individually or in parallel) did not increase the voltage THD over the existing background levels.

\section{Table 3-6}

\section{EMT-1 Harmonics at the Davis Site}

\begin{tabular}{||ccccc||}
\hline & Power & Power & \multicolumn{2}{c|}{ THD } \\
\cline { 5 - 6 } System & \% of Rated & Factor & Current & Voltage \\
\hline 11:00 a.m. & & & & \\
SSI & 54 & 0.98 & 6.9 & 0.6 \\
Sovonics & 48 & 0.99 & 6.8 & 0.6 \\
UPG & 45 & 1.00 & 5.5 & 0.6 \\
All three on & - & 0.99 & 3.6 & 0.6 \\
All three off & - & - & - & 0.6 \\
1:00 p.m. & & & & \\
SSI & 68 & 0.99 & 5.2 & 0.8 \\
Sovonics & 56 & 1.00 & 5.5 & 0.8 \\
UPG & 49 & 0.99 & 5.5 & 0.8 \\
All three on & - & 1.00 & 3.8 & 0.8 \\
All three off & - & - & - & 0.8 \\
\hline
\end{tabular}

\section{Other Tests and Characteristics}

Run-On. A run-on (islanding) test on Unit 1 (SSI) was performed at the time of startup as part of the conditions for paralleling with the grid. When a $480-\mathrm{Vac}$ circuit breaker was opened, the PCU voltage decayed to zero within a second. Further tests were performed in 1991 using a load bank with the two DECC PCUs connected to the SSI and UPG arrays. The step-variable resistive load bank was adjusted to have varying amounts of the load power supplied by the PCU, with the utility line absorbing or supplying the difference. The PCU/SSI array was generating a maximum of about $15 \mathrm{~kW}$ ac (56 percent of rated 
power). The resulting run-on times for the PCU/SSI array, singly and in parallel with the UPG PCU, are shown in Figure 3-10.

As can be seen from the figure, the PCU turns off within 1.5 to 2 seconds for loads up to the initially generated PCU power and in less than $1 / 4$ second for initial loads more than 20 percent above the initial PCU power. (The first test mentioned was with no load and the PCU successfully shut down.) However, the PCU can run on if the load is on the order of 10 to 20 percent above the PCU generated power. The maximum run-on time measured was 11 minutes (off the scale of the graph in Figure 3-10). This could present a problem in some circumstances. For example, the PCU(s) could run on if the irradiance is such that the power is slightly below that of various loads at the site when the utility line is opened. For the most part, this type of balance would be difficult to maintain and the PCU would probably drift to instability and turn off. However, caution dictates that an ac bus should not be assumed to be safe to touch unless both ends of the wire are disconnected. It should also be noted that the run-on characteristic is required in applications such as uninterruptible power supplies (UPSs) and for remote, non-gridconnected PV systems.

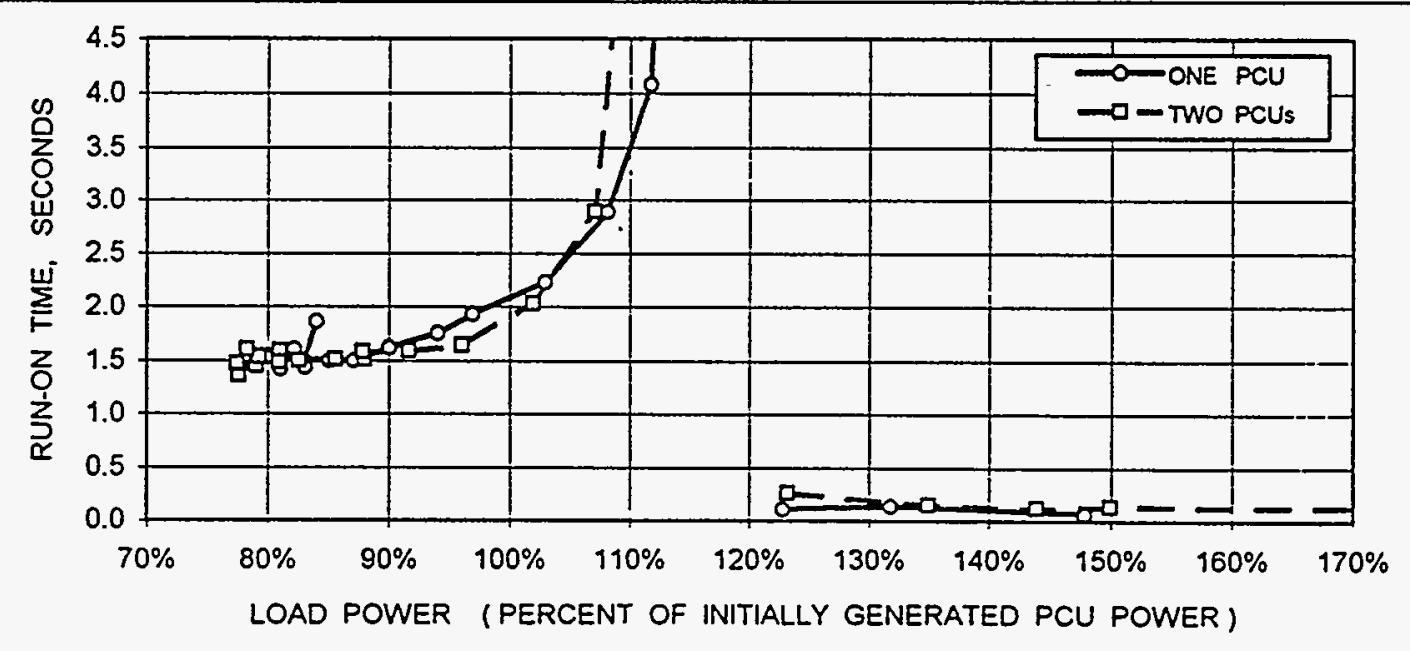

Figure 3-10. Run-on characteristics of DECC EMT PCU.

EMU/RFI. A receiver (IFR Communications Service Monitor Model FM/AM-1200S/A), spectrum analyzer, and several antennas were used to measure for possible electromagnetic/radio frequency interference (EMI/RFI) generated by the EMT-1 PCUs (and for externally generated signals) that might interfere with onsite equipment. The tests covered a frequency range from $250 \mathrm{kHz}$ to $250 \mathrm{MHz}$ and were performed by PG\&E personnel on April 13, 1990. Measurements were taken with all three PCUs 
operating, one PCU operating, and all PCUs turned off. Nothing attributable to the PCUs was found. Several ambient signals were detected at the Davis site visitor center:

- AM broadcast station $\quad 1.1 \mathrm{MHz} \quad-38 \mathrm{dBm}$

- $\quad$ TV Channel 3 sound $\quad 67.8 \mathrm{MHz} \quad-58 \mathrm{dBm}$

- FM broadcast station $\quad 90.3 \mathrm{MHz} \quad-52 \mathrm{dBm}$

- FM broadcast station $\quad 102.5 \mathrm{MHz} \quad-26 \mathrm{dBm}$

- Military radar $\quad 61.5 \mathrm{Mhz} \quad-56 \mathrm{dBm}$

$\begin{array}{cc}\text { 83.3 MHz } & \text { to } \\ 193.3 \mathrm{MHz} & -60 \mathrm{dBm}\end{array}$

$211.3 \mathrm{MHz}$

Further tests were performed on June 13, 1990 in an attempt to determine the cause of interference with a portable telephone. The measuring equipment was set up close to the EMT-1 arrays. A broadband signal (approximately 32 to $37 \mathrm{MHz}$ ) with a varying amplitude $(-62$ to $-70 \mathrm{dBm}$ ) was found. This signal was strongest with the antenna aligned with buried cables and/or near metal structures. There was a small, but detectable, change in the signal when the PCUs were shut off. However, it was determined that the signal was not emanating from any of the PCUs. No signals were detected in the coaxial cables connecting to the site data acquisition system.

While there undoubtedly are some low-level emissions, no signals of significance were observed to emanate from the PCUs.

Magnetic Fields. Magnetic field strengths were measured at the Davis and Kerman sites. Details are presented in a separate report [3-3]. The broadband (40 to $800 \mathrm{~Hz}$ ) magnetic fields were found to be strongest at ac conduits leading to the SSI EMT-1 PCU at Davis. Fields at this point were found to be as high as 1,000 milligauss, but only 100 milligauss at the face of the PCU. These fields fall off rapidly with distance and typically decrease to a few milligauss beyond 3 feet from the PCUs. Health effects due to magnetic (and electric) fields are currently being evaluated, but there are no magnetic field exposure standards at present. The American Conference of Governmental and Industrial Hygienists calls for a threshold limit exposure value (in milliteslas) of 60/f, where $\mathrm{f}$ is the frequency in $\mathrm{Hz}$ and the result is the root-mean-square (RMS) field amplitude. Thus, for $f=60 \mathrm{~Hz}$, the RMS threshold limit exposure would 
be 1 millitesla, or 10 gauss. The maximum fields measured at the PCU cabinet are about the same as produced by household electrical appliances (e.g., 5 to 110 milligauss by an electric blanket [3-4]).

\section{SUMMARY}

The DECC Model 61635 was specifically designed to meet the specifications for the diverse parameters of the PVUSA EMT systems. In general, the units have done so.

The characteristics of the DECC units include an average efficiency (in the region above half power) that is the second highest among all of the PCUs at PVUSA. This is particularly noteworthy considering that higher power units tend to have higher efficiencies and that the DECC units are 1/20 the power of the highest efficiency PCU. However, the efficiency of the DECC PCU falls off more rapidly with decreasing power than that of any of the other units. The units' harmonics are high, but well within the less stringent EMT procurement specifications and essentially within the specifications for the US-1 and US-2 PCUs. The power factor is unity at full power. At an average of 3 percent, the unbalance of the ac output currents is about a percentage point above the unbalance in two of the US-1 PCUs.

Many of the problems discussed could be expected to occur with newly designed equipment, even equipment that has passed factory and field acceptance tests. The overall design, diagnostics, and layout of components facilitate maintenance. Still, many hours were spent by PVUSA personnel in resetting nuisance trips, diagnosing and remedying problems, and communicating with DECC. Additionally, DECC personnel expended hours analyzing these problems, and traveling to and working at the Davis site to implement solutions. However, the net result is that the site personnel view the EMT PCUs as functioning satisfactorily at this point in time, despite the nuisance of resetting synchronization error shutdowns.

A recommendation would be to pursue modifications to the PCU which might eliminate the synchronization error shutdowns.

\section{REFERENCES}

3-1 Installation and Operation Manual for the Photovoltaic Power Conversion Unit Model 61635, DECC Division of Helionetics, Inc., Manual \# 523-1254 [19271-PC-D27-010(1)-2], February 7, 1991. 
3-2 Acceptance Test Procedure for the Model 61635 Photovoltaic Power Conversion System, DECC Division of Helionetics, Inc., Drawing 570-1084, October 1988.

3-3 C. J. Chang and C. Jennings (PG\&E), August 1994, Magnetic Field Survey at PG\&E Photovoltaic Sites, DOE/AL/82993-12.

3-4 Electric and Magnetic Fields from $60 \mathrm{Hertz}$ Electric Power: What do we know about possible health risks?, published by the Department of Engineering and Public Policy, Carnegie Mellon University, Pittsburgh, PA 15213, 1989, page 3. 

Section 4

\section{US-1, IPC/OMNION}

This section presents data on the Omnion PCU installed at Davis, California.

\section{PCU DESCRIPTION}

The 200-kW ac (PTC) Integrated Power Corporation (IPC) US-1 PV system is installed at the PVUSA site in Davis, Califomia. It uses a power conditioner supplied by Omnion Power Engineering Corporation of East Troy, Wisconsin. The PCU is an Omnion Series 3200 static power converter and is rated at $200 \mathrm{~kW}$.

Table 4-1 summarizes the manufacturer's ratings for these units [4-1]. The simplified single-line diagram in Figure 4-1 provides an overview of the PCU electrical configuration [4-1].

Table 4-1

Summary of Manufacturer's Ratings for IPC/Omnion PCU

\begin{tabular}{|ll|ll||}
\hline \multicolumn{2}{|c|}{ Dc Input } & \multicolumn{1}{c|}{ Ac Output } \\
\hline Voltage Range & \pm 310 to $\pm 390 \mathrm{Vdc}$ & Rated Power & $200 \mathrm{~kW}$ (nominal) \\
Max. Voltage (Open Ckt.) & $\pm 540 \mathrm{Vdc}$ & Voltage & $12.47 \mathrm{kV}$ ac $\pm 10 \% 3 \mathrm{\phi}, 3 \mathrm{~W}$ \\
Maximum Current & $380 \mathrm{Adc}$ & Power Factor & $>0.98(1 / 4-$ full power) \\
Maximum Ripple Voltage (PP) & $5 \%$ & Frequency Range & 59 to $61 \mathrm{~Hz}$ \\
Array Grounding & Solid, center & Efficiency & $95 \%$ (full power) \\
& & THD & $<5 \%(1 / 3-$ full power) \\
\hline
\end{tabular}

Features of the PCU include automatic wakeup (when the array voltage exceeds $\pm 413 \mathrm{Vdc}$ for 1 minute, field-adjustable) and shutdown (when the power is less than 2 percent of rated power for 2 minutes, factory set). On/off cycling is prevented by the programmed times delays and by setting the startup voltage slightly below the open-circuit voltage at shutdown. The controls also include automatic restart after out-of-tolerance utility line conditions return to normal for 2 minutes (frequency $\pm 1 \mathrm{~Hz}$, factory-set; voltage \pm 10 percent, field-adjustable). 


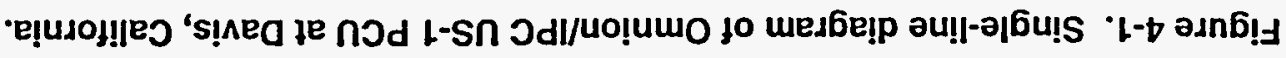

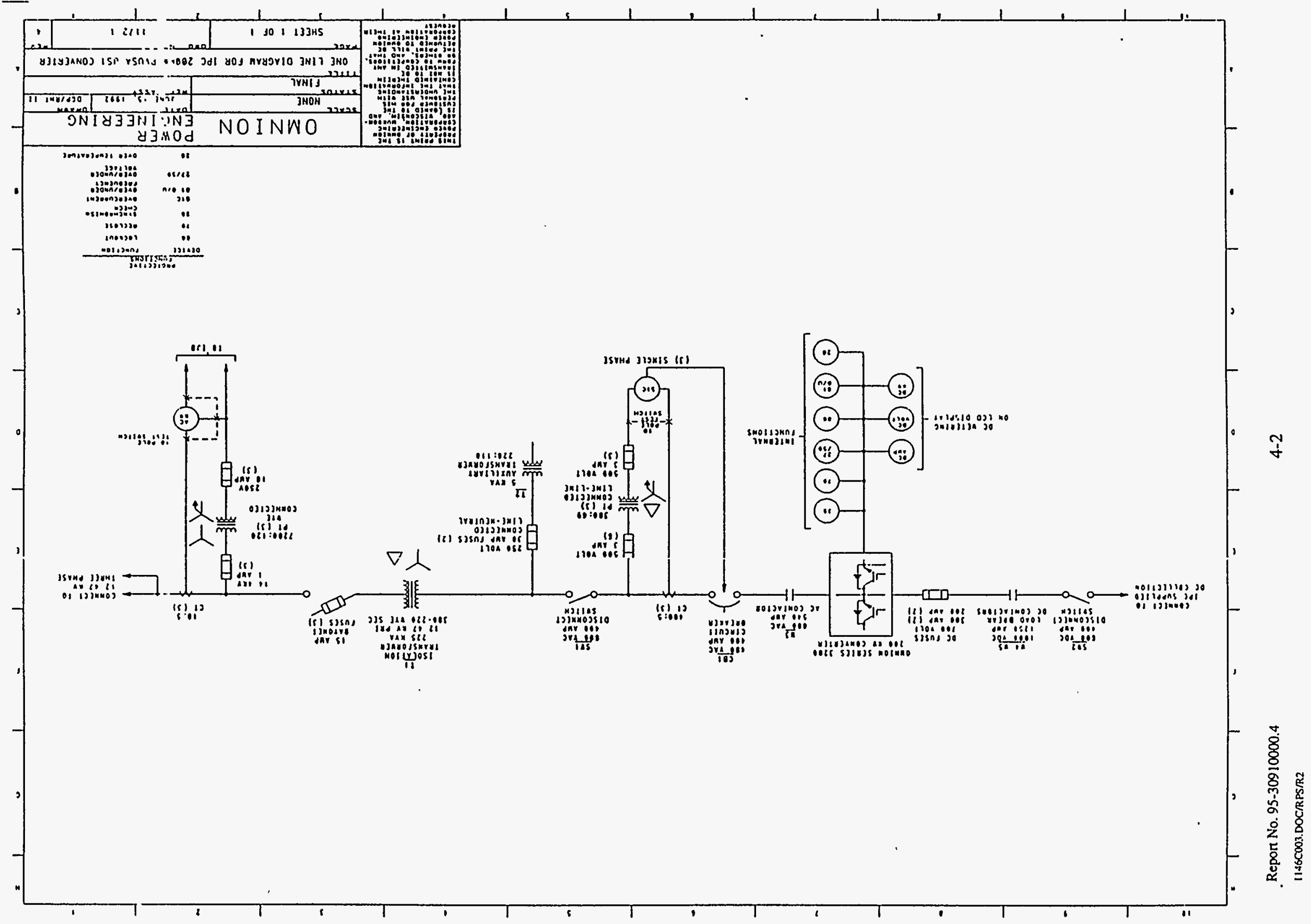


The dc input is supplied by 11 PV source circuits, mounted on single-axis tracking arrays. North and south monopole plus and minus buses are connected to disconnect switches, and combined to form a plus, minus, and neutral. Metal-oxide varistors (MOVs) provide surge protection on the buses. The source circuits are a nominal $\pm 400 \mathrm{~V}$ (STC, $\pm 341 \mathrm{~V}$ PTC). Two of the source circuits are connected through load-break contactors, thereby allowing shedding of circuits should the power exceed a preset limit of $218 \mathrm{~kW}$ ac. The PCU will shut down if the power exceeds $224 \mathrm{~kW}$ ac. The plus and minus buses are connected to the PCU through a two-pole disconnect switch, load-break dc contactors (two per pole), and fuses (two per pole). Auxiliary contacts fumish control information on switch and contactor positions. MOVs (1,960 joules, fused) protect the dc input from voltage spikes. The neutral is not switched, and is connected to the system ground through a Hall effect sensor and circuit to monitor ground fault currents (trip adjustable from 1 to $10 \mathrm{~A}$ ).

Voltage dividers and isolation amplifiers measure the dc bus voltages for the panel meters, $\mathrm{kW} d c$ transducer, DAS, and overvoltage circuit and control. A current shunt, Hall effect sensors, and associated circuits provide similar data on the dc current.

The dc current is shared among five IGBT bridges. Each bridge has shunt capacitors from the plus and minus dc input buses to the neutral, and a fuse in the negative bus to the IGBTs. The capacitors are rapidly discharged through a contactor and resistor when the PCU is shut down. Other resistors limit inrush current when the units are started. Snubber circuits limit switching and ac line transients across the IGBTs. The IGBTs are mounted on heat sinks cooled by thermostatically controlled fans.

Each bridge includes gate driver circuits and local control circuits. Control signals to and from the bridge circuits go through an isolation circuit board. The local control circuits receive signals from a master control. The master control, in turn, receives inputs from several sensors, a utility interface circuit board, settings; programmed logic, and control software. The utility interface circuit board supplies input on over/under frequency and over/under voltage, and uses a phase-locked loop to synchronize the PCU with the utility line by detecting zero crossings on Phase A. The master control also provides for dc voltage regulation, array maximum power tracking, ac current limiting, and status and alarm signals to an LCD panel display and to the DAS. Maximum power tracking is achieved by increasing the dc operating voltage by $2.5 \mathrm{~V}$. If the power increases, the voltage is increased further; if the power decreases, the voltage is decreased. This cycle is repeated every 2 seconds. 
Each bridge ac output has a fused series reactor in each phase. The bridges are connected in parallel, and their combined output is connected to a circuit breaker and disconnect switch. From there, the ac is connected to the low side (wye) of a $225-\mathrm{kVA}$ isolation transformer to step the output to $12.47 \mathrm{kV}$ (delta). The transformer output is connected to the ac line through bayonet fuses integral to the transformer. Current transformers (CTs) and potential transformers (PTs) furnish control and display data. Voltagerestrained overcurrent relays are included. Fuse-protected MOVs (2,400 joules) provide surge protection.

A single-phase, 5-kVA transformer supplies 120-Vac power (through a load center and circuit breakers) for fans, heaters, utility outlets, array tracking drive, relay and contactor coils, and the four internal power supplies, which provide $5, \pm 15$, and $24 \mathrm{Vdc}$ for the internal electronics and relay coils.

The front panel includes an LCD display which furnishes details via some 33 messages. Front panel controls include an operating mode switch (manual and automatic power tracking), and buttons for manual start, fault reset, and emergency off. The PCU also supplies signals for remote monitoring.

The PCU is housed in three NEMA 3 enclosures, shown in Figure 4-2. The inverter cabinet is 92 inches wide by 48 inches deep by 90 inches high, including the ac and dc disconnect switches mounted on the sides of the enclosure. The isolation transformer enclosure is 64 inches wide by 46 inches deep by 56 inches high. The PT/CT enclosure is 49 inches wide by 42 inches deep by 85 inches high. The enclosure dimensions result in a power density of $3.1 \mathrm{~kW} / \mathrm{ft}^{2}$. There is an adjacent dc collection box (by IPC), which is 31 inches wide by 20 inches deep by 74 inches high. This equipment is mounted on a 11- by 16foot concrete pad.

The photographs in Figure 4-3 show the exterior and interior of the PCU.

\section{FACTORY AND STARTUP.TESTS}

The test program included testing at the manufacturer's facility prior to shipping, startup testing at PVUSA's Davis site, initial operation, and special tests. 

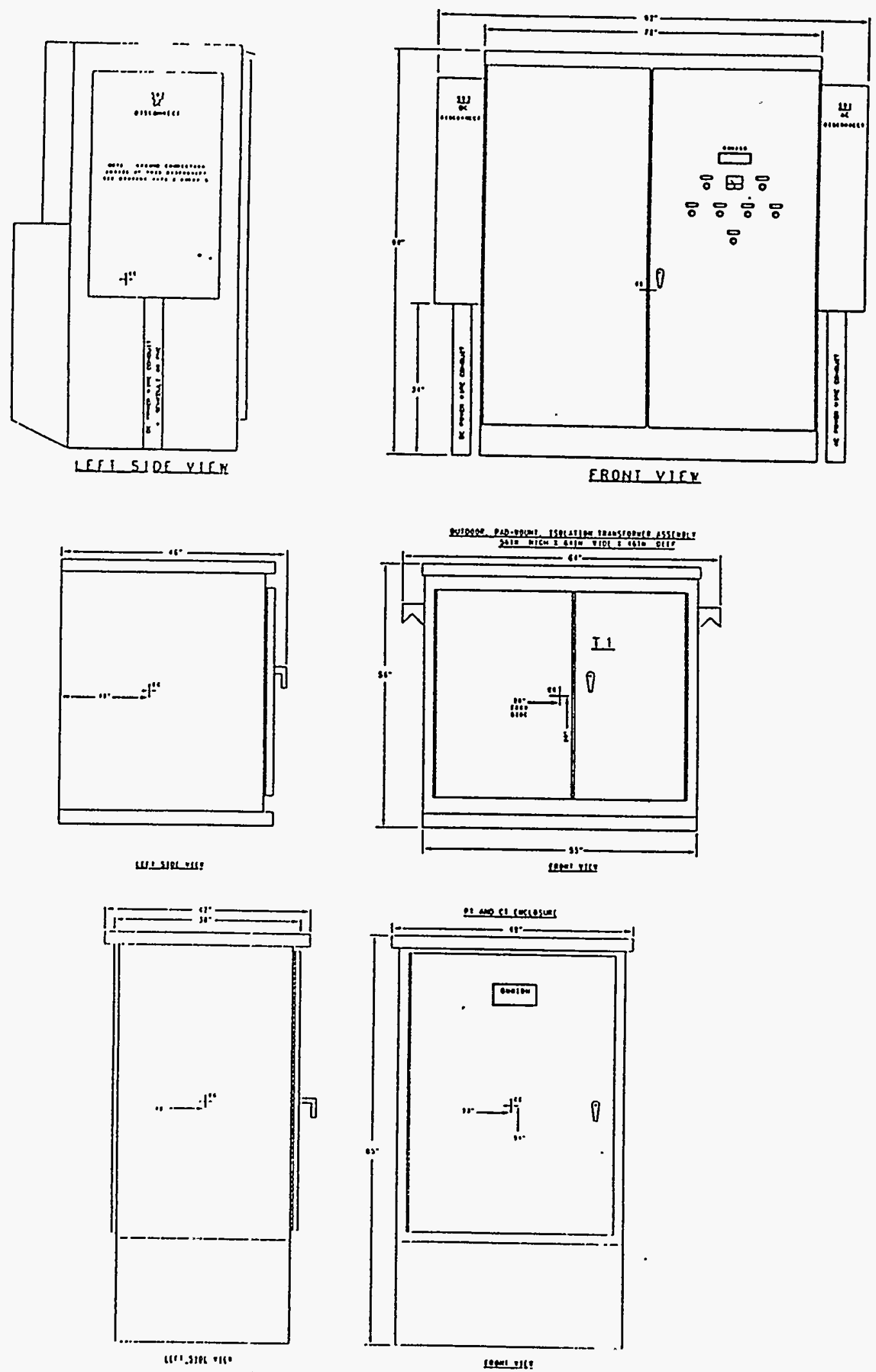

Figure 4-2. Enclosures for Omnion US-1 PCU. 

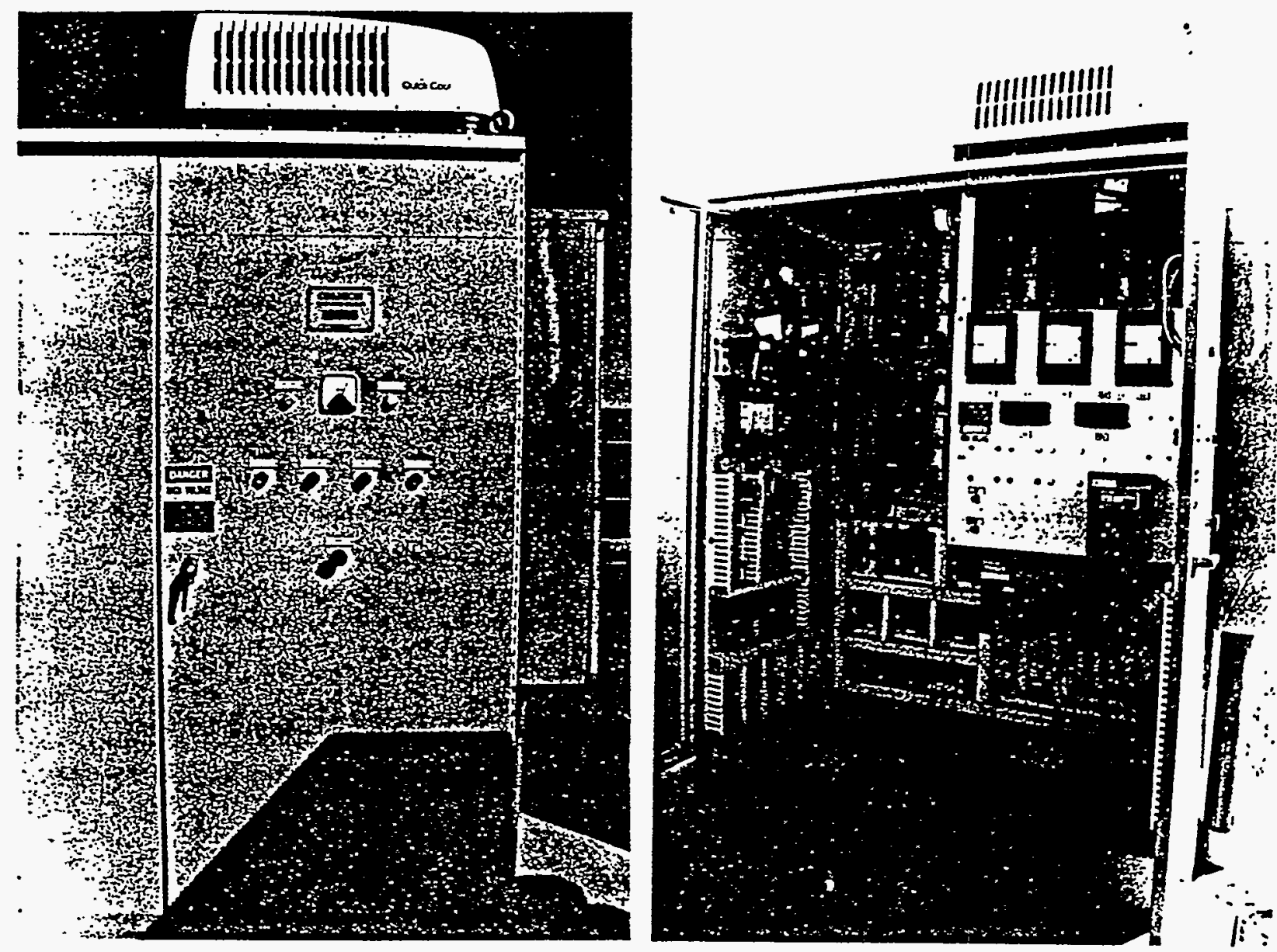

Figure 4-3. Exterior and interior of Omnion US-1 PCU.

\section{Factory Tests}

Omnion prepared a Factory Test Plan for its PCU. The format includes blank spaces to record data so that the document becomes a factory test report for the unit tested. Table 4-2 summarizes the tests performed on the component boards and modules; Table 4-3 summarizes the tests performed on the completed PCU. The availability of test equipment at the factory (e.g., a dc power supply to simulate the PV arrays) limited test power to approximately $100 \mathrm{~kW}$. Hand-written changes were made to both test documents (apparently derived from previous similar testing) to accommodate the design of the unit under test. 
Table 4-2

\section{Summary of Factory Tests on Circuit Boards for Omnion US-1 PCU}

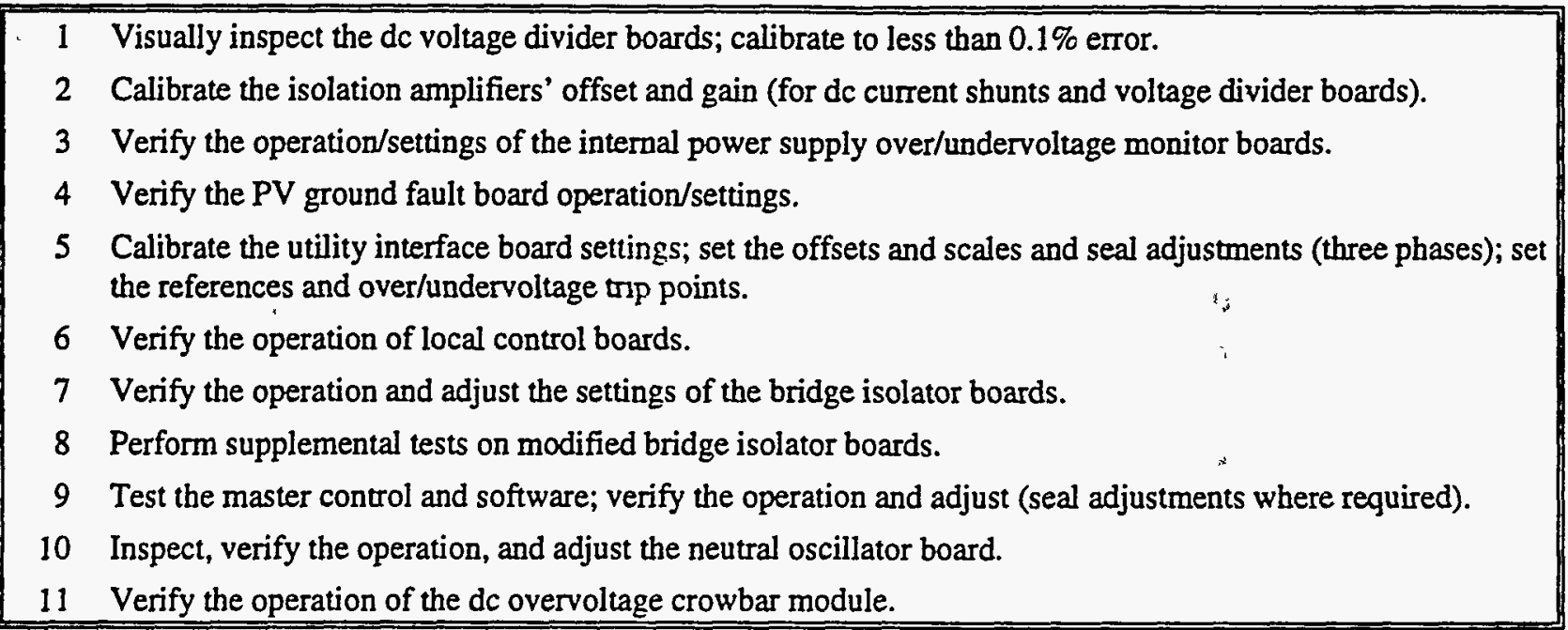

Most of the components and circuit boards were tested (see Table 4-2) in October and November 1990. The tests were signed off as completed on July 11,1991 . However, some individual tests were dated later (Table 4-2, Item 10,8/11/91 and Item 11,11/11/91), and some items were partially retested (utility interface board, Item 5 and master control, Item 9). Factory testing of the "completed" PCU per Table 4-3 was performed on July 11, 1991. The tests were generally successful and uneventful, with one exception. The monitor on the $+24-\mathrm{V}$ power supply failed to trip on overvoltage.

The test data consist mostly of internal voltage readings, checkmarks indicating successful completion of test items, signoffs, and dates. PCU efficiency was not measured. Voltage and THDs were measured (Item 30). The results are presented in Figure 4-4 as functions of power level, up to the $100-\mathrm{kW}$ limit of the factory test equipment. Data on the harmonics measured after field installation are presented in the section on PCU characteristics. The power factor was measured to be above 0.996 at four power levels $(12,25,38$, and 50 percent of rated power). Data taken during the 8-hour heat runs (Item 31) indicated that the bridges run $14^{\circ} \mathrm{C}$ to $21^{\circ} \mathrm{C}$ above the ambient temperature and that the snubbers are $20^{\circ} \mathrm{C}$ to $34^{\circ} \mathrm{C}$ above ambient. 


\section{Table 4-3}

\section{Summary of Factory Tests for Omnion US-1 PCU}

\begin{tabular}{|c|c|}
\hline 1 & Verify that the printed circuit boards were tested and that their test reports are completed. \\
\hline 2 & Verify that test setup connections to the unit are correct. \\
\hline 3 & Visually inspect the unit and verify that the wiring is in accordance with the latest drawing. \\
\hline 4 & Remove fuses; bring up 120 Vac to control power circuits; verify voltages. \\
\hline 5 & Remove all bridges and MOVs; hi-pot with 1-kV megger; record resistances. \\
\hline 6 & Adjust dc supplies to verify trips for undervoltages and overvoltages; record trip voltage levels. \\
\hline 7 & Set the dc power supply voltages to the proper levels and record the values. \\
\hline 8 & Verify the control voltages and LCD display indicator for the ac disconnect open. \\
\hline 9 & Verify the control voltages and LCD display indicator for the dc disconnect open. \\
\hline 10 & Measure and record PT voltages. \\
\hline 11 & Verify the operation of the dc ground fault detector and indicators; measure and record trip ranges. \\
\hline 12 & Verify the operation of the door interlocks. \\
\hline 13 & Verify the operation of the smoke detector. \\
\hline 14 & Measure and record ac overvoltage and undervoltage trip levels. \\
\hline 15 & Verify the operation of controls and LCD for emergency stop, manual and automatic start and stop. \\
\hline 16 & Remove the fuses and control cable to verify the local control missing function for all five bridges. \\
\hline 17 & Start the unit without fuses to verify proper startup control sequence. \\
\hline 18 & Verify the proper stopping control sequence. \\
\hline 19 & Test the hardware backup to the master control. \\
\hline 20 & Verify the opening of the ac and dc contactors upon master control CPU fault. \\
\hline 21 & Test overtemperature indications and control functions for all five bridges. \\
\hline 22 & Verify cleared fuse fault LCD indications for all bridge fuses. \\
\hline 23 & Test the dc voltage feedback circuit; measure and record voltages. \\
\hline 24 & Test the current feedback circuits in all three phases of all five bridges; measure and record the voltages. \\
\hline 25 & Test bridges one at time; verify acceptable waveforms and IGBT temperatures. \\
\hline 26 & Test the complete PCU overpower and dc voltage range (limited by test power supply). \\
\hline 27 & Measure and record $\mathrm{CT}, \mathrm{PT}$, and wattmeter readings. \\
\hline 28 & Verify proper operation in the constant voltage and automatic power tracking modes. \\
\hline 29 & Verify automatic start and stop. \\
\hline 30 & Record harmonics and power factors at four power levels (power limited by test equipment). \\
\hline 31 & Operate 8 hours at full power; record bridge and reactor temperatures (power limited by test equipment). \\
\hline 32 & Open the ac switch to verify shutdown upon loss of utility voltage (perform at $70 \mathrm{~kW}$ ac output). \\
\hline 33 & Test tripping of the ac circuit breaker by stored energy ( 10 times - without ac power available). \\
\hline 34 & Test the dc crowbar and detector circuit for loss of control power, overvoltage, and single phasing. \\
\hline 35 & Complete the test record paperwork. \\
\hline
\end{tabular}




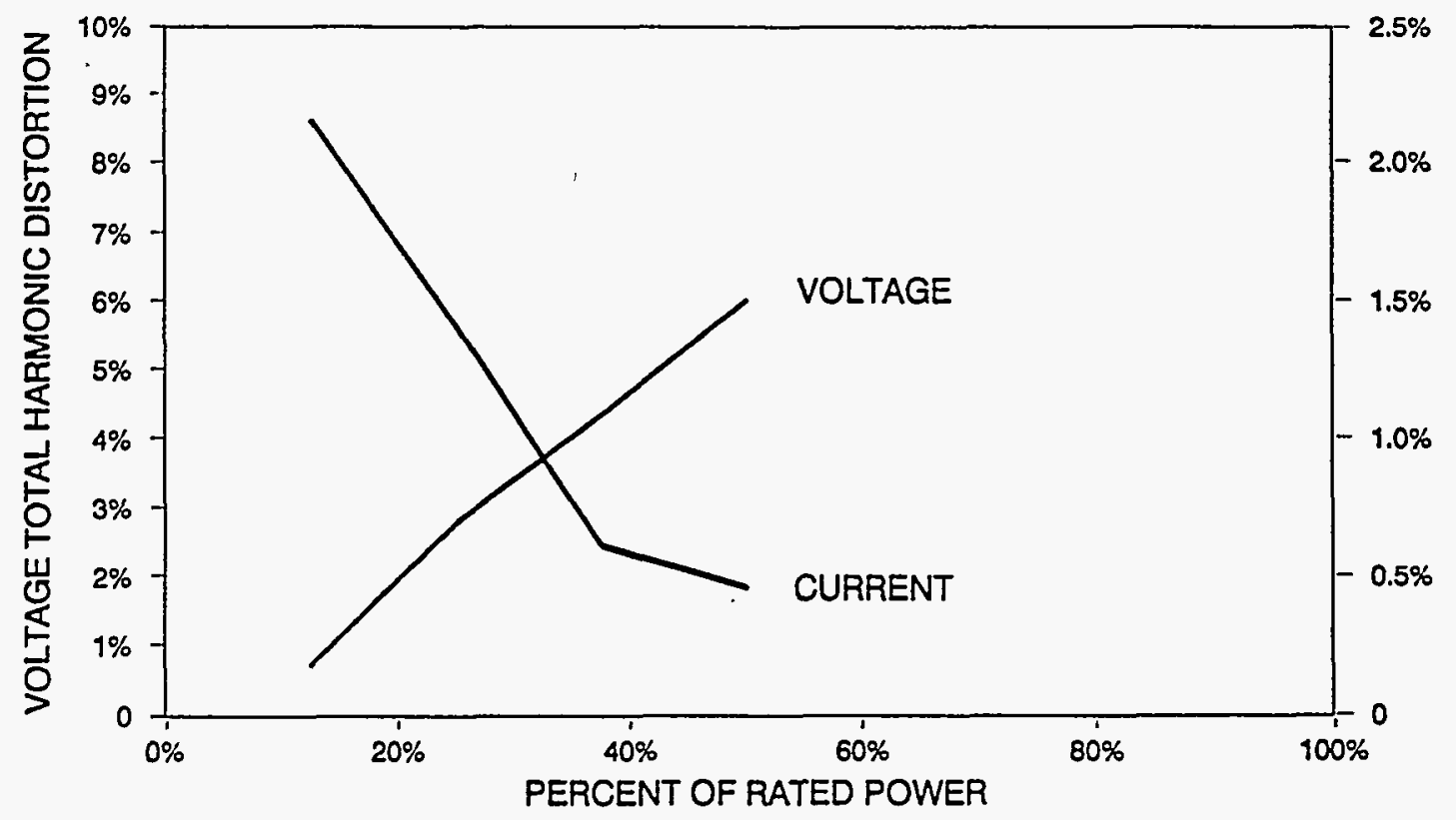

Figure 4-4. Total harmonic distortion versus power.

On July 18, 1991, PVUSA personnel inspected the PCU at Omnion's facility prior to releasing the unit for shipment to the Davis site. A test of single-phasing shutdown resulted in the failure of two IGBTs and the clearing of most fuses. These were replaced in $1 \frac{1}{2}$ hours, but further testing was canceled. A fault in the test power supply was suspected, but the cause was not determined with certainty. Except for resolution and remediation of the foregoing failure, the PCU was found to be acceptable. Additional actions to be taken included the following:

- Wire the ac and dc disconnects so that the blades are wired to the deenergized PCU.

- Add door restraints to stabilize the doors in windy conditions.

- Define the color codes for wiring in the O\&M Manual.

- Add a cover to protect the rear of the LCD display when the door is open.

- Change one LCD message (from "IJB shutdown" to "remote disable").

- Set startup delay at 2 minutes and shutdown delay to 1 minute.

- Resolve one occurrence of incorrect phase sequence sensing.

- Resolve missing "old ac undervoltage" LCD message. 


\section{Startup Tests}

Omnion developed a set of startup tests, which are summarized in Table 4-4. PVUSA developed a set of tests to verify the operational readiness of the PCU. These tests are summarized in Table 4-5. As can be seen, the PVUSA and Omnion tests contain several similar items and the field tests replicate many, but not all, of the factory tests.

\section{Table 4.4}

\section{Summary of Field Test Sequence for Omnion US-1 PCU}

\begin{tabular}{|rl|}
\hline 1 & Verify that factory tests have been completed. \\
2 & Visually inspect the unit and verify that the wiring is correct. \\
3 & Verify and record the 120 -Vac control power voltage. \\
4 & Verify and record the voltages on internal dc power supplies and their monitor board. \\
5 & Verify the voltages and LED illuminations for the ac breaker positions. \\
6 & Verify the voltages and LED illuminations for the dc disconnect positions. \\
7 & Measure and record PT voltages. \\
8 & Verify the operation of the dc ground fault detector. \\
9 & Verify the operation of the door interlocks. \\
10 & Verify the operation of the smoke detector. \\
11 & Verify the operation of controls and LCD for emergency stop, manual and automatic start and stop. \\
12 & Test the missing local control functions for all six bridges. \\
13 & Verify the operation of all local control boards. \\
14 & Start the unit without fuses to verify the proper startup control sequence. \\
15 & Verify the proper stopping control sequence. \\
16 & Test the hardware backup to the master control and opening of ac and dc contactors upon CPU fault. \\
17 & Test the overtemperature shutdown function and error display for all five bridges. \\
18 & Test the cleared fuse function for all five bridges. \\
19 & Verify the operation of the voltage feedback. \\
20 & Test the complete PCU, starting with a portion of the PV array, and continue to the point where the entire \\
21 & array is connected. \\
22 & Oerify the operation of the voltage and current regulators. \\
23 & Verify the operation of the automatic maximum power tracker. \\
24 & Verify PCU automatic start and stop functions. \\
\hline
\end{tabular}




\section{Summary of PVUSA Preparallel Field Test for US-1 PCUs}

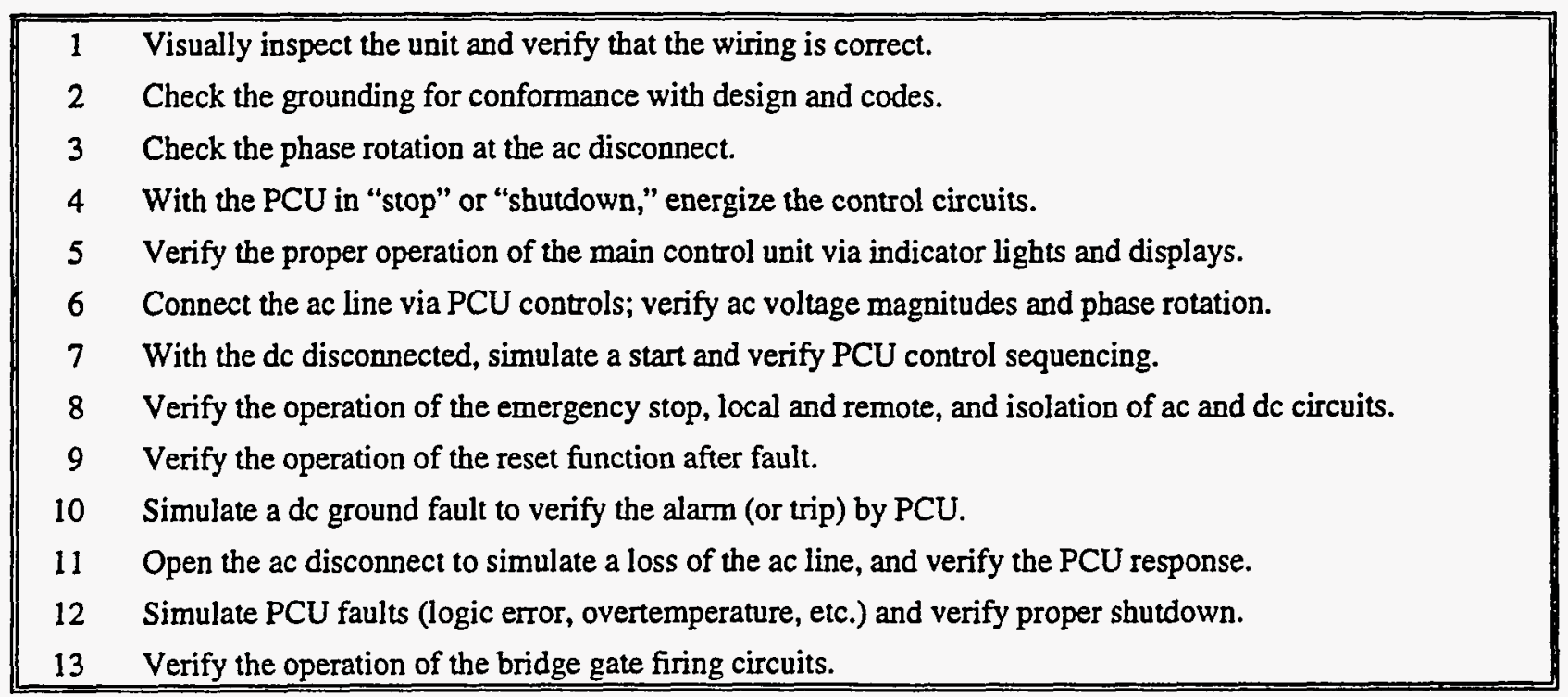

Preparalleling tests were performed in October and November 1991. Startup tests were performed in the period October 24-31, 1991. In the initial testing, the PCU passed most of the tests listed in Table 4-5. Exceptions included:

- A power supply monitor board failed to trip for several over/under voltage conditions.

- There was interference by a PVUSA interface junction box (IJB) signal (adding pulldown resistors remedied the problem).

- There was a broken solder connection in the cleared fuse indicator circuit.

- The unit did not lock out on detection of bridge overtemperature.

- "High voltage" signs were to be added to the PT/CT cubicle; the door needed to be aligned; a door stop was to be added; and devices needed to be labeled.

- A label and a door stop had to be added to the main transformer.

- The enclosures for the dc and ac disconnects and the PCU had to be grounded. 
A set of run-on tests were performed (on November 11, 1991) under several conditions:

- IPC at $78 \mathrm{~kW}$ ac and SSI US-1 disconnected

- IPC at 75,80 , and $85 \mathrm{~kW}$ ac and SSI US-1 Inverter $A$ at $48 \mathrm{~kW}$ ac

Test results showed the IPC/Omnion PCU ac contactor opened in 0.025 to 0.110 second after the loss of utility voltage. This is better than the design value of 0.250 second. Figure $4-5$ shows representative voltage and current waveforms from the first test (IPC at $78 \mathrm{~kW}$ ac and SSI disconnected).

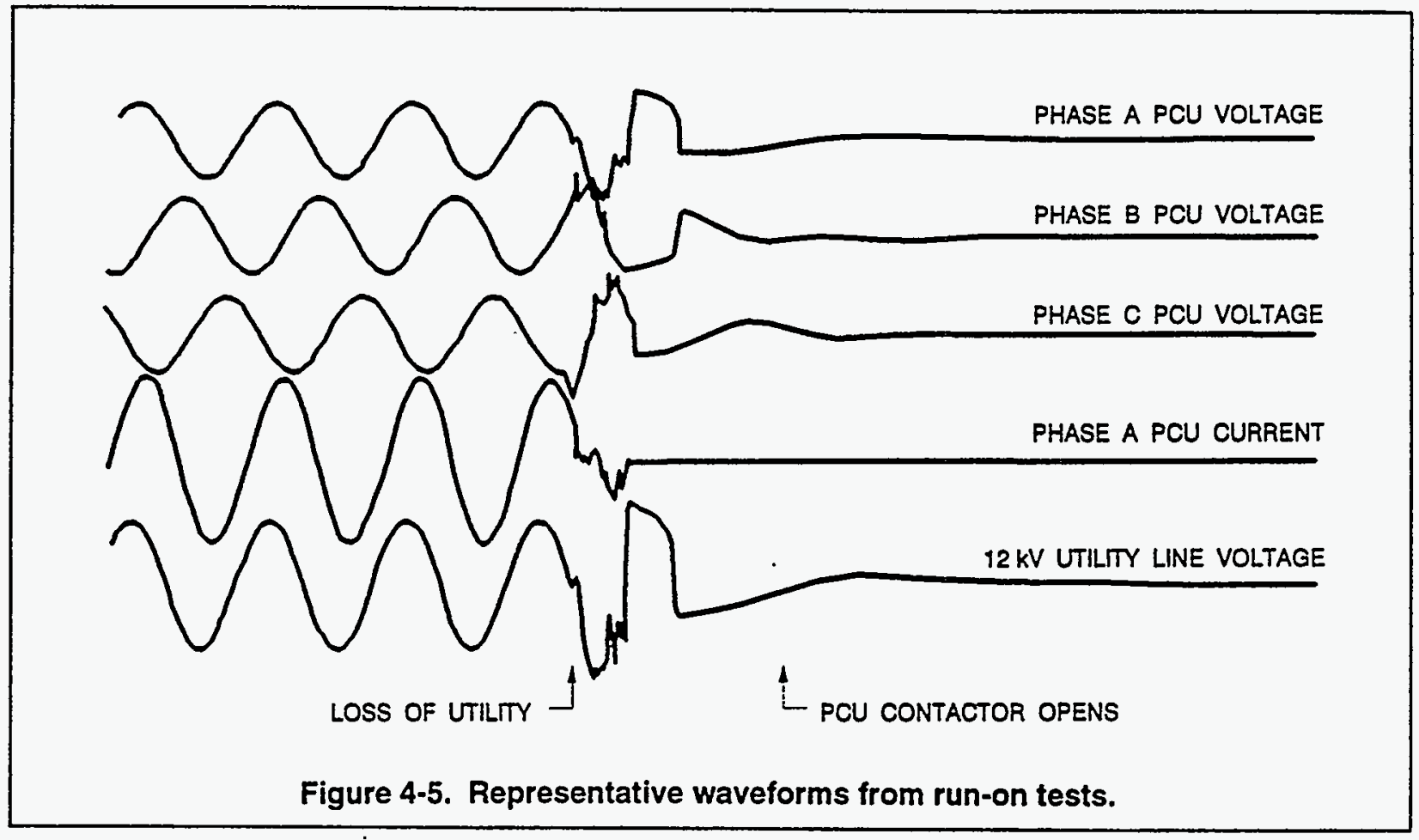

The PCU successfully passed three run-on tests. However during a fourth test, fuses cleared in the PT/CT enclosure and in an inverter bridge, and an IGBT was damaged. The master control printed circuit board was returned to Omnion for inspection.

\section{OPERATION AND MAINTENANCE}

Since the PCU passed its startup tests, there have been over 100 trips. These are listed in Appendix C. The frequency of these events is illustrated and compared with that of the other PVUSA PCUs in Figure 3-7 and in Table 3-4. Further details on selected failures and symptoms are presented below. 
In December 1991, a transient on the 12-kV line resulted in the clearing of fuses on the PTs and in damage to several MOVs. In February 1992, IPC was asked to add a shutdown/lockout function with a 5minute timer for loss of utility voltage.

The IPC system was unavailable for 1992 and part of 1993 (14 months) while IPC corrected problems with the module electrical connectors. Testing and operation at partial power were started in April 1993, and acceptance testing at full power began in June 1993. In May 1993, Omnion personnel were at Davis to inspect old ac undervoltage error messages and other PCU trips.

Due to high irradiance levels and other problems, Omnion modified the PCU's software (in June), to operate the reduce power contactor at $200 \mathrm{~kW}$ (versus $218 \mathrm{~kW}$ originally) and to shut down if the power from the remaining source circuits exceeded $224 \mathrm{~kW}$.

In August 1993, there were 11 shutdowns due to bridge faults. It was suspected that these were caused by high temperatures. Except for one occasion, the ambient temperatures at the site during the times of the shutdowns ranged from $91^{\circ} \mathrm{F}$ to $104^{\circ} \mathrm{F}$ and temperatures within the $\mathrm{PCU}$ enclosure ranged from $123^{\circ} \mathrm{F}$ to $140^{\circ} \mathrm{F}$. The PCU was down for most of August and September. In October, Omnion retrofitted the PCU enclosure with an air conditioning unit, and a newly programmed EPROM was installed. The air conditioning unit can be seen on top of the PCU cabinet in Figure 4-3. Its performance and its effect on cabinet air temperature are indicated in Figure 4-6. The cycling of the air conditioner might indicate that it was oversized, but it should be noted that the maximum ambient outside air temperature was $89^{\circ} \mathrm{F}$ on the day of the test. Ambient temperatures of $115^{\circ} \mathrm{F}$ occur at the Davis site and would result in less cycling. In addition, as a point of practicality, the unit was the same as the one Omnion installed on the higher power PCU at Kerman.

Unfortunately, these changes had little effect on the failures. The master control board was returned to Omnion for evaluation at the factory. After repairs by Omnion and restart in early November 1993, there were seven occasions where the PCU did not come on line in the morning and displayed a dc overvoltage error message. In December 1993, a line disturbance resulted in several fuses clearing and failed IGBTs. After repair, the PCU continued to experience dc overvoltage trips. 


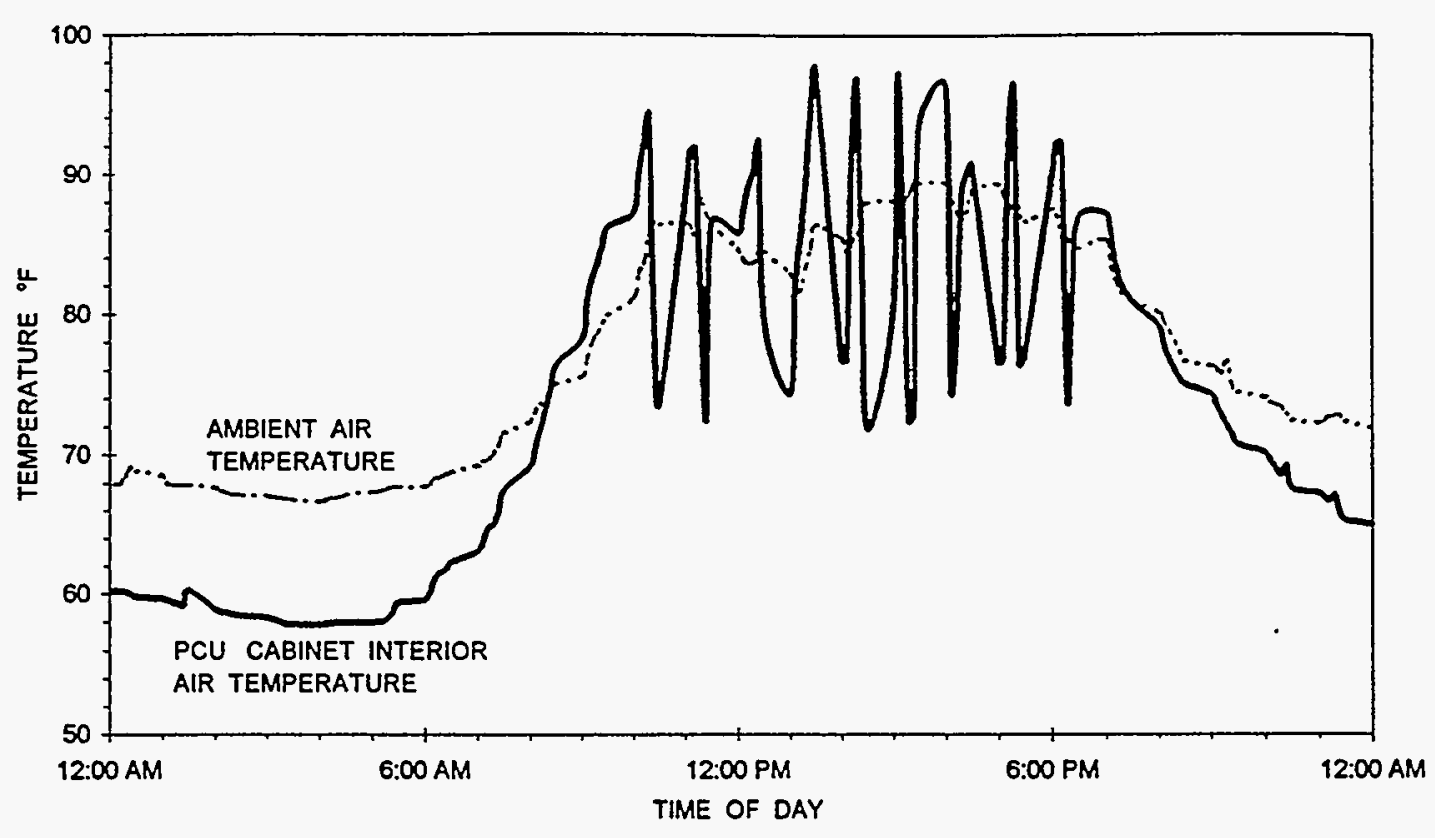

Figure 4-6. IPC/Omnion PCU temperatures.

On January 19, 1994, several connectors were cleaned to solve an intermittent problem. One hour after restart, the PCU tripped on a bridge fault error. Ac and dc bridge fuses cleared, as did the IGBTs in the affected bridge. These were replaced on January 20, and the PCU operated normally until 1:00 p.m., when the PCU tripped on a bridge fault and smoke alarm. The fuse and IGBT were damaged again. The affected parts were replaced on February 1, and the unit operated normally until 12:40 p.m., when the PCU tripped on a crowbar fault. This was reset and the unit operated normally. There were a number of trips due to low utility voltage in February. This may have been caused by low line voltages for a cycle or two. Dc overvoltage trips continued through May. Several printed circuit (PC) boards, cables, and the EPROM were replaced, but the problem continued. On May 28, a failure resulted in damage to 2 IGBTs, 3 snubber PC boards, and 11 fuses. The dc overvoltage problem seems to have been solved in October by replacement of integrated circuit amplifiers in the dc injection sense circuit and repair of a solder connection. No outages occurred from October 28 to December 14, but the problems returned thereafter.

\section{PCU CHARACTERISTICS}

\section{Efficiency}

Figure 4-7 shows the efficiency of the PCU as a function of power. The rated power is that of the PCU, $200 \mathrm{~kW}$ ac. The ac output is measured at the $12.47-\mathrm{kV}$ side of the isolation transformer. Several hundred 


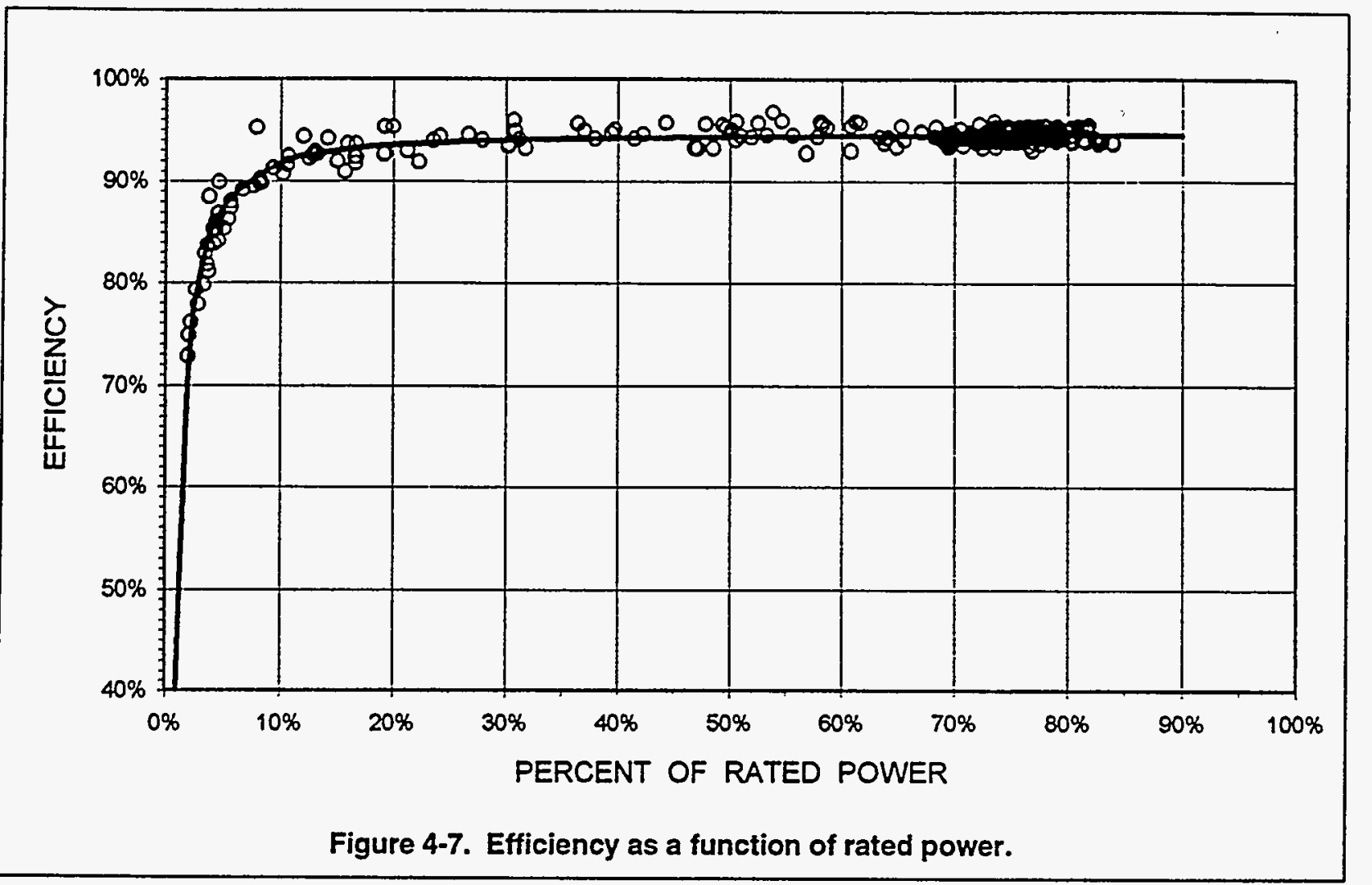

data points are used from 5 days of data (October 10-14, 1994). The average dc-to-ac efficiency above 20 percent of rated power is 93.9 percent. As can be seen in the figure, the efficiency in the region above 10 percent of rated power $(200 \mathrm{~kW} \mathrm{ac})$ is almost constant.

\section{Current Unbalance}

Figure 4-8 shows the ac output currents as functions of power level. The phase currents exhibit a slight unbalance with respect to their average. Averaged over the 5-day data set in the region above 30 percent of rated power, Phase $A$ is +2.9 percent, Phase $B$ is +0.05 percent, and Phase $C$ is -2.95 percent. The average unbalance is 2 percent. 


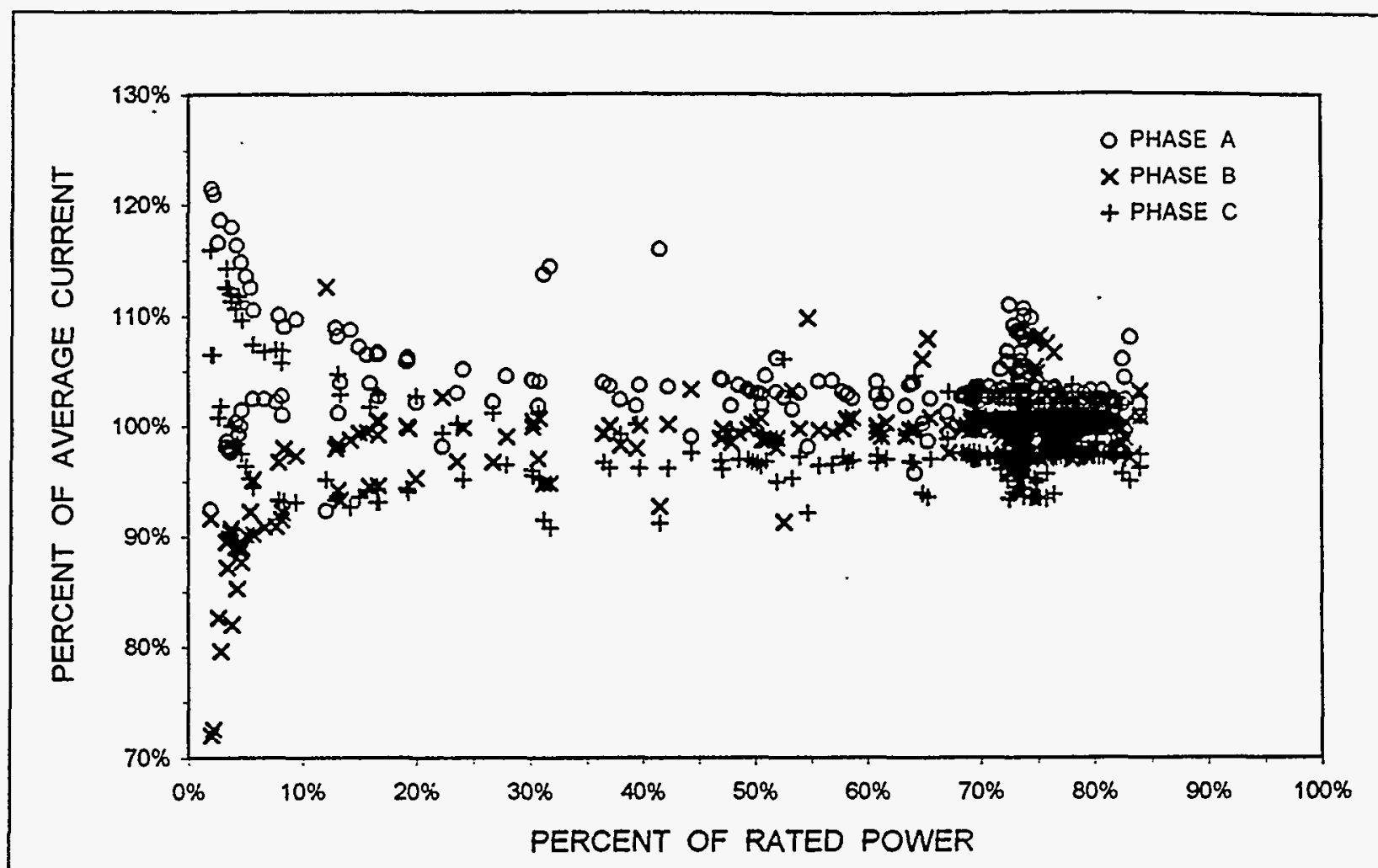

Figure 4-8. Ac output currents as a function of rated power.

\section{Power Factor}

Figure 4-9 shows the power factor and reactive power as functions of output power level for the 5-day data set. The power factor is greater than 0.99 for power levels above 8 percent of rated power.

\section{Harmonic Distortion}

Harmonic distortion measurements were made on May 4, 1993 with the PCU operating at $151 \mathrm{~kW}$ ac [4-2]. The measured THDs were 1.1 percent for voltage and 2.4 percent for current.

Further harmonic distortion measurements were made in November 1994. These measurements involved testing with several configurations and measurement points $(12.47 \mathrm{kV}$ and $480 \mathrm{~V})$ at the IPC, SSI, and APS PCUs. Details are presented in a separate report [4-3]. Figure 4-10 summarizes the percentage voltage and current harmonic distortions at the $12.47-\mathrm{kV}$ side of the IPC/Omnion PCU with the 


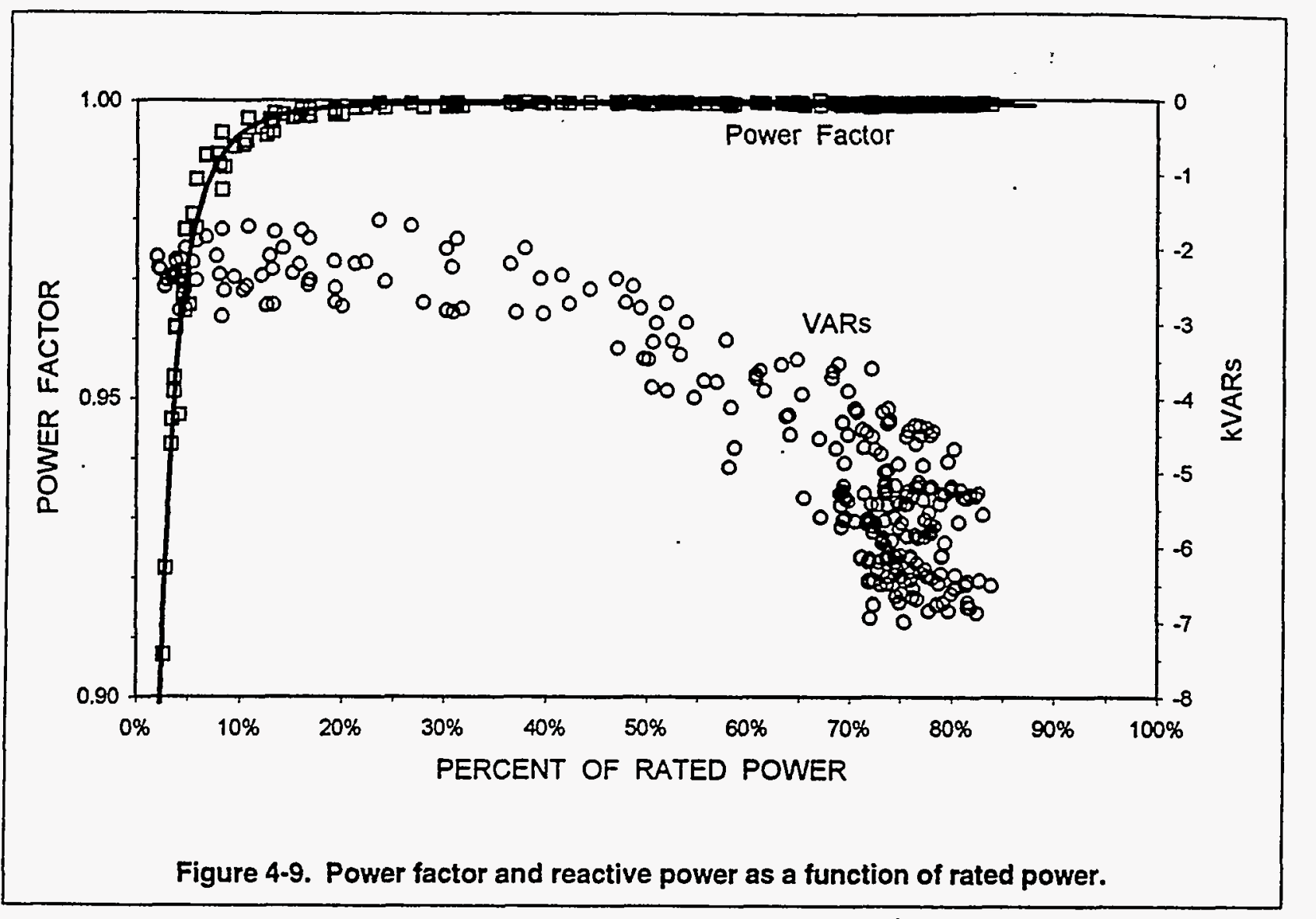

configurations tested. As can be seen, the voltage THDs range from about 1 to $1 \frac{1}{2}$ percent and the current THDs range from about $2 \frac{1}{2}$ to 4 percent for all of the configurations tested. The harmonic currents are expressed as a percentage of the current at the measurement power level (about 60 percent of rated) versus percent of current at full power. The measurements agree with the earlier 1993 data.

\section{SUMMARY}

Over 100 PCU trips occurred between startup and the end of 1994 . Most required only a reset, but many resulted in damage to the PCU. In some instances, the unit was off line for weeks or months. Many hours were spent by PVUSA, Omnion, and IPC personnel for diagnosis and repair. Although the unit operated several months without a trip, the most recent data indicate that the trips have returned. The major indications are dc overvoltage and bridge fault trips. The trips seem to be related. Corrosion and loose connectors in the control circuitry, along with component aging (due to high temperatures prior to 


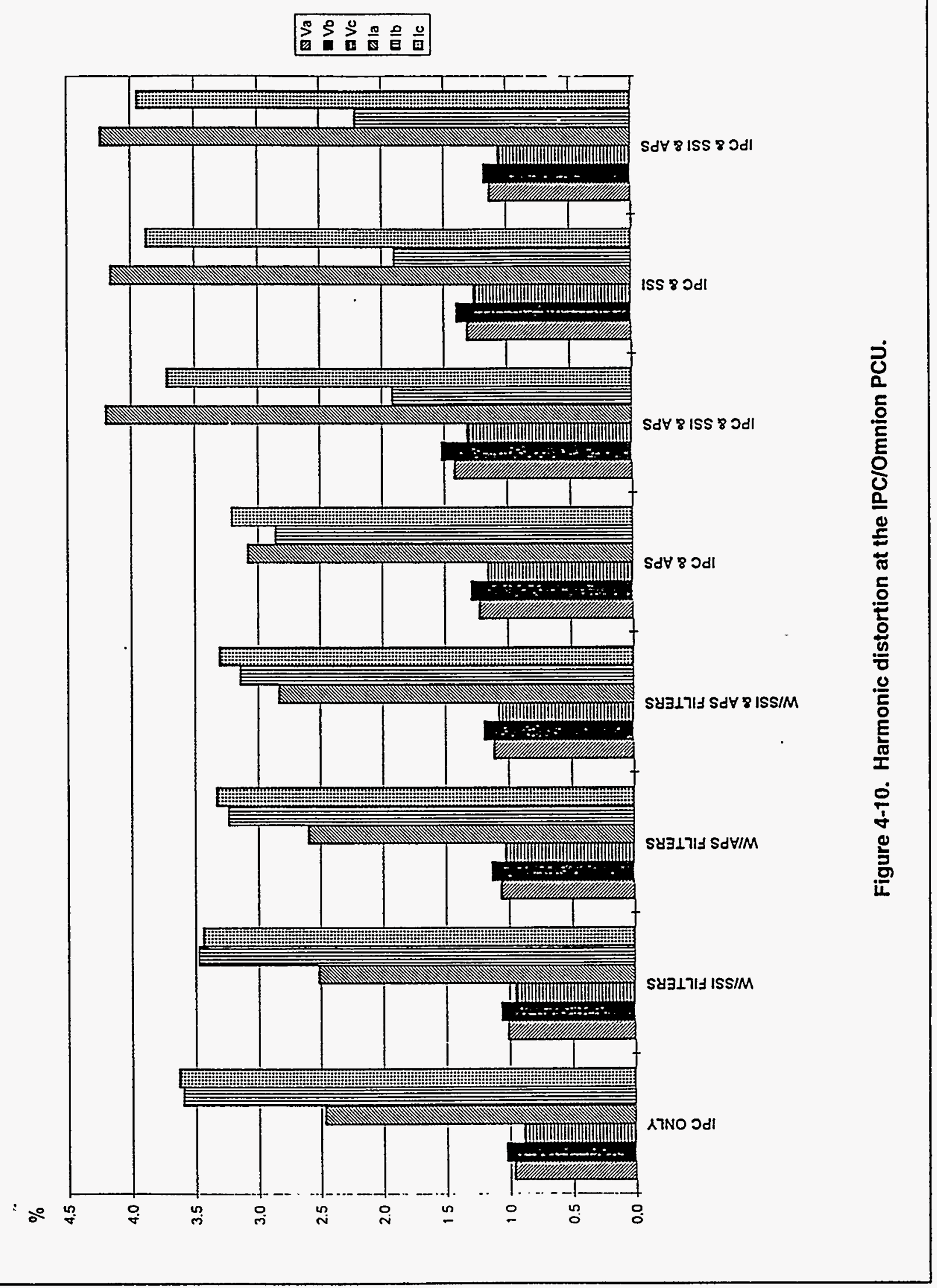

Repor No. 95-30910000.4

4-18 
installation of the air conditioning unit), may have been contributing factors. However, no root cause was ever firmly established. The layout of components in the enclosure facilitates maintenance, but the bayonet fuses proved to be difficult to maintain and their use would not be recommended for future units.

When operating, the IPC/Omnion PCU has a 94 percent efficiency (above 20 percent of rated power), fair total harmonic current distortion ( $31 / 2$ percent), fair current unbalance (about 2 percent), and excellent power factor ( $>0.99$ for power $>8$ percent of rated). It appears to successfully track the maximum power point of the connected PV array. While not immune to line voltage transients, this unit has survived transients that damaged other PCUs at Davis.

\section{REFERENCES}

4-1 O\&M Manual - PVUSA US-1, Integrated Power Corporation, January 1992, 19271-SC-D099-76-2.

4-2 L. Kendrick, PG\&E Memo, May 6, 1993.

4-3 T. Geiger, Harmonic Analysis Tests at PVUSA, PG\&E Technical and Ecological Services, Report \# 005-94.16, issued January 6, 1995. 


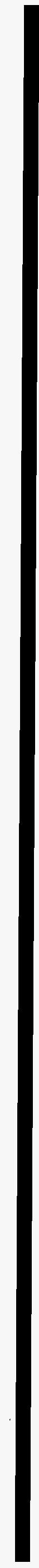


Section 5

\section{US-1, SSIDICKERSON}

This section presents data on the Bluepoint PCU installed at Davis, California.

\section{PCU DESCRIPTION}

The Siemens Solar Industries (SSI) US-1 PV system is installed at the PVUSA site in Davis, California. It uses two Dickerson 100-kW power conditioners supplied by Bluepoint Associates, Ltd. of San Luis Obispo, California [5-1]. Table 5-1 summarizes the manufacturer's ratings for several PCU parameters.

Table 5-1

Summary of Manufacturer's Ratings for SSI/Dickerson PCU

\begin{tabular}{|c|c|c|c|}
\hline Voltage & $12.47 \mathrm{kV} \mathrm{ac} \pm 10 \%$ & Power Factor & $0.97 @ 200 \mathrm{~kW}$ \\
\hline Frequency Range & $59-62 \mathrm{~Hz}$ & & $0.96 @ 150 \mathrm{~kW}$ \\
\hline \multirow[t]{2}{*}{ Current THD } & $<5 \%$ & & $0.95 @ 100 \mathrm{~kW}$ \\
\hline & & & $0.89 @ 50 \mathrm{~kW}$ \\
\hline Voltage Unbalance & Tolerates to $\pm 11 \%$ & Efficiency & $97.5 \% @ 200 \mathrm{~kW}$ \\
\hline Tare Losses & $1.1 \mathrm{~kW}$ & & $97.3 \% @ 150 \mathrm{~kW}$ \\
\hline \multirow[t]{2}{*}{ Run-On (Islanding) } & $<0.2 \mathrm{sec}$ & & $97.1 \% @ 100 \mathrm{~kW}$ \\
\hline & & & $95.8 \% @ 50 \mathrm{~kW}$ \\
\hline
\end{tabular}

The two Dickerson Model 3B 100-kW inverters are designated "Inverter A" and "Inverter B." Each of these inverters consists of two 50-kW inyerter "cores." In turn, each of these core inverters consists of two 25-kW, 6-pulse SCR inverter bridges, which are phase-controlled and combined to yield a 12-pulse output.: The electrical configuration of these two-bridge core inverters is shown in the schematic in the upper half of Figure 5-1. One of the 480-Vac outputs is connected to a delta winding on the low-voltage side of a 200-kVA output transformer. The other output is connected to a wye winding on the transformer. The delta and wye outputs of one $100-\mathrm{kW}$ inverter are connected in parallel with the corresponding delta and wye outputs of the second $100-\mathrm{kW}$ inverter. These connections and the configuration of the two $100-\mathrm{kW}$ inverters are shown in the schematic in the lower half of Figure 5-1. 


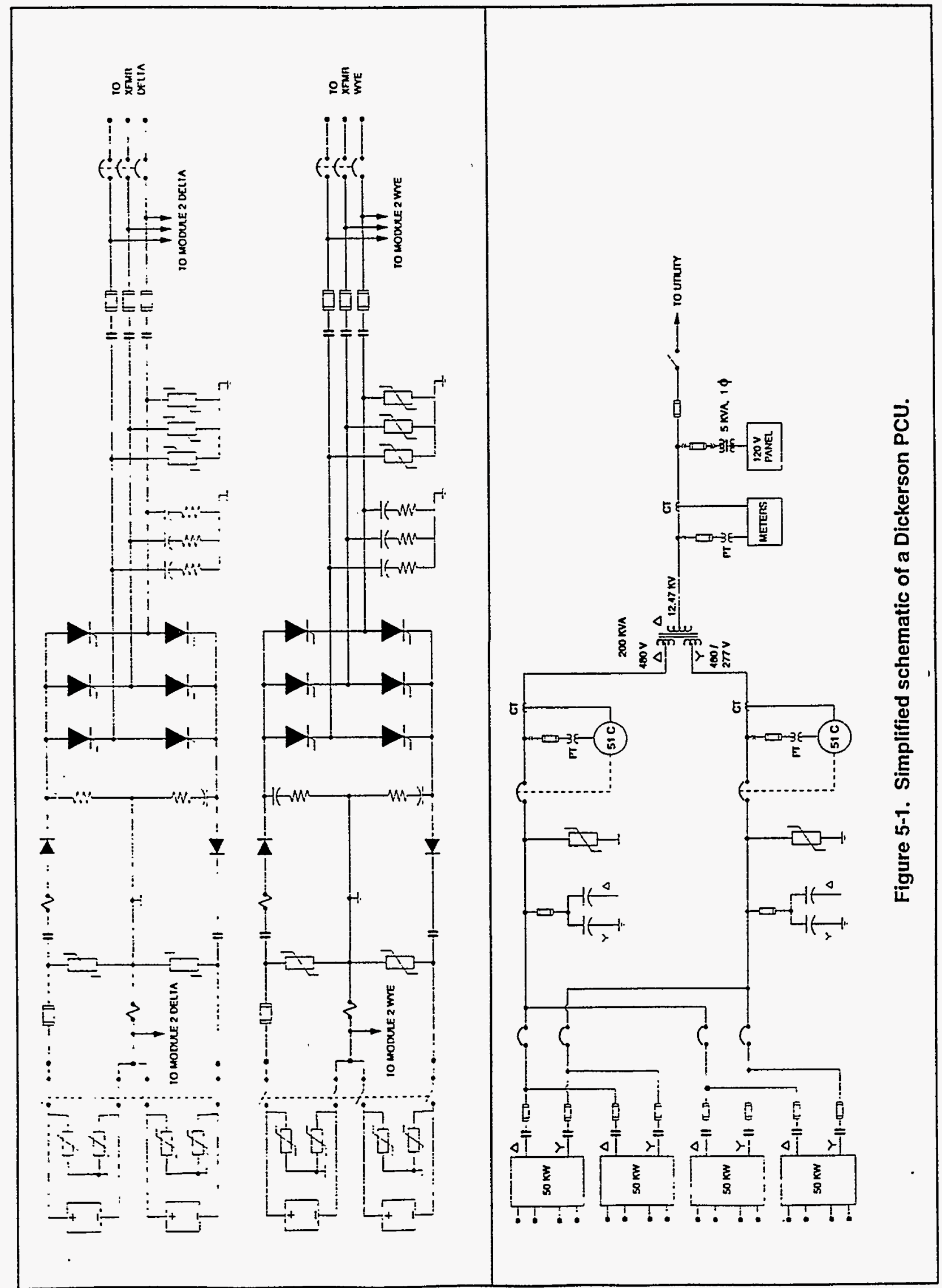

Repor No. 95-30910000.4 
There are 16 monopolar dc inputs from the PV array field, eight per 100-kW inverter. Each dc input pole is protected against voltage surges by an MOV to ground. Pairs of monopolar inputs are connected in series to form eight $\pm 330 \mathrm{Vdc}$ ( $38 \mathrm{~A}$ ), center-grounded bipolar inputs (plus, minus, and neutral), one per $25-\mathrm{kW}$ bridge circuit. The inputs to be paired each go through a four-pole dc disconnect switch. The dc neutral from one delta bridge is paralleled with the neutral from the second delta bridge in a $100-\mathrm{kW}$ unit and connected to ground through a current shunt. The same configuration is used on the wye bridges.

The ground current shunt signals (after going through amplifiers) are routed to an externally located (in a PVUSA interface junction box) data logger and relay driver. The delta and wye circuit neutral currents are sampled twice per second, averaged over 5 seconds, and combined. If the averaged current in either neutral exceeds 11 A (field-adjustable, value set to eliminate nuisance trips), the data logger sends a trip signal to the inverter. Reset must be performed at the remote data logger by entering commands to reset the data logger status.

Both the plus and minus poles of a bridge have an MOV to ground and go through a dc contactor. The plus pole includes a fuse (as a backup to the fuse in the ac output in the event of a commutation failure) and a current shunt (with isolating amplifier). Voltage transducers measure the bipolar dc voltage. Both poles of a bridge have a pass diode and an $\mathrm{RC}$ filter to ground $(0.47 \mu \mathrm{F}$ and 11 ohms). Each bridge has three dual SCRs (two SCRs in a single package) in a standard 6-pulse configuration. The SCRs are mounted on heat sinks which protrude through the enclosure wall into a forced-air cooling duct. The bridges include snubber, timing, and gate driver circuits (not illustrated). The output of each bridge has wye-connected (grounded) filters ( $0.47 \mu \mathrm{F}$ and $11 \mathrm{ohms}$, as on the dc side) and MOV surge protection. Resistive dividers measure voltage to detect unbalance. Each bridge output is connected to a three-pole ac contactor and fuses. The outputs of the two (per 100-kW unit) delta bridges are connected in parallel. This combined output is connected to an ac circuit breaker, which is mounted through the front door of the inverter enclosure. The configuration is repeated for the two wye circuits. Bridge delta and wye output wires are threaded through a current transformer (and $51 \mathrm{C}$ relay) to detect major faults.

The two $100-\mathrm{kW}$ inverters are located in the middle of the PV array field, separated by approximately 200 feet, with their common output transformer/substation located midway between the two units. The delta outputs of the two $100-\mathrm{kW}$ units proceed via underground conduit to the substation, where they are connected in parallel. There are two sets of simple capacitive harmonic filters, connected wye 
(90 $\mu \mathrm{F} /$ phase, grounded) and delta (70 $\mathrm{F} /$ phase), and MOV surge protection (connected wye, grounded). PTs and CTs are connected to an overcurrent relay with voltage restraint. The paralleled combination of the two inverter outputs is connected to the delta low-voltage winding of the output transformer. This configuration is repeated for the wye circuits from the two inverters, connecting to a set of wye windings (ungrounded) the transformer.

The high-voltage side of the transformer is at $12.47 \mathrm{kV}$ (delta). PTs and CTs provide input to local meters and the PVUSA data system. A 5-kVA transformer is connected to supply 120-Vac power to both inverters and local circuits via a distribution panel. The $12.47-\mathrm{kV}$ output is connected to the ac lines via a fused disconnect switch.

Each of the two $100-\mathrm{kW}$ inverters is capable of independent operation and includes a control microprocessor which sets the mode of the inverter (standby, run, dormant, or trip). The design includes automatic wakeup and shutdown (from/to the dormant mode). A small PV panel mounted on the inverter enclosure is used to sense when available irradiance exceeds $75 \mathrm{~W} / \mathrm{m}^{2}$ (field-adjustable), which changes the inverter to the standby mode. After a programmed delay to ensure that the irradiance level has persisted, parameters are checked to ensure that they are within tolerance. At this point, the ac contactor closes, the dc contactor closes, and the SCRs are gated. This sequence is reversed for normal nightly shutdown.

The inverters do not track the PV arrays' maximum power point. They operate at a fixed dc voltage set by the ac line voltage (and the inverter design). The manufacturer indicates that this design yields 98 percent of the annual energy that would be available with power tracking (if the ac line remains within a few percentage points of $12.47 \mathrm{kV}$ ). The manufacturer suggests changing the taps on the output transformer twice a year (April and October) to attain this annual output.

The PCU is designed so that it can be set to operate at unity power factor (at a given power level). The power factor of each bridge is field-adjustable, and is normally set 15 to 20 degrees leading at the inverter, which results in a few degrees leading on the $12.47-\mathrm{kV}$ side of the output transformer. The power factor remains relatively constant from 50 to 100 percent of rated power. Below 25 percent of rated power, the power factor and efficiency begin to decrease rapidly. 
The inverter is designed to ride through momentary faults on the ac line. The microprocessor will trip the inverter (open the ac and dc contactors) for overtemperature, loss of ac line or control power, interlock open, smoke detected, dc below minimum level, or ac current unbalance. The microprocessor includes a battery backup and programming to display a code for the cause of the trip. The inverter will trip to the standby mode on loss of the ac line and will attempt a restart after a 15-minute delay (if restoration of normal conditions is detected). If there is a second fault within 30 minutes of a restart, the inverter will trip and require a local or remote reset signal. Inverter trips due to smoke or overtemperature also require a local or remote reset signal. The local reset is accomplished by toggling a switch on the microprocessor from "run" to "stop" to "run." Toggling the run/test switch on the microprocessor cancels the time delays for startup and reset. A remote stop signal will override all other controls and requires a remote run signal to restart. A remote run signal cannot override local out-of-tolerance conditions and signals. A front panel emergency stop button directly opens the coils of the ac and dc contactors.

Each inverter front panel includes a window to view the microprocessor display, which furnishes details in the form of two-digit codes. Front panel controls include buttons for manual start, fault reset, and emergency off. The PCU also provides signals for remote monitoring. An enclosure at the transformer substation includes meters for dc voltage, current, and power, and for ac power.

Each 100-kW inverter is housed in a NEMA 12 enclosure, shown in Figure 5-2. The inverter cabinet itself is 36 inches wide by 24 inches deep by 90 inches high. The several dc disconnects, air-cooling duct, and other protuberances result in overall dimensions of 50 inches wide by 37 inches deep by 95 inches high. The inverter cabinet is mounted on a 48 -inch by 54 -inch concrete pad. The isolation transformer/substation (shared by two $100-\mathrm{kW}$ inverters) consists of several enclosures mounted on a 21by 10-foot concrete pad, as shown in Figure 5-3. The low-voltage enclosure is 32 inches wide by 49 inches deep by 90 inches high. The transformer enclosure is 46 inches wide by 45 inches deep by 90 inches high. The high-voltage enclosure is 94 inches wide by 89 inches deep by 95 inches high. The junction box is 46 inches wide by 10 inches deep by 60 inches high. The footprint of all of these enclosures is $2 \mathrm{~kW} / \mathrm{ft}^{2}$. The overall footprint of the three concrete pads is $0.84 \mathrm{~kW} / \mathrm{ft}^{2}$.

The photographs in Figure 5-4 show the exterior and interior of one of the $100-\mathrm{kW}$ inverter units. 

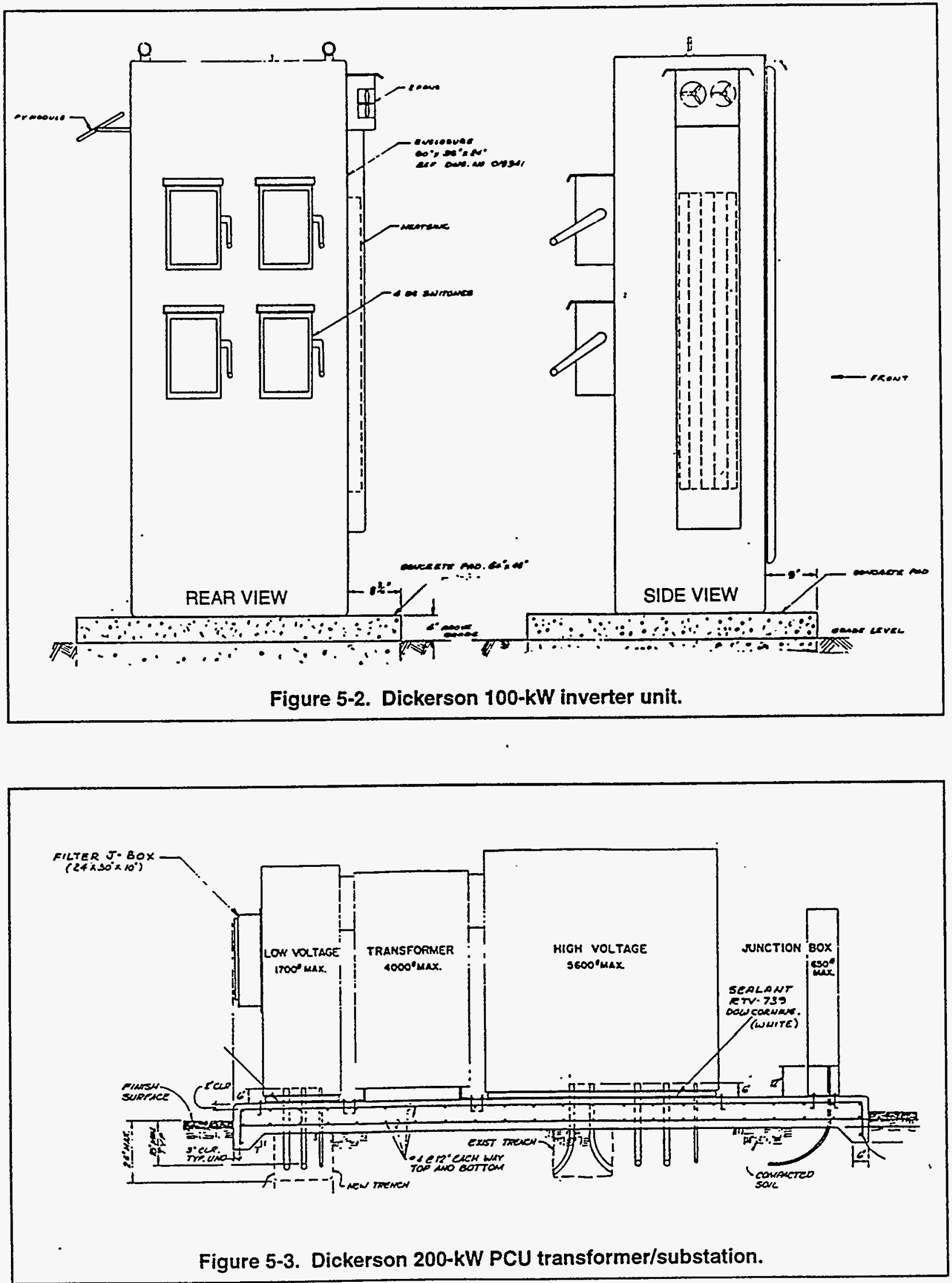

- Report No. 95-30910000.4

1146CO04.DOCRPS/RI 

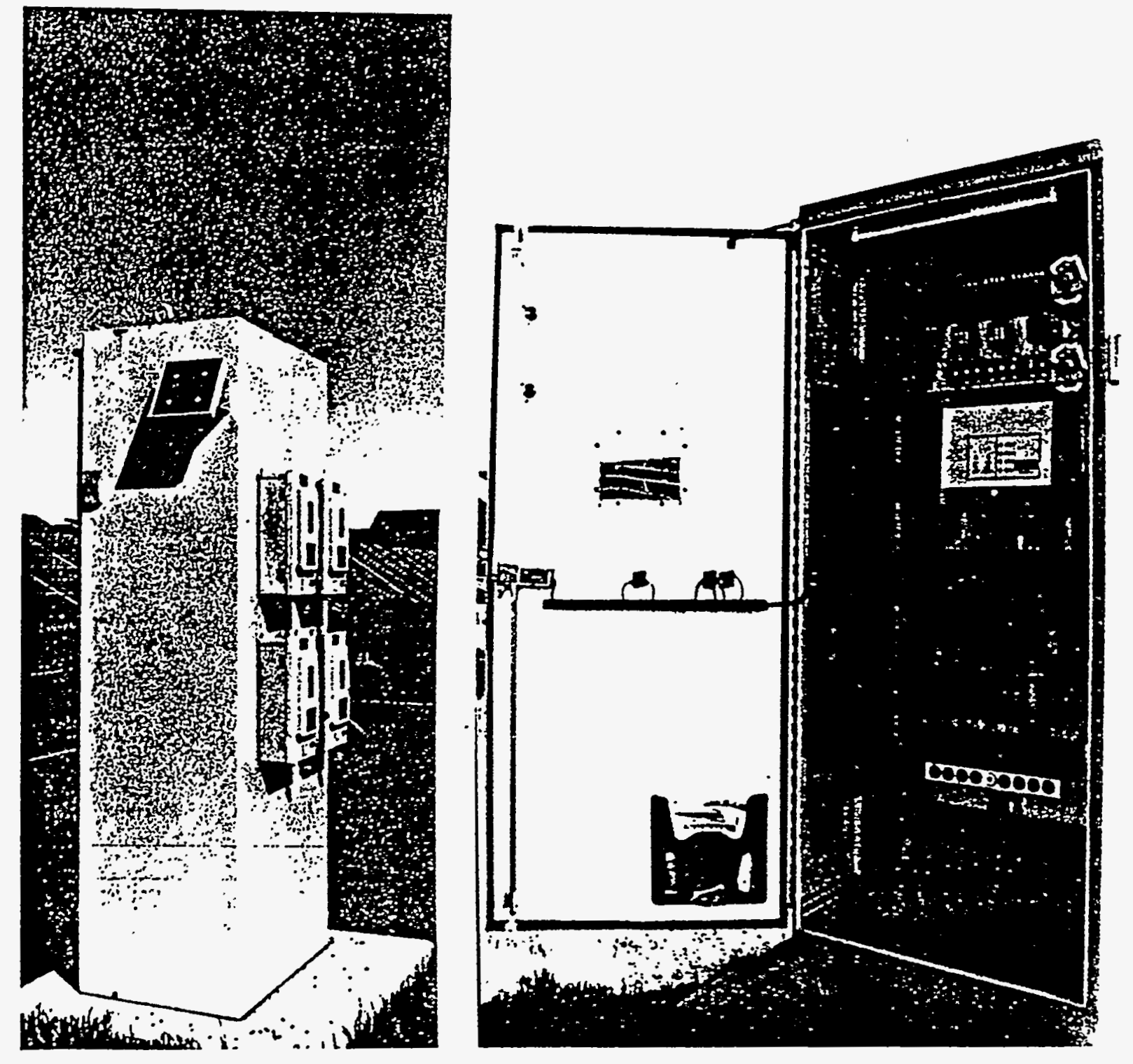

Figure 5-4. Exterior and interior of a Dickerson 100-kW inverter unit. 
The Dickerson Model 3 inverter has undergone several modifications and a repackaging of components after its initial installation. The inverter described above is the latest version, called the Model 3B. (This should not be confused with the designation of the two installed units as Inverters A and B.) A photograph of the initial configuration for a $100-\mathrm{kW}, 480-$ Vac inverter is shown in Figure 5-5.

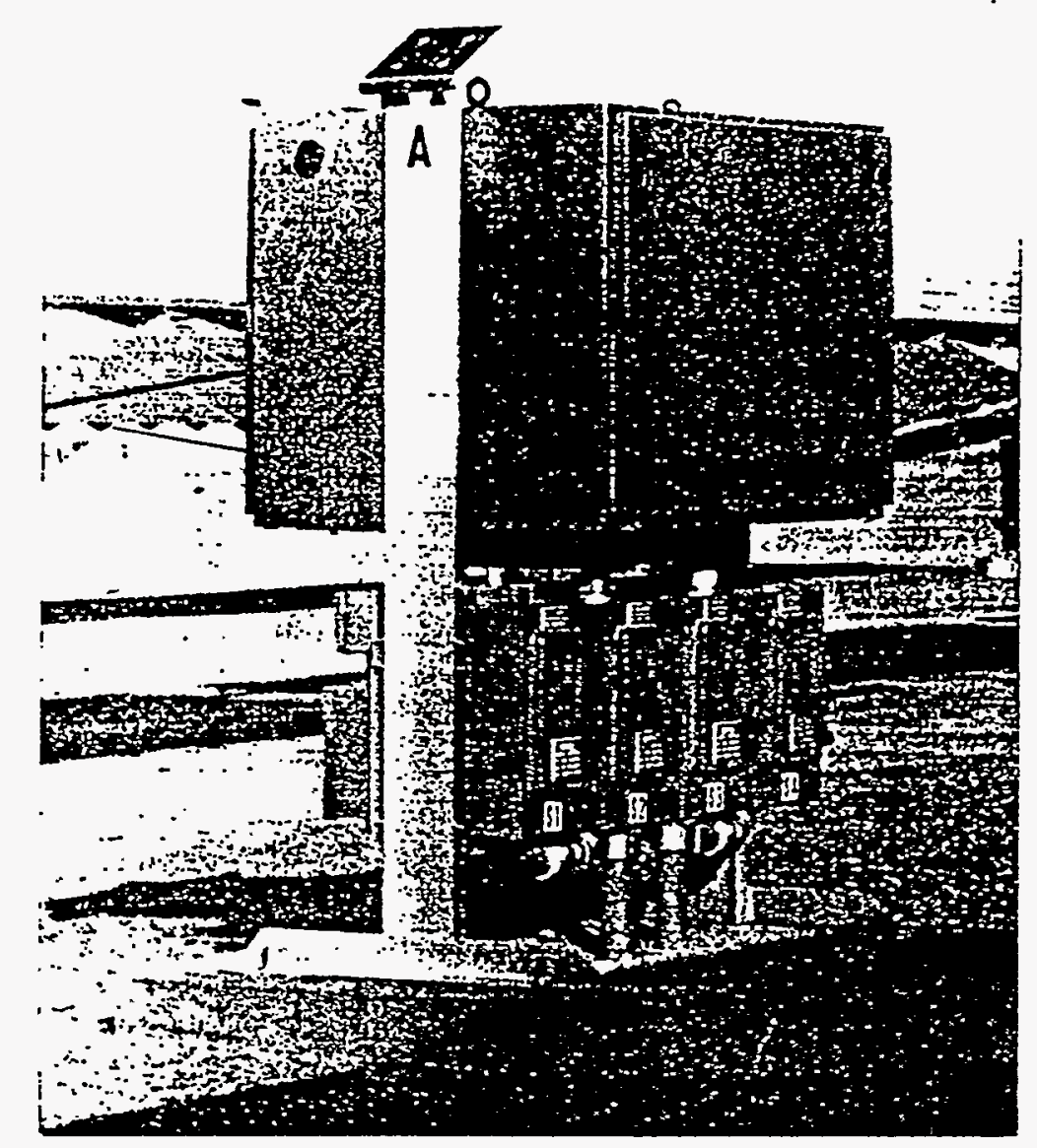

Figure 5-5. Original configuration of a Dickerson 100-kW inverter.

\section{FACTORY AND STARTUP TESTS}

The program included testing at the manufacturer's facility prior to shipping, startup testing at PVUSA's Davis site, initial operation, and special tests. 


\section{Factory Tests}

Dickerson prepared a Factory Test Plan for the PCU. A summary of the tests is shown in Table 5-2. These tests are less exhaustive than those for other US systems (e.g., see Table 4-3). The availability of equipment limited test power to approximately $3 \mathrm{~kW}$.

Partial "factory" tests were performed on August 2, 1990 at the manufacturer's facility (Electrical Engineering Laboratory, California State Polytechnic University, where Dr. Dickerson was a professor). The test equipmènt included a dc power supply capable of providing four outputs at $340 \mathrm{Vdc}$ at $2 \mathrm{~A}$ (to simulate four PV monopoles) and $460 \mathrm{Vdc}$ at zero current (to simulate open-circuit voltage). A transformer with wye and delta secondary windings was also available. This permitted operation of one $50-\mathrm{kW}$, two-bridge unit at low power and full $\mathrm{dc}$ open-circuit voltage, as well as paralleling with an ac line. At the time of the tests, only one $50-\mathrm{kW}$ unit was completed.

The tests were expanded to include additional activities such as a visual inspection. Several of the tests listed in Table 5-2 were not performed. Because of limitations, efficiency and harmonics were not measured and the remote reset/stop circuit was not functional. However, as a result of the visual inspection and testing performed, it was deemed that the PCU would be acceptable when completed. There were exceptions, requirements, and recommendations. Two conduits had lock nuts missing; conduit top entries had questionable water-tightness; and wires and components were unlabeled. Resulting requirements and recommendations for completion included:

- Label wires and components.

- Hard-wire the emergency off button to contactors rather than through logic circuits.

- Reprogram to attempt restarts 15 minutes after trip versus 15 minutes after fault clears.

- Replace pilot relays with solid state relays with higher current ratings.

- Adequately close off the cooling air plenum.

- Correct nonfunctional controls (remote reset/stop and smoke detector).

- Add required ac and dc metering (by SSI rather than Dickerson).

- Correct miscellaneous deficiencies (missing lock nuts). 
Table 5-2

\section{Summary of Factory Tests for SSI/Dickerson US-1 PCU}

\begin{tabular}{|rl|}
\hline 1 & Connect PCU to the test setup and demonstrate the autostart function by removing the cover from the sun \\
2 & With the inverter operating, demonstrate interlock shutdown by opening an enclosure door. \\
3 & Demonstrate the remote reset function by closing the contact on the remote reset line. \\
4 & Demonstrate the remote stop function by closing the contact on the remote stop line. \\
5 & Demonstrate the manual start from the control panel in the inverter enclosure. \\
6 & Demonstrate the manual stop from control panel in the inverter enclosure. \\
7 & Verify the operation at low power; display ac voltage and current; calculate power factor. \\
8 & Demonstrate loss-of-ac trip by opening one ac disconnect. \\
9 & Demonstrate loss-of-dc trip by opening one dc disconnect. \\
10 & Demonstrate loss-of-control-power trip by opening the 120-Vac breaker. \\
11 & With the inverter operating, demonstrate the auto shutdown function by covering the sun sensor. \\
12 & Demonstrate that a remote start signal will not turn the unit on when the inverter is in the dormant state due \\
13 & Wo the lack of sensed sun. \\
14 & Whilh the inverter operating, remove the ac line from the transformer to demonstrate loss-of-ac-line trip.
\end{tabular}

\section{Startup Tests}

Startup field tests are summarized in Table 5-3.

Partial testing of Inverter A started in January 1991, and initial acceptance testing was performed on March 21, 1991, with three of its four bridges operating. Subsequently, there were several voltage unbalance faults (traced to the PV array) and an inability to restart the inverter. Dickerson modified both Inverters $\mathrm{A}$ and $\mathrm{B}$ in April, but problems continued. Both inverter cores were taken back to Cal Poly for modifications in May. Additionally, a high level of audible noise from the main transformer was thought to be indicative of a problem. A representative of the transformer supplier visited the Davis site and pronounced the noise level normal, but questioned the suitability of the transformer enclosure. Modifications and air filters were added in June. Both inverters were operating at Davis in June, but problems with trips continued when both inverters were operated simultaneously.

Startup tests on Inverter B were performed on July 7, 1991, with approximately 77-kVA output. The unit passed most of the tests listed in Table 5-3. Exceptions included: 
Table 5-3

\section{Summary of Field Test Sequence for SSI/Dickerson US-1 PCU}

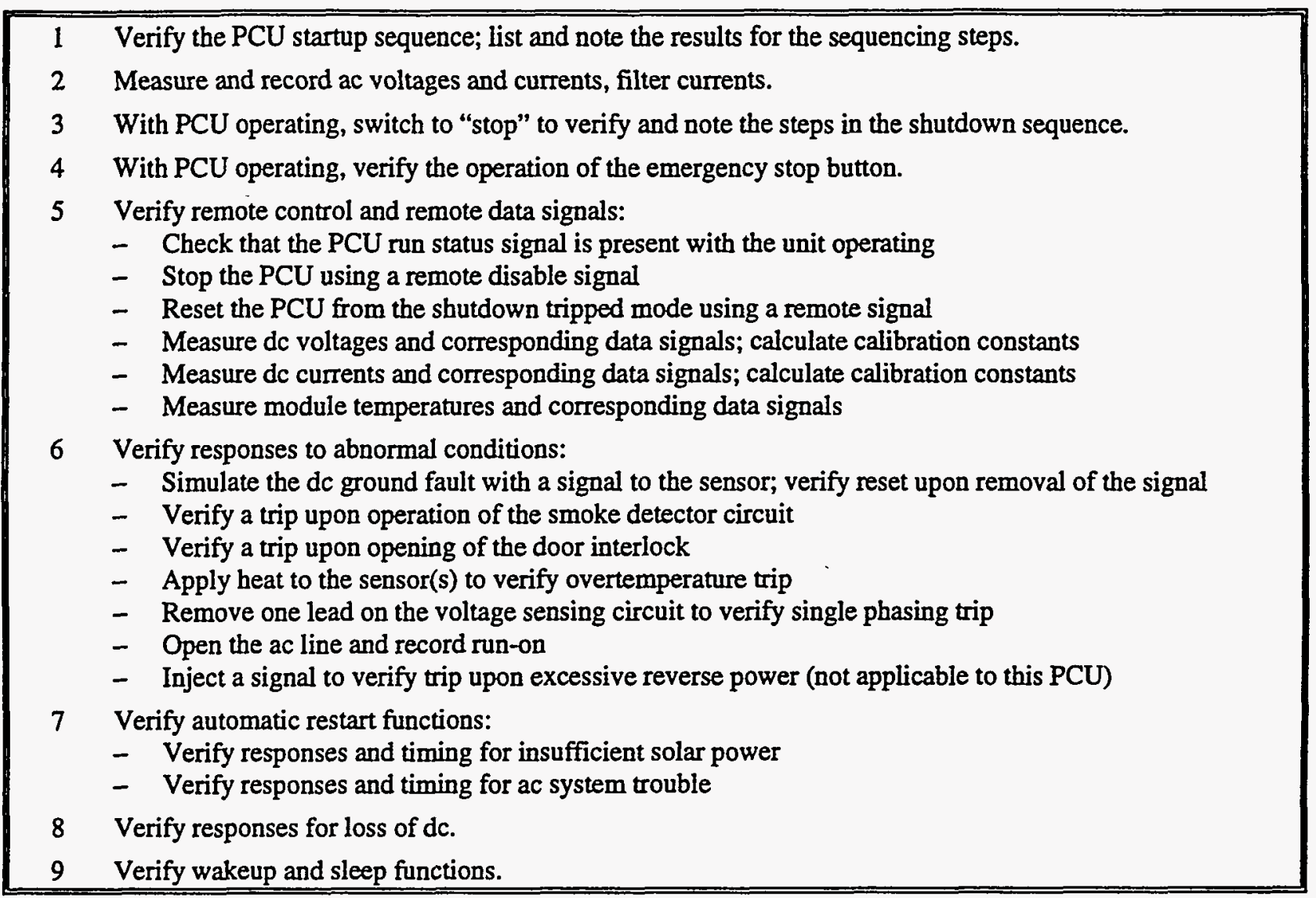

- The run LED remained on after the emergency stop (Test 4).

- Opening the enclosure door did not trip the unit (Test 6C).

- The system design is such that a loss of de trips the PCU via a remote unit, which must be manually reset; the inverter can operate with zero dc input.

- The wakeup and sleep functions were not tested at this time (Test 9).

Figure 5-6 shows an oscillograph recording for loss-of-ac run on tests (Test 6F). The traces are for the three-phase voltages, Phase A current, and auxiliary contacts on the ac contactor. As can be seen, the ac contactor opens within 0.032 second. The anomalous pulse in the phase voltages at 0.19 second was believed to be due to the opening of the dc contactor. 

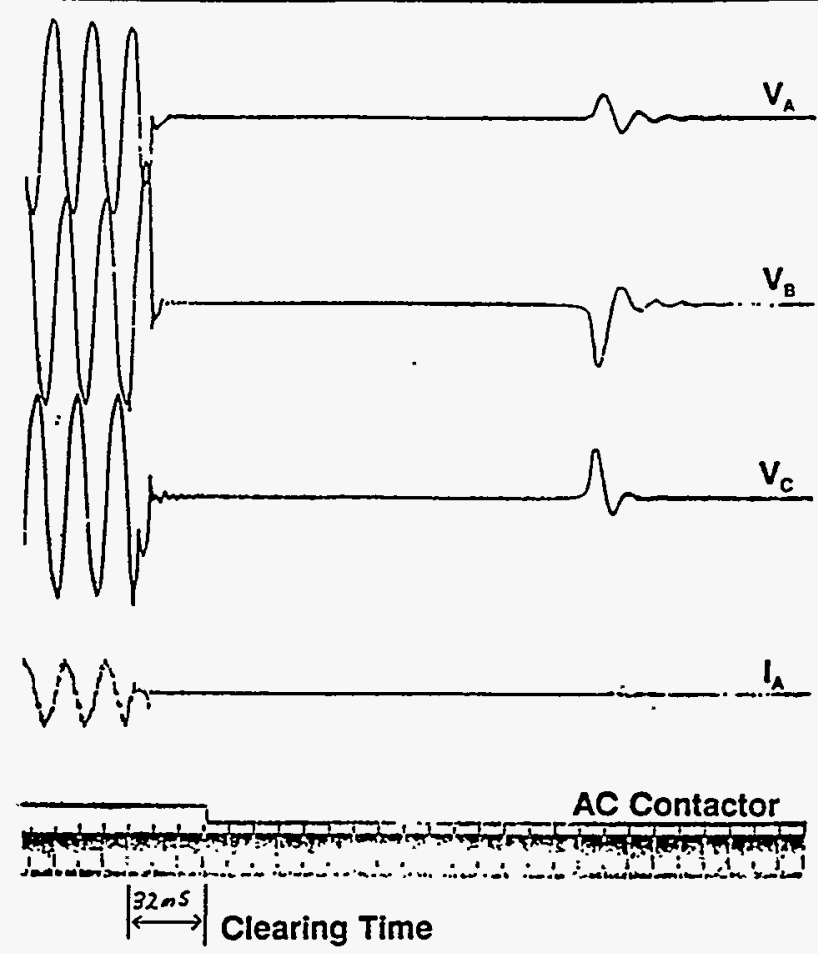

Figure 5-6. Run-on test for the SSIDickerson inverter.

\section{OPERATION AND MAINTENANCE}

Since the testing began on the first inverter, there have been approximately 140 trips. These are listed in Appendix C. The frequency of these events is illustrated and compared with that of the other PVUSA PCUs in Figure 3-7 and in Table 3-4. There has been difficulty in getting both inverters to operate reliably, and at present the contract with SSI has ended without having both Dickerson inverters functioning. Further details on selected failures and symptoms are discussed below.

The PCU experienced a number of difficulties during its initial operation. While working to repair one of these problems in August 1991, an SSI representative received an electrical shock, bumped the prop holding open the horizontally hinged inverter door, and was hit by the door. The configuration of the doors was subsequently modified. Problems continued with various PCU trips; electrical noise; commutation failures; cleared fuses; and failed SCRs, MOVs, opto-isolators, integrated circuits, power supplies, and wiring. There was disagreement between SSI and Dickerson as to whether the external ground fault detector (supplied by SSI) caused improper ground fault trips, but the software was modified and the ground fault trips ceased for the time being. The several damaged and failed components were replaced. By November 18 , Inverter A was operating acceptably and Inverter B was operating with three 
of its four bridges. Over the Thanksgiving weekend, there was a fire in Inverter B, which severely damaged the unit. Inverter $\mathrm{A}$ was taken off line as a precaution.

At the suggestion of PVUSA, SSI engaged an outside consultant to review the Dickerson design. It was decided to make several modifications, including repackaging of the units (see Figure 5-5, initial configuration, and Figures 5-2 and 5-4, present configuration). Modifications included:

- A crowbar circuit was removed. This circuit was designed to minimize fuse operation, but in practice the fuses operated when the marginal-quality crowbar components failed. The control circuits were otherwise unaltered.

- An error was corrected in the shutdown sequence software. This error had caused fuses to clear.

- Erratic SCR firing was corrected when mislabeled current-limiting resistors were replaced with resistors having the proper value.

- Changes were made to accommodate array voltage unbalance (due to irregular cloud cover).

- Capacitors were added to the filters to reduce transients on ungrounded circuits.

- Ac unbalance was traced to aluminum/copper interface problems in the SSI-supplied switchgear. These were corrected, and the PCU was changed to reset rather than lockout for ac unbalances.

- The cause(s) of intermittently recurring de ground faults was (were) not found, but it was planned to raise the trip level from 1 to $5 \mathrm{~A}$ and evaluate the effect.

- Wiring of the MOVs to protect the SCRs was changed from phase-to-ground to phase-tophase, and shields were added to protect other components from failed MOVs.

The rebuilt Inverter B passed a factory witness test on April 12,1992, and there was an acceptance test at Davis on May 14. Onsite troubleshooting and repairs continued, but consistently reliable performance was not achieved. The rebuilt Inverter A was back at PVUSA Davis by January 1993 and passed testing, which allowed it to be paralleled with the utility. The intermittent ground fault trips continued. However, a wet megger test of the SSI array field identified 60 failures involving modules, bypass diodes, and wiring which may have contributed to the problem. Array field repairs were made and the ground fault circuit's software was modified, but trips continued. The ground fault current sensors were replaced in April 1993, and the PCU failed to restart. In September, the PCU was operated with the ground fault circuit disconnected, which eliminated PCU ground fault trips. There were numerous other trips and 
instances of damage to the inverters (fuses cleared and damaged MOVs, opto-isolators, and integrated circuits). Aside from requiring several manual resets, Inverter A operated successfully in August and September; Inverter B still had problems.

In November 1993, PVUSA met with SSI to develop an acceptance test for the PCU and SSI PV system. The system, including both inverters, was to operate for 28 consecutive days. The PCUs were repaired again and successfully completed a 28-day demonstration run on January 17, 1994.

Taking of data to determine the PV system's rated power was postponed to April and the expected arrival of more suitable weather conditions. In the interim, there were frequent PCU trips and several failures. These included cleared fuses and failed PCU components, such as power supplies, ribbon cables, and connectors. Attempts to repair the units continued. In May, SSI decided not to continue with further repair of the PCU and requested that its US-1 contract be closed out. The PVUSA Steering Committee agreed. Acceptance of the PV system on an as-is basis was negotiated. Inverter B was used for a 30-day test to determine a rating of $67 \mathrm{~kW}$ ac for half of the SSI US-1 PV system. This is less than the expected $87 \mathrm{~kW}$ ac (half of the bid $174 \mathrm{~kW} \mathrm{ac}$ ). However, the shortfall was attributed mainly to the dc array field rather than to the PCU. At present, Inverter B is operating, but there are frequent failures to start in the morning. Inverter $\mathrm{A}$ is not operating.

\section{PCU CHARACTERISTICS}

\section{Efficiency}

Figure 5-7 shows the efficiency of Inverter B as a function of power. The rated power is $100 \mathrm{~kW}$ ac (i.e., half that of the total PCU). The ac output is measured at the $12.47-\mathrm{kV}$ side of the main transformer. The data points are for 5 complete, sunny days (October 10-14, 1994). The average dc-to-ac efficiency above 40 percent of rated power is 93.6 percent. It could be argued that the PCU efficiency is slightly higher since Inverter B bears the full transformer magnetization losses for this data set.

\section{Current Unbalance}

Figure 5-8 shows the ac output currents of Inverter B as a function of power level. The phase currents exhibit an unbalance with respect to their average. Averaged over the 5-day data set, Phase $A$ is +1.8 percent, Phase $B$ is -3.5 percent, and Phase $C$ is +1.6 percent for power levels greater than 40 percent of rated power. The average unbalance in this region is 2.3 percent. 


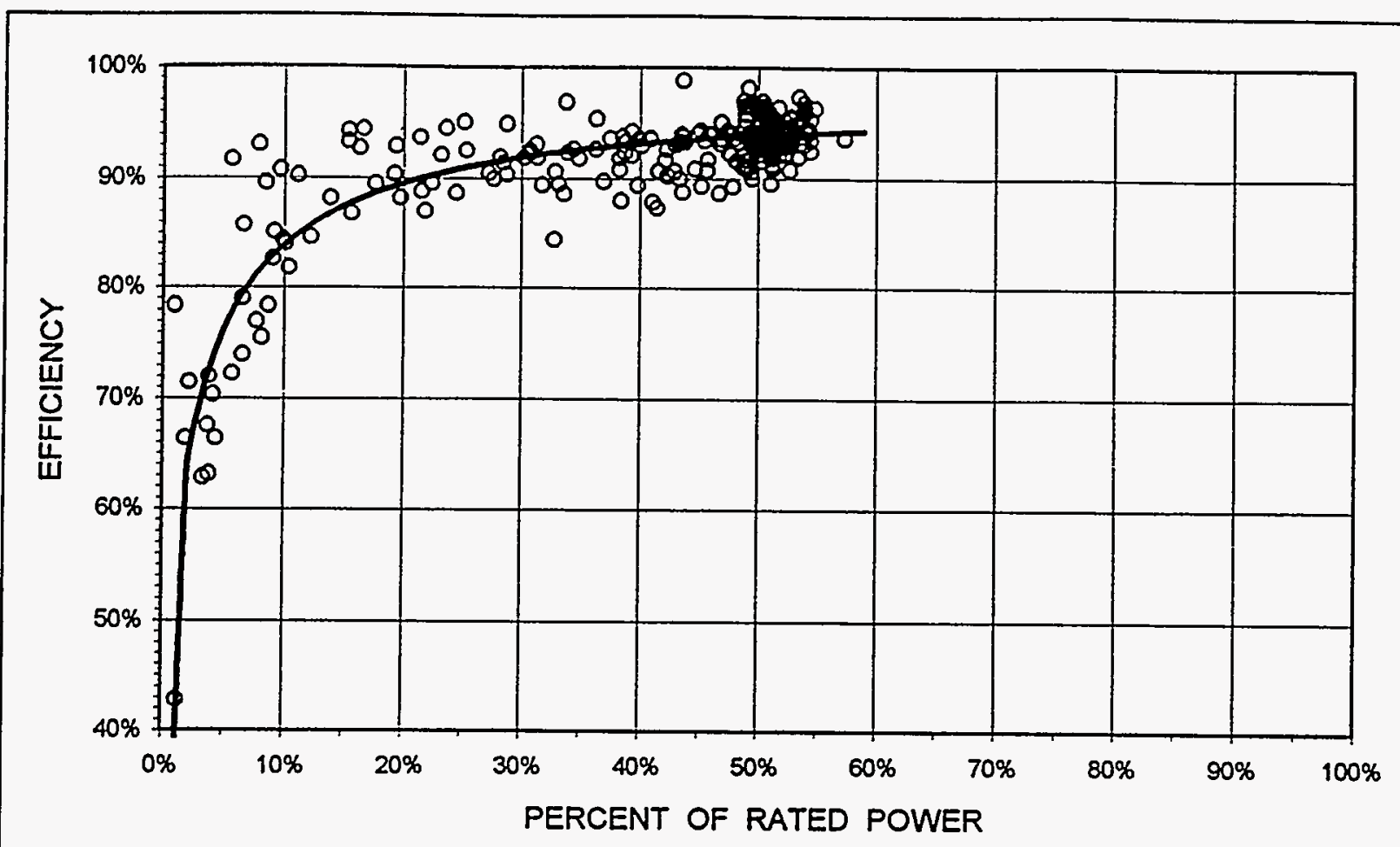

Figure 5-7. Efficiency as a function of power.

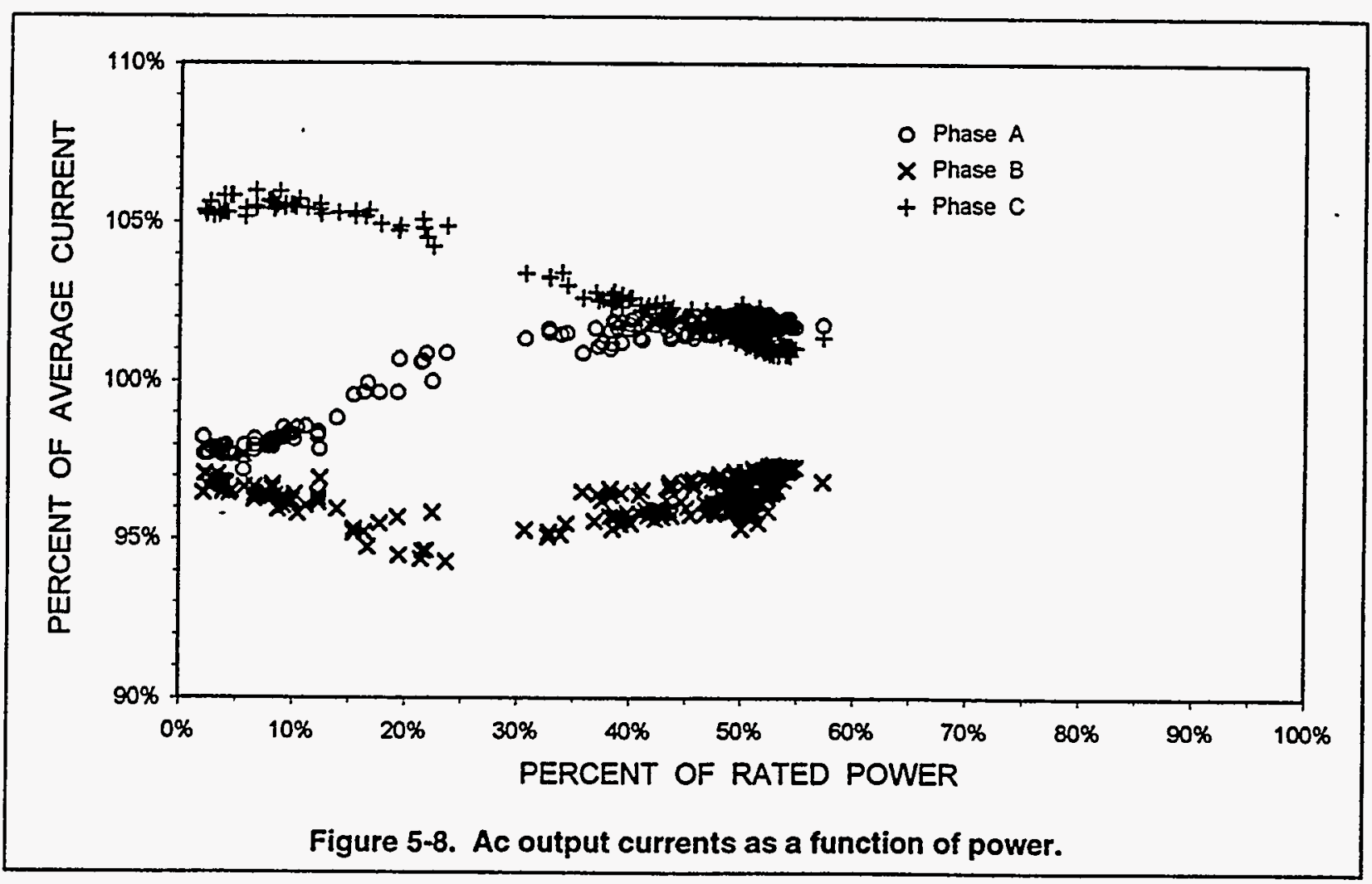




\section{Power Factor}

Figure 5-9 shows the power factor and reactive power as functions of output power level for the 5-day data set. As power levels decrease, the power factor becomes quite low.

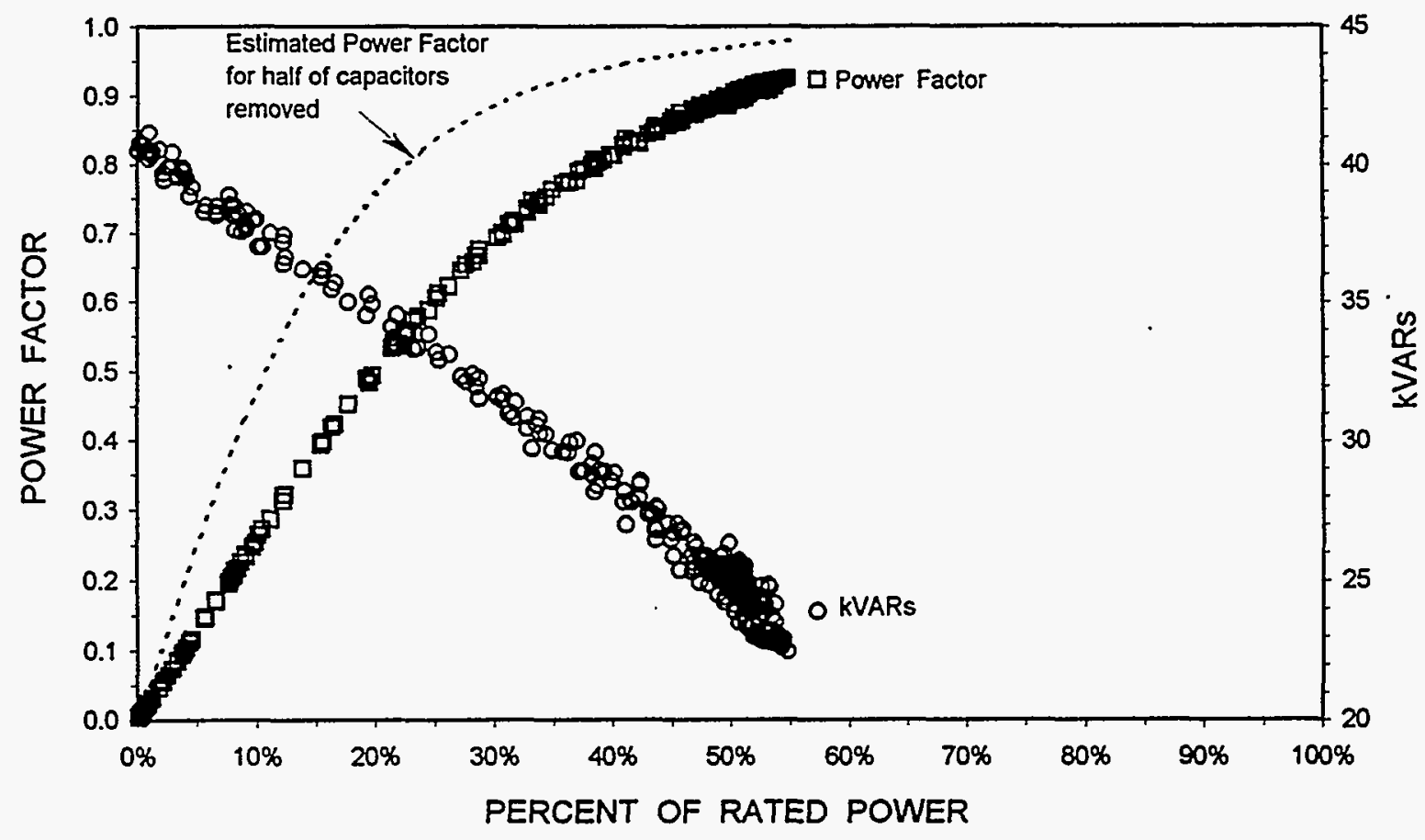

Figure 5-9. Power factor and reactive power as a function of power.

The PCU configuration at that time was such that all of the capacitors were in place (see lower diagram of Figure 5-1), but only Inverter B was operating. The power factor might be improved if half of the capacitors were removed. Even more capacitors might be removed to improve the power factor, since the power of the connected PV system is less than expected, and the PCU seldom operates above 65 to 70 percent of its rated power. The dc voltage level, firing angle, transformer reactance, and other factors would also have to be considered. The effect on harmonics is not known.

\section{Harmonics}

As discussed in Section 4, harmonic distortion measurements were made in November 1994 and involved testing Inverter B in conjunction with the IPC and APS PCUs. The details are presented in a separate report [5-2]. It is not clear that the PCU was functioning correctly at the time of the tests, and the harmonic data for the Dickerson PCU are inconclusive. 


\section{SUMMARY}

SSI and Dickerson are to be commended for trying to improve the state of the art of PCU technology. Unfortunately, their efforts do not appear to have succeeded as well as might have been hoped, at least at the present time.

The PCU appears to have been at a more developmental stage than originally thought and required more than a simple scaleup and improvement of a previous unit tested at Sandia. The PCU was beset with problems. Some of these may have been related to inadequate components, errors, and design flaws that could not have been recognized until the units were operated at full power in the field. Despite efforts to remedy the problems, the inverters continued to be subject to faults. However at present, Inverter B is continuing to function satisfactorily, except for morning start failures.

Few SCR failures occurred. Most of the failures were with other components, such as power supplies, capacitors, surge arresters, crowbar circuits, and transducers. The fact that one unit continued to operate fairly successfully after the other unit had been shut down indicates that there might have been some cross talk between the units, which either stressed components or caused firing errors on the bridges. The power factor correction capacitors were undersized since utility line harmonics had not been adequately accounted for.

The state controller approach operated well for controlling the unit. One of the advantages of the control design was greater diagnostics through the state table to understand what condition led to the present state. While the state codes displayed under trip conditions were quite detailed, they were unfortunately found to be confusing and subject to misinterpretation.

Mr. Dickerson claims the Sandia unit demonstrated 99 percent conversion efficiency, but this figure did not include transformer losses and probably did not include auxiliary power losses, if the unit was configured similar to the Davis unit. PVUSA calculated only total PCU efficiency. The 93.6 percent measured is all-inclusive, but at only 50 percent load. Full-load efficiency could be higher. Hence, it is unclear whether the targeted high efficiency was obtained.

The efficiency of the Dickerson PCU near rated power (93.9 percent) is neither the highest nor the lowest among the PCUs installed at PVUSA. However, the decrease in efficiency at low power levels is more pronounced than for any of the other PCUs, except the DECC EMT units. Similarly, the decrease in 
power factor at power levels away from its optimum point is more rapid than for the IGBT-based unit, even when an allowance is made for only one inverter operating. The current unbalance ( 2.3 percent) is higher than that of the other US unit, but close to that of the Omnion US-1 unit.

Overall, if the unit is regarded as a proof-of-concept or prototype, the design and testing may be considered a moderate success. Clearly, however, the units provided for the Davis SSI US-1 system require additional development and testing before they become a commercial product.

\section{REFERENCES}

5-1 PVUSA US-1 Operation and Maintenance Manual, Volume 2, Siemens Solar Industries, 19271-SCD100-96(2)-3.

5-2 T. Geiger, Harmonic Analysis Tests at PVUSA, PG\&E Technical and Ecological Services, Report \# 005-94.16, issued January 6, 1995. 


\section{US-1, APS}

This section presents data on the Advanced Photovoltaic Systems (APS) US-1 PCU installed at Davis, California.

\section{PCU DESCRIPTION}

APS (successor to Chronar) of Fairfield, California, fabricated the PCU for its US-1 PV system. The APS bid was for a $400-\mathrm{kW}$ ac (PTC) PV system. The initial rating of this PV system was $479 \mathrm{~kW}$ ac, well over the power bid. The output has since degraded. The PCU includes four collocated 125-kVA inverter modules whose outputs are combined in a single 530-kVA transformer. The rating of this linecommutated PCU is $500 \mathrm{kVA}$. Table 6-1 summarizes the manufacturer's ratings for several PCU parameters. The simplified single-line diagram in Figure 6-1 provides an overview of the PCU electrical configuration [6-1].

Table 6-1

Summary of Manufacturer's Ratings for APS PCU

\begin{tabular}{|c|c|c|c|}
\hline Voltage & $12.47 \mathrm{kV} \mathrm{ac} \pm 5 \%$ & Power Factor & 0.97 lagging @ $400 \mathrm{~kW}$ \\
\hline Frequency Range & $60 \pm 2 \mathrm{~Hz}$ & & $@ 300 \mathrm{~kW}$ \\
\hline Current THD & $<5 \%$ & & 0.87 leading @ $200 \mathrm{~kW}$ \\
\hline Single Frequency & $<3 \%$ & & 0.40 leading @ $100 \mathrm{~kW}$ \\
\hline Voltage Unbalance & $2 \%$ & & 170 kVAR (cap.) with PCU off \\
\hline Tare Losses & $6 \mathrm{~kW}$ & Efficiency & $97 \% @ 400 \mathrm{~kW}$ \\
\hline & & \multicolumn{2}{|c|}{$\begin{array}{l}95-97 \% @ 300 \mathrm{~kW} \\
72-95 \% @ 100-300 \mathrm{~kW}\end{array}$} \\
\hline
\end{tabular}

Amorphous silicon modules mounted on five rows of south-facing, fixed-tilt arrays supply the dc input to the PCU. The rows are split by a north-south central roadway. Wiring from the arrays proceeds via underground conduit to a dc interconnection box mounted on the PCU enclosure. The wiring is connected to form four separate dc input circuits, each of which is made up of 240 parallel PV source circuits, nominally $350 \mathrm{Vdc}$ pole to pole. A diode and parallel $10-\mathrm{k} \Omega$ resistor are connected from each 


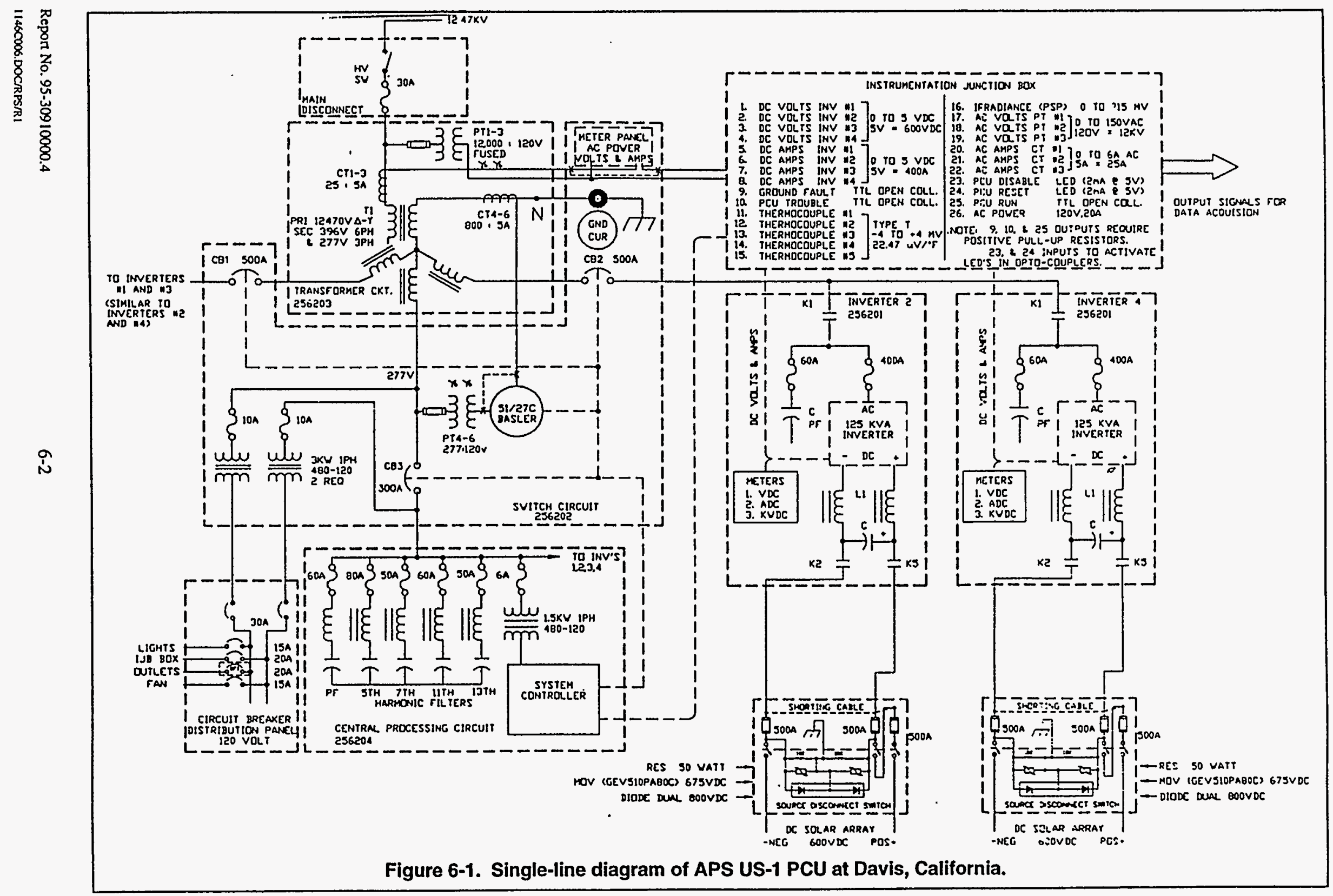


pole to ground to form a virtual de ground. Each input circuit pole also has a fuse, a disconnect switch, and MOV surge protection. Each of the four input circuits supplies the input to one of the four identical inverter modules. The inverter dc input is fed through a bipolar dc contactor to a filter consisting of an inductor in each pole and a shunt capacitor (fused). De voltage, current, and watt transducers and a current shunt provide signals to the display circuit boards and meters. A current transducer provides signals to the control circuit board.

The inverters use SCR switching elements in a 3-phase, 6-pulse bridge configuration. The four inverter bridges are phase-controlled, and their outputs are combined into two pairs to give a 12-pulse output. Each bridge includes snubber, gate driver, switch shutdown, PCU shutdown, emergency shutdown, control, fuse monitor, and diagnostic circuits. These circuits interface with a central processing module (CPM), which controls the PCU.

Bridge outputs are at $396 \mathrm{Vac}$, 3-phase, with a fuse in each phase. Fused power factor correction capacitors are connected (delta) across each bridge output. The output then proceeds through a three-pole ac contactor. The output of Inverter 1 is paralleled with the output of Inverter 3 and sent through a circuit breaker in the ac switch module to the output transformer. Inverter 2 and 4 outputs are combined in the same manner (but separate from Inverters 1 and 3).

The low-voltage (inverter) side of the 530-kVA output transformer has a forked wye configuration. Two sets of windings connect to the inverters. A third set of windings, $480 \mathrm{Vac}$, is connected to harmonic filters and an LC power factor correction circuit through a circuit breaker in the ac switch module. There are four filters, which are designed to trap the 5 th, 7 th, 11 th, and 13 th harmonics. Several single-phase transformers are connected to this circuit to supply 120 -Vac power to components in the PCU. PTs on this circuit and CTs on the transformer are connected to Basler protective relaying, which includes a UPS in its 120 -Vac power supply. The $12.47-\mathrm{kV}$ side of the output transformer (delta) is connected to the $12.47-\mathrm{kV}$ utility line through fuses and a disconnect switch. PTs and CTs supply panel meters on the ac switch module front panel and in the PVUSA remote data system. Figure 6-1 shows the signals supplied to the data system; Figure 6-2 shows the displays on the several modules in the PCU enclosure. 


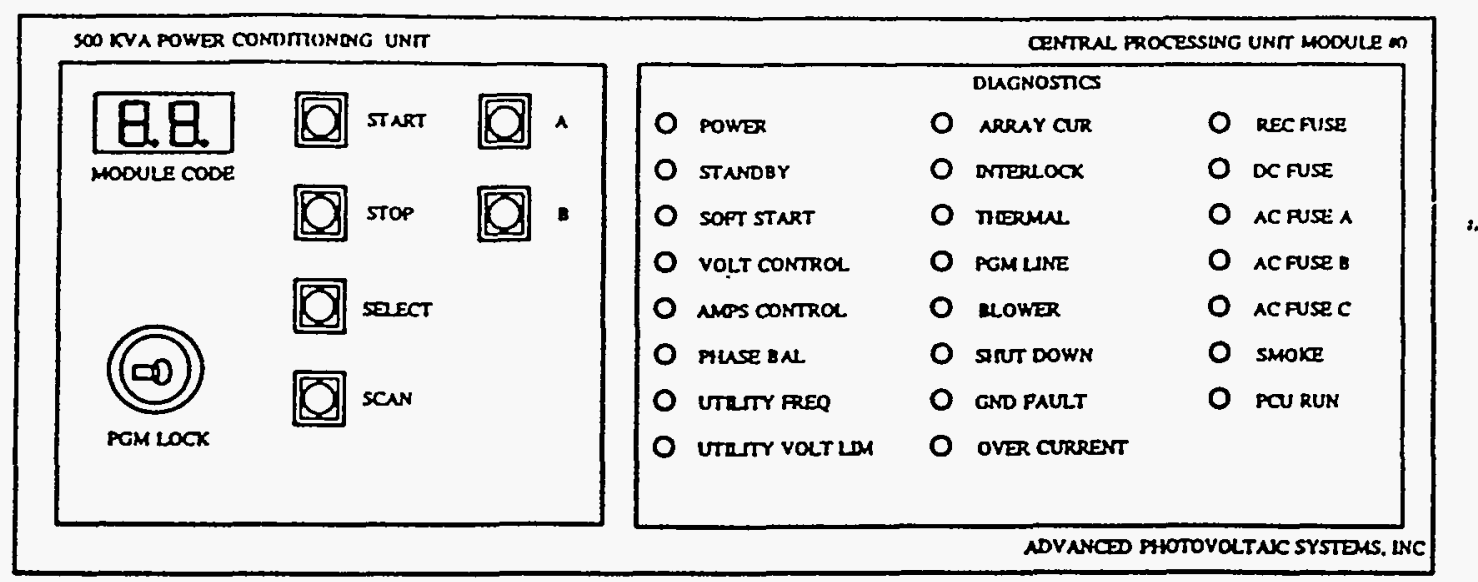

\section{CPM FRONT PANEL}

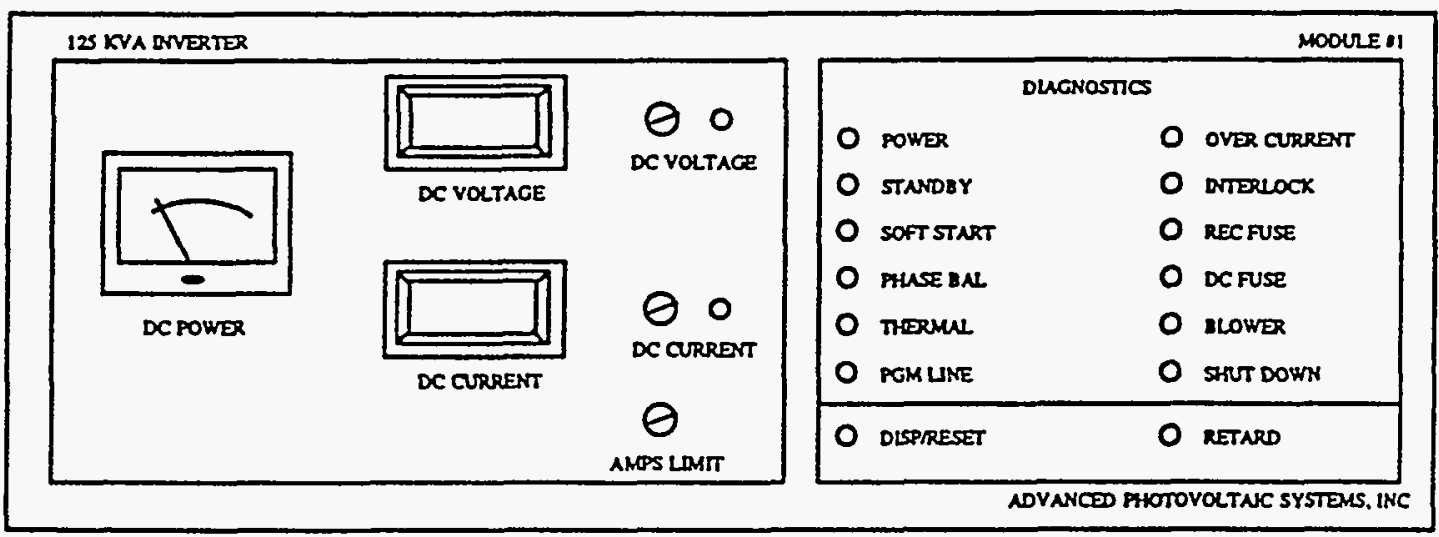

INVERTER MODULE FRONT PANEL

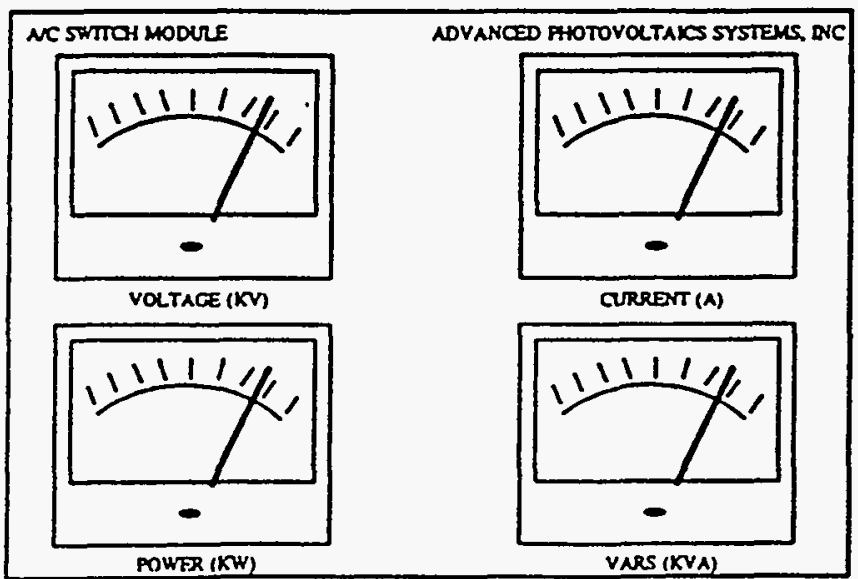

A/C SWITCH MODULE FRONT PANEL

Figure 6-2. APS PCU panel displays. 
The PCU has three operating modes: scan, select, and shutdown. In the scan mode, the CPM controls the PCU. This is the normal operating mode and is initiated at startup. The CPM includes a Micromint BCC52X single-board Basic computer with EPROM memory. The CPM microcomputer monitors diagnostic signals from the four inverter modules, other modules, and remote inputs. The CPM obtains status signals or delivers control signals to each inverter module sequentially through the scan cycle. A complete scan takes about 6 seconds.

The select mode allows local control of individual inverters or the entire system from the CPM front panel and is intended for use as a maintenance tool, rather than an operating mode.

Depending on the type of fault, the shutdown mode may be either partial or complete. Partial shutdown means that ac and dc contactors in the inverters are open, but ac breakers are closed and the control power remains on; complete shutdown means that ac breakers are open. The PCS is shut down for ac over/under voltage or frequency, low dc current, dc disconnect switches open, system shutdown button, or cooling failure or interlocks open in the CPM or ac switch modules. Individual inverter modules are shut down for ac phase unbalance, overtemperature, overcurrent, open fuse detected, cooling failure, interlocks open, or front panel shutdown button on. The emergency stop button on the ac switch module and smoke detector will put the PCU into the complete shutdown mode. The remote emergency stop signal first causes the PCU to shut down and then open the ac breakers. For array or ac line-related faults, the CPM automatically attempts to restart after the fault has been cleared. Other faults require a local or remote reset.

The inverters operate in one of three submodes: voltage control, current control, or standby. In the voltage control submode (normal operation), the inverters operate at a constant voltage, as set by controls on the inverter front panel (see the middle illustration in Figure 6-2). In the current control submode, the inverters operate at a constant current, also set on the inverter front panel, and the inverter module control circuitry causes the inverters to go from constant voltage to constant current (or back), when the voltage limit is exceeded. In the standby submode, the inverters operate at maximum voltage and minimum current. This submode is used in the event of inverter faults and as a diagnostic tool.

Most of the PCU is housed in a "sea van" container. The output transformer and ac disconnect cabinets are mounted on separate concrete pads adjacent to the container, as in the layout drawing of Figure 6-3. 


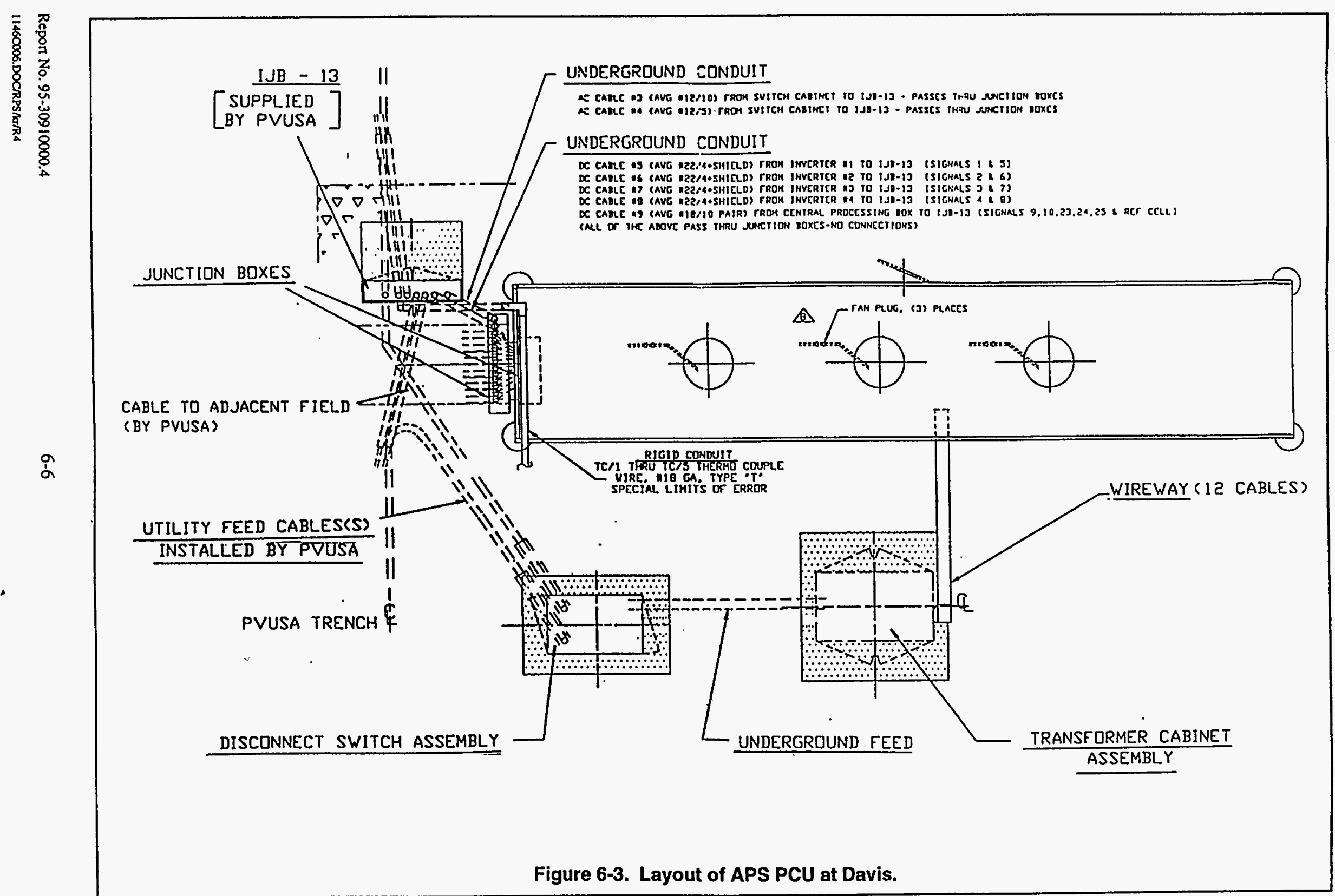


The drawing also shows the junction boxes for the dc cables from the array field and the interface junction box (IJB), which connects to the PVUSA data and control systems.

Figure 6-4 shows two photographs of the PCU. The upper photograph shows the exterior of the container, which is located under the APS array structure. In the lower photograph, the interior of the container and a portion of the cabinets can be seen.

The sea van container is 8 feet wide by 40 feet long by $8 \frac{1}{2}$ feet tall. The transformer cabinet is $3 \frac{1 / 2}{2}$ feet wide by 6 feet long by 6 feet tall. The ac disconnect switch cabinet is 3 feet wide by 5 feet long by 6 feet tall. Exclusive of the area between these items, the footprint of the PCU is $1.4 \mathrm{~kW} / \mathrm{ft}^{2}$. Figure $6-5$ shows the principal cabinets in the container. The cabinets are all 2 feet deep by 6 feet tall. The four inverter cabinets and CPM cabinet are each 5 feet wide; the ac switch cabinet is $2 \frac{1}{2}$ feet wide. Thus, these cabinets occupy about two thirds of the length of the trailer. These cabinets alone, along with the transformer and disconnect cabinets, have a footprint of $5.5 \mathrm{~kW} / \mathrm{ft}^{2}$.

Sensors in an air plenum above the inverter modules turn on fans when the temperature exceeds $110^{\circ} \mathrm{F}$. The fans and portions of the plenum above the cabinets can be seen in the lower photograph in Figure 6-4. When the fans are on, the outside air is drawn through filters, up through the bottom of the modules, into the air plenum and out through the roof. As mentioned earlier, fan operation and inverter temperature are used in the diagnostic/interlock circuit for shutdown. Three manually controlled 10-inch fans mounted in the roof of the sea van container supply additional cooling. A switch, mounted at the door of the container, allows the fans to be turned on manually when additional airflow is required.

\section{FACTORY AND STARTUP TESTS}

The program included testing at the manufacturer's facility prior to shipping, startup testing at PVUSA's Davis site, initial operation, and special tests.

\section{Factory Tests}

On November 11, 1991, PVUSA personnel visited the APS facility to verify compliance of the PCU with specifications. Fabrication was nearing completion and, in general, the equipment was found to be acceptable. Outstanding requirements for work in progress were noted. Representative items included:

- Adding several warning signs and labeling the components 

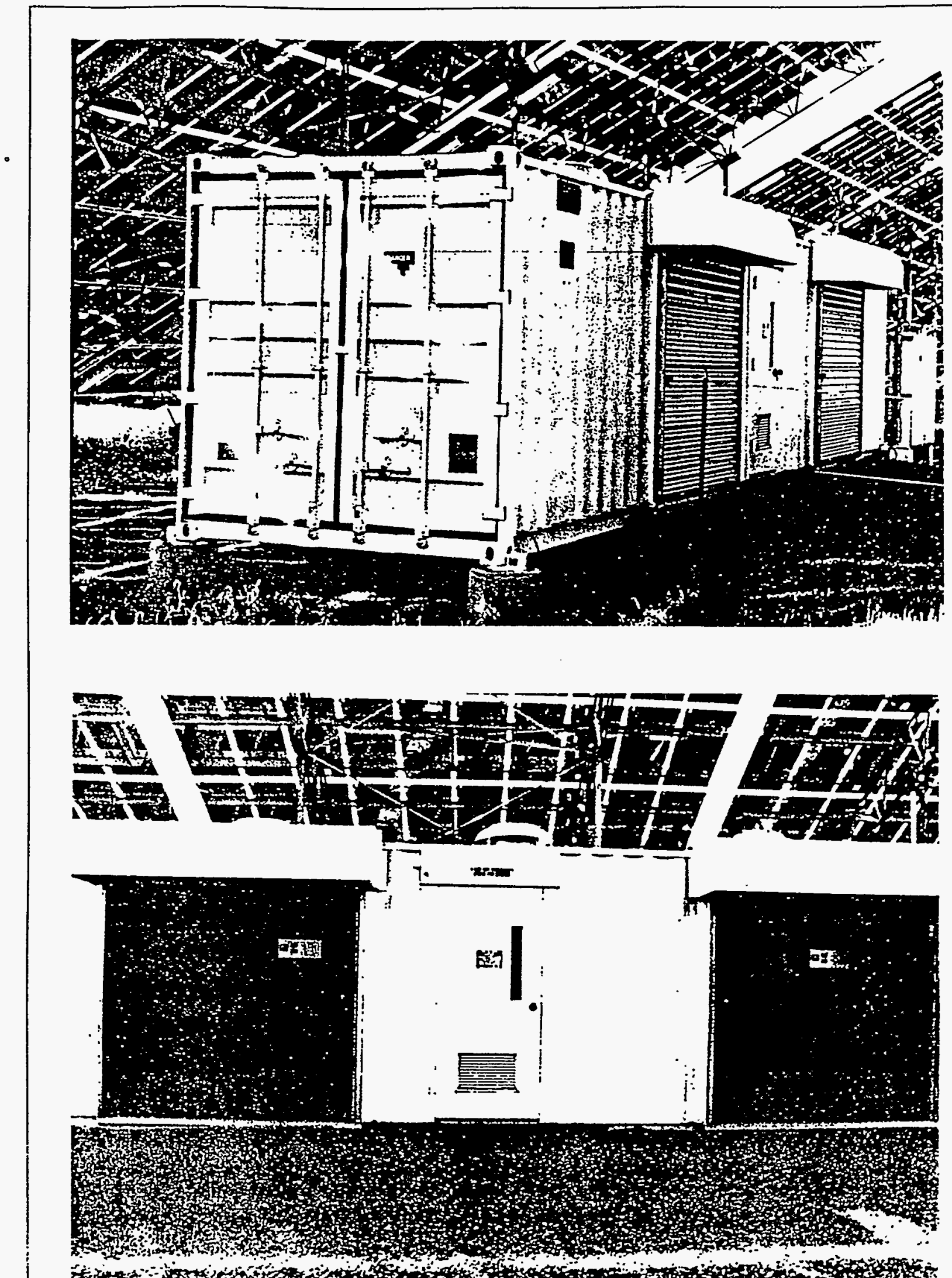

Figure 6-4. Photographs of the exterior and interior of the APS PCU container at Davis. 


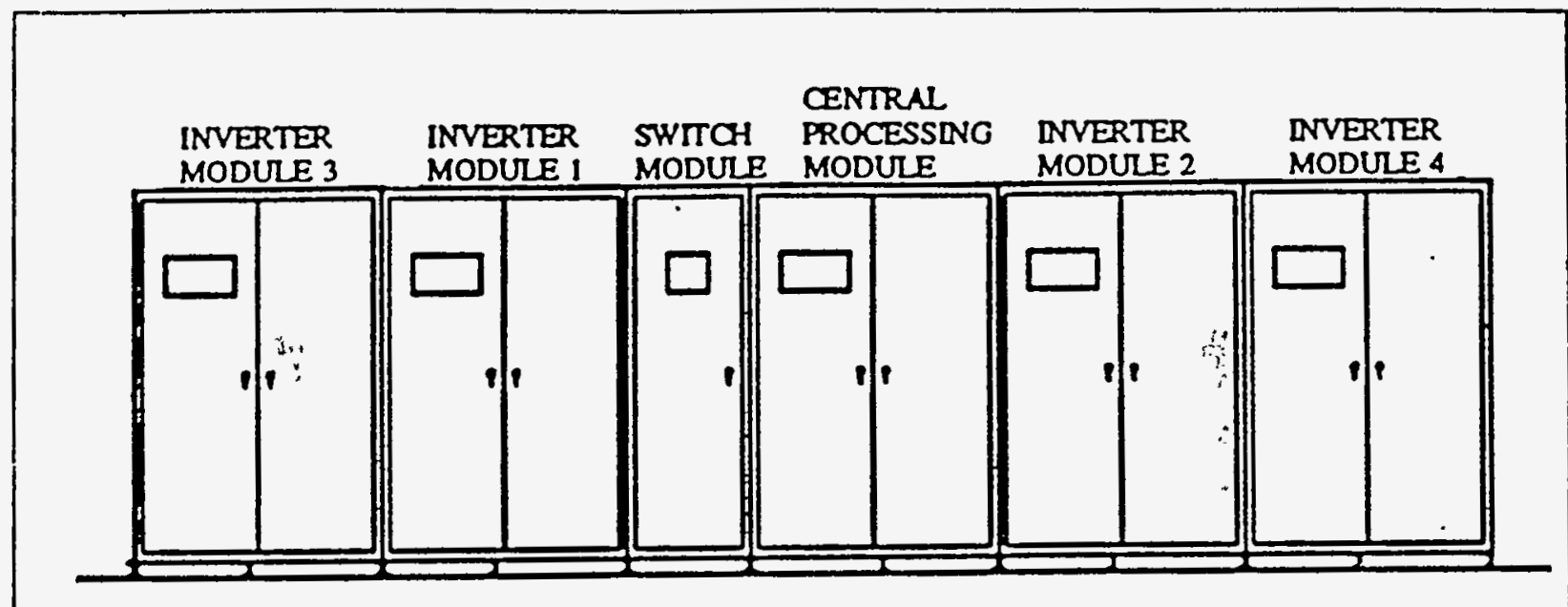

Figure 6-5. Lineup of APS PCU modules in container.

- Verifying fuse and disconnect dc ratings

- Adding a barrier to protect personnel near the 480 -Vac breaker handle

- Modifying PCU module doors to be removable for maintenance

Several PVUSA preferences were requested relating to labeling components, provision of a separate signal from the smoke detector, and moving the hinge on the container air filter/escape window from the bottom to the side.

APS prepared a Factory Test Plan for its PCU [6-2]. The format includes blank spaces to record data so that the document becomes a factory test report as the unit is tested. A summary of the tests is shown in Table 6-2.

The tests were performed on May 21-29, 1992. (Because an errant test lead bumed out an integrated circuit, the last two tests in Table 6-2 were performed on June 3.) A 12.47-kV utility line was not available at the APS factory. Tests were performed at $480 \mathrm{Vac}$, with current limited to $400 \mathrm{~A}$. The array was simulated by operating one of the units as a six-pulse rectifier. 
Table 6-2

\section{Summary of Factory Tests for APS US-1 PCU}

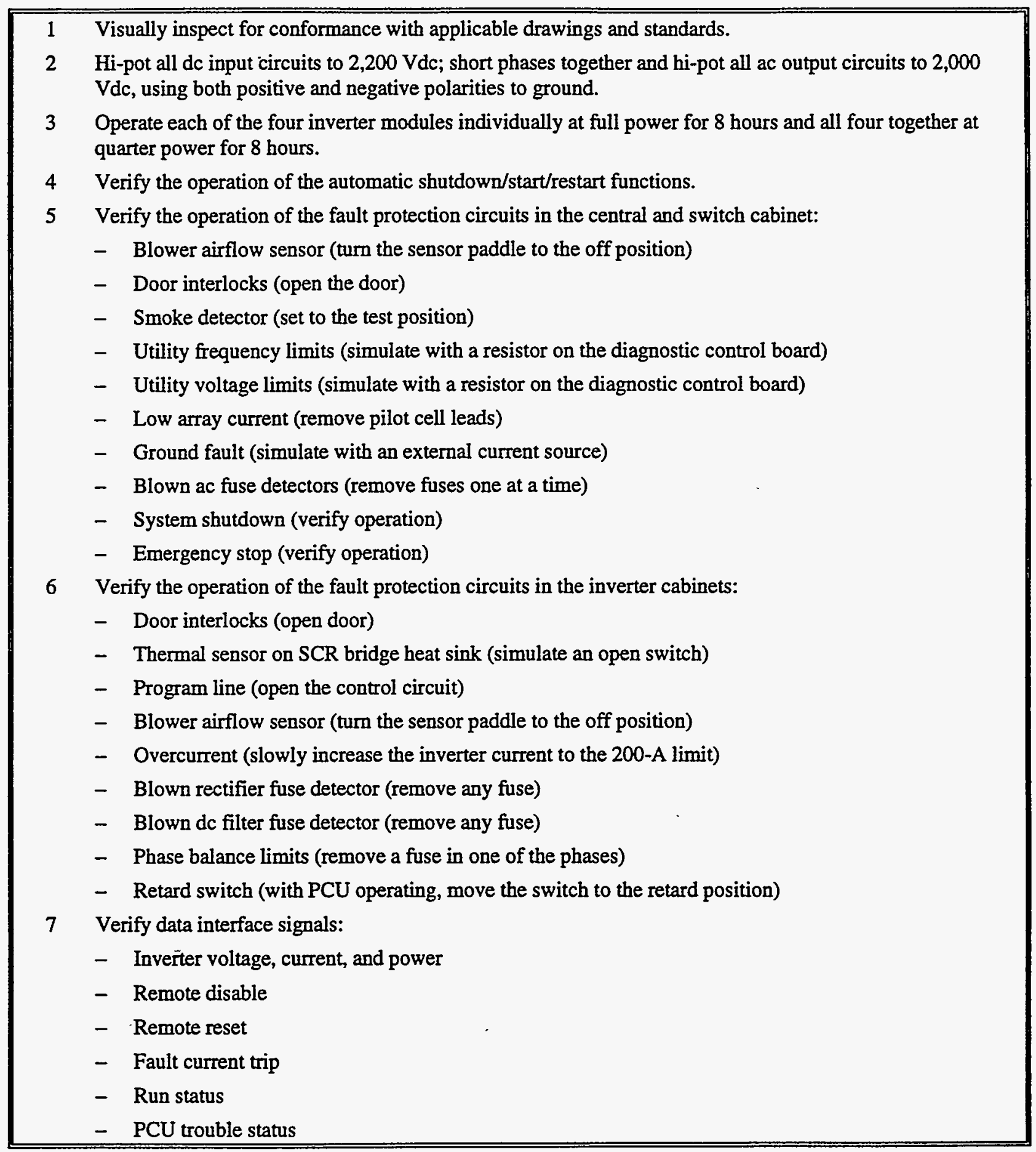


The PCU generally passed the factory acceptance tests. Exceptions and remedial actions included:

- Remedy the inability to start a single inverter module using the select start controls.

- Install ground lugs on the sea van container's exterior.

- Label SCR heat sinks as energized devices.

- Hi-pot dc cables between dc disconnect switches and dc contactors.

- Change the ac undervoltage trip from $-5 \%$ to $-10 \%$.

- Repair and test the low dc current trip and pilot cell.

- Repair and test the ground fault trip; verify the remote status signal.

- Upgrade the array grounding resistor to a higher wattage.

- Repair and test the run and trouble remote status signals.

- Modify the logic to the trip harmonic filter breaker on the detection of smoke.

\section{Startup Tests}

Startup tests were performed for the APS PCU on August 7-14, 1992. The preparalleling tests are as listed in Table 4-5; the startup tests are similar to those listed in Table 4-4. PCU performance in these tests was found to be acceptable.

A set of run-on tests were performed. With one and two inverters on line, shutdown was achieved in 0.03 to 0.05 second. With all four inverters operating (at $400 \mathrm{~kW} \mathrm{ac}$ ), shutdown was achieved in 0.10 to 0.12 second.

\section{OPERATION AND MAINTENANCE}

Prior to the start of the 30-day data collection period in September 1992, the PCU tripped several times because of a smoke alarm. Since there were no signs of fire or damage, it was postulated that the "smoke" was due to outgasing of new components being heated up. But this could not be verified and the symptoms disappeared. These trips were followed by several trips due to cleared fuses and other problems. APS personnel made minor onsite repairs. Data collection continued into October, accompanied by several trips and failures to wake up at sunrise. APS personnel replaced several components and resoldered a few connections at the end of October. 
The PCU continued to operate with only a few failures until April 20, 1993, when there was a utility line fault that took some time to clear. While other PCUs restarted, the APS unit suffered damage - 10 of 12 ac fuses cleared, several MOVs were burned, and circuit breakers and terminal boards were damaged. Repairs were completed on May 28. Upon restart there was a ground fault through two failed MOVs and arcing which damaged two of the four dc disconnect switches. APS replaced the two pole-to-ground diodes with a single pole-to-pole diode, but the dc system retained its virtual ground via two pole-toground $10-\mathrm{k} \Omega$ resistors. PCU repairs were successfully completed on June 29 . However, there were cleared fuses after utility line outages in August, September, and October. In December, while repairing several ribbon cable connectors, APS noticed another failed dc contactor. This problem was traced to underrated coils. Replacement of all of the dc contactor coils was completed in April 1994. Failures after line transients seemed to be less frequent in late 1993 and early 1994. However, site monitoring equipment also indicated fewer and less severe transients on the $12-\mathrm{kV}$ line during this period. Failures and clearing of fuses after utility line transients have persisted, and the line-commutated APS PCU seems to be more sensitive to line transients than other PCUs.

The APS inverters operate at a fixed, manually adjustable dc voltage. Owing to aging of the amorphous silicon array field and/or other causes, the desired maximum power point dc operating voltage has decreased to a point below the adjustment range. Additionally, the bottoms of the adjustment ranges of the four inverters differ slightly from one another so that they operate slightly unbalanced.

Other problems and corrective actions included revising the control software to prevent a recurrence of PCU shutdown instead of going to standby at sunset. A faulty meter was replaced.

\section{PCU CHARACTERISTICS}

\section{Efficiency}

Figure 6-6 shows the efficiency of the PCU as a function of power. The rated power is that of the PCU, $500 \mathrm{~kW}$ ac. The ac output is that measured at the $12.47-\mathrm{kV}$ side of the isolation transformer. The data are for October 10-14, 1994. The average dc-to-ac efficiency above 20 percent of rated power is 95.8 percent ( 96.1 above 40 percent power). 


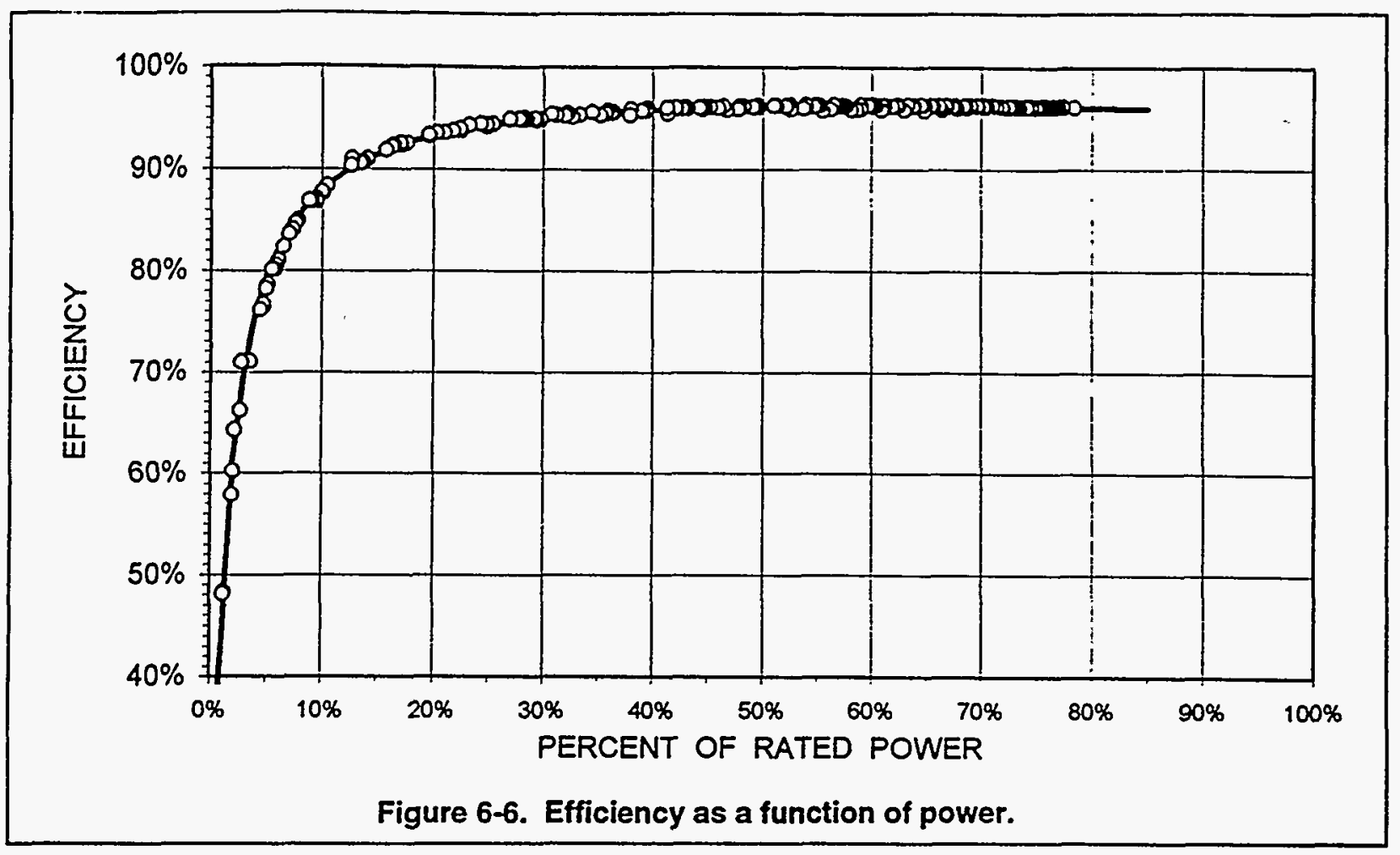

\section{Current Unbalance}

Figure 6-7 shows the ac output currents of the PCU as a function of power. The currents exhibited a small unbalance with respect to their average. Averaged over the 5-day data set, Phase A was -0.5 percent, Phase $B$ was +0.2 percent, and Phase $C$ was +0.3 percent.

\section{Power Factor}

Figure 6-8 shows the power factor and reactive power as a function of output power level for October 10-14, 1994. The characteristics of a line-commutated inverter, unswitched capacitors, and harmonic filters result in a very low power factor at low power levels. The power factor reaches unity at approximately 50 percent of rated PCU power and becomes lagging at higher power outputs. The data indicate that the specifications are not met (power factor greater than 0.95 lagging above 20 percent power) beyond 70 percent power. Assuming a PCU sized appropriately for the array, unity power factor should occur between 70 and 80 percent power, or switched capacitors are needed (if the power factor is important). 

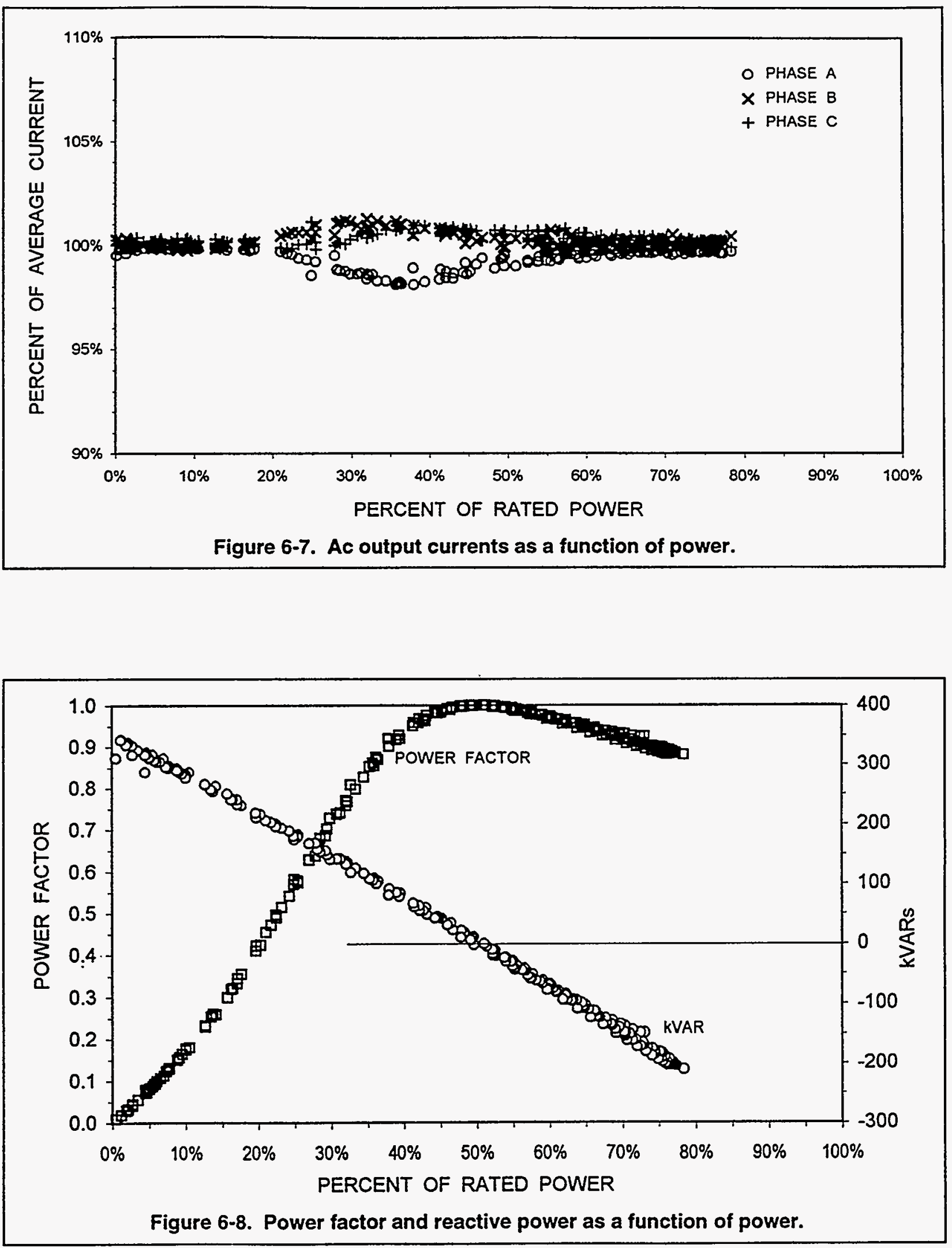


\section{Harmonic Distortion}

Harmonic distortion of the APS PCU output was measured several times. Figure 6-9 shows voltage and current THDs as functions of power for measurements made on September 30 and October 22, 1992. Except for the point at 20 percent power, which may in error, the voltage THD is below 1.6 percent. Current THDs ranged from 3.6 percent near full power to 23 percent at half power (and 64 percent near zero power).

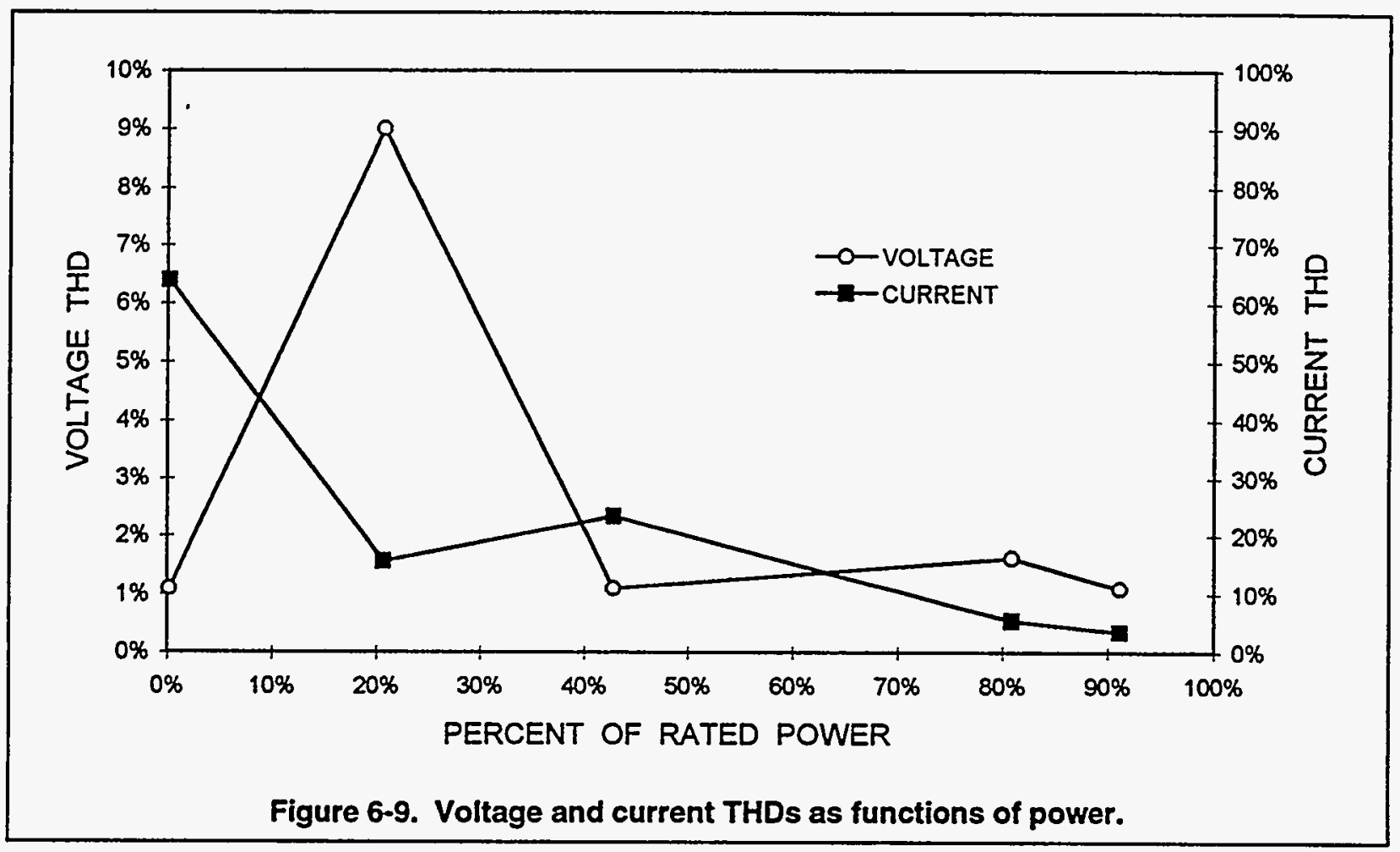

Further harmonic distortion measurements were made in November 1994. These measurements involved testing with several configurations and measurement points $(12.47 \mathrm{kV}$ and $480 \mathrm{~V})$ at the APS, IPC, and SSI PCUs. Details are presented in a separate report [6-3]. The percentage voltage and current harmonic distortions at the 12.47-kV side of the APS PCU for the configurations tested are summarized in Figure 6-10. As can be seen, for all of the configurations tested the voltage THDs range from about 0.8 to 1.2 


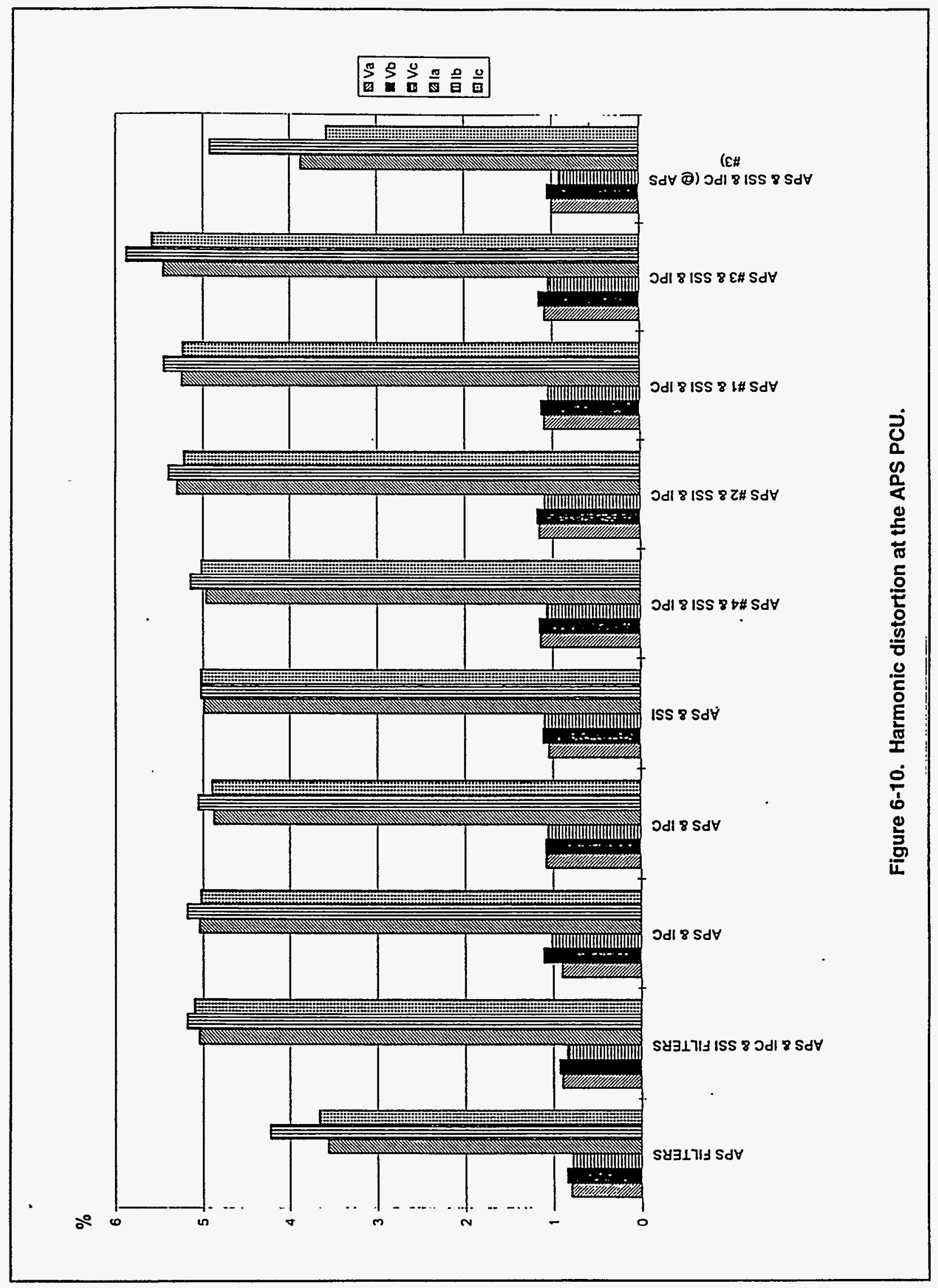

Report No. 95-30910000.4 
percent and the current THDs range from about $3 \frac{1}{2}$ to $5 \frac{1}{2}$ percent. The harmonic currents are expressed as a percentage of the current at the measurement power level (about 50 to 60 percent of rated).

\section{SUMMARY}

The APS PCU had several problems during its initial operation. More recently, the unit has performed well - there were only five unplanned trips in the 5 months between October 1994 and February 1995. However, the array's maximum power point voltage seems to have gone below the adjustable range of the PCU. The PCU was prone to clear fuses when utility line voltage transients occurred. At this point in time, it appears that APS has gone out of business and will not be manufacturing PCUs for sale to others.

From a design viewpoint, the PCU appears to be robust enough to endure field conditions. The central processor has worked well. Component selection has prevented any substantial component failures, and the cooling has been adequate to prevent overtemperature trips. Dust accumulation in the inverters has not been a problem so far. Testing indicates that harmonic levels are marginal, but that the power factor capacitance probably should have been increased to meet the desired minimum. Operating at a fixed setpoint is perhaps acceptable for amorphous silicon or other products with low fill factors since the power does not drop off quickly when moving away from the peak power point. However, the sharper the knee, the more critical it is to be able to track accurately, or else energy loss can be substantial.

The shipping container is large and could be a problem if space were a criterion (but still, the unit has the highest overall power density $\left(\mathrm{kW} / \mathrm{ft}^{2}\right)$ of any of the PCUs in the PVUSA project). The "indoor" design affords protection during maintenance, but working clearances are tight. Another disadvantage is the number of inductors and capacitors in the unit. Most capacitors do not have a 20-year life, especially when subjected to high levels of harmonics. Failures (usually ruptures) will occasionally occur, and the capacitors may need to be replaced after only 10 years.

At 96.1 percent (above 40 percent of rated power), the APS PCU has the highest efficiency of the units discussed in this report. Its harmonic levels are acceptable and the output currents are balanced. The power factor is poor at power levels away from 50 percent of rated power. 


\section{REFERENCES}

6-1 Operation and Maintenance Manual for APS PV-1 Solar System, Advanced Photovoltaic Systems, A1001001, Revision 5, March 1993.

6-2 Acceptance Test Procedure for the Advanced Photovoltaic Power Logic Engineering (APPLE) Division 500-256-1 500 kilowatt Photovoltaic Power Conditioner, Advanced Photovoltaic Systems, Revision 3.1a, September 22, 1992, 19271-SC-D101-76(1)-3.

6-3 T. Geiger, Harmonic Analysis Tests at PVUSA, PG\&E Technical and Ecological Services, Report \# 005-94.16, issued January 6, 1995. 


\section{Section 7 \\ US-2, SSU/OMNION, KERMAN}

This section presents data on the Omnion PCU installed at Kerman, California.

\section{PCU DESCRIPTION}

A 498-kW ac (PTC) Siemens Solar Industries, Inc. US-2 PV system is installed at Kerman. It uses two power conditioners supplied by Omnion Power Engineering Corporation [7-1]. Both are Omnion Series 3200 static power converters. The two $275-\mathrm{kW}$ units are connected in parallel on a $374-\mathrm{Vac}$ bus to an isolation transformer; the $12.47-\mathrm{kV}$ side of this $550-\mathrm{kVA}$ transformer is connected to the utility line.

Figure 7-1 shows a single-line diagram for the PCUs and Kerman site.

The dc input is supplied by 17 PV source circuits, with 9 connected to Unit 1 and 8 to Unit 2 . The source circuits are a nominal $\pm 360 \mathrm{~V}$, with plus, minus, and neutral buses. Several of the source circuits on each unit are connected through load-break contactors which permit shedding of circuits should the input exceed preset limits. There are three such circuits in Unit 1 and two in Unit 2. The neutral is connected to the system ground through a Hall effect sensor. This sensor feeds a circuit board that monitors ground fault currents, with a 0.1- to 0.2-A field-adjustable trip level. The plus and minus buses are connected to the units through non-load-break switches, which provide a positive visible means of disconnect to isolate the source circuits for maintenance. Load-break contactors (normally open) on both buses isolate the source circuits when the PCU is off. Auxiliary contacts furnish control information on switch and contactor positions. MOVs (2,200 joules, fused) provide surge protection on the dc input buses.

Several sets of resistive voltage dividers and isolation amplifiers measure the dc bus voltages for the panel meters, $\mathrm{kW}$ dc transducer, data acquisition system, overvoltage circuit (set at about $825 \mathrm{Vdc}$ ), and master control. A current shunt, Hall effect sensor, and associated circuit boards furnish similar data on dc current. 


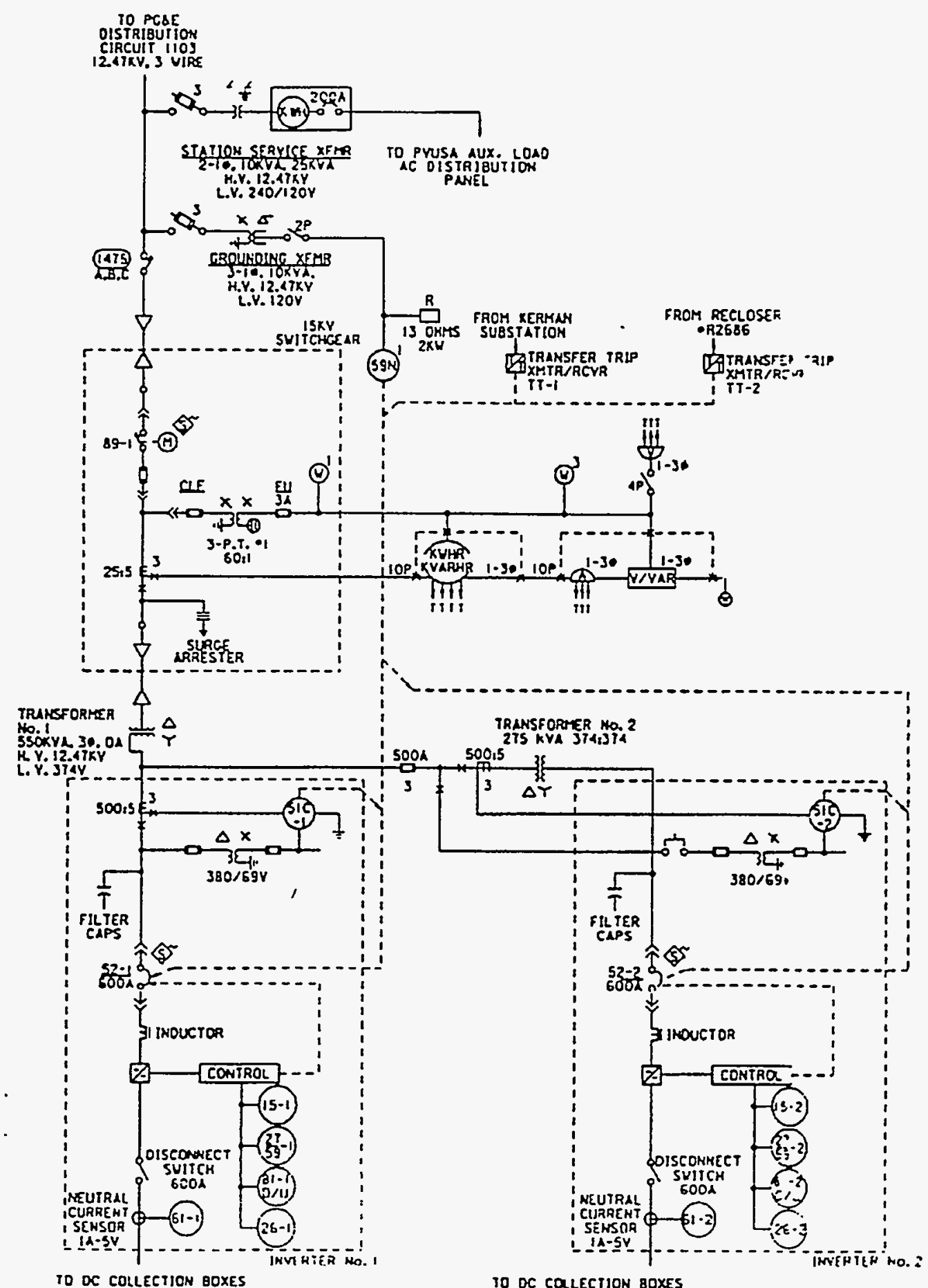

Figure 7-1. Single-line diagram of the US-2 PV system at Kerman, California. 
The dc current in each of the two units is shared by six IGBT bridges. Both the plus and minus dc input buses to each bridge are fuse-protected and have a shunt filter capacitor. Snubber circuits limit switching and ac line transients across the IGBTs. When the PCU is shut down, the capacitors are rapidly discharged through a contactor and resistor. When the PCU is started, other resistors limit in-rush current. The IGBTs are mounted on heat sinks which have bimetallic temperature switches to control cooling fans and to shut down the PCU in case of overtemperature.

The bridge modules include a gate driver circuit board for the IGBTs. The gate driver receives firing signals (about 6,000 $\mathrm{Hz}$ ) from a current regulator circuit board via fiber optic cables. A master control and current sensor feedback supply inputs to the current regulator. The master control, in turn, receives inputs from several sensors, settings, programmable logic controllers, and control algorithms. A utility interface circuit board supplies input on over/under frequency and over/under voltage, and uses a phaselocked loop to synchronize the PCU with the utility line. The master control also provides dc voltage regulation, array maximum power tracking, ac current limiting, and status and alarm signals to a liquid crystal display (LCD) panel display and to the DAS. Wakeup is achieved by sensing that the array voltage exceeds the setpoint; shutdown is achieved when the power goes below 2 percent of the rated power.

Each bridge ac output has series reactors in each phase. The bridges are connected in parallel, and their nominal 374-V output is connected to a circuit breaker. MOVs provide surge protection. From the circuit breaker, the ac is connected to the low side (wye) of a 550-kVA isolation transformer to step the output (delta) to $12.47 \mathrm{kV}$. A second $374 / 374-\mathrm{V}$ isolation transformer was added to Unit 2 to overcome difficulties with circulating currents encountered during startup. CTs and PTs supply control data and display data. Overcurrent relaying is included. MOVs provide surge protection.

Front panel displays include meters for plus and minus dc voltages, $d c$ current, and dc kilowatts. Nine pilot lights show PCU status and fault conditions, and an LCD furnishes further details via 36 distinct messages. Front panel controls include an operating mode switch (manual and automatic power tracking), and buttons for manual start, manual stop, fault reset, lamp test, and emergency off. The PCU also provides signals for remote monitoring. Individual contact closures indicate dc ground fault, PCU on, PCU fault, shutdown, standby/ready, standby/fault, ac breaker status, overtemperature, smoke detected, synchronization failure, and automatic power tracking mode enabled. Analog data are furnished on plus and minus dc voltages, dc current, 
ac currents, and enclosure temperature. Remote control inputs include open ac breaker, close ac breaker, reset, disable and restart.

Each unit is housed in a 108-inch wide by 44-inch deep by 72-inch high multidoor NEMA 3R enclosure $\left(8.3 \mathrm{~kW} / \mathrm{ft}^{2}\right)$. Internal component temperatures are maintained by several fans (exhaust and circulating) and an air conditioner in each enclosure. The PCU is designed to operate with an air ambient temperature range of $18^{\circ} \mathrm{F}$ to $111^{\circ} \mathrm{F}$. A dc disconnect switch enclosure is mounted on the side of each PCU enclosure. The $12.47-\mathrm{kV}$ transformer is adjacent to Unit 1. The PCU equipment is mounted on concrete pads, with an overall power density of $4.9 \mathrm{~kW} / \mathrm{ft}^{2}$ (3.8 kW/ft ${ }^{2}$, if the concrete apron in front of Unit 1 is included). Units 1 and 2 are 300 feet apart and are located on a roadway in the center of the array field.

The top photograph in Figure 7-2 shows the exterior of Unit 1. The photograph also shows the front panel instrumentation, the adjacent main transformer (right side), and the dc disconnect switch (left side). The lower photograph shows the interior of the unit.

\section{FACTORY AND STARTUP TESTS}

The program included testing at the manufacturer's facility prior to shipping, startup testing at the Kerman site, initial operation, and special tests.

\section{Factory Tests}

Omnion prepared and submitted a Factory Test Plan for its PCU [7-2]. The format includes blank spaces to record data so that the document becomes a factory test report for the unit tested. A summary of the test is shown in Table 7-1.

The availability of test equipment at the factory (e.g., a dc power supply to simulate the PV arrays) limited test power to $140 \mathrm{~kW}$. The Omnion PCU is made up of two $275-\mathrm{kW}$ units, which were tested separately. As indicated in the table, portions of the test were run with individual bridges or sets of bridges at their full rated power. 

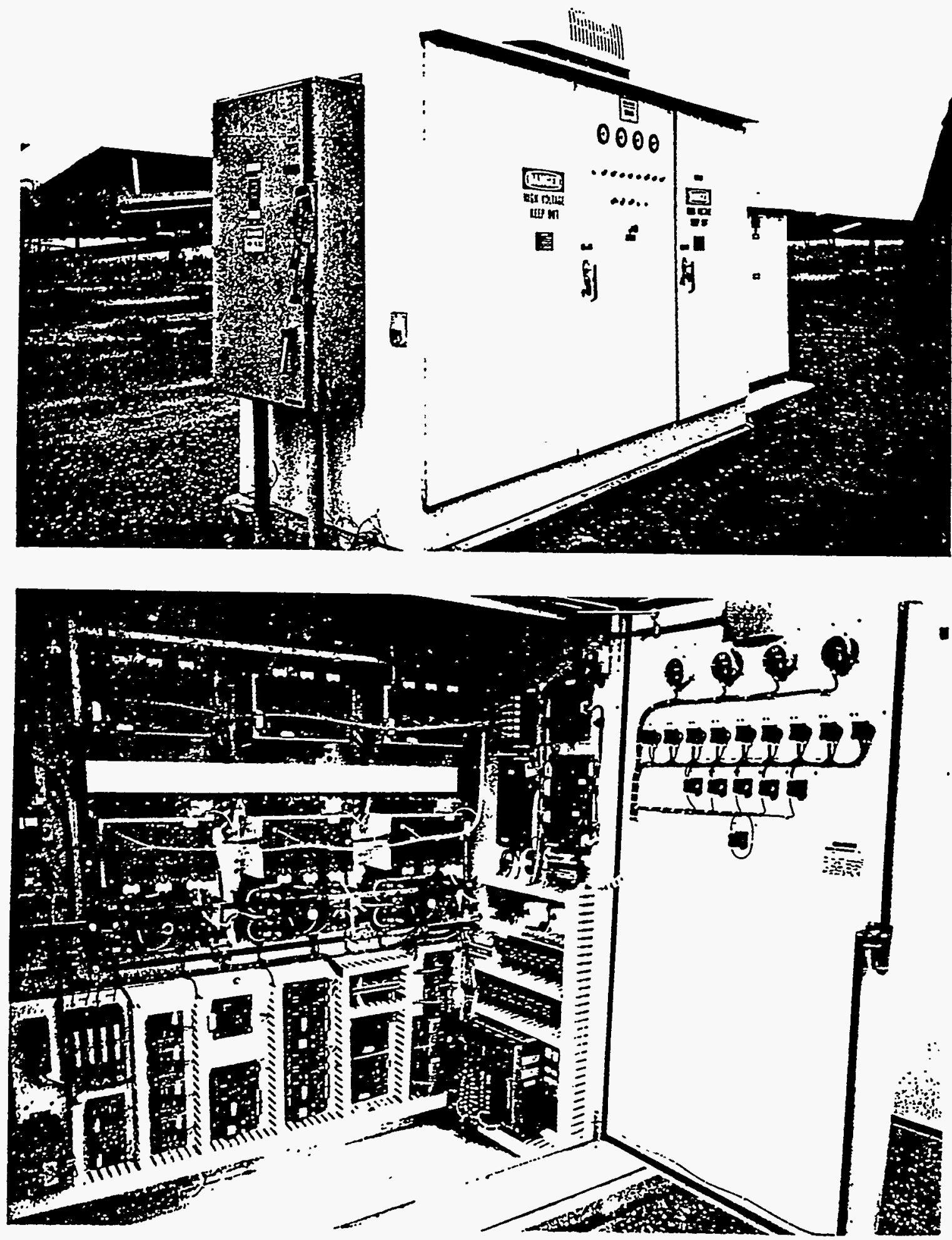

Figure 7-2. Photographs of the exterior and interior of Omnion PCU at Kerman, California.

Report No. 95-30910000.4 


\section{Table 7-1}

\section{Summary of Factory Test Sequence for US-2 (Kerman) PCU}

\begin{tabular}{|c|c|}
\hline 1 & Verify that the printed circuit $(\mathrm{PC})$ boards have been tested and their test reports are completed. \\
\hline 2 & Visually inspect the unit and verify that the wiring is in accordance with the latest drawing. \\
\hline 3 & Verify that the test setup connections to the unit are correct. \\
\hline 4 & Disconnect the PC boards that use dc; bring up the 120 -Vac test voltage; verify and record voltages. \\
\hline 5 & Remove all bridges and MOVs; hi-pot with the 1-kV megger; record the resistances. \\
\hline 6 & Check the de power supply voltages and record the values. \\
\hline 7 & Check the terminal dc voltages; install the PC boards; verify that each board powers up properly. \\
\hline 8 & Adjust dc supplies to verify trips for undervoltages and overvoltages; record the trip voltage levels. \\
\hline 9 & Set the de supply voltages to the proper levels and record the values. \\
\hline 10 & Adjust the LCD display contrast. \\
\hline 11 & Verify the operation of the cooling fans and air conditioner. \\
\hline 12 & Verify several voltages and LED illuminations for the ac breaker positions. \\
\hline 13 & Verify several voltages and LED illuminations for the de disconnect positions. \\
\hline 14 & Measure and record the PT voltages. \\
\hline 15 & Verify the operation of the door interlocks. \\
\hline 16 & Verify the operation of the smoke detector. \\
\hline 17 & Verify the dc ground fault detector; measure and record the forward and reverse current trip ranges. \\
\hline 18 & Measure and record the ac overvoltage and undervoltage trip level ranges. \\
\hline 19 & Verify the operation of controls and LCD for an emergency stop, manual and automatic start and stop. \\
\hline 20 & Start the unit without fuses to verify that the startup control sequence is correct \\
\hline 21 & Verify that the stopping control sequence is correct. \\
\hline 22 & Test the hardware backup to the master control. \\
\hline 23 & Open the main breaker to test the loss of the utility power control function. \\
\hline 24 & Force a synchronization error; test and adjust delays; verify if the PCU attempts to restart and reset. \\
\hline 25 & Test the remote disable and restart functions. \\
\hline 26 & Verify the operation of the ac breaker remote open/close function. \\
\hline 27 & Verify the operation of the remote reset. \\
\hline 28 & Check the SCADA status and fault outputs. \\
\hline 29 & Verify the opening of ac and dc contacts on a CPU fault. \\
\hline 30 & Verify the fiber optic cable runs. \\
\hline 31 & Test the overtemperature indications and control functions for all bridges. \\
\hline 32 & Test the cleared fuse functions for all six bridges (three ac phases and two poles per bridge). \\
\hline 33 & Test the missing connection functions for all six bridges. \\
\hline 34 & Verify the correspondences of control and transformer line-neutral voltages, and phase rotation. \\
\hline 35 & Adjust the zero offset on the current regulator. \\
\hline
\end{tabular}




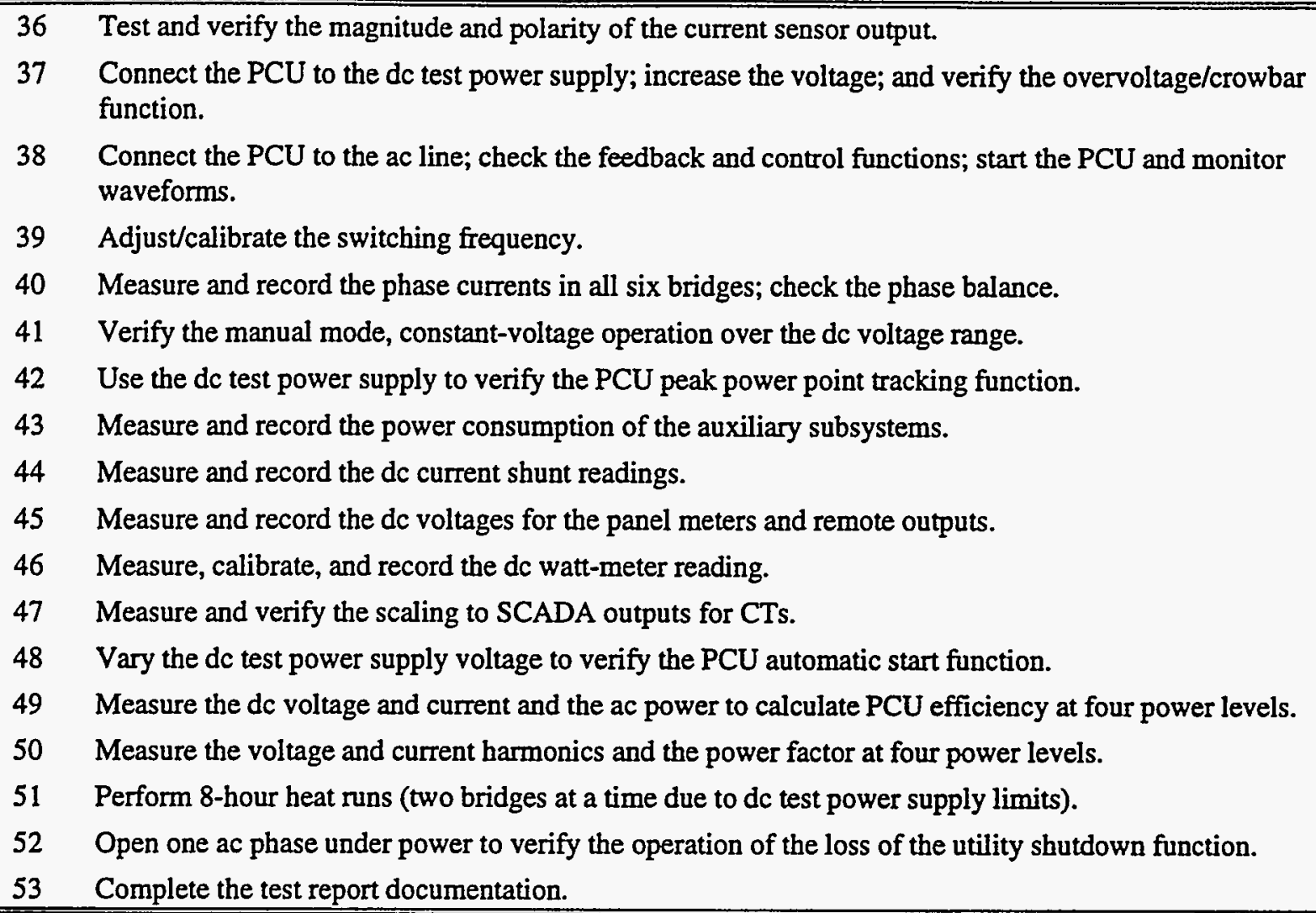

The tests in Table 7-1 were performed on Unit 2 between December 23, 1992 and January 18, 1993. The tests were generally successful and uneventful, with two exceptions. Instrumentation accuracies and/or errors led to calculated efficiencies over 100 percent (Item 49 in the table), and the ambient temperature in the test chamber became too high during the heat run for one set of bridges (Item 51). The factory tests for Unit 1 were performed on January 18-21, 1993. The tests on Unit 1 also were successful and uneventful, except that the calculated efficiencies were over 100 percent.

For the most part, the test data are not of general interest. They consist mainly of internal voltage readings, check marks indicating successful completion of test items, signoffs, and dates. No-load power consumption was recorded and is shown in Table 7-2. The air conditioning units installed at the time of these tests were very small and were later replaced in the field by much larger units. 
Table 7-2

No-Load Power Consumption for US-2 (Kerman) PCU ${ }^{1}$

\begin{tabular}{|lccc||}
\hline \multicolumn{1}{|c}{ Mode/Condition } & $\begin{array}{c}\text { Unit 1 } \\
\text { (W) }\end{array}$ & $\begin{array}{c}\text { Unit 2 } \\
\text { (W) }\end{array}$ & $\begin{array}{c}\text { Average } \\
\text { Percent of } \\
\text { Rated Power }\end{array}$ \\
\hline Shutdown & 182 & 127 & $0.06 \%$ \\
Standby Ready & 191 & 137 & $0.06 \%$ \\
Run & 506 & 471 & $0.18 \%$ \\
Run and Air Conditioner ${ }^{2}$ On & 715 & 694 & $0.26 \%$ \\
Run and Blowers On & 1,201 & 1,184 & $0.43 \%$ \\
Run and Blowers and Air Conditioner ${ }^{2}$ On & 1,425 & 1,418 & $0.52 \%$ \\
\hline ' Values do not include losses in the isolation transformer. & & \\
2 Later replaced in the field with a larger HVAC unit. & & \\
\hline
\end{tabular}

\section{Startup Tests}

The field tests are summarized in Table 7-3 [7-3]. As can be seen by comparison with Table 7-1, these tests replicate many, but not all, of the factory tests.

Startup tests were performed between February 22 and March 2, 1993. The two units passed the tests cited in Table 7-3, with the exception of a large error in the remote reading for the plus and minus dc voltages on both Units 1 and 2. This was traced to the external load on the measurement circuit.

There was a major difficulty in that the two Omnion units worked separately, but not together. The two separately controlled units are connected in parallel via a transformer bus. Attempting to parallel the units resulted in a dc ground fault trip in both units. The problem was traced to a high-frequency circulating current on the neutral of the transformer bus when the firing of a positive pole in one unit and the firing of a negative pole in the second unit occurred simultaneously. A number of solutions were explored. The problem was eliminated at the end of March 1993 when Omnion installed an isolation transformer between inverter Unit 2 and the transformer bus [7-4, 7-6]. 
Table 7-3

\section{Summary of Field Test Sequence for US-2 (Kerman) PCU}

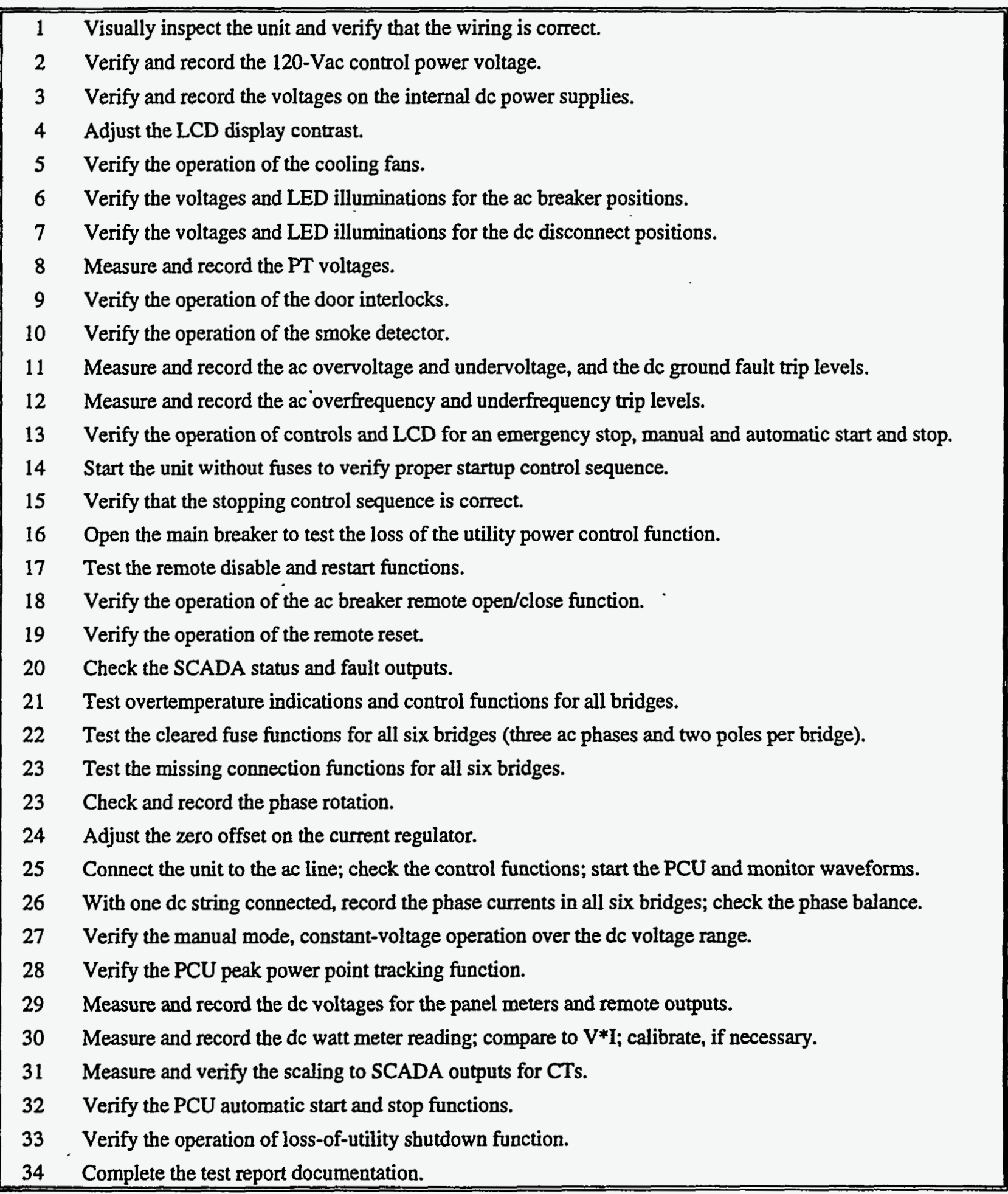




\section{OPERATION AND MAINTENANCE}

It was found that the inverter could interfere with the operation of other electronic equipment, in particular the smoke detectors and UPS in the electrical control building, and the digital clocks of two customers on the utility line. Measurements at one customer's residence showed a voltage THD of 1.7 percent with the loads on and 1.5 with most of the loads turned off, with a strong 5th harmonic presence. There also was high-frequency noise ( $4 \mathrm{kHz}$, in the range of the inverter switching frequency). At the time of the measurements, the PG\&E personnel repaired suspect loose connections at the service drop. Although initial measurements on the PCU showed the harmonics to be within the limits set by the specifications, capacitors were added on the ac output side of both inverter units. The additional filtering further reduced the harmonics, and the problem was eliminated by the end of August. The upper and lower portions of Figure 7-3 show the voltage waveforms before and after installation of the additional filtering. Figure 7-4 shows the corresponding frequency spectra of these waveforms. The levels of highfrequency distortion shown by the lower graph in Figure 7-4 appear to be sufficiently low to prevent interference with electronic equipment connected to the utility line, at least at the Kerman site [7-4].

There was one instance of a filter capacitor failing as a result of excessively high current. This was corrected by installing capacitors with higher ratings [7-4].

During initial operation in May 1993, Unit 1 tripped several times. These trips were due to a regulator or a crowbar fault, which in turn was due to cloud enhancement transients, which caused the dc input power to exceed the unit's $300-\mathrm{kW}$ limit before the dc contactors could shed source circuits. The problem was eliminated by reprogramming the EPROM with a 2-second delay on the crowbar and a 15-minute delay before reclosing the source circuit shed contactor, and by increasing the number of arrays shed during such conditions $[7-4,7-6]$.

There were 15 occurrences of Unit 1 tripping due to an ac overvoltage error message. The root of the problem was an erroneous control voltage reference signal caused by a cleared fuse in the neutral wire to the main transformer. Replacing the fuse in May 1993 eliminated this problem.

Another early problem involved the repair of panel meters to prevent entry of moisture into the meters. 

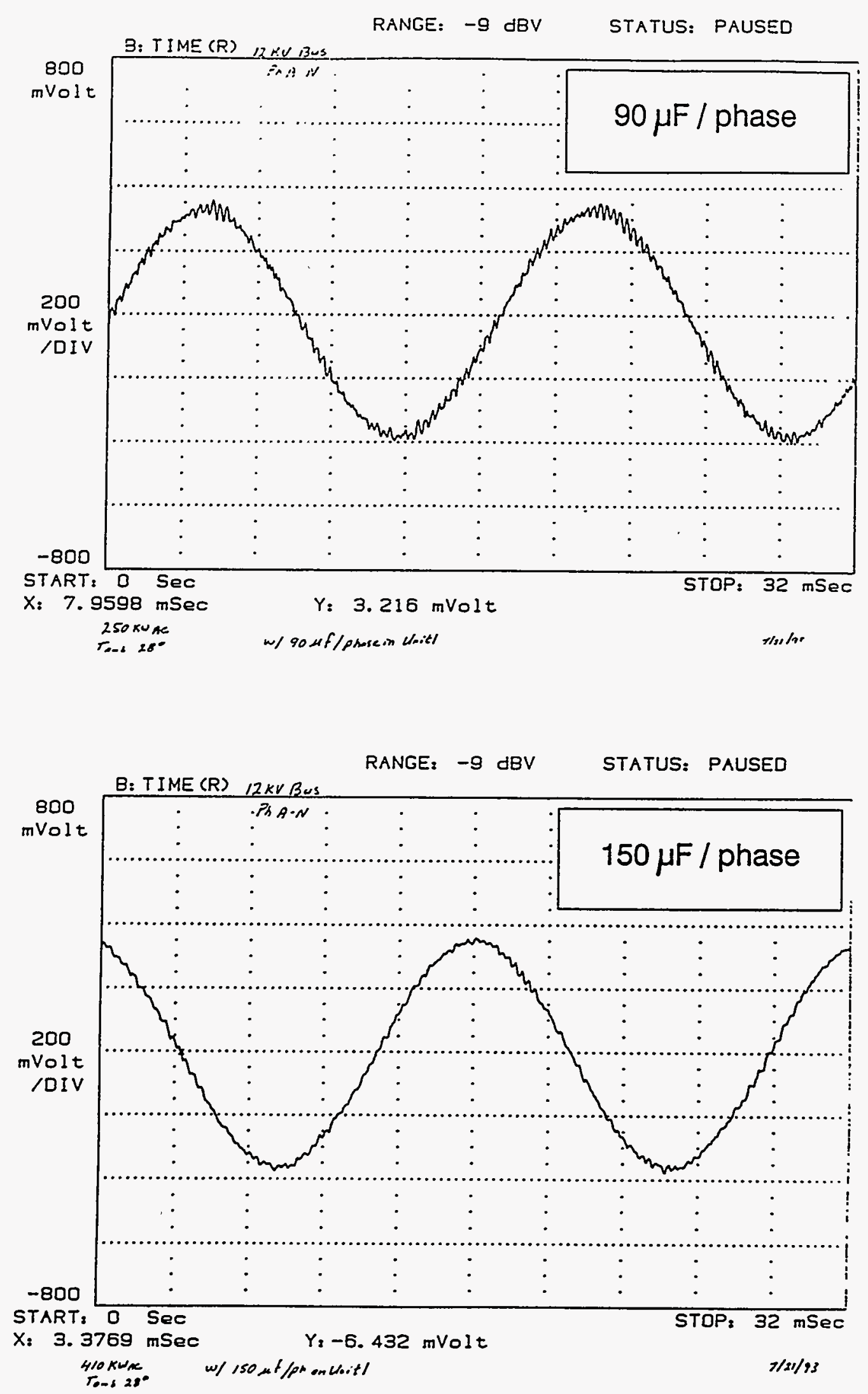

Figure 7-3. Kerman voltage waveform before and after additional filters. 

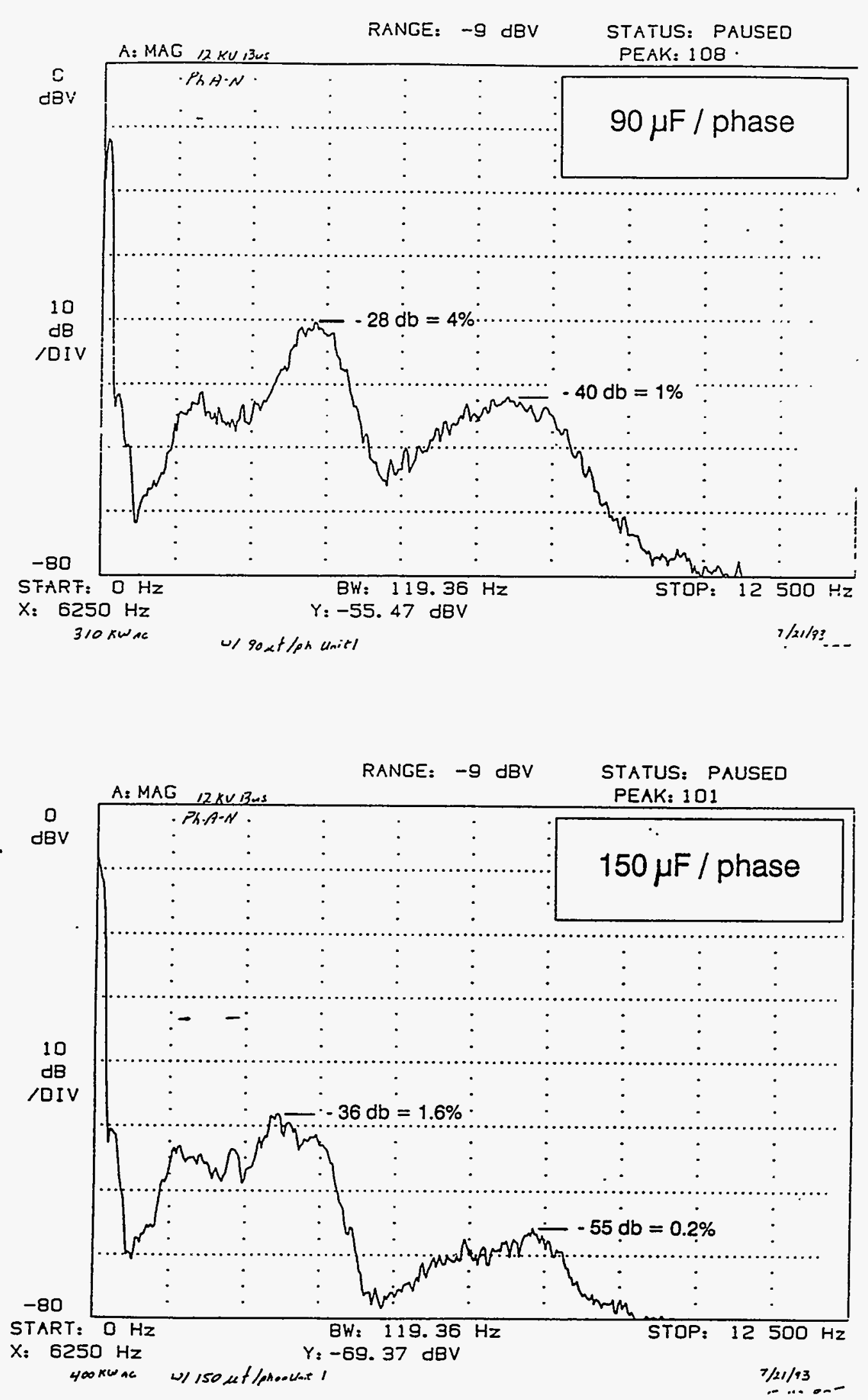

Figure 7-4. Kerman frequency spectra before and after additional filters. 
PCU overtemperature trips were corrected by replacing the original cabinet air conditioners with 1.25 -ton units (approximately 10 times as large as the original units) and modifying the control circuit.

Heating from a loose bus connection and close physical spacing caused an electronic current transducer to melt, and high voltage from a resulting short to the bus damaged several control PC boards [7-4].

These problems extended the startup from 30 to 110 days. After June 1993, the availability of the Kerman plant (PCU plus all other systems) was 92 percent. (This availability is defined as the percentage of daylight hours during which the system supplies net power to the grid.) A number of other PCU problems were corrected by maintenance personnel; other problems/events were only logged. In addition to the 8 hours to install capacitors, there were five PCU-related maintenance hours during the second half of 1993.

In July 1994, there was a series of intermittent trips. These trips were traced to a loose ribbon cable connector, which was then repaired.

Line switching by the division operators (after a car crashed into a utility pole) caused the PCU to be tied into another circuit. Afterward, it was noted that some of the trips no longer occurred. These trips reoccurred when the system was reconnected to the normal utility line. In October 1994, taps on the PCU transformer were adjusted, which resolved voltage out-of-range trips.

In August 1994, the master control board for Unit 1 was replaced with a spare and the original was returned to Omnion for repairs.

In September 1994, Unit 2 was down for 5 days between detection and replacement of a failed 5-V power supply (damaged capacitor; power supply repairable for use as spare). Since that time, Unit 2 has sometimes failed to wake up automatically and has required manual reset. Replacing a damaged wire lug resolved a failure in Unit 1 during this period.

\section{PCU CHARACTERISTICS}

\section{Efficiency}

Figure 7-5 shows the efficiency of the PCU as a function of power. The rated power is that of both PCUs, $550 \mathrm{~kW}$ ac $(2 \times 275 \mathrm{~kW})$. The dc power is the sum of the dc powers into Units 1 and 2 . These are calculated from the measured plus and minus dc voltages times the dc current. The ac output is that measured at the $12.47-\mathrm{kV}$ side of the main isolation transformer. Several hundred data points are used. 


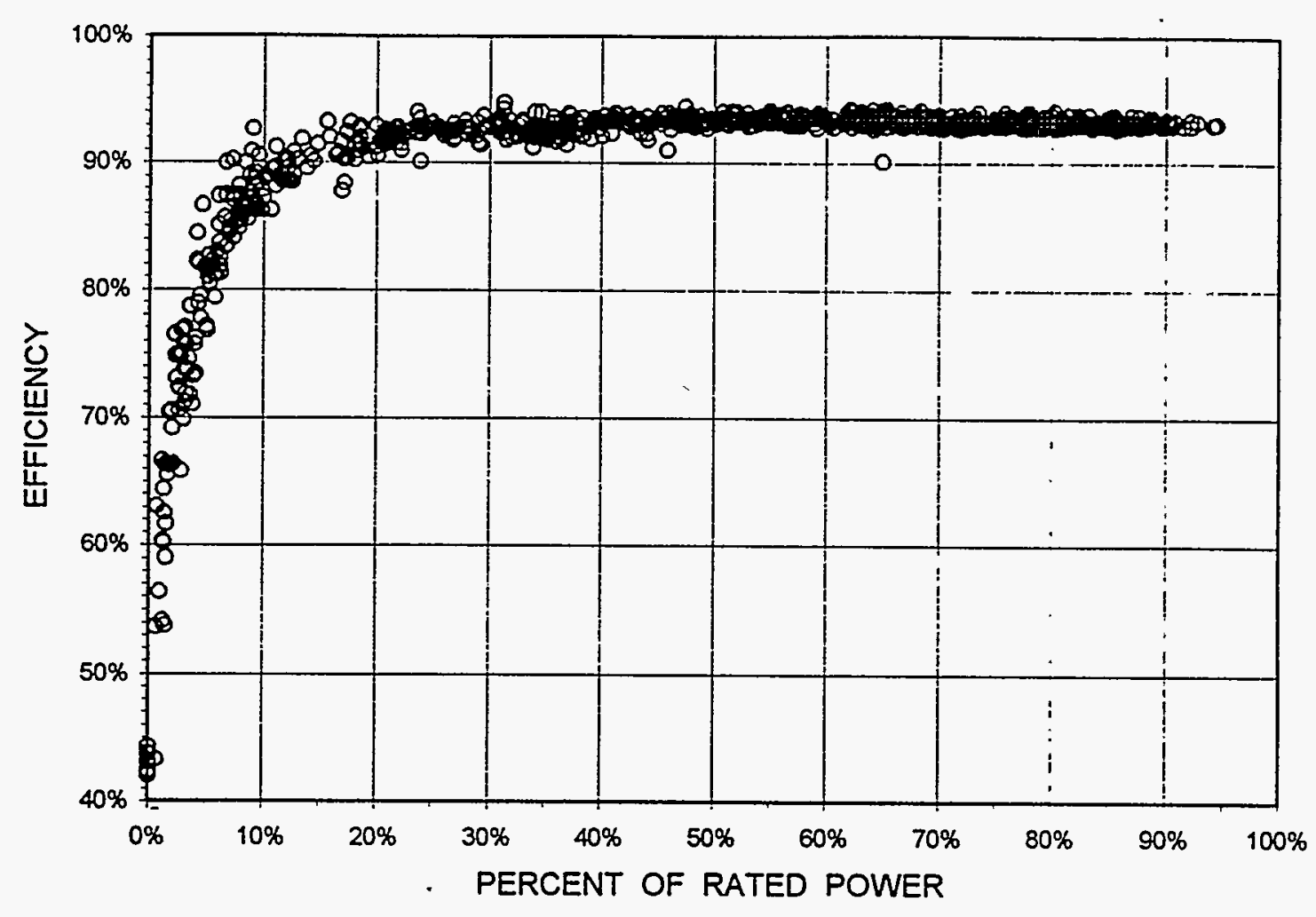

Figure 7-5. Efficiency as a function of rated power.

The average dc-to-ac efficiency near full power for the combined PCUs, including the transformers, is 93.3 percent. The average efficiency remains above 93 percent for 20 to 100 percent of rated power.

\section{Current Unbalance}

Tests performed on the 12-kV bus on April 29, 1993 showed a current unbalance of 0.4 percent, a voltage unbalance of 0.7 percent, and a neutral current of $0.76 \mathrm{~A}$ (line currents averaged $22.8 \mathrm{~A}$ ). Operating conditions during this test were $490.1 \mathrm{~kW}, 17.8 \mathrm{kVAR}$ leading [7-5].

\section{Power Factor}

Figure 7-6 shows the power factor and reactive power (VARs) as functions of power level. As indicated by the figure, the power factor of this PCU is above 0.99 for power levels above 8 percent of rated power. 


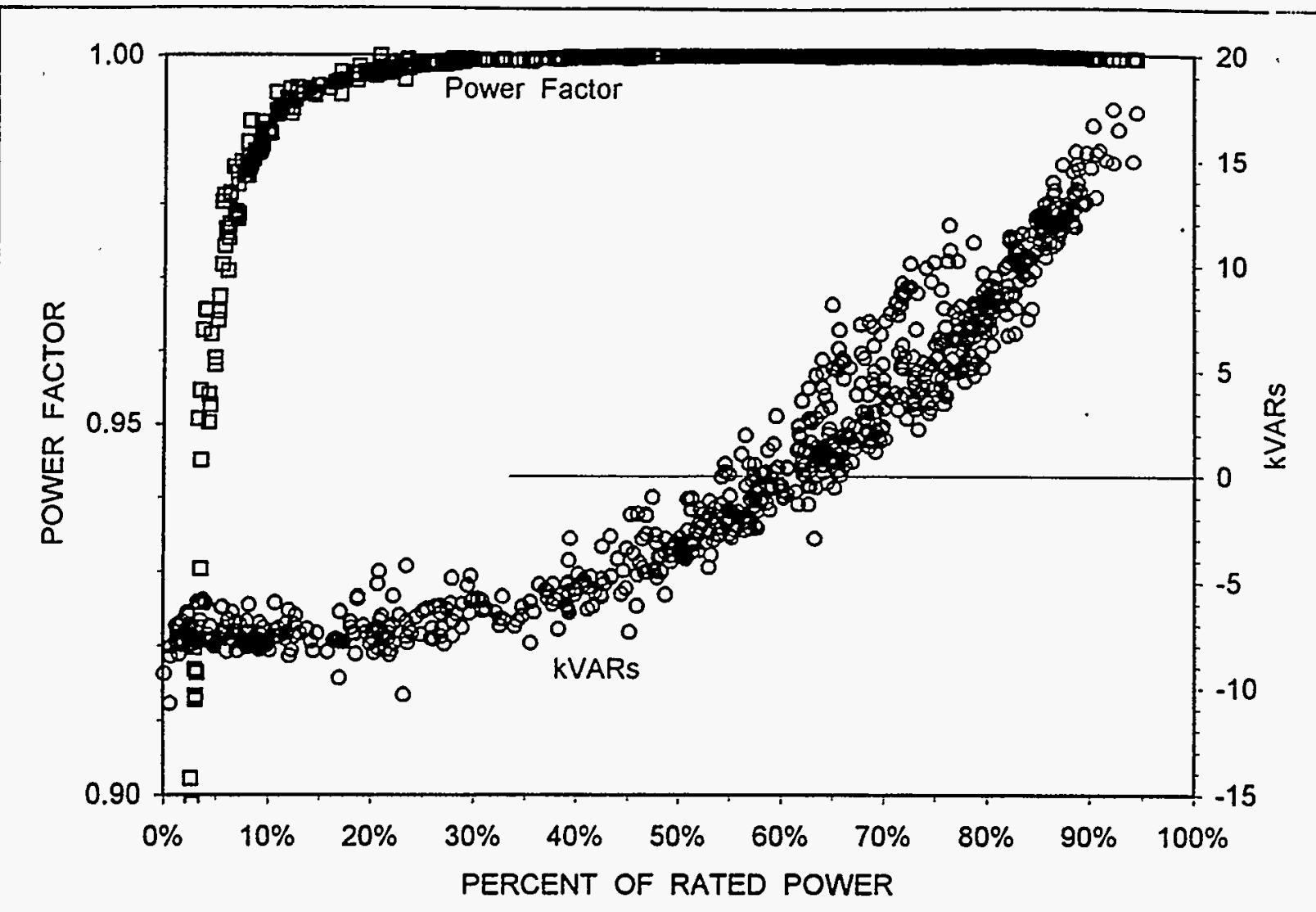

Figure 7-6. Power factor and reactive power as a function of power level.

\section{Harmonic Distortion}

Figures 7-7 and 7-8 show the current and voltage THDs, respectively. A separate measurement of current THD was made on the same day (April 29, 1993) and at approximately the same time, but with different equipment. It is not known why the two current THD measurements shown in Figure 7-7 disagree. Data from the BMI 3030 seem to agree with current THD measurements made during factory tests at the Omnion facility (circles on the lower curve) using other measurement equipment (one unit at a time, with capacitors disconnected). The upper curve (BMI PQ Node data) also includes data taken several days earlier (April 21, 1993) when the capacitor configuration was slightly different (140 $\mu \mathrm{F} /$ phase in Unit 1 and 90 $\mu \mathrm{F} / \mathrm{phase}$ in Unit 2 versus the later $90 \mu \mathrm{F} /$ phase in both units), and the curve fit to the data includes several points above 20 percent THD not shown on the graph. 


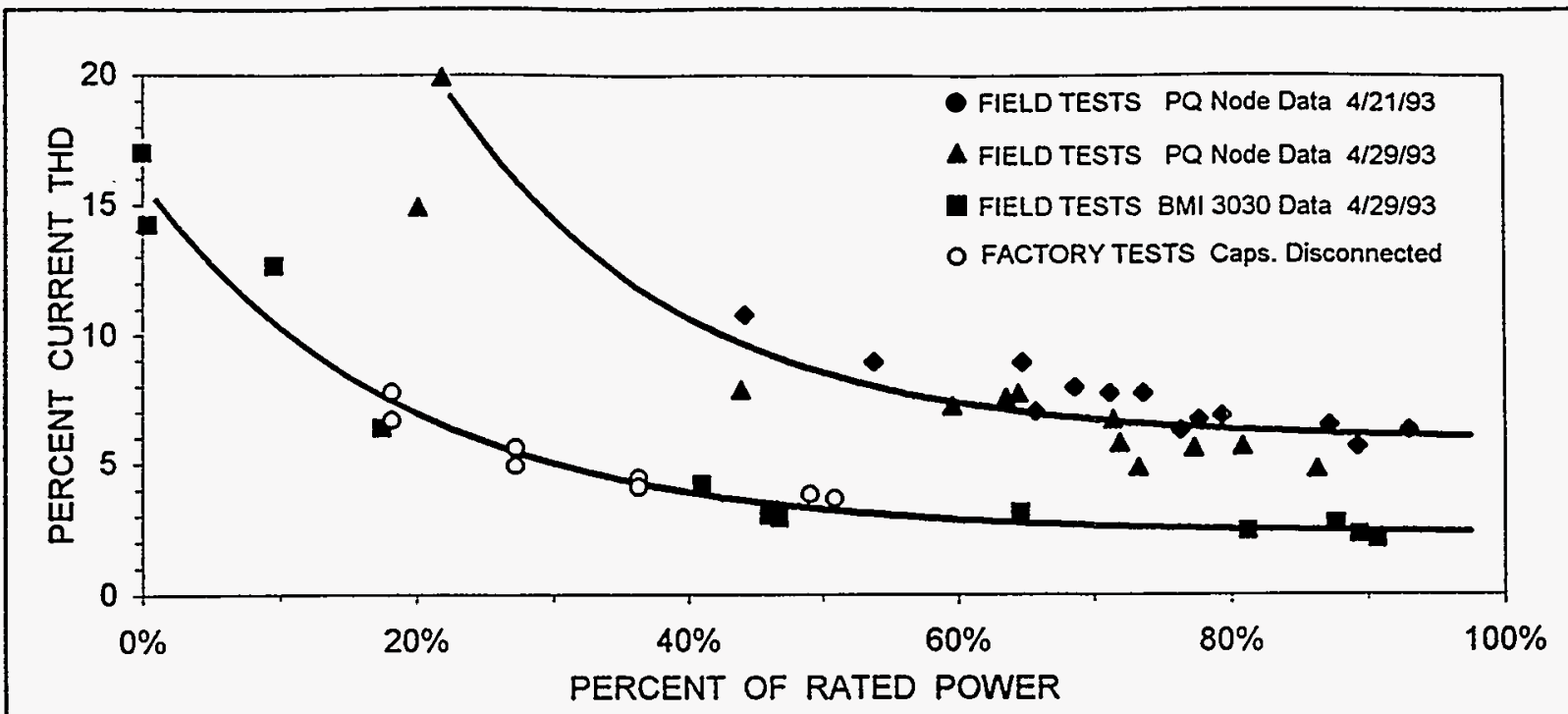

Figure 7-7. Current THD as a function of power level.

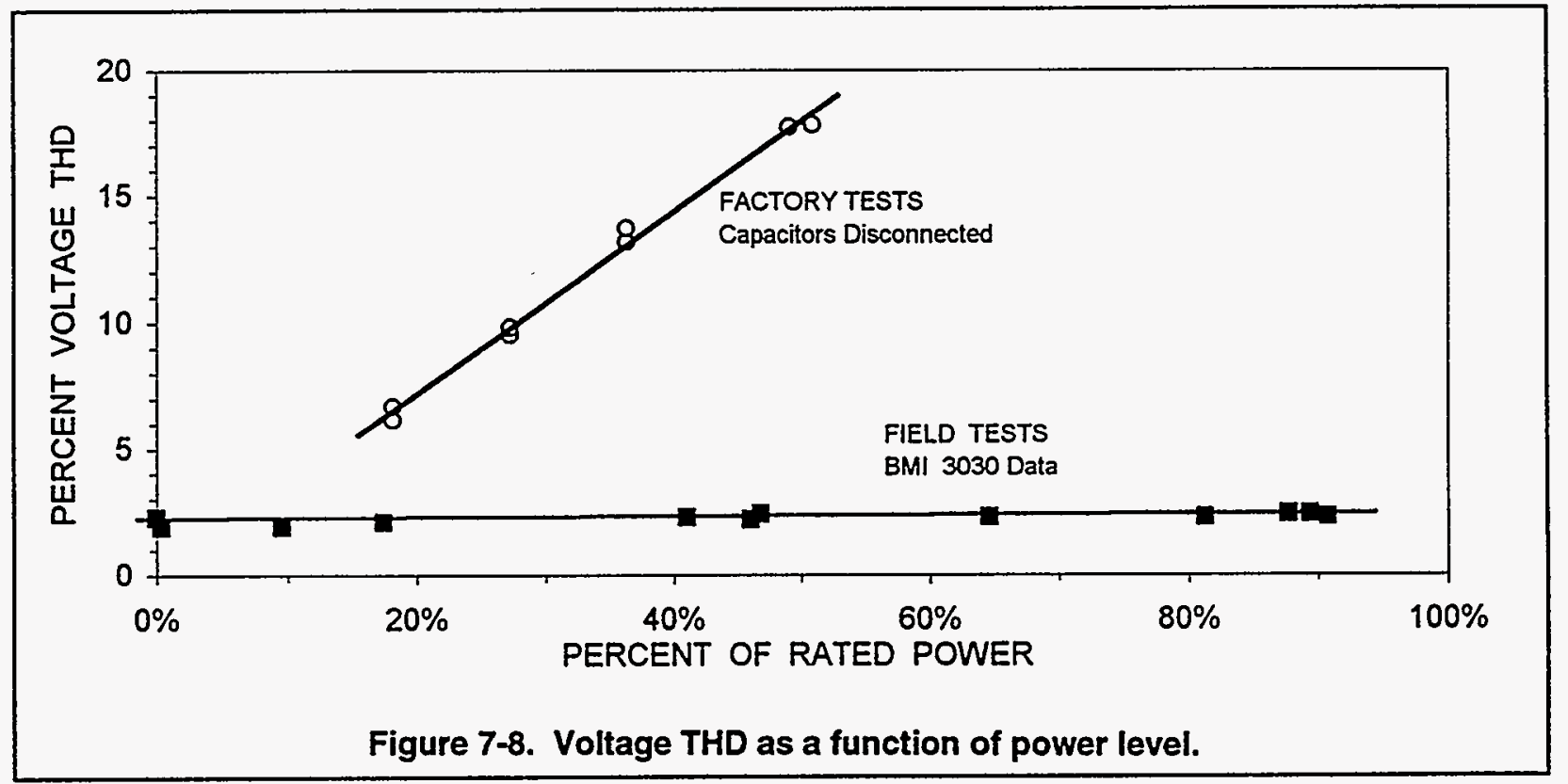

It is believed that the differences between the voltage THD curves in Figure 7-8 are a function of the relatively high impedance at the factory compared with that of the utility line at Kerman, as well as the capacitor configuration.

Additional data on the voltage waveform and harmonic spectra are shown in Figures 7-3 and 7-4, respectively. These include data taken both before and after further modification to the capacitor configuration. 


\section{SUMMARY}

This PCU had a number of startup problems that were corrected in the field and resulted in several lessons leamed. A key lesson was that THD can be within the acceptable limits, but still introduce power quality problems for some types of computers and clocks (a caution mentioned in IEEE 519). Another key lesson was that designs with PCUs operating in parallel should be reviewed carefully and tested at the factory, if possible, to eliminate the need for field retrofit to correct problems. Adequate cooling of PCUs should be given special consideration in design review. The cooling requirements should be conservatively estimated and the solar gain considered.

After correction of startup problems, this PCU has operated very well at times (e.g., it operated without a fault from the end of November 1994 until early January 1995). After January 1995, it experienced problems requiring field repair by Omnion.

The PCU's characteristics include average efficiency, acceptable harmonic levels, good current balance, and an excellent power factor.

\section{REFERENCES}

7-1 Operation and Maintenance Manual - PVUSA US-2, Siemens Solar Industries, October 1993, 19271-SC-D215-83(1).

7-2 Factory Test Procedure for Omnion Series 3200 Converters, Omnion, Test Complete January 18, 1993, Model \# 275-361247-6U/OS, 19271-SC-D215-74(2)-1.

7-3 Field Test Procedure for Omnion Series 3200 Converters, Omnion, Test Complete March 2, 1993, Model \# 275-361247-6I/OS.

7-4 1993 PVUSA Progress Report, B. Farmer, Project Manager, prepared by PVUSA Project Team, Report Number 007.5-93.8.

7-5 Lumus Kendrick, PG\&E R\&D, May 6, 1993 Memo to Ken Long, PG\&E Electrical Engineering, PVUSA Power Quality Reports. 

Section 8

\section{SUMMARY, CONCLUSIONS, AND RECOMMENDATIONS}

This section summarizes data on the five PCU models, and presents conclusions and recommendations derived from PVUSA's experience with PCUs.

\section{SUMMARY}

\section{PCU Characteristics}

Pertinent characteristics of the five PCU models in the PVUSA project are highlighted in Table 8-1.

Table 8-1

PCU Ratings, Data, and Characteristics

\begin{tabular}{|c|c|c|c|c|c|}
\hline & EMT & & US-1 & & US-2 \\
\hline System Integrator & PVUSA & IPC & SSI & APS & SSI \\
\hline PCU Manufacturer & DECC & Omnion & Dickerson & APS & Omnion \\
\hline Manufacturer's Rating & $25 \mathrm{~kW} \mathrm{dc}$ & $200 \mathrm{~kW}$ ac & $200 \mathrm{~kW} \mathrm{ac}$ & $500 \mathrm{~kW} \mathrm{ac}$ & $550 \mathrm{~kW}$ ac \\
\hline Unit Configuration & $1 \times 25 \mathrm{~kW} \mathrm{dc}$ & $1 \times 200 \mathrm{~kW} \mathrm{ac}$ & $2 \times 100 \mathrm{~kW} \mathrm{ac}$ & $4 \times 125 \mathrm{~kW}$ ac & $2 \times 275 \mathrm{~kW} \mathrm{ac}$ \\
\hline PV System Rating @PTC & 15 to $18 \mathrm{~kW} \mathrm{dc}$ & $196 \mathrm{~kW}$ ac & $134 \mathrm{~kW}$ ac & $479 \mathrm{~kW}$ ac & $498 \mathrm{~kW}$ ac \\
\hline PV System, \% of PCU kW & 60 to $72 \%$ & $98 \%$ & $67 \%$ & $96 \%$ & $91 \%$ \\
\hline Ac Output Voltage & $480 \mathrm{~V}$ & $12,470 \mathrm{~V}$ & $12,470 \mathrm{~V}$ & $12,470 \mathrm{~V}$ & $12,470 \mathrm{~V}$ \\
\hline Type of Commutation & $\mathrm{SCI}$ & $\mathrm{SCI}$ & $\mathrm{LCI}$ & LCI & SCI \\
\hline Switching Device & Transistor & IGBT & SCR & SCR & IGBT \\
\hline Bridges, Total for All Units & 2 & 5 & 8 & 4 & 12 \\
\hline Morning Wakeup Sensing & $\begin{array}{l}\text { Array } \\
\text { voltage }\end{array}$ & $\begin{array}{l}\text { Array } \\
\text { voltage }\end{array}$ & $\begin{array}{l}\text { Pilot } \\
\text { cell }\end{array}$ & $\begin{array}{l}\text { Pilot } \\
\text { cell }\end{array}$ & $\begin{array}{l}\text { Array } \\
\text { voltage }\end{array}$ \\
\hline Maximum Power Tracking & Yes & Yes & Fixed voltage & Fixed voltage & Yes \\
\hline Dc Voltage Range & \pm 120 to $\pm 270 \mathrm{~V}$ & \pm 310 to $\pm 390 \mathrm{~V}$ & $\pm 330 \mathrm{~V}$ & $350 \mathrm{~V}$ & $\pm 360 \mathrm{~V}$ \\
\hline Grounding &,,+- or center & Solid, center & Solid, center & Virtual, center & Solid, center \\
\hline Efficiency $^{1}$ & $94.1 \%$ & $93.6 \%$ & $93.9 \%$ & $96.1 \%$ & $93.3 \%$ \\
\hline Current Unbalance ${ }^{l}$ & $3.0 \%$ & $2.0 \%$ & $2.3 \%$ & $0.3 \%$ & $0.4 \%$ \\
\hline THD Current ${ }^{1}$ & $51 / 2 \%$ & $2 \frac{1}{2} \%$ & - & $31 / 2$ to $51 / 2 \%$ & $21 / 2$ to $51 / 2 \%$ \\
\hline THD Voltage ${ }^{1}$ & 0.6 to $0.8 \%$ & 1 to $1 \frac{1}{2} \%$ & - & 0.8 to $1.2 \%$ & $2 \frac{1}{1} / 2 \%$ \\
\hline Power Factor @ $>40 \% \mathrm{P}_{\text {RATED }}$ & 1.0 & 1.0 & 0.8 to 0.9 & 0.85 to 1.0 & 1.0 \\
\hline Run-On, sec & 1.5 & 0.03 to 0.11 & 0.03 & 0.1 to 0.12 & - \\
\hline Enclosure $\mathrm{kW} / \mathrm{ft}^{2}$ & 2.2 & 3.1 & 2.0 & 5.5 & 4.9 \\
\hline Cooling & Nonventilated & HVAC & Forced air & Forced air & HVAC \\
\hline Location & Under array & In sunlight & In sunlight & Under array & In sunlight \\
\hline
\end{tabular}


The power conditioners range in size from 25 to $550 \mathrm{~kW}$, with individual inverters of up to $275 \mathrm{~kW}$. These manufacturer-rated powers are attained with 1 to 4 inverter modules and 2 to 12 bridges total. Two systems use SCRs as the switching devices; these are line-commutated. The two Omnion units use IGBTs, and the DECC units use transistors. All three are self-commutated. The rated power of the PCU is determined by the interaction of several factors, including the ratings of available switching devices, a PCU manufacturer's existing designs, the power of the connected PV array, and its voltage and current. It is desirable that the PCU permit interfacing the PV system and ac line at minimum size and cost. The PCU rating and/or controls also must provide for irradiances over $1 \mathrm{~kW} / \mathrm{m}^{2}$. The US PCUs rated powers match the ratings of the connected PV systems at PVUSA Test Conditions (PTC) reasonably well. The IPC/Omnion has the narrowest margin, with the PV system rated at 98 percent of the PCU's rated power. The SSIDickerson unit is an exception; its PV system produced less power than expected (134 kW versus $174 \mathrm{~kW}$ ), resulting in a utilization factor of 67 percent. The DECC units were sized to make sure that they would not unduly restrict the array designs of EMT PV system suppliers.

Three of the PCUs track the maximum power point voltage of the connected source circuits, and two operate at a fixed voltage. Morning wakeup for the fixed-voltage PCUs is achieved by sensing current from pilot cells (modules); wakeup for the others is achieved by sensing that the array voltage has exceeded a setpoint. One supplier of a fixed-voltage PCU calculated that this type of arrangement, with seasonal transformer tap adjustment, should provide 97.4 percent of the energy that would be collected with maximum power tracking. As can be seen in Table 8-1, the DECC units have the widest dc operating voltage range, as is appropriate for what is essentially an item of test equipment.

Figure 8-1 shows efficiency as a function of power for the five different models of PCUs at Davis and Kerman. Above 40 percent of rated power, all of the PCUs have efficiencies of $941 / 2 \pm 1 \frac{1}{2}$ percent. However, at low power, the efficiency falloff differs from one model to another. The curves for the two Omnion PCUs (IPC and Kerman) are flatter at the top than those of the line-commutated SSI/Dickerson and APS units. The data for the DECC EMT PCUs are a composite of five units. Also, the ac outputs of the DECC units are not field-calibrated. All of the curves are fits to 5 days of data.

Unbalance among the ac output phase currents ranges from less than 0.3 to 2.3 percent for the US systems. Unbalance for the DECC units ranges from 1.4 to 5.1 percent, with an average of 3 percent. For the DECC units, the unbalance is believed to be caused by differences in the values of the output line-tie inductors and could be reduced if these components were more closely matched. 


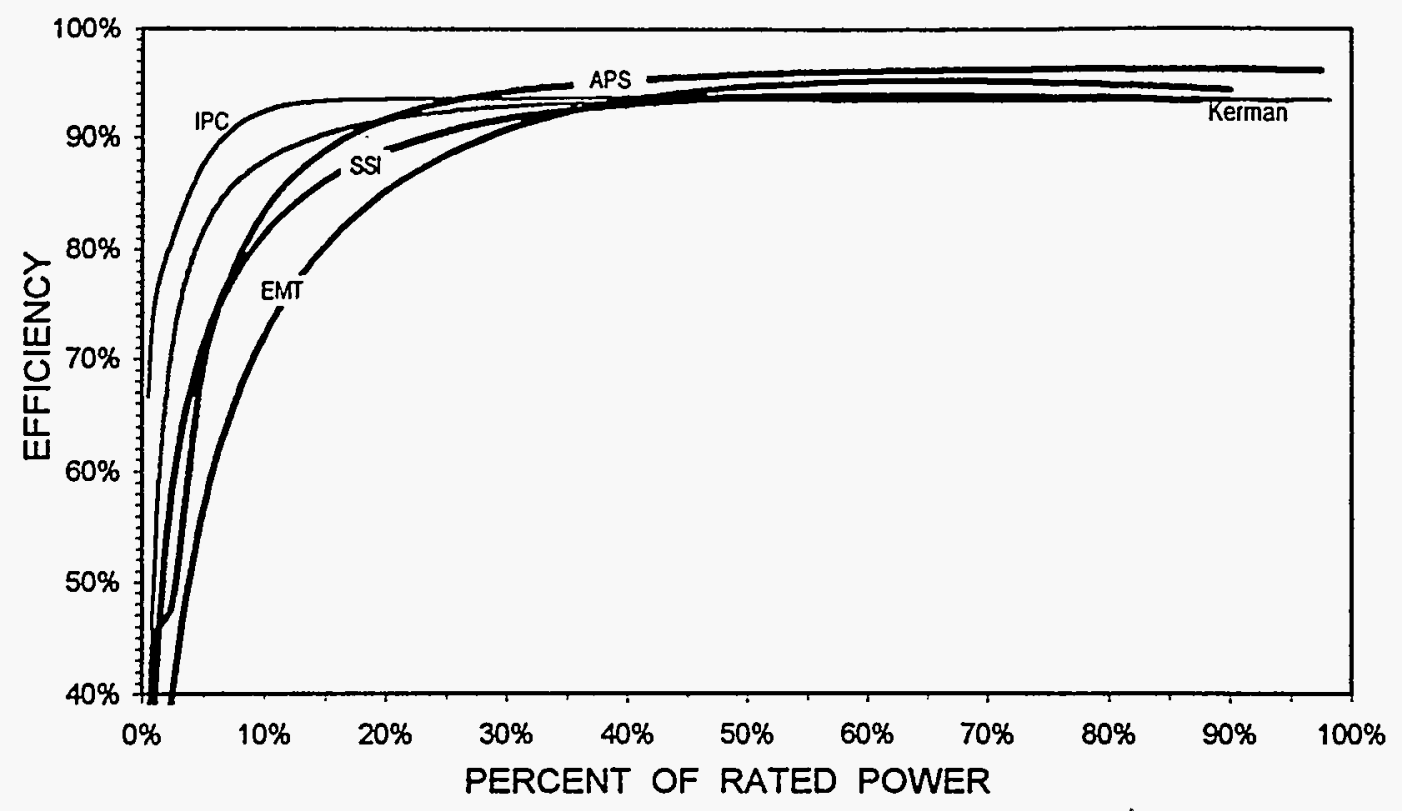

Figure 8-1. PCU efficiencies as a function of power.

For outputs near the PCUs' rated powers, voltage THD ranges from $1 / 2$ to $2 \frac{1}{2}$ percent and current THD ranges from $2 \frac{1}{2}$ to $5 \frac{1}{2}$ percent. Data for the Dickerson unit are insufficient and are not reported here. At lower output powers, the percentage current THD increases, but the magnitudes of the harmonic currents decrease. The PCU power levels are relatively low compared with those of the connected utility lines and thus do not greatly affect the voltage harmonics. These data should be used with caution, as the THD is affected by power level and the impedance of the utility line. Also, units such as the APS and SSIDickerson, which have multiple inverters feeding wye-delta transformer windings, depend on the balance between the inverters to give harmonic cancellation.

Since all of the PCUs use isolation transformers, dc injection is not possible.

Figure 8-2 shows the power factors of the US units as functions of power. The data clearly show the difference between the line-commutated units with fixed capacitors and the self-commutated, pulse-width-modulated units. The two Omnion PCUs (IPC and Kerman) are nearly identical and have a power factor above 0.99 for power levels greater than 10 percent of rated power. The data for the SSI/Dickerson PCU are for one of its two modules operating but with the capacitors for two units 
connected, and thus the operating power factor is lower than designed. Neither of the current-source inverters met the power factor specification at low powers.

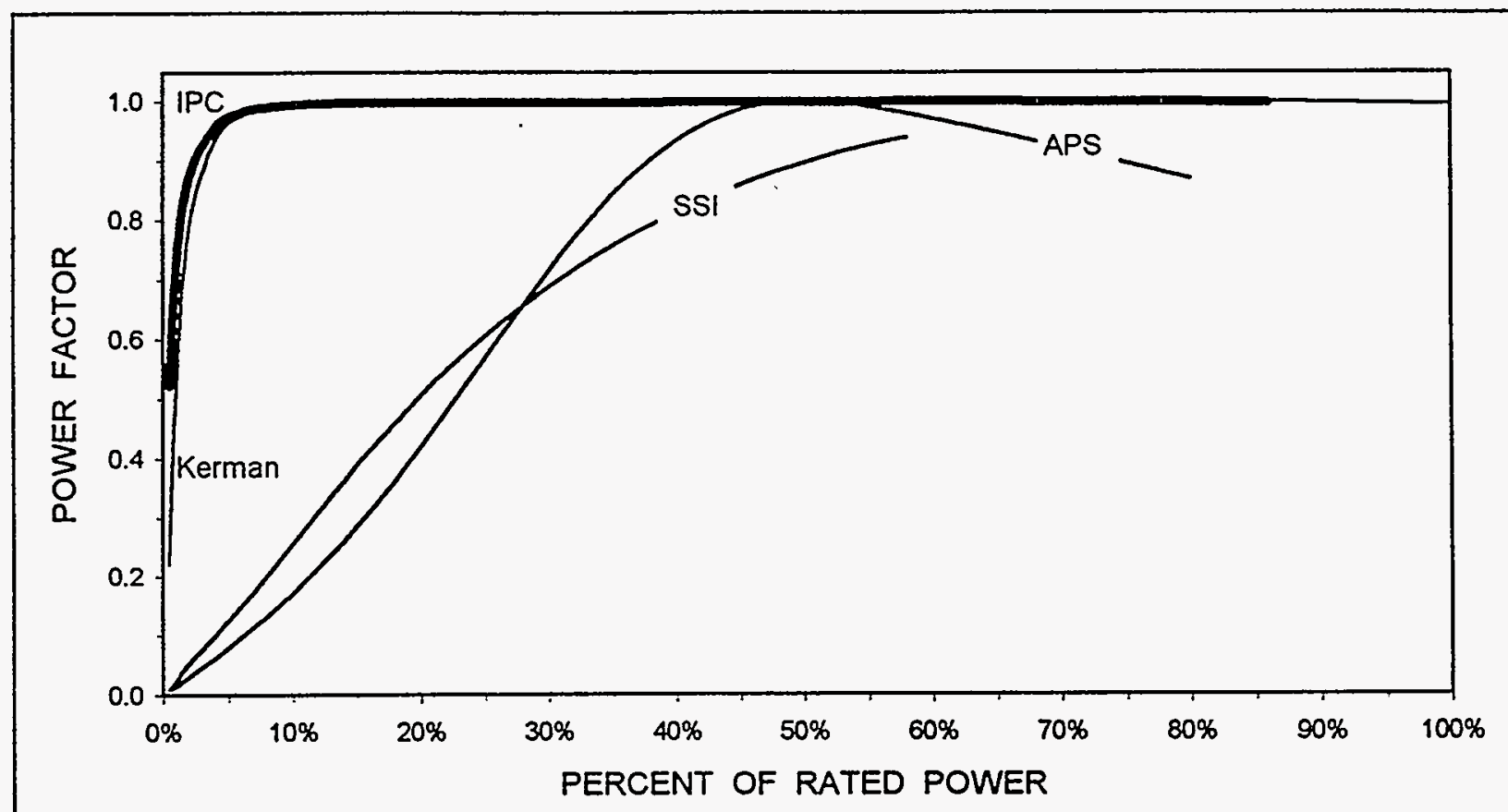

Figure 8-2. PCU power factors as a function of power.

Tests performed during startup indicated that the PCUs disconnect and do not run on upon loss of the utility line voltage (and when no load is present). However, special tests on the DECC PCUs resulted in run-on for up to several minutes when the connected load was 10 to 20 percent above the power being generated by the PCU. Given the correct load impedance, any of the PCUs might run on. Run-on (islanding) continues to be a concern for utility companies.

EMI/RFI and magnetic field strengths were measured for the DECC PCUs and, while detectable, their levels were so low that they were judged not to be a problem.

\section{PCU Maintenance}

Although the PCUs passed prescribed factory and field startup tests, all encountered difficulties that required corrective actions. For the US units, factory tests were limited to less than rated power due to 
the capacity of available dc array simulators. These tests were followed by major and minor difficulties during initial operation. Figure 8-3 shows the occurrences of failures and trips, but it does not show downtimes and times to effect repairs.

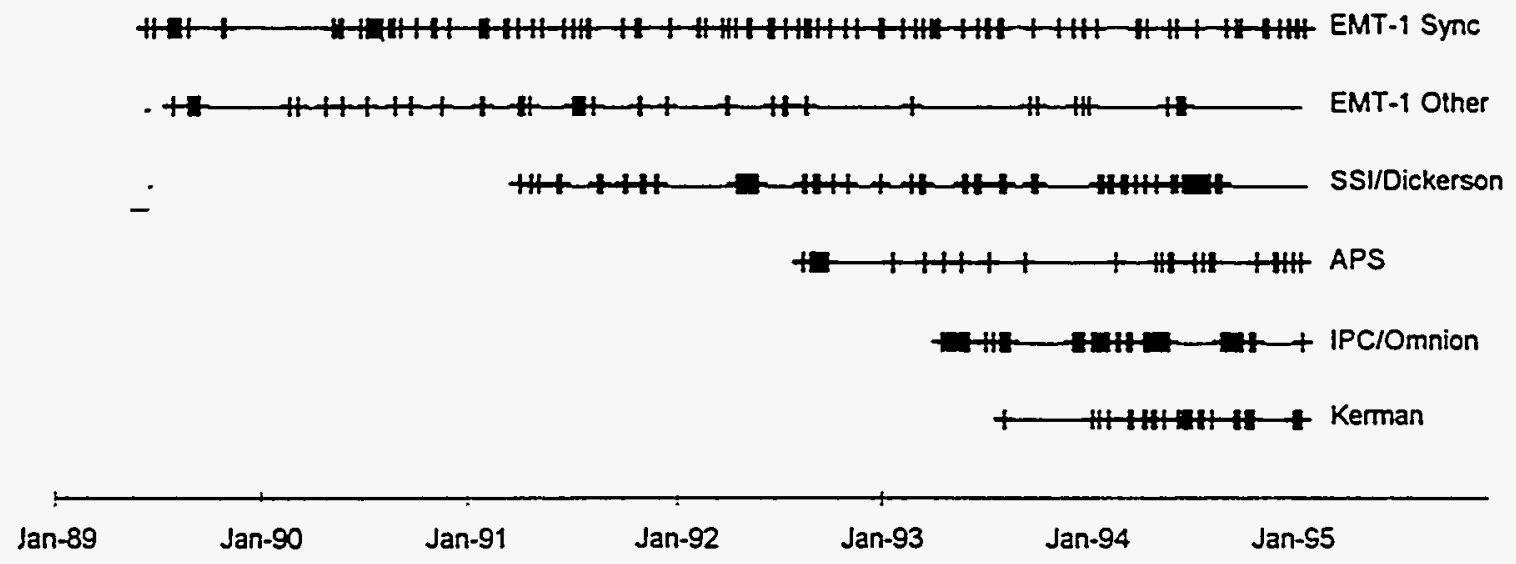

Figure 8-3. PCU failure chronology.

DECC. The Figure 8-3 data for EMT-1 are for five DECC units, brought on line when the EMT-1 PV systems were installed. These are presented in two categories: synchronization errors and other inverter failures. "Sync." errors have persisted and relate to the PCU morning wakeup process. This problem is largely ameliorated with biannual adjustment of the starting voltage to accommodate seasonal variations in array voltages. Other inverter failures included trips, failure to start, and failure to power track accurately. Corrective actions over time included adding capacitors across ac power transducer terminals, adjusting transducer gains, and adjusting delay times. Additionally, inverter failures were caused by loose or broken connections and faulty resistors. Also, the printed circuit (PC) boards were not identical for the several PCUs, which limited interchangeability and impeded maintenance.

-SSI/Dickerson. Mid-1991 field tests for the original PCUs included full-power tests deferred at the factory. One bridge core in PCU A was not functioning for these tests and was reworked at the factory. PCU B passed most of the field tests. However, operation of the two PCUs in parallel was unreliable. Repairs had limited success. At most, the PCUs operated in parallel for a few weeks at a time. At PVUSA's suggestion, SSI engaged a consultant to review the design. He concluded that the design was viable, but workmanship and material selection could be improved. The units were modified and 
repackaged, but control and logic board designs were not modified. Both PCUs were factory-tested, reinstalled, and field-tested. Numerous trips and failures followed. In late 1993, PVUSA (under the direction of its Technical Review Committee) met with SSI and developed an acceptance test which required both PCUs to operate reliably for 28 consecutive days. The PCUs passed this test, but the trips and failures continued. In May 1994, SSI notified PVUSA that it had exhausted all practical possibilities of repairing the PCUs. PVUSA agreed and settled the contract, and the system was accepted as is. Since then, PCU B has operated reliably. PCU A is inoperative and is used for spare parts.

IPC/Omnion. Because of high irradiance and other problems, Omnion modified the PCU's software to operate the reduce power contactor at $200 \mathrm{~kW}$ and to shut down if the power from the remaining circuits exceeded $224 \mathrm{~kW}$. There were numerous shutdowns due to bridge faults. Based on experience at Kerman, Omnion added an air conditioner to the PCU cabinet and installed a newly programmed EPROM. There was little improvement. Occasionally, the PCU did not start in the morning and displayed a dc overvoltage message. After repairs, the PCU continued to have dc overvoltage trips. In January 1994, several connectors were cleaned to solve an intermittent problem. One hour after restart, the PCU tripped on a bridge fault and several IGBTs were damaged. These were replaced, but after a few hours, the PCU tripped on a bridge fault, and the damage was repeated. Several PC boards, cables, and the EPROM were replaced, but the dc overvoltage problem continued. Replacing the integrated circuit amplifiers in the dc injection sense circuit and repair of a solder connection seemed to cure the problem. There were no outages for 2 months, but then the problem returned. Rather than continue troubleshooting problems for a superseded PCU design, the TRC in 1995 elected to replace the unit and use this opportunity to demonstrate another model of PCU.

APS. At the start of data collection, the PCU tripped several times because of a smoke alarm and outgasing of new components. This was followed by trips due to cleared fuses and other problems. APS made minor repairs. Data collection continued, accompanied by several trips and failures to wake up at sunrise. APS replaced several components and resoldered a few connections. The PCU ran with only a few failures until a utility line fault, which took some time to clear. Other PCUs restarted, but the APS unit was damaged. Upon restart after repairs, a ground fault through failed MOVs damaged a dc disconnect switch. The ground fault location was not determined, but APS modified its virtual ground on the dc system. While making repairs, APS noticed another failed dc contactor. This was traced to underrated coils, which were then replaced. There were instances of cleared fuses after utility line 
outages. Failures and clearing of fuses after utility line transients persist. The line-commutated APS PCU seems to be more sensitive to line transients than other PCUs. The APS PCUs operate at a fixed dc voltage, which is manually adjustable. Due to aging of the array or other causes, the maximum power point dc voltage during summer has decreased to a point below the adjustment range.

Kerman. During field tests, it was found that the two Omnion units could not be operated in parallel because of high-frequency circulating current in the neutral. An isolation transformer was installed on Unit 2. This eliminated the problem and both PCUs passed the field tests. It was suspected that the PCUs interfered with the digital clocks of two customers on the utility line and electronic equipment in the control building. Although the harmonics were within specifications, additional capacitance was added on the ac side of both PCUs, which further reduced high-frequency harmonics and eliminated the interference. Capacitors with higher current ratings were installed after a failure.

Unit 1 tripped several times as a result of transient cloud enhancement, which caused the dc input power to exceed the unit's $300-\mathrm{kW}$ limit before the dc contactors could shed source circuits. This was eliminated by reprogramming the EPROM with a 2-second delay on the crowbar and a 15-minute delay before reclosing the source-circuit-shed contactor, and by increasing the number of source circuits (Unit 1 only) shed. Tripping with ac overvoltage error messages was due to an erroneous control voltage reference signal caused by a cleared fuse in the neutral wire to the main transformer. PCU overtemperature trips were corrected by replacing the cabinet air conditioners with significantly larger units and modifying the control circuit. Heating from a loose connection caused a transducer to melt, and a resulting short to the bus damaged several PC boards. There were intermittent trips that eventually were traced to a loose ribbon cable connector. Other repairs over time included replacing a master control board, a failed 5-volt power supply, a damaged wire lug, and the panel meters (which had moisture ingress).

\section{CONCLUSIONS}

Although the PCUs at Davis and Kerman satisfactorily passed factory tests, numerous difficulties were encountered during startup of each unit. There were declines in maintenance activity after the PV systems were accepted by PVUSA. The factory tests proved useful for early identification and correction of several potential problems and design oversights. More problems would have been corrected at the factory had equipment been available to test units at full power. All of the PCUs had problems as 
components aged and as they were exposed to field operating conditions. These field conditions included line transients and other effects that would be difficult to duplicate in most factory settings.

The PCUs have been one of the major maintenance items at PVUSA. Labor (and travel) costs make field repairs and corrections expensive, both for PVUSA and the equipment manufacturer. It is relatively easy to detect a problem, but determining its root cause is more difficult and time-consuming. This has been particularly true for intermittent PCU failures and trips.

In many instances, hundreds of labor hours were expended in determining the cause of a problem, which was then remedied by replacement of a $\$ 10$ integrated circuit or a $\$ 2$ connector. It appears to be difficult for manufacturers to select components and set design margins that lead to high reliability while producing a PCU at an acceptably low price. There were several failures caused by PCU manufacturers receiving (and using) components mislabeled by their suppliers.

The DECC and Kerman PCUs were purchased as "commercial" equipment. In fact, the DECC unit was specifically designed for this project, and PVUSA received the first units. Similarly, the Kerman PCU design differed from that of previous units. Startup and repair problems with these units were only slightly less than for the US-1 units, where innovation was encouraged. Although they are acceptable for the present, PCUs are not truly a commercial product for the power levels and PV systems tested at PVUSA. There are probably two reasons for this: insufficient market volume has prevented full development and mass production, and PCU designs continue to evolve. However, over the 7-year project history, outward changes are not particularly apparent.

Design evolution and market forces have been such that none of the five PCUs installed and tested are commercially available. The Omnion PCU installed at Kerman has been supplanted by a newer design, just as that unit superseded the earlier Omnion unit installed at Davis. It is believed that none of the other suppliers are actively marketing PCUs for PV applications at present. However, additional manufacturers are bringing their PCUs to the PV market. For example, Kenetech has recently offered units for PV. PVUSA purchased a $225 \mathrm{~kW}$ Kenetech PCU in 1995, but did not have sufficient operating time to review its performance in this report. 
Some characteristics of the various PCUs are similar. All have efficiencies of $941 \frac{1}{2} \pm 1 \frac{1 / 2}{2}$ percent when operating above half of their rated power, and they do not run on without a load connected. However, the efficiency falloff at low powers differs, as do power factor characteristics.

Accommodating irradiance transients (cloud enhancement) is a design feature worth additional development. Most PVUSA PCUs had sufficient design margin to accommodate such transients, which can be as large as 150 percent. This is generally not cost-effective. Two PVUSA PCUs (Omnion) were designed to limit throughput, but the schemes required field modifications and incorporate some undesirable features (mechanical contractor wear; lost energy associated with time delay). The fast rise and fall times associated with cloud enhancement suggest electronic control as the best means of addressing this issue.

Among the US systems, there are two SCR and two IGBT PCUs. The latter are different models by the same manufacturer, Omnion. As shown in Figure 8-2, a major difference between the IGBT, selfcommutated units and the SCR, line-commutated PCUs is the low power factor away from an optimum power region. Table 8-1 shows most other characteristics to be similar between the IGBT and SCR units. The PVUSA data available are insufficient to generalize PCU performance (other than power factor) based on the switching device.

Aside from perhaps being more susceptible to utility line disturbances (protection by clearing fuses), the SCR PCUs seem to have fewer maintenance problems. This opinion must be tempered by the fact that the two Dickerson PCUs could not be made to operate trouble-free when they were connected in parallel. Additionally, the transistor DECC units are among the most reliable, aside from sync. error wakeup problems. Thus, as with performance characteristics, it is difficult to generalize PCU maintenance requirements based on the switching device. Maintenance requirements seem to be more a function of the manufacturer and its design.

Various layouts and enclosure designs were used for the PCUs supplied to the PVUSA project. Their power densities $\left(\mathrm{kW} / \mathrm{ft}^{2}\right)$ are more a function of power level (increasing with power level) than outdoor/indoor enclosure design, active/passive cooling, or switching device. Power density was relatively unimportant for the flat-plate PV systems, where the PCUs conveniently fit under the array structures (at $30^{\circ}$ tilt angle), thereby reducing solar heat gain. For tracking PV systems, PCU power density may affect array spacing and PCU height may affect shadowing. For small systems (such as 
residential), the PCUs will not be 6 to 8 feet tall and volume occupied $\left(\mathrm{kW} / \mathrm{ft}^{3}\right)$ becomes more significant than land area occupied $\left(\mathrm{kW} / \mathrm{ft}^{2}\right)$.

Nonventilated and ventilated (ambient air and air conditioned) cooling system designs have worked, but it is believed that high cabinet temperatures may have contributed to early component failure. Also, not adequately addressing solar heat gain or maximum site temperatures can lead to cooling system retrofit in the field. Filters on the ventilated systems let small amounts of dust into the enclosures, but this was not known to have caused any significant problems. However, control problems on more than one inverter have been linked to poor contact (corrosion) of control board edge connectors, requiring dressing of the fingers and contacts.

Enclosure and component layouts generally did not interfere with PCU maintenance, but some SCRs and IGBTs were found to be difficult to replace. PVUSA personnel and independent safety reviews recommended additional electrical barriers in some areas of PCU interiors.

The diagnostics were judged to be good to excellent on the DECC and Omnion units, detailed but not always clear on the Dickerson units, and acceptable for simple items on the APS PCU. The supplied O\&M manuals were found to be good for the Omnion units (troubleshooting section excellent), minimal on the DECC, detailed but not helpful on the Dickerson units, and detailed but insufficient for APS. The manufacturers' responsiveness to requests for assistance in troubleshooting varied from excellent to poor (key personnel left company; company out of business).

Present common practice utilizes a minimum number of PCUs for a system (economy of scale). This makes the PCU a driving factor in system reliability. PVUSA has had considerable exposure to the design, testing, and operation and maintenance of larger PCUs. PVUSA has worked purposefully with the suppliers, not only to correct problems and deficiencies, but to encourage suppliers to learn from this experience and incorporate appropriate changes. Purchasers should look forward to future product offerings which will resolve many of the issues addressed here. In the interim, the use of multiple, smaller PCUs in system designs might be considered for higher reliability. 


\section{RECOMMENDATIONS}

In preparing the specification for a PCU, one should include a careful evaluation of the requirements of the utility company where the unit will be connected. Expected responses to line transients, responses to external and internal faults, restart delay times, and similar items should be defined as clearly and explicitly as possible. Specification preparation should consider possible integration of PCU internal protective features with utility relaying requirements (e.g., over/under frequency and voltage) as long as these can be tested and set in the field using conventional test equipment.

The PCU supplier should be made aware of conditions at the site, including extremes. The PCU design should address (among other things):

- Site ambient temperature and humidity extremes

- Solar heat gain effects on cabinet interior and component temperatures

- Irradiance transients (up to $1,500 \mathrm{~W} / \mathrm{m}^{2}$ at Davis)

- Effects of seasonal changes in ambient temperature and irradiance spectra, and module aging on array wakeup voltage or pilot cell current

- Utility line disturbances, voltage surges and sags, and phase unbalance

Desirable features include:

- Nonvolatile memory to record causes of failure shutdowns and diagnostics

- Use of terminals (versus connectors) to minimize corrosion problems experienced at PVUSA

- Adequate design margins to account for component aging and operation off the design point

- Placement of PCU under fixed-tilt array to minimize solar heat gain

- Filtering and screens adequate to prevent ingress of dust and insects

- Design and component layout sufficiently spacious to facilitate testing, calibration, and maintenance; barriers to protect personnel during such activities; and separation of power and low-voltage control circuits

The problems PVUSA experienced at startup and during operation seem to be unique to each PCU; still, it is recommended that these problems be reviewed with potential PCU suppliers so that they can upgrade 
their designs, if necessary. The PCU purchaser and PCU supplier should discuss features of the specification or PCU design that might be changed to improve performance, reliability, or costeffectiveness.

PCU supplier personnel should be on site during startup of any PCU with design elements that have not been field-proven. Items covered by warranty should be described as thoroughly as possible. This should include a definition of when the warranty period starts (e.g., when the unit is delivered to the site or when it is accepted by the owner) and whether elapsed time while the unit is unavailable because of repairs is included in the warranty time.

If at all possible, the PCU should be tested at the factory at full power and in the configuration to be installed in the field. This may be difficult, or impossible, for high-power PCUs. The moming wakeup process should be simulated and tested as close to expected field conditions as possible. This would include simulating variations in array voltage that would be expected with seasonal variations in morning temperatures. It also would be desirable to test the PCU at off-design operating points, such as the ends of the ranges in $\mathrm{dc}$ and ac operating voltages. 
Appendix A 

Appendix A

\section{GLOSSARY}

APS Advanced Photovoltaic Systems (successor to Chronar) - A supplier of an amorphous silicon PV array for US-1

Bluepoint Bluepoint Associates (principally Professor A. Dickerson, formerly of California State Polytechnic University at San Luis Obispo) - The supplier of the PCU for the SSI US-1 PV system

Commutation The switching of current from one branch of an electric circuit to another

Converter See PCU

CPM Central processing module

CT Current transformer - A device for measuring ac current with electrical separation from the circuit being measured. Functionally similar devices (Hall effect) are available for dc circuits.

DAS Data acquisition system - The hardware and software used to obtain, process, and record data from the PV systems at PVUSA

DECC Delta Electronic Control Company (a division of Helionetics, Inc.) - The supplier of the EMT PCUs

EMI Electromagnetic interference - Interference with the normal operation of electronic equipment due to conducted or radiated electromagnetic fields

EMT Emerging module technology - A system using prototypical PV technology in the 15- to 20-kW range, obtained via one of several procurements (EMT-1, EMT-2, and EMT-3). 
EPROM Electrically programmable read-only memory - A solid-state memory integrated circuit used to hold control and other instruction codes

Gauss A unit of magnetic flux density

GTO Gate turn-off (thyristor) - A three-terminal, solid-state electronic switching device similar to an SCR, except that the gate signal can also turn off the flow of current from anode to cathode

Harmonic An integer multiple of a fundamental frequency such as $60 \mathrm{~Hz}$. High levels of harmonics distort the shape of the sine wave and produce undesirable effects rather than useful power (also see THD)

IGBT Insulated-gate bipolar transistor - A three-terminal, solid-state electronic switching device wherein a low-level signal controls the flow of a large current from anode to cathode

IJB Interface junction box

Inverter See "PCU"

IPC Integrated Power Corporation - A supplier of a US-1 PV system based on Mobil Solar crystalline silicon modules

\section{Islanding See "Run-On"}

Joule A unit of energy equal to 1 watt-second; used in rating MOVs and other electronic devices

LCD Liquid crystal display - A solid-state device used to display numbers (e.g., 1 meter) or alphanumeric characters for error, status, or other messages 
LCI Line-commutated inverter - A PCU (generally using SCRs) wherein commutation energy is supplied from a connected utility line. Also referred to as a naturally commutated inverter

LED Light emitting diode, used as an indicator (e.g., a solid-state light)

MOV Metal oxide varistor - A device whose resistance decreases nonlinearly with increasing voltage; used to limit voltage spikes

O\&M Operation and maintenance

Omnion Omnion Power Engineering Corporation - The supplier of the PCUs for the IPC US-1 and SSI US-2 PV systems

PC Board Printed circuit board

PCS Power conditioning system (see "PCU")

PCU Power conditioning unit - Equipment that changes dc to ac. It may include protective, alarm, data, voltage transformation, and other functions. Also referred to as an inverter, converter, or power conditioning system (PCS).

PT Potential transformer - A transformer for measuring high ac voltages, with the output at a lower voltage

PTC PVUSA Test Conditions - Conditions under which PV systems (or cells and modules) are measured or rated. For flat-plate modules, PTC is an irradiance of $1,000 \mathrm{~W} / \mathrm{m}^{2}$ in the plane of the module, an ambient air temperature of $20^{\circ} \mathrm{C}, 1 \mathrm{~m} / \mathrm{sec}$ wind speed, and an air mass 1.5 spectrum. For concentrator modules, the irradiance is $850 \mathrm{~W} / \mathrm{m}^{2}$ in the plane of the module 
RFI Radio frequency interference - High-frequency radiated electromagnetic fields, which may interfere with the normal operation of electronic equipment

Run-On A condition in which a PCU continues to operate and energize the ac line after separation (at some location along the feeder) from the main power grid

SCI Self-commutated inverter - A PCU wherein commutation energy is supplied by components in the inverter. Also referred to as a forced commutated inverter

SCR Silicon control rectifier - A three-terminal, solid-state electronic switching device wherein a low-level pulse applied to the gate terminal enables a large current to flow from anode to cathode

Solarex Solarex Corporation - A supplier of a polycrystalline silicon PV array for EMT-1

Sovonics Sovonics Solar Systems (now United Solar Systems Corporation), a subsidiary of Energy Conversion Devices - Supplier of an amorphous silicon PV array for EMT-1

STC Standard Test Conditions - Conditions under which PV cells, modules, and systems are measured or rated. For flat-plate modules, STC is an irradiance of $1,000 \mathrm{~W} / \mathrm{m}^{2}$ in the plane of the module, a cell temperature of $25^{\circ} \mathrm{C}$, and an air mass 1.5 spectrum. For concentrator modules, the STC irradiance is $850 \mathrm{~W} / \mathrm{m}^{2}$ in the plane of the module

SSI

Siemens Solar Industries, Inc. (formerly ARCO Solar Inc.) - A supplier of crystalline silicon PV arrays/systems for EMT-1, US-1, and US-2

Tesla A unit of magnetic flux density, equal to $10^{4}$ gauss

THD Total harmonic distortion - The ratio of the root-mean-squared magnitudes of harmonic components to the magnitude of the fundamental component, generally expressed as a percentage. Both voltage and current THDs are measured, and need to be distinguished from each other (also see "Harmonic") 
Thyristor See "SCR"

UPG Utility Power Group - Supplier of an amorphous silicon PV array for EMT-1

UPS Uninterruptible power supply

US Utility scale - A system using commercial PV technology in the 200- to 500-kW range, obtained via one of several procurements (US-1 and US-2). 

Appendix B 



\section{Appendix B \\ EXCERPTS FROM PG\&E'S \\ POWER PRODUCER'S INTERCONNECTION HANDBOOK}

\section{PURPOSE}

The Power Producer's Interconnection Handbook was complied by Pacific Gas and Electric Company (PG\&E) to serve as a guide for power producers to follow in interconnecting non-PG\&E-owned generation projects with the PG\&E system. The Handbook describes the interconnection process from the planning of a project through project operation. Electric Rule No. 21, as approved by the California Public Utilities Commission (CPUC), is the basis for the interconnection requirements contained in this Handbook.

The information contained in this Handbook is subject to change. PG\&E should be consulted in case of doubt on the current applicability of any item. Updates of this Handbook will be distributed periodically. Further information may be obtained by contacting: PG\&E, Marketing Department H28B, Attention: QF Project Coordinator, P.O. Box 770000, San Francisco, California 94177.

\section{PROJECT REQUIREMENTS}

PG\&E has established operating, metering, and equipment protection requirements for generators to be interconnected with its system. The requirements may vary according to the size of the generator, unless otherwise indicated. Table 1-1 summarizes these requirements. Additional requirements not found in this Handbook may be necessary as a result of the findings of the interconnection study for a specific project.

The power producer is responsible for the design, installation, operation, and maintenance of all necessary equipment for connection of the PG\&E system, unless otherwise agreed to in writing. The power producer is also responsible for submitting specifications and detailed plans for the installation of the control and protective devices to PG\&E for review and written approval prior to parallel operation. However, written approval by PG\&E does not indicate or ensure acceptance by local code authorities. PG\&E's requirements are designed to protect PG\&E facilities; they are not designed to protect the power producer's generators. 
Table 1-1

Summary of Interconnection Requirements ${ }^{(1)}$

\begin{tabular}{|c|c|c|c|c|c|c|c|}
\hline Protection Devices (2) & $\begin{array}{c}10 \mathrm{~kW} \\
\text { or } \\
\text { Less }\end{array}$ & $\begin{array}{c}>10 \mathrm{~kW} \\
\text { to } \\
40 \mathrm{~kW}\end{array}$ & $\begin{array}{c}240 \mathrm{~kW} \\
\text { to } \\
100 \mathrm{~kW}\end{array}$ & $\begin{array}{c}>100 \mathrm{~kW} \\
\text { to } \\
400 \mathrm{~kW}\end{array}$ & $\begin{array}{c}>400 \mathrm{~kW} \\
t 0 \\
1 \mathrm{~mW}\end{array}$ & $\begin{array}{c}21 \mathrm{~mW} \\
10 \\
10 \mathrm{~mW}\end{array}$ & $\begin{array}{l}\text { Over } \\
10 \mathrm{~mW}\end{array}$ \\
\hline Dedicared Transformer & $x^{12}$ & $\mathrm{x}$ & $\mathbf{x}$ & $\mathbf{x}$ & $\mathbf{X}$ & $x$ & $\mathbf{x}$ \\
\hline Disconnect Device (3) & $x$ & $x$ & $\mathbf{X}$ & $\mathrm{x}$ & $\mathbf{x}$ & $\mathrm{x}$ & $\mathbf{x}$ \\
\hline Generator Circuit Breaker & $x$ & $x$ & $\mathbf{x}$ & $\mathbf{X}$ & $\mathbf{x}$ & $\mathbf{x}$ & $\mathbf{x}$ \\
\hline Overvoltage Protection & $\mathrm{x}$ & $\mathbf{x}$ & $\mathbf{x}$ & $\mathbf{X}$ & $\mathbf{x}$ & $\mathbf{x}$ & $x$ \\
\hline Undervoltage Protection & $x^{(8)}$ & $x^{(8)}$ & $\mathbf{x}$ & $\mathbf{x}$ & $\mathbf{x}$ & $\mathrm{x}$ & $\mathbf{X}$ \\
\hline Over/Underfrequency Protection & $x$ & $x$ & $x$ & $\mathbf{x}$ & $\mathbf{x}$ & $\mathrm{x}$ & $x$ \\
\hline Ground Fault Protection & & & $x^{(9)}$ & $\mathbf{x}$ & $x$ & $x$ & $\mathbf{x}$ \\
\hline $\begin{array}{l}\text { Voltage Resurain/Voltage Control } \\
\text { Overcurrent Relay or Impedance Relay }\end{array}$ & & & & & $\mathbf{X}$ & $\dot{x}$ & $x$ \\
\hline Manual/Automatic Symchronizing & $\begin{array}{l}\text { Man or } \\
\text { Auto }\end{array}$ & $\begin{array}{c}\text { Man or } \\
\text { Auto }\end{array}$ & $\begin{array}{l}\text { Man or } \\
\text { Auto } \\
\end{array}$ & $\begin{array}{c}\text { Man or } \\
\text { Auto }\end{array}$ & $\begin{array}{c}\text { Man or } \\
\text { Auto }\end{array}$ & Auto & Auto \\
\hline $\begin{array}{l}\text { Vollage and Power Facior } \\
\text { Regulation }\end{array}$ & & & $\mathrm{x}$ & $\mathrm{x}$ & $x$ & $\mathbf{x}$ & $\mathbf{x}$ \\
\hline Utility Grade Relays (4) & & & & & & $x$ & $\mathbf{x}$ \\
\hline Telemetering (5) & & & & & & & $x$ \\
\hline Time-of Day Metering (5) & $x^{(10)}$ & $x^{(10)}$ & $x^{(10)}$ & $\mathbf{X}$ & $\mathbf{x}$ & $X$ & $\mathbf{X}$ \\
\hline Reactive Demand/VARH Metering & & & $x$ & $x$ & $x$ & $\mathbf{x}$ & $x$ \\
\hline Data Logging & & & & & & $x$ & $x$ \\
\hline Direct Phone Service & $x$ & $\mathbf{x}$ & $x$ & $x$ & $\mathrm{x}$ & $x$ & $\mathbf{x}$ \\
\hline 36 Fault interrupting Device (6) & & & & $x^{(11)}$ & $x^{(11)}$ & $x$ & $\mathbf{x}$ \\
\hline Event Recorder (7) & & & & & $\mathbf{x}$ & $x$ & $\mathbf{x}$ \\
\hline
\end{tabular}

1. All requirements are based on aggregate sum of generator nemeplate generation for the projoct, unless otherwise indicatod.

2. The protection equipment listed, fulfills only the minimum requirement. Additional protoctive devico(s) will be roquired to insure adequate protection, whenever nocessary.

3. Disconnect devices are required on the line and lasd side of the metering units for transmission interconnections.

4. Utility grade relays are required for any transmission volage ( $60 \mathrm{kV}$ and above) interconnection, regardless of generator output.

5. Requirement is based on deliveries to PG\&E, not necesearily generator nameplate. Additional time-of-day metering at generator for net power output may be required based on interconnection agreement and output option selected.

6. A 38 fault interrupting device is required at the point of intereonnection (ownership change) with PG\&E It is usullly located in the power producer's substation on the high-side of the generator step-up benk if the intereonnection does not involve a nonPG\&E-owned up line.

7. Event recorder required for unattended facilities with sutomatic or remotely-initiated paralleling capability, or those that do not have the capability of retaining relay targets following a loss of power.

8. This requirement can be met by the contactor undervoluge release.

9. For induction generators $41 \mathrm{~kW}$ to $100 \mathrm{~kW}$. ground fault detection requirements will be reviewed on a case-by-case basis.

10. Time-of day metering is required to administer standby uriff in conjunetion with a demand energy schedule.

11. Fuses may be used if the generator breaker is equipped to protect against single phasing conditions. When fuses are used, it is recommended that all of the Applieant's other equipment be protected against single-phesing conditions. Fuses must also be sized to coordinate with PG\&E relays for all faulied conditions within Applicant's facility.

12. Generztors less than $10 \mathrm{~kW}$ generating at a secondary voluge level may not require an isolation transformer. However, this must be approved by PG\&E after review of the projoct detuils.

(Rev. 3/93) 


\section{INTERCONNECTION PROCEDURE}

To allow PG\&E to efficiently coordinate all interconnection requests in a timely and consistent manner, all power producers should try to follow the steps outlined below (see Figure 1-1, Interconnection Flowchart). This flowchart includes steps required under the Qualifying Facility Milestone Procedure (QFMP) as adopted by the CPUC.

\section{Contact PG\&E}

The first step in developing a project in PG\&E's service area is to contact one of the local PG\&E representatives in the area where the project will be located. It is very important that PG\&E be contacted as early as possible about any potential generation project in its service area. The developer of a project should never make assumptions about location, voltage, interconnection cost, etc. Certain areas within the PG\&E system can accept only limited amounts of generation without costly reinforcements.

\section{Interconnection Studies}

An interconnection study will address many issues which may not be immediately obvious to a prospective power producer. Some of the areas that may be addressed are ampacity, voltage regulation, harmonics, line losses, right-of-way acquisition, revenue metering, system protection relaying, equipment ownership, and availability of long lead-time equipment. PG\&E may have to make substantial additions and/or modifications to its transmission or distribution system before a generator can be connected. The extent of these modifications/additions and the associated costs will be determined by an interconnection study performed by PG\&E at the power producer's expense.

Examples of typical facilities by an interconnection study include, but are not limited to, new rights-ofway, lines, circuit breakers, transformer banks, relays, voltage regulators, reactive power sources, revenue metering, telemetering, transfer trip devices, and ground fault sensing transformers. The study would also identify which, if any, existing PG\&E facilities would be upgraded, replaced, or modified. 


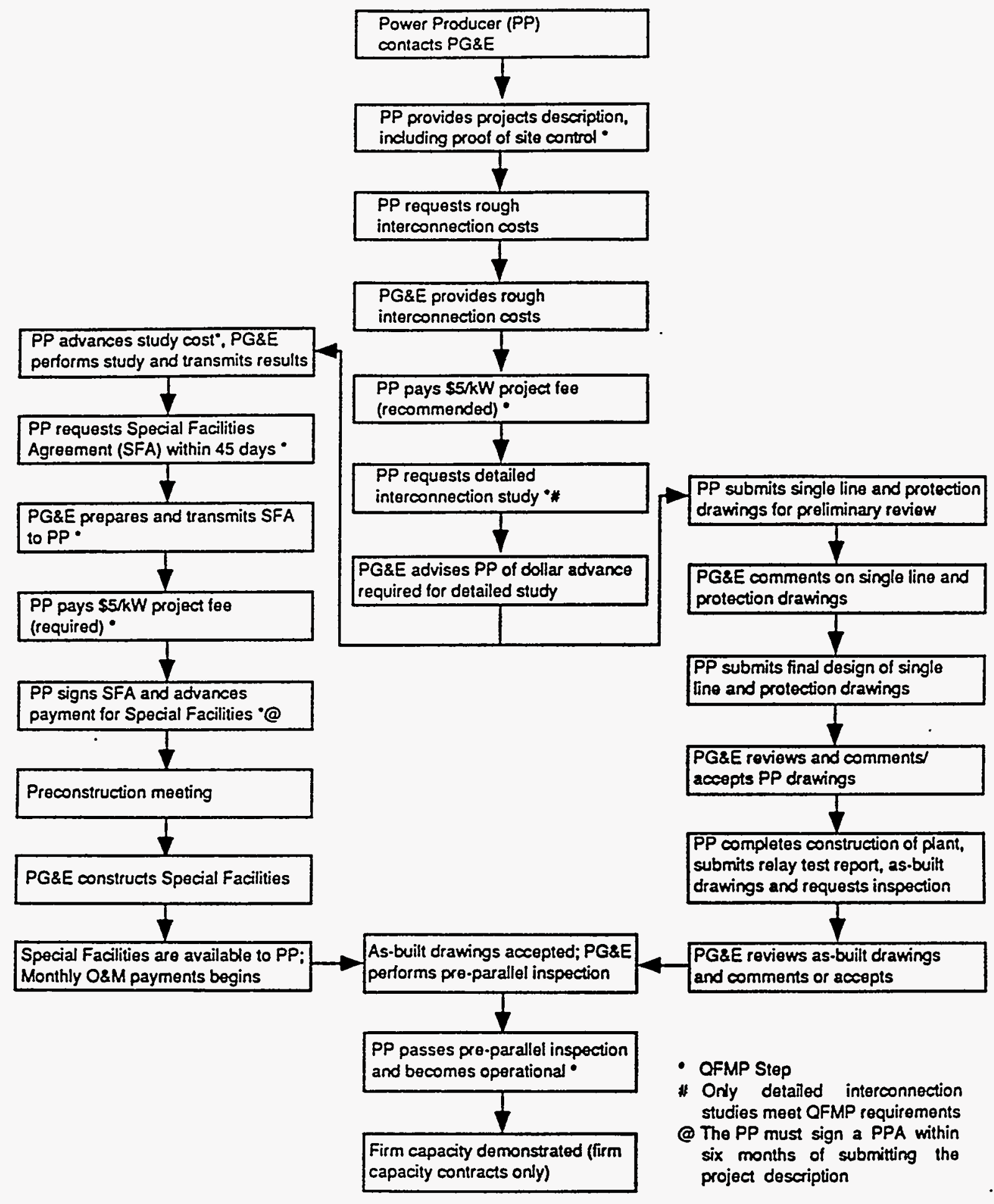

(Rev. 6/92)

Figure 1-1. Interconnection flowchart. 


\section{Special Facilities}

Design of special facilities follows the completion of the detailed interconnection study. Special facilities are those additions and reinforcements to the PG\&E system which are needed to accept delivery of energy and capacity from the power producer and those parts of the interconnection facilities which are owned and maintained by PG\&E at the power producer's request and expense.

A Special Facility Agreement (SFA) details the binding cost for the facilities, and requires an advance payment prior to PG\&E construction for the facilities to be installed and for any necessary rearrangement of the existing facilities to accommodate the power producer's project (costs for land acquisition will be budgeted to actual values). The direct material cost of those facilities which are considered to be removable and reusable may be financed by PG\&E at the power producer's option. These include:

- Metering

- VTs and CTs

- Meters

- Recorders

- Test switches

- Telemetering transmitters and receivers

- Equipment modifications

- Recloser/circuit breaker reclose blocking features

- Voltage regulators

- Other relay equipment

- Devices

- Primary disconnect switches

- Ground fault sensing banks

- Voltage regulators and boosters

- Dedicated transformer banks

- Capacitor banks 
- Reclosers/circuit switches/circuit breakers

- Voltage regulators/booster transfer switches (bi-directional)

- Transfer trip transmitters and receivers

In addition to any advance of rearrangement cost responsibilities, the power producer is also responsible for the monthly cost of ownership. This charge is designed to recover the continuing costs of the special facilities such as maintenance and operation, taxation, replacement, depreciation, etc. The monthly charge is based on a fixed percentage of the installed cost as approved by the CPUC and adjusted from time to time.

Facilities installed by the power producer, built to PG\&E standards and inspected and approved by PG\&E, can be deeded to PG\&E for use as special facilities. PG\&E would then operate and maintain these facilities like any other special facilities, and the power producer would be subject to a monthly cost of ownership charge based on a fixed percentage of PG\&E's estimate of the installed cost of the facilities.

\section{Final Interconnection Review}

Final review and approval of the power producer's plans should occur before any equipment for interconnection is acquired. PG\&E will provide comments on the plans and diagrams submitted by the power producer. The plans and diagrams may need to be modified based on those comments. The oneline meter and relay diagram should be submitted to PG\&E along with a complete list of proposed relays and other protection devices. In addition, the power producer will provide the names, models, and catalog numbers of these protection devices along with their settings.

\section{APPROVAL TO OPERATE}

The power producer cannot parallel with the PG\&E system until the approval to operate is received. The power producer must meet several requirements before obtaining an approval to operate, as follows: First, a power purchase agreement or paralleling agreement must be in effect. Second, the special facilities must be complete to accommodate the power producer's power deliveries. Third, the power producer's generation and interconnection facilities must be ready for operation, with all required permits filed and granted. Fourth, the required certificates and endorsements of insurance coverage as defined in the power purchase agreement or paralleling agreement must be approved by PG\&E. Fifth, the Standard 
Operating Agreement for Facilities of $40 \mathrm{~kW}$ and larger and Interim Solution Agreement, if applicable, must be executed. Finally, the facility must pass a preparallel inspection by PG\&E.

As-built drawings and the final generator data sheet should be sent to PG\&E as early as possible. The power producer will not be allowed to operate in parallel with PG\&E until this information is provided to PG\&E.

When all the above requirements are met, the power producer will be granted approval in writing to operate by PG\&E.

\section{OPERATION}

The following is a brief description of procedures with which the power producer must comply during operation.

The power producer must notify PG\&E of any unusual or emergency conditions or of any change in the power producer's mode of operation, including separating from or paralleling with the system. PG\&E also expects capacity and energy reports for all projects with deliveries greater than $1,000 \mathrm{~kW}$ when direct telemetering is not available. The frequency of reporting is specified in the operating and power purchase agreements. PG\&E must also be given notice of scheduled maintenance periods as specified in the power purchase agreement.

The power producer must maintain a daily operations log and make it available to PG\&E upon request. The log should have a record of all communications between the power producer and the designated PG\&E switching center and note all unusual occurrences and changes in operating mode.

All required equipment must be operable prior to delivering power into the PG\&E system.

\section{FURTHER DETAILS}

\section{Electric Metering}

The purpose of this section is to assist power producers in accommodating PG\&E metering for the measurement of electricity supplied to the PG\&E system. This section is applicable only to those selling power to PG\&E. The general requirements are similar to, if not identical to, the general requirements for 
metering the supply of electric service by PG\&E. Therefore, a copy of PG\&E's Electric and Gas Service Requirements book should be obtained from any PG\&E office and referred to for general requirements such as access height and enclosure standards. PG\&E's metering standards are consistent with the Electric Utilities Service Equipment Requirements Committee guidelines.

Usually, when a generator is installed with the intent of selling power to PG\&E, electric service to the auxiliary load associated with the generator plant is also needed. As such, power may flow into or out of the plant at different times. Deliveries to and from the plant must be separately recorded and treated as separate transactions under PG\&E's tariffs. Therefore, additional metering will be required in most cases. All meters are equipped with detents which prevent reverse registration.

At the power producer's request, PG\&E will install net generator metering which may be used to satisfy qualifying facility status as outlined in the Code of Federal Regulations (18 CFR 292; Public Utility Regulatory Policies Act). KVAR metering may be installed at PG\&E's discretion at the power producer's expense.

\section{Protective Relaying}

An important concern in the delivery of electrical power to PG\&E's system is the potential hazard to life and property. A unit's ability to go off-line immediately when a fault is detected is a primary safety requirement for generators interconnected to PG\&E. A unit must also go off-line when the utility's load or power is disconnected from the line into which the unit is generating.

To achieve this result, a number of relays and protective devices are needed, the requirements for which are outlined on the following pages. Some protection requirements can be standardized; however, most line relaying depends on the generator size, number of generators, line characteristics (i.e., voltage, impedance, and ampacity), and existing system protection.

PG\&E's minimum protection requirements are designed and intended to protect PG\&E's system only. It is the power producer's responsibility to protect their system and equipment. The basic protective devices are listed in Table 1-1. When the generator is connected to a voltage higher than $21 \mathrm{kV}$, additional protection is usually required, even though specific lines may require more or less protection. 
A test report for all relays is required prior to paralleling and every 3 years thereafter for interconnections at $230 \mathrm{kV}$ and above, or every 4 years thereafter for all others. PG\&E will not test the power producer's equipment, but will witness the testing performed by a qualified testing firm obtained by the power producer. On-site power (120 volts typically) is required for the test equipment. Circuit breakers must be tested every 6 years after the preparallel inspection for interconnections at $230 \mathrm{kV}$ and every 8 years for all others.

All relays must include manually resettable relay targets. All relay power supplies must be powered by station battery dc voltage, and should include dc undervoltage detection device and alarm. All relays should be submitted to PG\&E for approval prior to ordering. Approval of relays will not indicate the quality of reliability of a product or service. No endorsements or warranties will be implied.

The following are examples of relays commonly used for interconnection protection. The relays are divided into two groups: industrial grade relays and utility grade relays.

Industrial Grade Relays. These relays have a lesser degree of reliability than utility grade relays. Industrial grade relays can be installed in generation projects up to $1,000 \mathrm{~kW}$ (nameplate) on distribution circuits.

Exceptions:

- Generators $400 \mathrm{~kW}$ or larger must have utility grade overcurrent with voltage restraint or voltage-controlled relays.

- Relays that are used in a ground fault detection scheme must be utility grade.

Utility Grade Relays. These relays are used by electric utilities and have a much higher degree of reliability and accuracy than industrial grade relays. Utility grade relays must be installed in the following circumstances:

- For all generation projects in excess of $1,000 \mathrm{~kW}$ aggregate nameplate on distribution circuits

- Any generator interconnected to PG\&E's transmission system

Utility grade auxiliary relays must be used in the tripping circuits of utility grade protection relays. 


\section{Preliminary Tests}

Prior to initial energizing, the power producer will be required to have a qualified relay tester perform the preliminary tests listed below and to submit to PG\&E documentation that all tests have been properly completed. These tests should be done when the unit is de-energized, and test reports should be submitted to PG\&E at least 10 working days prior to scheduling the parallel inspection. The following tests must be performed:

- Current transformers shall be primary or secondary ratio-tested. If secondary ratio-tested, a voltage ratio must be done to verify the turns ratio.

- Individual relays shall be secondary bench-tested by applying the appropriate currents, voltages, or frequencies. The relays must be tested at their specified setting to verify the following:

- Minimum operating point at which relay picks up (minimum pickup)

- Time delay at three multiples of minimum pickup

- Phase angle characteristic of directional and impedance relay

- The primary bus on the generator side of an open PG\&E disconnect switch shall be meggered phase-to-ground and phase-to-phase, including high-voltage cable runs with all primary breakers and fuses racked open. Primary breakers and major auxiliary equipment (potential transformers, station service transformers, etc.) shall be individually meggered as applicable.

\section{Protective and Control Devices}

Minimum protection requirements are necessary for safe and reliable parallel operation of the Applicant's equipment and PG\&E's electric system. While most commercially available generators are equipped with some protective and control devices, the following additional equipment may be required to permit parallel operation with the PG\&E system, depending on the location, type, and size of the generator. The following paragraphs describe the requirements of protective and control devices for generators.

Circuit Breaker. A circuit breaker allows the Applicant's generation equipment to be separated from the PG\&E system. This breaker must have sufficient interrupting capacity to interrupt the maximum available fault current at its location and be equipped with accessories to:

- Trip the breaker with an external trip signal supplied through a battery (shunt trip)

- Telemeter the breaker status when it is required 
- Lock out if operated by protective relays required for interconnection

Overvoltage and Undervoltage Relays/Overfrequency and Underfrequency Relays. This protection is used to trip the circuit breaker when the voltage or frequency goes below/above PG\&E's normal operating level, and relay settings.

Ground Fault Sensing Scheme. This scheme detects system ground faults and trips the circuit breaker, thus preventing the Applicant's generator from continuously contributing to a ground fault. This scheme must be able to detect ground faults between the PG\&E system side of the dedicated transformer and PG\&E's end-of-line. A single generator or an aggregate of generators exceeding $40 \mathrm{~kW}$ may not be connected to a single phase line without special consideration to provide for ground fault tripping. Such situations must be discussed with PG\&E in advance.

The following transformer connections along with appropriate relaying equipment are commonly used to detect system ground faults:

- System side-grounded wye; generator side-delta

- System side-grounded wye; generator side-wye; tertiary-delta

For a transformer with a delta connection on the system side, a separate grounding transformer, in addition to the appropriate relaying equipment, would be used.

Impedance Relay or an Overcurrent Relay with Voltage Restraint/Voltage Control. These relays are used to detect phase-to-phase faults and initiate a generator circuit breaker trip. They must be located on the individual generator feeder. A group of generators, each less than $1,000 \mathrm{~kW}$, must have an impedance relay or an overcurrent relay with voltage restraint located on each generator greater than $100 \mathrm{~kW}$. Generators greater than or equal to $1,000 \mathrm{~kW}$ must have an impedance relay or an overcurrent relay with voltage restraint or an overcurrent relay with voltage control. If the generator step-up transformer is connected wye-delta or delta-wye, a delta-wye or wye-delta auxiliary potential transformer must be installed on the potential circuit to the voltage restraint or voltage-controlled overcurrent relay.

Line Protection. Line protection relays must match the protective relays at the PG\&E breakers for the line on which the generator is connected. These relays must be located so that a fault on any phase of all 
phases of the PG\&E line will be detected. If transfer trip protection is required, the power producer shall provide at their own expense a voice grade communications circuit for this purpose. This circuit may be leased from the local telephone company or provided via dedicated cable and must have special isolating equipment, a $300 \mathrm{VA}$ inverter, and isolation transformer so the transfer trip equipment will operate properly during fault conditions.

Isolation Transformer. The isolation transformer is used to serve the Applicant and no other PG\&E customer. The impedance of an isolation transformer limits fault currents on the generator bus from the PG\&E system and also limits fault currents on the PG\&E system from the generator. It also reduces the generator harmonics entering the PG\&E system. Generators above $10 \mathrm{~kW}$ require the use of an isolation transformer. Generators less than $10 \mathrm{~kW}$ and generating at a secondary voltage level may require an isolation transformer. This can be determined and identified in the detailed study. A high-side fault interrupting device is required for the transformer protection.

\section{Dc Generators with Inverters}

There are several generators connected to the PG\&E system through inverters. The commutation in the inverter is controlled by the system's frequency and normally cannot become self-commutated. Usually, it is acceptable to have the frequency and voltage devices built into the electronics of the inverter; the acceptance of built-in protective devices depends on how easily and reliably the setpoints of the relays can be tested. Inverter-type generators connected to the PG\&E system must be approved by PG\&E.

\section{Manual Disconnects}

A PG\&E-operated disconnect device must be provided as a means of electrically isolating the PG\&E system from the generator. This will be used to establish visually open working clearance for maintenance and repair work in accordance with PG\&E safety rules and practices. A disconnect device must be located at the point of interconnection (ownership change) with PG\&E for interconnections 2.4 $\mathrm{kV}$ and above. It should be a gang-operated, three-pole lockable switch.

The disconnect device must not be used to make or break parallels between the PG\&E system and the generator(s). Only PG\&E personnel shall operate the device. For this reason, the device enclosure and operating handle (when present) shall be kept locked at all times with PG\&E padlocks. 
The device shall be physically located for ease of access and visibility to PG\&E personnel. When installed in the power producer's wiring, the device shall normally be located in close proximity, to the metering. The PG\&E-operated disconnect shall be identified with a PG\&E-designated switch number plate.

\section{Reactive and Voltage Requirements}

Reactive power (VARs) is a vital component of the PG\&E system load. It is therefore essential that PG\&E receive both real and reactive power from power producers. Where the power producer is unable to furnish reactive power support (because of interconnection limitations, type of generator, or the generator loading), PG\&E will charge for the installation of equivalent reactive support.

The manner in which PG\&E's reactive requirements will be met by a power producer's generator depends on the type and size of generator. Synchronous generators have an inherent reactive flexibility that allows them to operate within a range to either produce or absorb VARs. On the other hand, induction generators operate at a p6wer factor absorbing VARs and require reactive support from the interconnected system, unless the power producer installs corrective equipment.

\section{PG\&E System Modifications}

PG\&E will provide equipment and labor necessary to perform all system modifications at the power producer's expense under the terms of a special facilities agreement, as outlined in Electric Rule No. 21. The following modifications are required.

PG\&E automatic restoration equipment will be prevented from operating until the power producer's side voltage, at the restoration equipment, is below 25 percent of nominal voltage. Generator damage and system disturbances may result from the restoration of power by automatically re-energizing PG\&E's facilities. Modifications will be required when the generator(s) have the capability of energizing a line when the PG\&E system is disconnected. The Applicant's generator(s) will not be allowed to automatically re-energize PG\&E's facilities.

All existing single-phase fault interrupting devices located in series between the high-voltage side of the generator transformer with generation greater than $1 \mathrm{MW}$ aggregate nameplate and PG\&E's substation must be replaced with three-phase interrupting devices. 
In situations where the generator is on a distribution circuit fed from a fused transformer bank, the bank's high-side fuses must be replaced with a three-phase fault interrupting device if the bank's minimum load is equal to or less than 200 percent of the generator's nameplate rating. Additional protection devices may also be required, possibly including a transfer trip.

\section{Direct Telephone Service}

Direct telephone service from the local telephone company must be provided so that operating instructions from PG\&E can be given to the designated operator of the power producer's equipment. The phone company lease line for transfer trip must be in service at least 30 days prior to energization.

\section{Performance Criteria}

Harmonic Requirements. The harmonic content of the voltage and current waveforms in the PG\&E system must be restricted to levels which will not cause interference or equipment-operating problems for PG\&E or its customers. There are many methods that may be used to restrict harmonics.

The preferred method is to install a transformer with at least one delta connection between the generator and the PG\&E system. This transformer significantly limits the effect of voltage and current harmonics on PG\&E's system. A star-grounded generator connected to PG\&E through a two-winding star-grounded transformer will not be allowed.

Any harmonic problems will be handled on a complaint basis. A facility causing harmonic interference is subject to being disconnected from the PG\&E system until the condition has been corrected. If the cause of the problem is traceable to the power producer's facilities, all costs associated with determining and correcting problems will be at the power producer's expense.

Power Performance.Compliance. All synchronous, induction, and single-phase generators shall comply with 1977 ANSI Standards C50.10 and C50.13, dealing with waveform and telephone interference.

Power Factor Requirements. All generation sources must be capable of either: (1) operating continuously at any power factor between 90 percent lagging and 95 percent leading at any voltage level within \pm 5 percent of rated voltage, or (2) providing an equivalent amount of reactive power support. The 
value and the extent of the ability to vary the power factor are dictated by the system requirements at the location of the generation source. This information will be given to the power producer by PG\&E.

\section{Preparallel Inspection}

The following is PG\&E's procedure for performing preparallel inspections. It is important that all time constraints be adhered to for PG\&E to provide timely service.

Relay test reports must be received by PG\&E a minimum of 10 working days prior to performing a preparallel inspection, and two copies should be sent to PG\&E. Written verification of receipt for the test report will be returned to the power producer. Discrepancies in the relay coordination with PG\&E relays will be handled via the phone and followed up in writing.

Functional tests will be performed by the power producer, and all tests will be observed by PG\&E as outlined below. The project developer will provide all test equipment and qualified personnel to perform the required tests. PG\&E will be there strictly as an observer. It is the power producer's responsibility to assure that all relays and other protective devices are adjusted and working properly prior to the preparallel inspection. In the event that problems arise with equipment during test, the PG\&E representative may elect to cancel the test and reschedule for another time.

\section{Operating Procedures}

The power producer's generator(s), while operating in parallel with PG\&E system, is at all times under the jurisdiction of PG\&E's system dispatcher. The system dispatcher shall normally delegate such control to the designated local PG\&E switching center.

The power producer shall maintain telephone service from the local telephone company to the generator location. In the event that such location is remote or unattended, telephone service shall be provided to the nearest building normally occupied by the generator operator. PG\&E and the power producer shall maintain operating communications through the designated switching center. The power producer shall provide a 24-hour per day access phone number to PG\&E.

Unusual operating conditions or other factors that may affect the capability or the reliability of the power producer's generation should be reported to the designated switching center as soon as practicable. 
Conditions imperiling life or property should be reported to the designated switching center immediately. The switching center should be notified of any "forced outage," and the switching center will notify the power producer of any unusual PG\&E conditions that may affect the producer's generation.

Unattended facilities having automatic or remotely initiated paralleling capacity may parallel with the PG\&E system only after verifying that the circuit to which the facility will be connected is energized by a PG\&E source of energy. For all unattended facilities with automatic or remotely initiated paralleling, in the event of loss of power:

- Relays must have the capability of retaining targets on loss of power. If not, an event recorder must be provided which will permanently record all relay target information, including time and duration.

- Automatic reparalleling must be accomplished in less than 5 minutes after the initial trip. In the event that a reparallel attempt after the initial trip is unsuccessful, the automatic reparalleling equipment must lock out and no subsequent reparalleling attempt must be made under any of the following conditions:

- One unsuccessful attempt to reparallel was made

- A successful reparallel was followed by a subsequent trip within 5 minutes due to lack of electrical potential on the circuit to which the facility would be connected.

After the automatic reparalleling equipment has locked out, the switching center must be notified and permission received, before reparalleling either automatically or manually.

Unattended facilities with automatic or remotely initialed paralleling are not required to notify the designated switching center prior to making an automatic or remotely initialed parallel with the PG\&E system or following an automatic separation, unless a lockout condition has occurred.

\section{Operating and Maintenance Procedure}

Once parallel is initiated and approved for normal operation, the power producer is responsible for observing the operating maintenance schedules and procedures of protective and control devices. 
Appendix C 


\section{PCU TROUBLE LOG DATABASE}

\section{EMT-1}

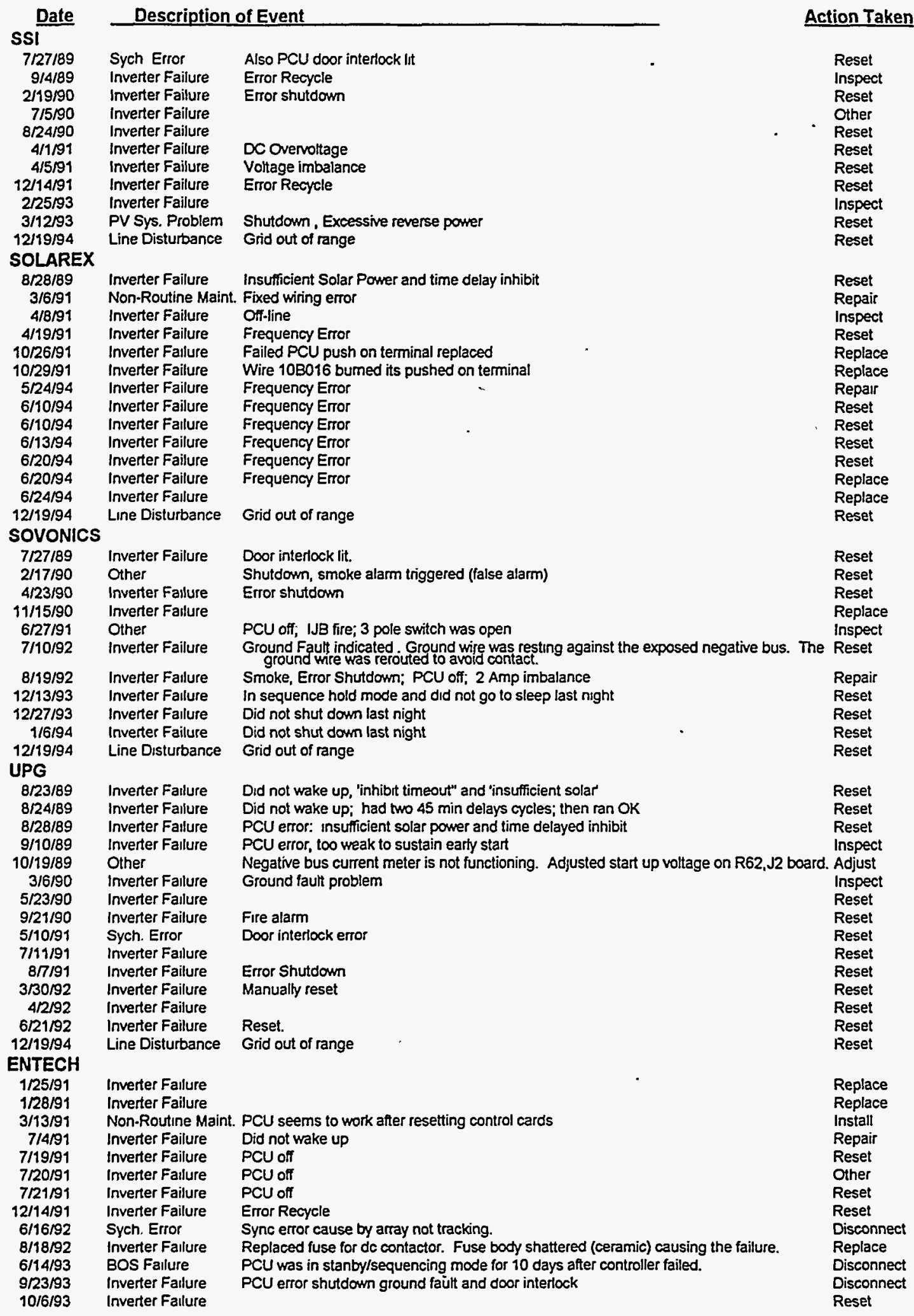

Note: Dates of Synch. Errors are not listed - see Table 3-4 and Figure 3-7. 


\section{US-1, IPC}

\begin{tabular}{|c|c|c|c|}
\hline Date & Description & of Event & tion Take \\
\hline$\overline{4 / 2 / 92}$ & DAS Problem & Power restored to inverter and IJB. Datalogger program installed \& tracker power restored. & Reset \\
\hline $4 / 20 / 93$ & Inverter Failure & IPC inverter down. Old over voltage indication. New DC overcurrent. & Reset \\
\hline $4 / 22 / 93$ & Line Disturbance & Inverter went off due to $12 \mathrm{kV}$ low voitage transient at $1: 05 \mathrm{pm}$ on $4 / 21 / 93$. Running Ok now. & Reset \\
\hline $4 / 29 / 93$ & Inverter Failure & Reset PCU & Reset \\
\hline $4 / 30 / 93$ & Inverter Failure & Repaired of Control board by Omnion & Warranty \\
\hline $5 / 6 / 93$ & Inverter Failure & & Reset \\
\hline $5 / 7 / 93$ & Non-Routine Maint & Installed new controller IC & Replace \\
\hline $5 / 11 / 93$ & Inverter Failure & DC overvoltage trip & Reset \\
\hline $5 / 12 / 93$ & Inverter Failure & DC overvoltage trip & Reset \\
\hline $5 / 21 / 93$ & Inverter Failure & AC Overvoltage & Reset \\
\hline $5 / 26 / 93$ & Inverter Failure & Unplanned shutdown of IPC system. & Reset \\
\hline $6 / 1 / 93$ & Inverter Failure & Abort Power Reached & Reset \\
\hline $6 / 5193$ & Inverter Failure & , & Reset \\
\hline $7 / 6 / 93$ & Inverter Failure & Unplanned shutdown & Reset \\
\hline $7 / 19 / 93$ & Inverter Failure & Inverter shutdown. & Reset \\
\hline $8 / 2 / 93$ & Inverter Failure & Bridge Fault, DC Overvoltage, Old AC Overvoltage, Old AC Underfrequency & Reset \\
\hline $8 / 2 / 93$ & Inverter Failure & Inverter shut down with Bridge Fault message. & Reset \\
\hline $8 / 3 / 93$ & Inverter Failure & Inverter shut down with Bridge Fault message. & Reset \\
\hline $8 / 3 / 93$ & Inverter Failure & Inverter shut down with Bridge Fault message. & Reset \\
\hline $8 / 5 / 93$ & Inverter Failure & Inverter shut down with Bridge Fault message. & Reset \\
\hline $8 / 9 / 93$ & Inverter Failure & Inverter shut down with Bridge Fault message. & Reset \\
\hline $8 / 10 / 93$ & Inverter Failure & Inverter shut down with Bridge Fault message. & Reset \\
\hline $8 / 11 / 93$ & Inverter Failure & Inverter shut down with AC Undervoltage, Bridge 1 or 5 Fault, Bridge Fault messages. & Reset \\
\hline $8 / 16 / 93$ & Inverter Failure & Inverter shut down with Bridge Fault message. & Reset \\
\hline $8 / 16 / 93$ & Inverter Failure & Inverter shut down with Bridge Fault message. & Reset \\
\hline $12 / 9 / 93$ & Inverter Failure & & Replace \\
\hline $12 / 10 / 93$ & Inverter Failure & Inverter shut down with Bridge Fault message. & Repair \\
\hline 12/13/93 & Inverter Failure & DC Overvoltage & Reset \\
\hline 12/14/93 & Inverter Failure & DC Overvoltage & Reset \\
\hline $12 / 20 / 93$ & Inverter Failure & DC Overvoltage & Reset \\
\hline 12/23/93 & Inverter Failure & DC Overvoltage & Reset \\
\hline $12 / 27 / 93$ & Inverter Failure & DC Overvoltage & Reset \\
\hline $1 / 12 / 94$ & Inverter Failure & DC Overvoltage & Reset \\
\hline $1 / 17 / 94$ & Inverter Failure & DC Overvoltage & Reset \\
\hline $1 / 17 / 94$ & Inverter Failure & DC Overvoltage & Reset \\
\hline $1 / 20 / 94$ & Inverter Failure & Bridge 2 failure of $1 / 19 / 93$ & Replace \\
\hline $1 / 21 / 94$ & Inverter Failure & Bridge 2 failed similar to failure of $1 / 19 / 94$ & Repair \\
\hline $1 / 25 / 94$ & Inverter Failure & & Repair \\
\hline $2 / 1 / 94$ & Inverter Failure & Dc overvoltage & Reset \\
\hline 2/1/94 & Inverter Failure & & Replace \\
\hline $2 / 8194$ & Inverter Failure & Inverter shutdown immediately after first restart, restarted again successfully. & Reset \\
\hline 2/8/94 & Inverter Failure & DC Overvoltage & Reset \\
\hline $2 / 9 / 94$ & Inverter Failure & DC Overvoltage & Reset \\
\hline $2 / 9 / 94$ & Inverter Failure & DC Overvoltage & Reset \\
\hline $2 / 24 / 94$ & Inverter Failure & DC Overvoltage & Reset \\
\hline $2 / 27 / 94$ & Inverter Failure & Omnion work on inverter & Modify \\
\hline $2 / 28 / 94$ & Inverter Failure & DC Overvoltage & Reset \\
\hline $3 / 14 / 94$ & Inverter Failure & DC Overvoltage & Reset \\
\hline $3 / 17 / 94$ & Inverter Failure & DC Injection / Bridge Fault & Reset \\
\hline $3 / 18194$ & Inverter Failure & DC Overvoltage & Reset \\
\hline $3 / 20 / 94$ & Inverter Failure & Abort power reached & Reset \\
\hline $3 / 21 / 94$ & Inverter Failure & DC Overvoltage & Reset \\
\hline $4 / 12 / 94$ & Inverter Failure & Line Disturbance - Abort power reached, old ac overvoltage & Reset \\
\hline $4 / 18 / 94$ & Inverter Failure & DC Overvoltage & Reset \\
\hline 4/19/94 & Inverter Failure & Abort power reached, old ac overvoltage & Reset \\
\hline $4 / 27 / 94$ & Inverter Failure & DC Overvoltage & Replace \\
\hline $4 / 29 / 94$ & Inverter Failure & Abort power reached, dc overvoltage & Reset \\
\hline $4 / 29 / 94$ & Inverter Failure & DC Overvoltage & Reset \\
\hline $5 / 2 / 94$ & Inverter Failure & DC Overvoltage & Reset \\
\hline $5 / 2 / 94$ & Inverter Failure & Abort power reached & Reset \\
\hline $5 / 2 / 94$ & Inverter Failure & Abort power reached & Reset \\
\hline $5 / 3 / 94$ & Inverter Failure & Abort power reached & Reset \\
\hline $5 / 3 / 94$ & Inverter Failure & Abort power reached & Reset \\
\hline $5 / 4 / 94$ & Inverter Failure & DC Overvoltage & Reset \\
\hline $5 / 4 / 94$ & Inverter Failure & DC Overvoltage & Reset \\
\hline $5 / 4 / 94$ & Inverter Failure & DC Overvoltage & Reset \\
\hline $5 / 4 / 94$ & Inverter Failure & Bridge fault (Bridge 40 & Connect \\
\hline $5 / 5 / 94$ & Inverter Failure & Abort power reached, old ac undervoltage & Reset \\
\hline
\end{tabular}




\section{US-1, IPC}

\begin{tabular}{|c|c|c|c|}
\hline Date & Description & $A C$ & tion Taker \\
\hline$\overline{5 / 5 / 94}$ & Inverter Failure & Abort power reached & Reset \\
\hline $5 / 5 / 94$ & Inverter Failure & DC Overvoltage, abort power reached & Reset \\
\hline $5 / 5 / 94$ & Inverter Failure & Abort power reached & Reset \\
\hline $5 / 1+1 / 94$ & Inverter Failure & DC Overvoltage, abort power reached & Reset \\
\hline $5 / 12 / 94$ & Inverter Failure & DC Overvoltage & Reset \\
\hline $5 / 12 / 94$ & Inverter Failure & Dc overvoltage, abort power reached & Reset \\
\hline $5 / 15 / 94$ & Inverter Failure & Abort power; Bridge Fault & Reset \\
\hline $5 / 18 / 94$ & Inverter Failure & Abort power reached & Reset \\
\hline $5 / 18 / 94$ & Inverter Failure & & Reset \\
\hline $5 / 19 / 94$ & Inverter Failure & De overvoltage, ac undervoltage & Reset \\
\hline $5 / 19 / 94$ & Inverter Failure & Abort power reached & Reset \\
\hline $5 / 19 / 94$ & Inverter Failure & Abort power - enhanced irradiance & Reset \\
\hline $5 / 19 / 94$ & Inverter Failure & Abort power reached & Reset \\
\hline $5 / 19 / 94$ & Inverter Failure & Abort power reached & Reset \\
\hline $5 / 19 / 94$ & Inverter Failure & Abort power reached & Reset \\
\hline $5 / 21 / 94$ & Inverter Failure & DC Overvoltage, abort power reached & Reset \\
\hline $5 / 21 / 94$ & Inverter Failure & DC Overvoltage, abort power reached & Reset \\
\hline $5 / 23 / 94$ & Inverter Failure & & Reset \\
\hline $5 / 23 / 94$ & Inverter Failure & DC Overvoltage, abort power reached & Reset \\
\hline $5 / 23 / 94$ & Inverter Failure & DC Overvoltage, abort power reached & Reset \\
\hline $5 / 23 / 94$ & Inverter Failure & Two resets at $7: 30$ and $7: 47 a$ & Reset \\
\hline $5 / 24 / 94$ & Inverter Failure & DC Overvoltage, abort power reached & Reset \\
\hline $5 / 24 / 94$ & Inverter Failure & DC Overvoltage, abort power reached & Reset \\
\hline $5 / 24 / 94$ & Inverter Failure & DC Overvoltage, abort power reached & Reset \\
\hline $5 / 24 / 94$ & Inverter Failure & DC Overvoltage, abort power reached & Reset \\
\hline $5 / 25 / 94$ & Inverter Failure & Bridges 4 \& 5 Failed & Inspect \\
\hline $8 / 29 / 94$ & Inverter Failure & & Replace \\
\hline $8 / 30 / 94$ & Inverter Failure & DC Overvoltage; Bridge faults 2, 3 \& 4; Smoke Alarm; Breaker Open & \\
\hline $9 / 5 / 94$ & Inverter Failure & Old ac undervoltage; Abort power; Bridge or Bridge 5 Fault;dc overvoltage; Bridge 5 - CO-+ & - Test \\
\hline $9 / 7 / 94$ & Inverter Failure & Bridge fault $5 ;$ CO-CF LED Lit & Test \\
\hline $9 / 13 / 94$ & Inverter Failure & Bridgo fault $5, \mathrm{CF}$ & Reset \\
\hline $9 / 19 / 94$ & Inverter Failure & Bridge fault 5 ; CO-CF LED Lit & Reset \\
\hline $9 / 19 / 94$ & Inverter Failure & Bridge fault 5 ; CO-CF LED Lit & Reset \\
\hline $9 / 26 / 94$ & Inverter Failure & Bridge fault 5 ; CO-CF LED Lit & Reset \\
\hline $9 / 27 / 94$ & Inverter Failure & Bridge fault 5 ; CO-+CF LED Lit & Reset \\
\hline $9 / 30 / 94$ & Inverter Failure & DC Overvoltage & Reset \\
\hline $10 / 3 / 94$ & Inverter Failure & Bridge fault $5 ; C 0-+C F$ LED Lit & Reset \\
\hline $10 / 4 / 94$ & Inverter Failure & Bridge fault $5 ; C 0-C F$ LED Lit. Would not start after Line Disturbance on $10 / 3$. & Reset \\
\hline 10/15/94 & Line Disturbance & iCS Fulat Line Disturbance & Reset \\
\hline 10/19/94 & Inverter Failure & Bridge Fautt 4; $A 0$, dc injection LED Lit & Reset \\
\hline $10 / 20 / 94$ & Inverter Failure & Bridge Fault 4; $A O$, dc injection LED Lit & Reset \\
\hline $10 / 24 / 94$ & Inverter Failure & Bridge Fault 4: $A O$, dc injection LED Lit; $A O$, dc injection LED Lit & Reset \\
\hline $10 / 25 / 94$ & Inverter Failure & Bridge Fault 4; $A O$, dc injection LED Lit; $A 0$, dc injection LED Lit & Replace \\
\hline $10 / 27 / 94$ & Inverter Failure & Abort power reached, old ac undervoltage & Reset \\
\hline $12 / 14 / 94$ & Line Disturbance & & Reset \\
\hline $\begin{array}{r}1 / 5 / 95 \\
1 / 10 / 95\end{array}$ & Line Disturbance & AC undervoltage & Reset \\
\hline
\end{tabular}




\section{US-1, SSI}

\begin{tabular}{|c|c|c|c|}
\hline Date & Description & f Event & tjon Taken \\
\hline$3 \longdiv { 2 1 / 9 1 }$ & Synch. Error & & Inspect \\
\hline $3 / 22 / 91$ & Synch. Error & & Reset \\
\hline $4 / 3 / 91$ & Inverter Failure & Ground Fault & Reset \\
\hline $4 / 22 / 91$ & Inverter Failure & Off-line due to 78 & Reset \\
\hline $5 / 6 / 91$ & Inverter Failure & & Reset \\
\hline $6 / 7 / 91$ & Inverter Failure & Overtemperature & Inspect \\
\hline $6 / 11 / 91$ & Inverter Failure & & Inspect \\
\hline $7 / 5 / 91$ & Other & Smoke Alarm & Inspect \\
\hline $8 / 15 / 91$ & Inverter Failure & Ground Fault & Reset \\
\hline $8 / 19 / 91$ & Inverter Failure & Inverter B shutdown on "81" ground fault & Reset \\
\hline $8 / 22 / 91$ & Inverter Failure & Inverter B shutdown on " $81^{\prime \prime}$ ground fault & Reset \\
\hline 9/28/91 & Synch. Error & & Reset \\
\hline $9 / 30 / 91$ & Inverter Failure & Ground Fault & Reset \\
\hline 10/3/91 & Inverter Failure & & Inspect \\
\hline 10/30/91 & Inverter Failure & SCR fault on source circuitt & Inspect \\
\hline $11 / 6 / 91$ & Inverter Failure & Replaced AC contactors & Replace \\
\hline 11/25/91 & Inverter Failure & Shutdown, found both Inverters off on Saturday and Sunday at the same time & Install \\
\hline 11/28/91 & Inverter Failure & Off-line & Reset \\
\hline $4 / 18 / 92$ & Inverter Failure & $\begin{array}{l}\text { Inverter A shutdown. Display shows } 93 \text { (Smoke/PV, reset and shows } 43 \text { (Smoke/Tripped). } \\
\text { Off-line until control power is removed on 4-21-93 }\end{array}$ & Inspect \\
\hline 4/18/92 & Inverter Failure & Inverter A down brieffy. Automatic reset & Reset \\
\hline $4 / 21 / 92$ & Inverter Failure & $\begin{array}{l}\text { Reset Inverter A. OK for } 20 \text { min: stopped due to a problem with bridge \#4. Remains off-line } \\
\text { SSI arrives for Inverter B installation. }\end{array}$ & Reset \\
\hline $4 / 27 / 92$ & Inverter Failure & $\begin{array}{l}\text { Inverter B started and A started. Both Inverters shutdown. Replace fuse in B and restarted. } \\
\text { inverter B shuts down with MOV failure., damages some opto-isolators and related timing iCs. }\end{array}$ & $\begin{array}{l}\text { Replace } \\
\text { s. }\end{array}$ \\
\hline 4/28/92 & Other & Bluepoint continues attempt to repair inverter $\mathbf{B}$ & Repair \\
\hline $4 / 29 / 92$ & Inverter Failure & SSI and Bluepoint continue troubleshooting Inverter B problem. & Repair \\
\hline $5 / 4 / 92$ & Inverter Failure & Bluepiont onsite to repair Inverter B & Repair \\
\hline $5 / 11 / 92$ & Inverter Failure & & Reset \\
\hline $5 / 12 / 92$ & Inverter Failure & & Reset \\
\hline $5 / 13 / 92$ & Inverter Failure & & Reset \\
\hline $5 / 14 / 92$ & Inverter Failure & & Reset \\
\hline $5 / 15 / 92$ & Other & $\begin{array}{l}\text { Inverter B shut down by GFI, SSI states program in GFI is the old and won't work properly. } \\
\text { Correct code being sent. }\end{array}$ & Reset \\
\hline $5 / 15 / 92$ & Other & Inverter B SSI-US1 goes down, controller latches up due to ground fault & Reset \\
\hline $5 / 15 / 92$ & Inverter Failure & & Reset \\
\hline $5 / 15 / 92$ & Inverter Failure & & Reset \\
\hline $5 / 22 / 92$ & Inverter Failure & Inverter B down due to indicated ground fault. Reset at 09:00. & Reset \\
\hline $5 / 24 / 92$ & Inverter Failure & Reset GFI and started Inverter B. & Reset \\
\hline $8 / 14 / 92$ & Inverter Failure & Tumed off Inverter $B$ and 480 Vac CBs. Y Circuit Breaker was tripped. & Reset \\
\hline 8/18/92 & Inverter Failure & Reset Y Circuit Breaker on Inverter B. & Reset \\
\hline 8/28/92 & PV Syst. Problem & US-1, SSI was only at $50 \%$ output from inverter B & Other \\
\hline $9 / 1 / 92$ & Inverter Failure & Reset Inverter B, was indicating ' 58 ' and not started. After reset the display indicated ' 70 '. & Reset \\
\hline 9/1/92 & Inverter Failure & & Other \\
\hline $9 / 2 / 92$ & Inverter Failure & & Reset \\
\hline 9/3/92 & Inverter Failure & & Reset \\
\hline 9/4/92 & Inverter Failure & Circuit breaker B trips: @ 12:20, reset; $15: 30$, reset & Reset \\
\hline $9 / 8 / 92$ & Inverter Failure & & Reset \\
\hline 9/9/92 & Inverter Failure & & Reset \\
\hline 9/10/92 & Inverter Failure & & Reset \\
\hline 9/10/92 & Inverter Failure & & Reset \\
\hline 9/10/92 & Inverter Failure & & Reset \\
\hline 9/11/92 & Inverter Failure & & Reset \\
\hline 9/11/92 & Inverter Failure & & Reset \\
\hline 9/11/92 & Inverter Failure & & Reset \\
\hline $10 / 6 / 92$ & Inverter Failure & Current transducers failed. Output was indicating 8.99 Amps continuos. & Replace \\
\hline $11 / 2 / 92$ & Inverter Failure & & Reset \\
\hline $12 / 31 / 92$ & Inverter Failure & & Inspect \\
\hline $2 / 23 / 93$ & Inverter Failure & Read condition of Inverters $A$ and $B$ & Inspect \\
\hline 2/24/93 & Inverter Failure & Resot from '94 Trip. & Reset \\
\hline 3/12/93 & Inverter Failure & & Reset \\
\hline 3/18/93 & Inverter Failure & & Reset \\
\hline $5 / 28 / 93$ & Inverter Failure & Unplanned shutdown of Inverters & Reset \\
\hline 6/1/93 & Inverter Failure & & Reset \\
\hline 6/18/93 & Inverter Failure & Found inverter A shutdown in mode 58. & Reset \\
\hline 6/18/93 & Inverter Failure & Found inverter A in mode 58. & Resel \\
\hline 6/19/93 & Inverter Failure & Unplanned shutdown of SSI Inverters. & Reset \\
\hline $6 / 23 / 93$ & Inverter Failure & Unplanned shutdown. & Reset \\
\hline $6 / 23 / 93$ & Inverter Failure & Found inverter $B$ in mode 37 . & Resot \\
\hline
\end{tabular}




\section{US-1, SSI}

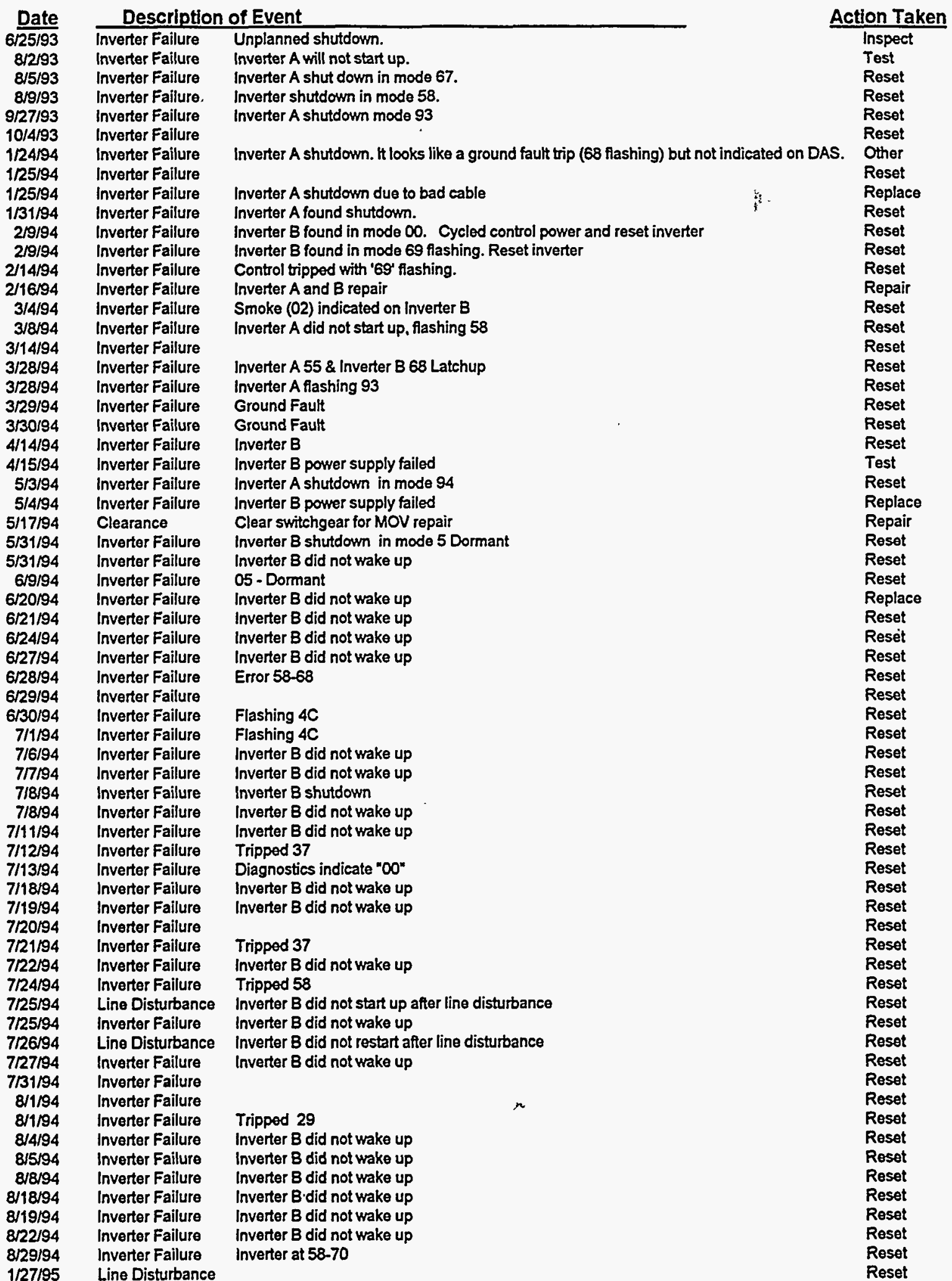




\section{US-1, APS}

Date

$8 / 14 / 92$

$8 / 27 / 92$

$8 / 27 / 92$

9/1/92

9/1/92

9/2/92

9/4/92

9/11/92

9/12/92

9/15/92

9/23/92

9/24/92

9/25/92

$1 / 7 / 93$

1/22/93

$3 / 19 / 93$

$3 / 22 / 93$

$4 / 22 / 93$

$5 / 24 / 93$

$7 / 12 / 93$

$9 / 14 / 93$

$2 / 23 / 94$

$5 / 3 / 94$

$5 / 13 / 94$

$5 / 26 / 94$

$5 / 27 / 94$

$5 / 27194$

$6 / 2194$

67194

$7 / 11 / 94$

$7 / 12194$

7126194

$8 / 8194$

$8 / 15 / 94$

10/31/94

11/29/94

$12 / 1 / 94$

1215194

$12 / 19 / 94$

1/3/95

$1 / 16 / 95$
Description of Event

Action Taken

Inverter Failure

Inverter 2 \& 3 shutdown due to smoke; restart resulted in another smoke trip. MOVs failed Repair Smoke alarm trip. Suspect trip due to outgassing, but can not verify.

Inverter Failure

Inverter Failure

Inverter Failure

Inverter Failure

Inverter Failure

Inverter Failure

Inverter Failure

Inverter Failure

Inverter Failure

Facility Imprvmn

Inverter Failure

Other

Inverter Failure

Inverter Failure

Synch. Error

Inverter Failure

Inverter Failure

Inverter Failure

Inverter Failure

Inverter Failure

Inverter Failure

Inverter Failure

Inverter Failure

Inverter Failure

Inverter Failure

Inverter Failure

Non-Routine Maint

Inverter Failure

Inverter Failure

Inverter Failure

Inverter Failure

Inverter Failure

Inverter Failure

Smoke alarm trip

Reset Inverter \#1. Blown fuse blown indicated.

Inverter 1 did not start on wake up, briefly indicated a fuse failure.

Inverter 1 shutdown; \#2 power only; \#3 shutdown lit; \#4 shutdown lit.

Other

Inspect

Other

Reset

Other

Inspect

Reset

Reset

System did not wake up this morning

APS requested that shorting jumpers in Inverter $2 D C$ Disc. switch.

Reset

Reset

Reset

Smoke alarm trip

Off-line

Attempted restart of PCU's under direction of APS

Unplanned shutdown.

Inverter $\mathbf{4}$ failed to start after outage for resistor installation in Inverters 2 and 3

Inverter 4 dc voltage meter indicates wrong voltage

Inverter 4 DC Voltage needed adjustment

Inverter 2 shutdown.

Inverter 4 will not start

Inverter 2 did not wake up

Inverter 3 did not wake up

Inverter Repair

Inverter 4

Inverter 4 DC Voltage intermittent

Inverters 1 \& 3 did not start up after line disturbance. Inverter 1 \& 3 each cleared 2-fuses

System did not wake up this morning

Inverter 3 did not wake up

System did not wake up this morning

Non-Routine Maint Replace voltage meter on inverter 4

Inverter Failure Inverter $\mathbf{3}$ failed to start

Inverter Failure

inverter Failure

Inverter Failure

Inverter Failure

Adjusted Inverter 2 voltage from $395 \mathrm{~V}$ to $350 \mathrm{~V}$ and $\# 4$ from 470 TO $350 \mathrm{~V}$.

inverters $1,3, \&$ \& did not start up after line disturbance

Inverter \#4 only
Reset

Reset

Inspect

Reset

Reset

Warranty

inspect

inspect

Adjust

Reset

Repair

Repair

Reset

Warranty

Inspect

Adjust

Replace

Reset

Reset

Reset

Adjust

Reset

Adjust

Replace

Reset

Reset 


\section{US-2, SSI}

Date

$8 / 8 / 93$

$1111 / 94$

$1 / 24 / 94$

2/9/94

$3 / 16 / 94$

$3 / 22 / 94$

$4 / 11 / 94$

$4 / 15 / 94$

$4 / 26 / 94$

$4 / 26 / 94$

$5 / 2 / 94$

$5 / 16 / 94$

$5 / 17 / 94$

$6 / 11 / 94$

Q/19194

6/22194

$6 / 29 / 94$

$7 / 5 / 94$

$7 / 18 / 94$

$7 / 18 / 94$

$7 / 19 / 94$

$7 / 19 / 94$

$7 / 21 / 94$

$7 / 25 / 94$

$8 / 10 / 94$

$8 / 10 / 94$

$9 / 21 / 94$

$9 / 26 / 94$

9/26/94

$9 / 27 / 94$

$9 / 28194$

$9 / 28 / 94$

9/29/94

9/29/94

$10 / 11 / 94$

10/13/94

$10 / 17 / 94$

$10 / 21 / 94$

10/24/94

$1 / 2 / 95$

$1 / 5 / 95$

$1 / 5 / 95$

$1 / 5 / 95$

$1 / 11 / 95$

$1 / 12 / 95$

1/19/95
Description of Event

Inverter Failure

Inverter Failure

Inverter Failure

Inverter Failure Inverter Failure

Inverter Failure

Inverter Failure

Inverter Failure

Inverter Failure

Inverter Failure

Inverter Failure

Inverter Failure

Inverter Failure

Inverter Failure

Inverter Failure

Inverter Failure

Inverter Failure

Inverter Failure

Inverter Failure

Inverter Failure

Inverter Failure

Inverter Failure

Inverter Failure

Inverter Failure

Inverter Failure

Inverter Failure

Inverter Failure

Inverter Failure

Inverter Failure

Inverter Failure

Inverter Failure

Inverter Failure

Inverter Failure

Inverter Failure

Inverter Failure

Inverter Failure

Inverter Failure

Inverter Failure

Inverter Failure

Synch. Error

Synch. Error

Other

Inverter Failure

Inverter Failure

Inverter Failure

Inverter Failure

Inverter 2

Inverter 1

Inverter 1
Data indicates the plant was not reset and is still shut down.

Inverter did not wake up. District Office in Fresno reset inverter per request

Inverter 1 shutdown. District Office in Fresno reset inverter per, request

inverter 1 shutdown. District Office in Fresno reset inverter per request

Inverter 2 Air Conditioner Failed

Both Inverters shutdown

Both Inverters shưtitown

Inverter 1 shutdown

Inverter 1 shutdown

Both Inverters shutdown

Undervoltage shutdown

Overtemperature trip

Inverter 1 Air Conditioner Failed

Inverter 1 shutdown

Inverter 1 did not start

Inverter 1 shutdown

Inverter 1 shutdown

Inverter 1 shutdown

Inverter 1 shutdown

Inverter 1 shutdown

+5 Volt power supply failed

Inverter 2 did not start

Replaced diode in Inverter 2 power supply

Both Inverters failed to startup

Inverter 1 shutdown with Old ac Overvoltage \& regulator or Crowbar fault

Inverter 2 shutdown with Old ac Overvoltage faut

Inverter 1 Crowbar problem

Inverter has not auto-started since power supply was replaced

Inverter shutdown

Both Inverters failed to startup

Inverter 2 did not start

Both Inverters down; line disturbance

Both Inverters shutdown

Transfer trip on 1-4-95 @ 5:10 pm - power restored @ 9:45 am on 1/5/95.

After transfer trip on 1/4/95, inverter 2 did not reset remotely

Inverter 1 did not start
Action Taken

Reset

Reset

Reset

Reset

Reset

Reset

Reset

Disconnect

Reset

Reset

Reset

Reset

Reset

Reset

Repair

Reset

Reset

Reset

Reset

Reset

Connect

Reset

Connect

Replace

Replace

Reset

Replace

Reset

Test

Reset

Replace

Adjust

Reset

Reset

Reset

Reset

Reset

Reset

Reset

Inspect

Reset

Inspect

Inspect

Reset 


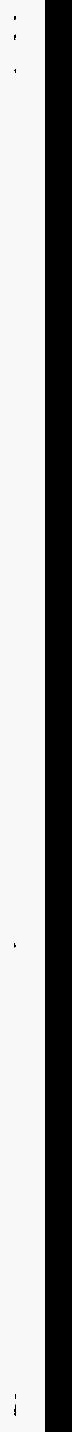

